\title{
Out of balance : serotonergic studies in affective disorders
}

Citation for published version (APA):

Klaassen, T. (2002). Out of balance : serotonergic studies in affective disorders. [Doctoral Thesis, Maastricht University]. Datawyse / Universitaire Pers Maastricht. https://doi.org/10.26481/dis.20020412tk

Document status and date:

Published: 01/01/2002

DOI:

10.26481/dis.20020412tk

Document Version:

Publisher's PDF, also known as Version of record

\section{Please check the document version of this publication:}

- A submitted manuscript is the version of the article upon submission and before peer-review. There can be important differences between the submitted version and the official published version of record.

People interested in the research are advised to contact the author for the final version of the publication, or visit the DOI to the publisher's website.

- The final author version and the galley proof are versions of the publication after peer review.

- The final published version features the final layout of the paper including the volume, issue and page numbers.

Link to publication

\footnotetext{
General rights rights.

- You may freely distribute the URL identifying the publication in the public portal. please follow below link for the End User Agreement:

www.umlib.nl/taverne-license

Take down policy

If you believe that this document breaches copyright please contact us at:

repository@maastrichtuniversity.nl

providing details and we will investigate your claim.
}

Copyright and moral rights for the publications made accessible in the public portal are retained by the authors and/or other copyright owners and it is a condition of accessing publications that users recognise and abide by the legal requirements associated with these

- Users may download and print one copy of any publication from the public portal for the purpose of private study or research.

- You may not further distribute the material or use it for any profit-making activity or commercial gain

If the publication is distributed under the terms of Article $25 \mathrm{fa}$ of the Dutch Copyright Act, indicated by the "Taverne" license above, 


\section{Out of Balance}

Serotonergic studies in affective disorders 
The study presented in this thesis was conclucted at the Brain \& Behaviour Institute, Department of Psychiatry and Neuropsychology, Maastricht University, Maastricht, The Netherlands. The study was made possible by a grant from the Maastricht University's Clinical Research Fund ("Profileringsfonds").

\section{ISBN 90-5278-316-0}

Toon Tellegen: "Een meisje"

o Springer Verlag: chapter one, four

(C) Sociely of Biological Psychiatry: chapter two

(c) Elsevier Sciences treland Ltd: chapter five, six, nine

Cambridge University Press: chapter three

c) Tineke Kiaassen other chapters

All rights reserved. No part of this book may be reporduced or transmitted in any form or by any means, electronic or mechanical, including photocopying, recording, or by any information storage and retrieval system without written permission from the publisher, except for the inclusion of brief quotations in a review.

\section{Book praparation: T. Klaassen}

Cover design. J. Schonck and Datawyse

Printing: Datawyse/ Universitaire Pers Maastricht

Publication of this thesis is financially supported by Smith Kline Beecham: BV. Eli Lilly Nedertand BV. Nutricie Nederland BV, Lundbeck BV, Janssen-Cilag BV and UCB Pharma BV 


\title{
Out of Balance Serotonergic Studies in Affective Disorders
}

\author{
Proefschrift \\ ter verkrijging van de graad van doctor \\ aan de Universiteit Maastricht, \\ op gezag van de Rector Magnificus, \\ Prof. Dr. A.C. Nieuwenhuijzen Kruseman \\ volgens het besluit van het College van Decanen, \\ in het openbaar te verdedigen \\ op vrijdag 12 april 2002 om 12.00 uur \\ door
}

Tineke Klaassen

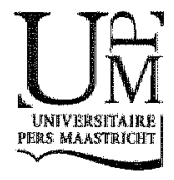




\section{Promotores}

Prof. Dr. E. Griez

Prof. Dr. H.M. van Praag

\section{Co-promotor}

Dr. W.J. Riedel

\section{Beoordelingscommissie}

Prof. Dr. M. Maes (voorzitter)

Dr. A.J.W. van der Does (Universiteit Leiden)

Prof. Dr. A.T.M. Jansen

Prof. Dr. H.L.G.J. Merckelbach

Prof Dr. H.W.M. Steinbusch

Dr. S.N. Young (Mc. Gill University, Montreal, Quebec) 
Een meisje

\section{Ze wacht.}

Nee, denkt ze, ik wacht niet,

ik dans.

Ze danst,

ze danst met lange, ranke passen,

langzaam en aandachtig.

ze houdt haar ogen dicht,

ze danst door deuren en door ramen

en door lange, lankmoedige dagen -

hout, glas en uren vallen in splinters rond haar neer -

en telkens als ze niet meer kan

en bijna, bijna valt

denkt ze: ik?

ik val niet, ik dans.

Toon Tellegen

(Uit: Kruis en munt, 2000) 



\section{Contents}

Introduction

Outline of the methods used in this thesis ...................................14

The functional approach .............................................. 15

Hypotheses .......................................................... 16

1 Specificity of the tryptophan depletion method

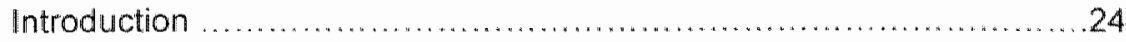

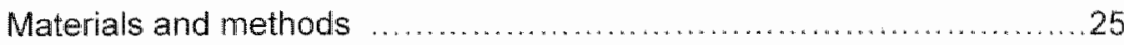

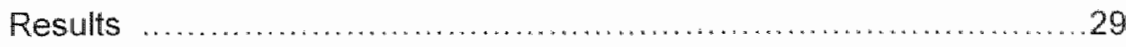

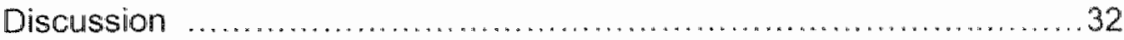

2 Mood effects of 24 hour tryptophan depletion in healthy firstdegree relatives of patients with affective disorders

Introduction ............................................................40

I Main behavioral study ..............................................41

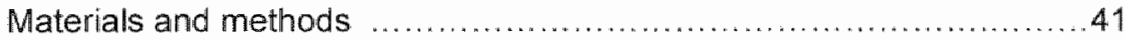

Results ..............................................................45

II Study on the pharmacokinetics of 24 hour TRP depletion...............48

General Discussion............................................................50

3 Mood-congruent memory bias induced by tryptophan depletion

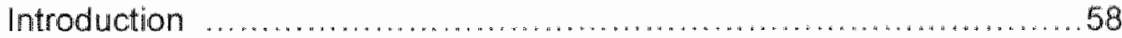

Materials and methods ............................................. 59

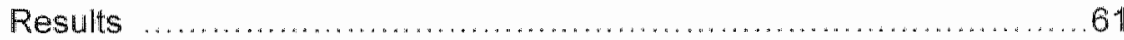

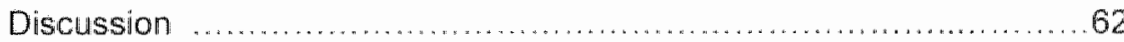

4 Tryptophan depletion in normal volunteers produces selective impairment in memory consolidation

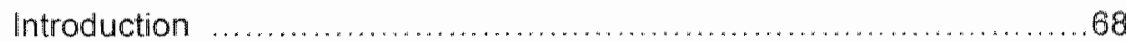

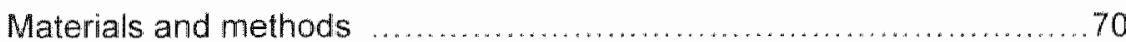

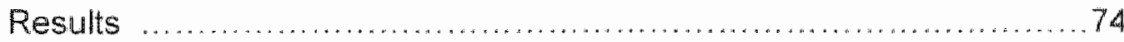

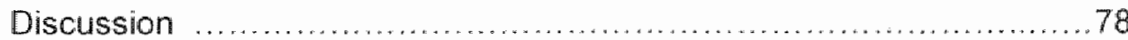


5 Effects of tryptophan depletion on anxiety and on panic provoked by carbon dioxide challenge

Introduction .............................................................. 86

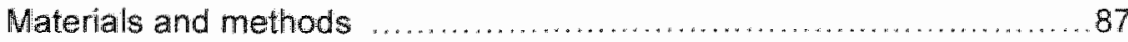

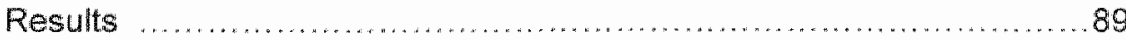

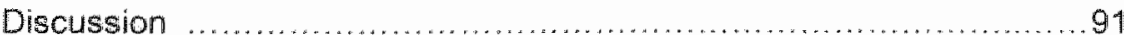

6 Effects of tryptophan depletion on carbon dioxide provoked panic in panic disorder patients

Introduction ............................................................... 98

Materials and methods ............................................. 98

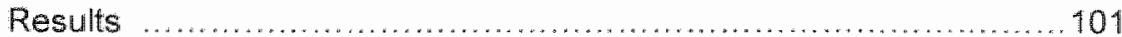

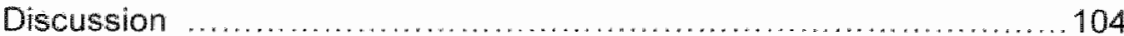

7 Neuroendocrine response to m-CPP and ipsapirone in relation to anxiety and aggression

Introduction ....................................................... 112

Materials and methods ............................................ 113

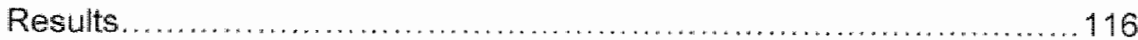

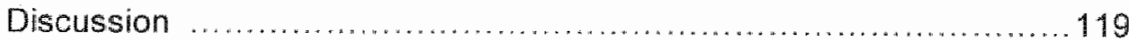

8 Dissociable hormonal, cognitive and mood responses to neuroendocrine challenge: evidence for receptor-specific serotonergic dysregulation in depressed mood

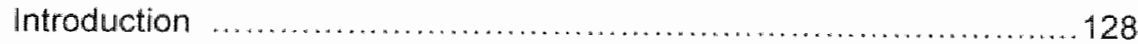

Materials and methods ............................................... 129

Results ................................................................ 133

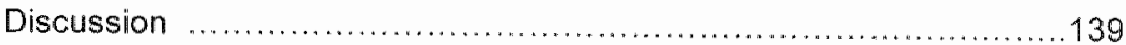

9 Serotonin syndrome after challenge with the 5-HT agonist meta-chlorophenylpiperazine

Introduction ......................................................... 144

Case histories ........................................................... 144

Discussion ...................................................... 146

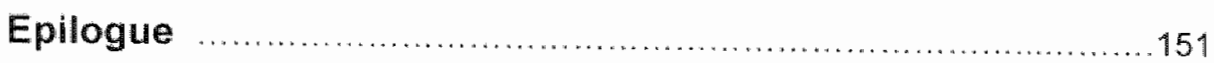

Samenvatting (summary in Dutch) .................................. 159

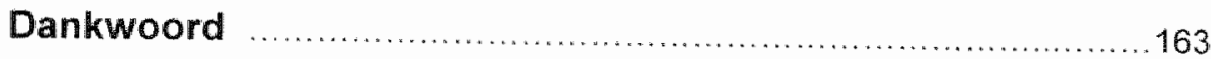

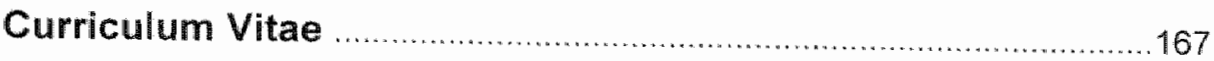






\section{Introduction}

Serotonin (5-hydroxytryptamine, 5-HT) is one of the major neurotransmitters responsible for modulating the state of activation of the brain. In a large variety of psychiatric syndromes, such as depression, obsessive-compulsive disorder, panic disorder, bulimia, and schizophrenia, disturbances in the 5-HT system have been identified. Also, 5-HT has long been known to mediate such diverse functions as anxiety and aggression regulation, sexual behavior, appetite, temperature regulation, sleep, mood, movements, gastrointestinal motility, and more (Stahl, 1998).

Disturbances in the 5-HT system may influence these functions, which may develop into symptoms of psychiatric disease.

Current views on the 5-HT system depict a complex entity with multiple discrete projections and over 14 subtypes of receptors. It is thought that the diverse pathways and receptors all have their own specific physiological functions. It follows that among the various psychiatric disorders that are at least partly 5-HT-related, each may involve its own combination of dysregulated $5-\mathrm{HT}$ pathways and receptor subtypes.

In this thesis, the focus will be on 5-HT disturbances in depressive and anxiety disorders, referred to as affective disorders. There is ample evidence that deregulation of the 5-HT system plays a major role in these disorders (for reviews see Mann, 1999; Handley, 1995). The role of 5-HT in anxiety and depression, however, is not an unambiguous one, and contradictory hypotheses have been advocated in the past.

As early as in the late 1960 s, increased vulnerability to depression was attributed to decreased serotonergic function (Van Praag, 1962; Coppen, 1967; Lapin \& Oxenkrug. 1969). Although some authors postulated that increased 5-HT function was related to depression (Aprison et al., 1977), most data supported the deficiency theory, namely, that low cerebrospinal fluid 5-hydroxyindolacetic acid (5-HIAA, the metabolite of 5-HT) levels were found in depressed subjects, which was considered to be a sign of lowered 5-HT metabolism (Asberg et al., 1984; Westenberg and Verhoeven, 1988). Other studies reported reduced platelet serotonin uptake in depressed subjects (Meltzer et al., 1981; Kaplan and Mann, 1982). In the early 
1990s, challenge tests reveiled decreased hormonal responses to several indirect 5HT agonists, such as fenfluramine and 1-tryptophan, in depressed subjects compared to normal controls (O'Keane and Dinan, 1991; Deakin et al. 1990; Mann et al., 1995). Such decreased hormonal reactivity is thought to reflect hyposensitivity of $5-\mathrm{HT}$ receptors. This hyposensitivity was found more specifically with regard to $5-H T_{1 A}$ receptors, as challenge tests with ipsapirone (Lesh et al. 1990; Meltzer and Maes. 1995. Shapira et al, 2000) and buspirone (Cowen, 1994) showed, while challenge tests with other probes, such as metachlorophenylpiperazine (m-CPP), a $5-\mathrm{HT}_{2 \mathrm{C}}$ agonist, showed conflicting results (Arnand et al., 1994; Kahn et al., 1990).

Furthermore, imaging studies revealed a decrease in $5-\mathrm{HT}_{1 \mathrm{~A}}$ binding potential in multiple regions of the brain (Drevets et al, 1999) and an increase in 5-HT2 receptors in the frontal cortex of depressed patients (D'Haenen et al., 1992), suggesting a downregulation or hyposensitivity of 5-HT 1 A receptors and an upregulation or hypersensitivity of 5- $\mathrm{HT}_{2}$ receptors, respectively. The method of tryptophan (TRP) depletion, a laboratory procedure that artificially decreases brain TRP, was shown to induce a recurrence of symptoms in depressed subjects in remission (Delgado et al. 1994). As TRP is the precursor of 5-HT, this suggests that decreased $5-H T$ function may be a factor in depression. Finally, a large group of depressed subjects were found to benefit from serotonin-related antidepressants such as the selective serotonin reuptake inhibitors (SSRls), leading to full remission (Boyer and Feigner. 1991).

In sum, there seems to be ample evidence of decreased serotonergic function in depression. However, the case is not that simple. Far from all depressed patients display the above described abnormalities. The group is probably heterogenous, both biologically and psychopathologically.

On the other hand, one thing is sure: there is a subgroup of depressed subjects with specific 5-HT abnormalities. This observation has led to the concept of a specific serotonin-related subtype of depression (wan Praag, 1996). According to van Praag, subjects with this type of depression have trait 5-HT distubances, i.e., their 5-HT system is chronically dysregulated, even at times when there is no clinical evidence of depression. Thus, the 5-HT disturbances are trait-related. This biological vulnerability is supposedly linked to unstable anxiety and aggression regulation which, in turn, causes these subjects to react with exaggerated anger and anxiety under conditions of stress. Accordingly, anxiety and suppressed aggression are thought to act as the pacemakers for mood lowering, driving the subjects into a fullblown major depression.

The hypothesis of a specific serotonin-related subtype of depression invites further exploration into the exact nature of the 5-HT abnormalities. For example, the disorder could be related to a particular receptor subtype, to a disturbed 5-HT metabolism, to the second messenger system, or to a disorder in the 5-HT uptake mechanism, just to cite a few possible factors. Also, it is still unclear what the exact nature of the genetic vulnerability is and how sustained stress or acquired brain damage may give 
rise to depression. There is evidence that a genetically detemined or acquired vuinerability of the hypothalamic pituitary adrenal (HPA) axis results in a predisposition for the development of affective disorders (Stokes, 1995). Sustained stress may thereby lead to chronic overstimulation of the HPA axis, characterized by high cortisol levels. Furthemore, chronic hyperactivity of the HPA system may lead to $5-H T_{\| A}$ receptor downregulation, while $5-H T_{1 A}$ receptors play a role in the negative feedback control of the HPA system (Mc Allister-Wiliams et al., 1998). It thas been hypothesized that 5-HTIA receptor downregulation is one of the features accompanying major depression (Maes and Meltzer, 1995; Van Praag, 1996), together with an upregulation of $5-\mathrm{HT}_{2 \mathrm{C}}$ receptors.

With regard to anxiety, the role of $5-\mathrm{HT}$ is even more complex. Although $5-\mathrm{HT}$ is a stress-related neurotransmitter and physical stress leads to increased 5-HT turnover (Chaoulloff, 1993), increasing 5-HT function in the absence of threat does not lead to fear-like behavior in animal studies (Handley, 1995). In humans, it is far from clear whether normal controls react with increased anxiety to challenges with 5-HT agonists. Panic patients have been reported to do so, but these highly aroused subjects also react with increased anxiety to other aversive stimull. It is, therefore. not at all certain that 5-HT itself fosters anxiety. 5-HT supposedly modulates a general propensity to react to aversive stimuli with increased anxiety. One of the diverse hypotheses on the role of 5-HT in anxiety (Handley, 1995) proposes that 5-HT plays a role in the way humans perceive and react to threats. In the case of long-term, lowered 5 HT function, neuronal activity can be compared to that during relaxation and drowsiness. This is a situation in which the subject is not in control of its environment and can only react to unexpected threats in an impulsive. primitive way. The subject is not able to trust its own judgment. Under these conditions, it is understandable that threats are perceived with panic-anxiety. Increased 5-HT function on the other hand, mimics active waking, a situation in which the cortical areas of the brain are in full control and are able to assess perceived threats with great accuracy. Primitive reactions are no longer necessary and are inhibited by increased 5-HT function of lower areas of the brain. Thus, 5uHT pathways are unlikely to mediate anxiety in a direct manner, but rather play an important role in the assessment of, and reaction to, perceived threats. The well known therapeutic action of SSRIs in the treatment of anxiety disorders (Den Boer et al., 1995) can also fit this theory.

In conclusion, there is ample evidence of a crucial role of 5-HT in both depressive and anxiety disorders. The exact pathophysiological mechanism is, however, still unclear and remains to be elucidated. In this thesis, studies are presented to further clarify the role of 5.HT in the pathophysiology of affective disorders. 


\section{Outline of methods used in this thesis}

Several methods have been developed to gain insight into 5 -HT function in the brain. The work reported in the present thesis relies on two of these methods. One procedure inhibits the 5-HT system, the so-called tryptophan depletion method. The other one is meant to stimulate the 5 -HT system and is referred to as the neuroendocrine challenge method.

\section{Inhibition of the 5-HT system}

As mentioned earlier, in depressive and anxiety disarders, disturbances have been identified that indicate a shortage of $5-\mathrm{HT}$. Furthermore, it has become clear that medication, aimed at increasing the turnover of 5-HT (e.g. SSRls) or at stimulating 5-HT receptors (e.g. Buspirone) has beneficial therapeutic effects in affective disorders (Landen et al., 1998; Mourithe and Stokes, 1998). Strictly speaking, however, these two facts do not provide us with evidence that 5-HT disturbances are indeed part of the pathophysiological mechanisms underlying anxiety and depression. In order to reveal an etiological relationship between anxiety or depression and 5-HT, one should ideally use an experimental approach in which the 5-HT available in the brain is diminished, for example, by depletion of its precursor, TRP. In the 1970s, a technique called tryptophan (TRP) depletion was developed, aimed at decreasing serotonergic activity in the brain with the help of an amino acid mixture lacking TRP and rich in competing amino acids.

TRP, the precursor of 5-HT, is one of the essential amino acids, which means that it can only be supplied through nutrition. By administering an amino acid mixture containing all essential amino acids except TRP, a decrease in the synthesis of 5-HT is attained as follows: Available plasma TRP is captured by the liver in order to be incorporated in proteins, whereby blood levels of TRP decrease substantially. As TRP is carried over the blood-brain barrier by a competitive transport mechanism, together with several other amino acids, low plasma levels of TRP, in combination with high plasma levels of competing amino acids, lead to a substantial decrease in the uptake of TRP in the brain. As a result, only little 5-HT can be formed. An extensive review of the method and results of studies has been given by Reilly et al. (1997) and Moore et al. (2000).

With this method, an $80 \%$ depletion of TRP in plasma can be attained within 5-7 hours. Modern imaging techniques have indicated that serotonin synthesis in the human brain is decreased even more after 5-7 hours (Nishizawa et al., 1997). 


\section{Stimulation of the 5-HT system}

Neuroendocrine challenges are used to gain insight into 5-HT receptor sensitivity (Yatham and Steiner, 1993). 5-HT binds to specific 5-HT receptors that are located both pre-and postsynaptically, thereby initiating such effects as homonal release, temperature rise, or emotional changes. When 5-HT release is chronically reduced. 5-HT receptors will compensate by increasing their sensitivity (Stahl, 1996) in order to maintain homeostasis of physiological processes. This is called receptor upregulation'. Conversely, when 5-HT release increases, receptor sensitivily decreases as a consequence. Thus, the sensitivity of 5-HT receptors is an index of 5$H T$ reactivity. This sensitivity can be measured by administering a substance that binds to the 5-HT receptor, a receptor agonist or antagonist, and measuring a function that is 5-HT-mediated. The height of the hormonal, temperature, or behavioural response to a 5-HT receptor agonist is an index of 5-HT receptor sensitivity. A large response suggests a high receptor sensitivity and a small response indicates hyposensitivity.

\section{The functional approach}

One of the problems in 5-HT research is that dysregulated 5-HT activity in the brain is not specific for any of the defined psychiatric diseases. As mentioned before, 5-HT disturbances are found in a wealth of psychiatric syndromes. Most investigators in biological psychiatry typically apply experimental tests to patients with a given diagnosis, usually following the Diagnostic and Statistical Manual of Mental Disorders (DSM) or the International Classification of Diseases (ICD) systems. This so-Galled nosological approach is intended to identify differences between patients and normal controls. It is implicitly assumed that entities defined by these classification systems possess sufficient validity. However, strikingly, when group differences are observed between patients and normal controls, differences do not necessarily apply to all individual subjects. Conversely, it often appears that when differences are not evident in the group as a whole, a subset of subjects does show disturbances. Thus. the search for specific biological markers for each disease has thus far been futile and may very likely be an unattainable goal, especially if one considers the fact that disorders in psychiatry have been defined more by consensus than on the basis of generally accepted and confirmed scientific evidence. Some have argued that repetitive revision of the DSM system is a demonstration of the limits of the system (Van Praag, 1989).

Yet, seen from a different frame of reference, 5-HT disturbances and perhaps other pathophysiological features regain specificity if one adheres to a so-called functional approach (Van Praag, 1996). In this approach, psychopathological syndromes are 
dissected into specific psychological dysfunctions, such as disturbances in mood, perception, cognition, memory, and information processing. Psychological dysfunctions are generally considered to be the elementary units of psychiatric syndromes. These psychological dysfunctions are nosologically non-specific and they occur across different diagnoses. In biological psychiatry, meaningful associations between biological and psychological dysfunctions may be sought across different diagnoses.

A similar functional approach is used in general medicine. For example, in subjects with myocardial infarction, cardiac state is assessed in terms of cardiac output, rhythm, beat frequency, and conductance. Treatment is aimed at these specific functions, not at the nosological description "myocardial infarction". Furthermore, at least some of these specific functions are also assessed in subjects with cardial decompensation, tricuspidal insufficiency and conductance disorders.

The functional approach has been proposed elaborated upon and supported for a long time by Van Praag et al. (van Praag et al., 1975;1987). In this thesis, one does not propose replacing the nosological with the functional approach, but rather considering the latter as a useful complement to the former.

In the neuroendocrine challenge studies, a functional approach is adhered to. The idea of comparing subjects on the basis of DSM IV-defined disorders is abandoned. Instead, groups of subjects with various types of affective disorders are studied, bearing in mind the hypothesis that specific psychic dysfunctions, rather than DSM IV disorders, are associated with 5-HT disturbances. Associations are sought between these psychic dysfunctions and particular 5-HT disturbances.

\section{Hypotheses}

With the above frame of reference in mind, the following general hypotheses were formulated, underlying the successive studies in this thesis.

\section{PART 1: TRYPTOPHAN DEPLETION}

\section{On the efficacy of the method}

1. Are the effects of TRP depletion caused by lowered 5-HT synthesis? What is the role of disturbed brain protein synthesis?

A shortage of TRP not only leads to diminished 5-HT synthesis, but also to disturbances in brain protein metabolism. The latter process can be influenced in a similar manner by depletion of another essential amino acid, such as lysine. 5-HT 
synthesis is not affected by lysine depletion. It is hypothesized that the effects of TRP depletion will not occur after lysine depletion.

In chapter 1, a study is described in which the effects of TRP depletion and lysine depletion are compared in a group of normal volunteers.

\section{On mood and the role of predisposition}

2. Are possible emotional effects of TRP depletion greater in a group of subjects with depressed first-degree relatives than in subjects without, and will these effects be augmented after a longer-lasting depletion?

It is known that depression is seen more frequently in some families than in others. There is probably a hereditary component that makes certain subjects more vulnerable to depression than others. In one early study (Benkelfat et al., 1994), subjects with depressed family members reacted to TRP depletion with more mood effects.

A group of nomal subjects with and one without depressed first-degree relatives are compared with regard to emotional effects. It is hypothesized that depressed firstdegree depressed relatives will respond with larger effects.

Furthermore, it has become apparent that TRP depletion has more prominent effects in formerly depressed subjects than in subjects who have never experienced a depressive episode (Delgado et al., 1990; Moreno et al., 1999). The latter group only shows very mild subclinicial mood effects in response to TRP depletion. It may be that the 5-HT system in the first group is more easily deranged, e.g., due to a lack of sufficient 5-HT stores. In that case, it may be possible to elicit depressive symptoms by TRP depletion in a group of normal subjects, provided the TRP depletion lasts long enough to deplete available 5-HT stores in the brain. It is thus hypothesized that effects of TRP depletion will be greater after 24 hours of depletion than after 6 hours. A report of a prolonged TRP depletion siudy, using first-degree relatives of depressed subjects and subjects without depressed family members, is presented in chapter 2.

\section{On cognition and the role of predisposition}

3. What are the cognitive effects of TRP depletion, especially with regard to learning. memory, and aftention, and can differential effects be found between subjects with and without depressed first-degree relatives?

There is some evidence that the 5-HT system plays a role in cognitive function (McAllister-Williams et al., 1998; Buhot et al. ,2000). However, only little research has been done into the cognitive effects of TRP depletion. In one study, a specific effect 
on leaming and memory was reported (Park ef al. 1994) in the absence of an effect on mood. Another study found effects of TRP depletion on attention and the speed of stimulus-incompatible responses (Coull et al. 1995).

These findings are extended by using a mixed group of male and female subjects instead of only male subjects, as used in the former studies. Furthermore, although several studies have shown that vulnerability lo depression may be linked to mood effects of TRP depletion, an association between cognitive effects of TRP depletion and vulnerability to diepression has not been reported.

Results of a study addressing cognitive effects of TRP depletion can be found in chapter 3.

\section{On memory bias and the role of predisposition}

4. Is if possible to induce memory bias by TRP depletion? Will this memory bias be more pronounced in first-degree relatives of depressed subjects, and will the memory bias be mood-congruent?

In chapter 4, we will address the subject of thought content after TRP depletion. In depressiom, information processing is often disturbed and thought content is generally negatively colored. With regard to the past, depressed subjects tend to remember more negatively colored information, thus maintaining their depression. This phenomenon is called "mood-congruent memory bias", a term used by cognitive psychologists. In clinical practice, both cognitive and biological theories are used to explain psychopathology, but the interrelationship between cognitive and biological theories is often unclear.

It is hypothesized that TRP depletion induces a mood-congruent memory bias and that this memory bias will be contingent upon depressed mood. The role of family history in this respect is also explored.

\section{On anxiety}

5. Will the TRP depletion method enhance panic symptoms after $35 \% \mathrm{CO}_{2}$ ? How does TRP depletion influence generalized anxiety?

Although the 5-HT system is involved in anxiety regulation, TRP depletion generally does not lead to increased generalized anxiety.

The $35 \% \mathrm{CO}_{2}$ inhalation test is a provocation method that induces panic in paric patients, but seldom does so in normal controls (Griez et al., 1987; Perna et al., 1994). The exact mechanism underlying the $35 \% \mathrm{CO}_{2}$ inhalation test is still unclear. It is hypothesized that the 5-HT system plays a role in its action and that TRP depletion will sensitize anxiety related mechanisms so that increased anxiety becomes apparent after provocation with $35 \% \mathrm{CO}_{2}$ (Kent et al. 1996). 
In chapter 5, we present a study that addresses the abovementioned hypothesis in normal subjects, while in chapter 6 the same hypothesis is tested in panic patients.

\section{PART II: STIMULATION OF 5-HT RECEPTORS}

\section{On the interplay between subreceptors}

6. How is 5-HT $T_{1 A}$ and $5-H T_{2 C}$ receptor sensitivity in a group of subjects with mixed affective disorders compared to that in a group of nomal controls?

5-HT $1 \mathrm{~A}$ and $5-H T_{2 \mathrm{C}}$ receptor function is monitored in a group of subjects with depressive and/or anxiety disorders and in a group of normal controls. There is some evidence of interactions between the abovementioned 5-HT receptors, whereby the first receptor exerts an inhibitory effect on the latter, and vice versa (Maes and Meltzer, 1995). It is hypothesized that heightened $5-\mathrm{HT}_{2} \mathrm{C}$ receptor sensitivity will be accompanied by lowered 5-HT, 1 receptor sensitivity, and vice versa. This hypothesis has not been addressed in one group of subjects before, especially not in a group of subjects with depressive and/or anxiety disorders. A study on this matter is presented in chaper 7 .

\section{On the interplay between receptors and psychollogical functions}

7. Is there a correlation between 5-HT 1 and/or 5-HT 20 receptor sensitivity and measures of aggression and anxiety in a group of subjects with mixed affective disorders?

Based on earlier research, van Praag (1996) suggests that anxiety and aggression may be two psychological factors that are directly related to measures of 5-HT function, irrespective of diagnosis. Using a functional approach, $5-H T_{1, A}$ and $5-H T_{2} \mathrm{C}$ receptor function is measured in a group of subjects with depressive and/or anxiety disorders and in a group of normal subjects. It is hypothesized that a correlation between measures of anxiety/aggression and 5 HT receptor sensitivity will exist across diagnoses. Results of a study on this subject are presented in chapter 8 .

\section{On side effects of the method}

Chapter 9 describes a major side effect of m-CPP - the serotonin syndrome, a syndrome caused by hyperstimulation of the 5-HT system - in three subjects. 
This thesis concludes with an epilogue; in which the results of the studies are discussed and suggestions for further research are made.

\section{References}

Anand, A. Charrey, D.S., Delgado, P.L., McDougle. C.J., Heninger, G.R., and Ppice, L.H. (1994) Neuroendocine and behavioural responses to intravenous m-Chlorophenylpiperazine (m-CPP) in depressed patients and thealthy comparison subjects. American Journal of Psychiatry 151: 16261630

Aprison, M. H. Takahasti, R, and Tachiki, K (1977) Hypersensitive serotonegic receptors involved in clinical depression-a theory. In: Neuropharmacology and Behavior (eds B. Haber \& M. Aprison). pp. 23-53. New York: Pergamon Press

Asberg, M. Bertilssan "L., Martensson, B., Scalia Tomba "G.P. Thorén "P., and Träskman-Bendz, L. (1984) CSF monoamine metaolites in melancholia. Acta Psychiatrica Scandinavica 69: 201-219

Benkelfat, C. Ellentogen, M.A., Dean, P., Palmour, R.M., and Young, S.N. (1994) Mood-lowering effect of tryptophan depletion. Enhanced susceptibility in young men al genetic risk for major affective disorders. Archives of General Psychiatry 51: 687-697

Delgado, P. L. Chamey, D.S., Price, L.H. Aghajanian, G.K., Landis, H., and Heninger, G.R. (1990) Serotonin function and the mechanism of antidepressant action: Reversai of antidepressantinduced remission by rapid depletion of plasma tryptophan. Archives of General Psychiatry 47: $411-4.18$

Den Boer J.A., Westenberg, H.G.M., De Leeuw, A.S, and Van Vliet, I.M. (1995) Biological dissection of anxiety disorders: The clinical role of selective serotonin reuptake inhibitors with particular reference to fluvoxamine. International Clinical Psychopharmacology 9 suppl. $4: 47-52$

Boyer, W.F., and Feighner, J.P. (1991) The efficacy of selective serotonin re-uptake inhibitors in depression. In: Selective serotonin re-uptake inhibitors. (eds. J.P. Feignhner and W.F. Boyer) pp.89-108. Chichester, England: John Wiley \& Sons L.td.

Buhot, M. Martin, S, and Segu, L. (2000) Role of serotonin in memory impairment. Annals of Medicine 32: $210-221$

Chaouloff, F. (1993) Physiopharmacological interactions between stress homones and central serotonergic systems. Brain Research Reviews 18:1-32

Coppen A. (1967) The biochemistry of affective disorders. British Journal of Psychiatry 113: 12371264

Couli, J.T., Sahakian, B.J., Middleton, H.C., Young, A.H.,Park, S.B., McShane, R.H., Cowen, P.J., and Robbins, T.W. 1995) Differential effects of clonidine, haloperidol, diazepam and tryptophan depletion on focused attention and attentional search. Psychopharmacology 121:222-230

Cowen, P.J.. Power, A.C. Ware, C.J. and Anderson, I.M. (1994) 5-HT A receptor sensitivity in major depression. A Neuroendocrine study with buspirone. British Journal of Psychiatry $164: 372-379$

Deakin, J.W.F., Pernell, I., Upadhyaya, A.J., and Lofhouse, R. (1990) A neuroendocrine study of 5Hif function in depression: evidence for biological mechanisms of endogenous and psychosocial causation. Psychopharmacology 101: 85-92

D'Haenen, H., Bossuyt, A., Mertens, J., Bossuytt.Piron, C. Gijsemans, M., and Kaufman, L. (1992) SPECT imaging of serotonin 2 receptors in depression. Psychiatry Research 45: 227-237 
Delgado, P.L., Price, L.H., Miller, H.L., Salomon, R.M., Aghajanian, G.K, Heninger, G.R., and Charney, D.S. (1994) Serotonin and the neurobiology of depression. Effects of tryptophan depletion in drug-free depressed patients. Archives of General Psychiatry 51: 865-874

Drevets, W.C., Frank, E., Price, J.C., Kupfer, D.J., Holt, D., Greer, P.H., Huang Y., Gautier, C. and

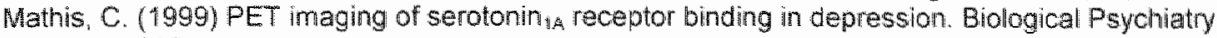
46: $1375-1387$

Griez, E., Lousberg, H., wan de Hout, M.A., and van der Molen, G.M. (1987) $\mathrm{CO}_{2}$ vulnerability in panic disorder. Pisychiatry Research 20:87-95

Handley. S.L. (1995) 5-Hydroxytryptamine pathways in anxiety and its treatment. Pharmacology and Therapeutics 66: 103-148

Kahn, R.S., Wetzler, S., Asnis, G.M. Papolos, D., and van Praag. H.M. (1990) Serotonin receptor sensitivity in major depression. Biological Psychiatry 28: 358-362

Kaplan, R.D. and Mann, J.J (1982) Altered platelet serotonin uptake kinetics in schizophrenia and depression. Life Science 3: 583-588

Kent, J.M., Coplan, J.D. Martinez, J. Karmaly, W., and Gorman, J.M. (1996) Ventilatory effects of tryptophan depletion in panic disorder, a preliminany report. Psychiatry Research 64: 83-90

Landen, M., Bjorling, G., Agren, H., and Fahlen. T. (1998) A randomized, double-blind, placebocontrolled trial of buspirone in combination with an SSRI in patients wit treatment-refractory depression. The Journal of Clinical Psychiatry 59(12): 664-668

Lapin, I.P., and Oxenkrug, G.F. (1969) Intensification of the central serotoninergic processes as a possible determinant of the thymoleptic effect. Lancet 1 (7586): 132-136

Lesch, K.P., Mayer, S., Disseikamp-Tietze, J., Hoh, A., Wiesmann, M., Osterheider, M., and Schulte, H.M. (1990) $5-H T_{4,}$ receptor responsivity in unipolar depression. Evaluation of ipsapirone-induced ACTH and cortisol secretion in patients and controls. Biological Psychiatry 28 (7) 620-628

Maes, M., and Meltzer, H.Y. (4995) The Serotonin Hypothesis of Major Depression. In: Bloom FE, Kupfer DJ (eds) Psychopharmacology: The Fourth Generation of Progress. Raven Press, New York

Mann, J.J., McBride, P.A., Malone, K.M., DeMeo, M.D., and Keilp, J. (1995) Blunted serotonergic responsivity in depressed patients. Neuropsychopharmacology $13: 53-64$

Manm, J.J. (1999) Role of the serotonergic system in the pathogenesis of major depression and suicidal behawior. Neuropsychopharmacology 21 suppl.: $99-105$

Maes, M., Meltzer, H.Y., D'Hondt, P. Cosyns, P., and Blockx, P. (1995) Effects of serotonin precur'sors on the negative feedback effects of glucocorticoids on hypothalamic-pituitary-adrenal axis function un depression. Psychoneuroendocrinology 20: 149-467

McAllister-Williams, R.H., Ferrier, IN. and Young. A.H. (1998) Mood and neuropsychological function in depression: the role of corticosteroids and serolonin. Psychological Medicine 28: $573-584$

Meltzer, H.Y., Arora, R.C.,Baber, R, and Tricou, B.J. (1981) Serotonin uptake in blood platelets of psychiatric patients. Archives of General Psychiatry 38: 1322-1326

Meltzer, H.Y. and Maes, M. (1995) effects of ipsapirone on plasma contisol and body temperature in major depression. Biological Psychilatry 38(7): 450-457

Moore, P. Landolit, H, Seifritz, E., Clark, C., Bhatti. T., Kelsoe, J., Rapaport, M. and Gillin, J C. (2000) $C$ linical and physiological consequences of rapid tryplophan depletion. Neurpsychophamacology 23 (6): $601-622$

Moreno, F. A., Gelenberg, A.J., Heninger, G. R., Potter, F.L., McKnight, K.M. Allen, J. Phillips, A.P. and Delgado, P.L. (1999) Tryptophan depletion and depressive vulnerability. Biological Psychiatry 46: 498-505

Mourihe, P., and Stokes, P.E. (1998) Risks and benefits of selective serotonin reuptake inhibitors in the treatment of depression. Drug Safety $18(1) .57-82$ 
Nishizawa, S., Benkelfat, C. Young. S.N., Leyton, M., Mzengeza, S., de Montigny, C., Biler, P., and Diksic, M. (1997) Differences between males and females in rates of serotonim synthesis in human brain. Proceedings of the National Academy of Sciences of the USA 94: $5308-5313$

Okeane, $V$ and Dinan, T.G. (1991) Prolactin and cortisol responses to d-Fenfluramine in major depression: Evidence for diminished responsivity of central serotonergic function. American Joumal of Psychiatry 148: 1009-1015

Park, S.B. Coult, J.T. McShane, R.H., Young, A.H., Sahakian, B.J., Robbins, T.W., and Cowen, P.J. (1994) Tryptophan depletion in normal yolunieers produces selective impaiments in leaming and memory. Neuropharmacology 33: $575-588$

Perna, G. Battagira, M. Garberi, A., Arancio, C. Bertani, A, and Bellodi, L. (1994) $35 \% \mathrm{CO}_{2} 65 \% \mathrm{O}_{2}$ inhalation test in panic patients. Psychiatry Research 31 : 159-171

Van Praag, H.M., Korf, J., Lakke, J.P.W.F., and Schut, T. (1975) Dopamine metabolism in depression, psychoses and Parkinson's disease the problem of the specificity of biological variables in behawiour disorders. Psychological Medicine $5: 138-146$

Van Praag, H.M., Kahn, R.S. Asnis, G.M., Wetzler, S., Brown, S.L. Bleich, A., and Kom, M.L. (1987) Denosologization of biological psychiatry or the specificity of 5-HT disturbances in psychiatric disorders. Journal of Affective Disorders 13: 1-8

Van Praag, H. W. (1989) Diagnosing depression - looking backward into the future. Psychialric Developments 4: $375-394$

van Praag, H.M. (1996a) Serotonin related, anxiety/aggression-driven stressor-precipitated depression. A psycho-biological hypothesis. European Psychiatry 11:57-67

Van Praag, H.M. (1996b) Faulty cortisollserotonin interplay: psychopathological and biological characterisation of a new, hypothetical depression subtype (seca depression). Psychiatry Research 65: $143-157$

Reilly, J.G., McTavish, S.F.B., and Young, A.H. (1997) Rapid depletion of plasma tryptophan a review of studies and experimental methodology. Journai of Psychopharmacology 11(4): 381-392

Shapira, G., Newman, M.E., Gelfin, Y., and Lerer, B. (2000) Blunted temperature and cortisol responses to ipapirone in major depression: lack of enhancement by electroconvulsive therapy. Psychoneuroendocrinology 25 (5): $421-438$

Staht, S.M. (1996) Neurotransmitter receptor hypothesis of depression in: Essential Psychopharmacology. pp. 123-125. Cambridge: Cambridge University Press

Stahl, S.M. (1998) Mechanism of action of serotonin selective reuptake inhibitors. Serotonir receptors and pathways miediate therapeutic effects and side effects. Journal of Affective Disorders $51: 215$ 235

Stokes, P.E. (1995) The potential role of excessive cortisol induced by HPA hyperfunction in the pathogenesis of depression. European Neuropsychopharmacology 5 suppl: $77-82$

Westenberg. H.G.M., and Verhoeven, W M.A. (1988) CSF monoamine metabolites in patients and controls: support for a bimodah distribution in major affective disorders. Acta Psychiatrica Scandinavica 478 : $306-317$

Yatham, L.N., and Steiner, M. (1993) Neuroendocrine probes of serotonergic function: a critical review. Life Sciences 53: $447-463$ 


\title{
Specificity of the tryptophan depletion method
}

T. Klaassen, W.J. Riedel, N.E.P. Deutz, A. van Someren \& H.M. van Praag

Published in: Psychopharmacology (1999) 141: 279-286

\begin{abstract}
Thirteen healthy subjects were subjected to tryptophan (TRP) depletion, lysine (LYS) depletion, and a placebo condition in a double blind cross-over study. The aim of the study was to test the specificity of psychological effects induced by TRP depletion. Subjects ingested a $100 \mathrm{~g}$ amino acid mixture with or without TRP or LYS. Six hours later, plasma TRP levels had decreased by $77 \%$ in the TRP depletion test and LYS levels by $51 \%$ in the LYS depletion condition. After six hours of TRP depletion, subjects reported significantly more tiredness and lowering of mood, compared to subjects in the placebo group, and memory performance declined. After six hours of LYS depletion, no significant differences in mood and memory compared to placebo were found. We conclude that the effects of TRP depletion on mood and memory are specific for the depletion of TRP and are not caused by the depletion of an amino acid per se. This supports the hypothesis that TRP depletion affects brain serotonin metabolism and not only brain protein metabolism in general.
\end{abstract}

KEY WORDS: Tryptophan, Lysine, Amino acids, Mood, Memory 


\section{Introduction}

The tryptophan (TRP) depletion method is widely used to study the behavioural effects of reduced serotonergic metabolism in the brain. The aim of the procedure is to lower serotonin (5-hydroxytryptamine; 5 -HT) levels in the brain by lowering 5 -HT synthesis via depletion of its precursor, tryptophan. In animal studies, the efficacy of the method has been confirmed by measuring brain serotonin and 5 mydroxyindoleacetic acid levels (Young et al., 1989; Schaechter and Wurtman, 1990). In humans, ingestion of 50-100 g of an amino acid mixture without TRP leads to a $75-90 \%$ reduction in plasma TRP within 4 to 6 hours (Young et al., 1985; Benkelfat et al., 1994).

After TRP depletion, a significant reappearance of depressive symptoms occurred in remitted depressed patients (Delgado et al., 1990; 1991; Lam et al., 1996), an effect which disappeared within 24-48 hours (Delgado et al., 1991). Several studies have shown that TRP depletion leads to a lowering of mood in normal subjects (Young et al., 1985; Smith et al., 1986; Ellenbogen et al., 1996) and particularly in subjects with a positive family history of depression (Benkelfat et al., 1994). Recovered depressed patients off drug treatment also show a significant mood lowering response to tryptophan depletion (Smith et al., 1997). Furthermore. TRP depletion in humans affects many psychological and physical functions such as cognition, nocturnal melatonin secretion, sleep, breathing patterns, memory and learning, anxiety, aggression, and food selection (Moja et al., 1989; Young et al., 1985; 1988; Zimmermann et al.. 1993; Benkelfat et al., 1994; Menkes et al., 1994; Park et al., 1994; Weltzin et al., 1994; 1995; Cleare and Bond, 1995; Miller et al., 1996; Moeller et al., 1996; Kent et al., 1996). In order to be considered an adequate challenge test for serotonergic functions, the TRP depletion method should be reliable, reversible, and specific. The first two issues have been addressed in other studies (Smith et al. 1987; Moja et al., 1989; Delgado et al., 1990; Ellenbogen et al., 1996). In monkeys, Young et al. (1989) found that TRP depletion did not change the metabolism of other neurotransmitters like tyrosine and the catecholamines, whereas levels of tryptophan and 5 hydroxyindoleacetic acid in the cerebrospinal fluid were lowered. Thus, if the effects of TRP depletion are linked to neurotransmission in the brain, it is probably the serotonergic system that is affected. In that sense, there seems to be specificity.

Theoretically. TRP depletion has two major effects on brain metabolism: it reduces the synthesis of serotonin (Gessa et al., 1974; Moja et al., 1989), and the synthesis of proteins in general (Blazek and Shaw, 1978; Cortamira et al., 1991). This latter effect is an aspecific effect that will also occur after depletion of any amino acid and could induce behavioural effects. We therefore questioned whether the effects of TRP depletion on mood and cognition could be mimicked by depletion of any amino acid. To our knowledge, no studies have addressed this question.

To study this aspect of the specificity of the TRP depletion method, normal subjects took part in three separate tests, in which they were given a mixture containing no TRP, a mixture containing no lysine (LYS), and a mixture containing both amino acids 
(placebo). We hypothesized that the behavioural effects of TRP depletion would not occur after LYS depletion. We assessed mood and memory measures, because earlier studies have demonstrated effects of TRP depletion on mood (Young et al., 1985; Smith et al., 1987; Benkelfat et al., 1994; Ellenbogen et al., 1996;) and memory (Park et al., 1994 ) in normal subjects. Furthermore, both depressed mood and impaired memory are part of the depressive syndrome, which can be elicited by TRP depletion in subjects that are prone to depression (Delgado et al., 1990; 1991; Lam et al., 1996; Benkelfat et al., 1994).

\section{Materials and methods}

\section{Subjects}

Sixteen subjects were recruited by newspaper advertisments. Inclusion criteria were good physical and mental health (as assessed by medical history, and physical examination), no history of psychiatric disorder, no current axis I DSM IV diagnosis [as assessed by the Mini International Neuropsychiatric Interview (Sheehan et al. 1994)], and no use of psychotropic medication in the week before the start of the test. Both men and women in the age range 18-65 were allowed to participate.

Of the sixteen subjects who entered the study, three subjects (all women, aged 20,21, and 32 years) dropped out after the first session due to nausea and vomiting. Two of them had received the placebo mixture, and the third had ingested the TRP depletion mixture. The thitteen subjects ( 3 men, 10 women) who completed the study had a mean age of $27 \pm 7 \mathrm{yrs}$, and had a mean body mass index $(\mathrm{kg} / \mathrm{m} 2)$ of $24 \pm 5$. Day of the menstrual cycle was recorded: while in the pre-menstrual week, 2 women received TRP depletion, 2 women received LYS depletion and 4 women received placebo. Hence, the distributions of day of the menstrual cycle did not differ between treatment conditions in a manner that would augment an effect of TRP depletion or LYS depletion on mood or memory.

\section{Procedure}

The study was approved by the Medical Ethics Committee of the University Hospital Maastricht, The Netherlands, as part of a larger project evaluating the effects of TRP depletion on mood and memory in relation to a family history of depression. The results of that study are reported elsewhere (Klaassen et al., 1999; Riedel et al., 1999). All subjects gave their written informed consent prior to their inclusion and were paid for their participation in the study. The subjects were informed that the study would investigate mood and memory in response to three different amino acid mixtures. On three occasions (spaced one week apart), subjects underwent TRP depletion, LYS depletion, and placebo depletion in a randomized, double-blind fashion. On each test day, subjects arrived at the clinic at 08:30, after an overnight fast. Behavioural 
questionnaires (describied later) were filled out by the subjects, and at 09:00 (10) the subjects then ingested (as quickly as possible, but within 2 hours) one of three amino acid mixtures (see table 1): without TRP or LYS or with both amino acids present (placebo).

\section{Table 1 Composition of the placebo amino acid mixture}

$\begin{array}{lr}\text { L-alanine } & 5.5 \mathrm{~g} \\ \text { L-arginine } & 4.9 \mathrm{~g} \\ \text { L-cysteine } & 2.7 \mathrm{~g} \\ \text { glycine } & 3.2 \mathrm{~g} \\ \text { L-histidine } & 3.2 \mathrm{~g} \\ \text { L-isoleucine } & 8.0 \mathrm{~g} \\ \text { L-leucine } & 13.5 \mathrm{~g} \\ \text { L-methionine } & 3.0 \mathrm{~g} \\ \text { L-phenylalanine } & 5.7 \mathrm{~g} \\ \text { L-proline } & 12.2 \mathrm{~g} \\ \text { L-threonime } & 6.5 \mathrm{~g} \\ \text { L-tyrosine } & 6.9 \mathrm{~g} \\ \text { L-valine } & 8.9 \mathrm{~g} \\ \text { L-lysine } & 8.9 \mathrm{~g} \\ \text { L-serine } & 6.9 \mathrm{~g} \\ \text { L-tryptophan } & 3.0 \mathrm{~g}\end{array}$

In the tryptophan depletion mixture, 1-tryptophan was left out. In the Iysine depletion mixture, l-lysine was left out.

The LYS depletion mixture and the placebo amino acid mixture contained $3 \mathrm{~g} \mathrm{TRP}$ Each mixture also contained, $63 \mathrm{~g}$ carbohydrates and $33 \mathrm{~g}$ fat in order to dissolve the amino acids. The mixtures were flavoured with artificial orange (first test day) or apricot flavour (second test day). On the third test day the flavour (orange or apricot) was chosen by the subjects themselves. The three mixtures were of identical appearance. For the 24 hours following ingestion of the mixture, all subjects were kept on a diet containing $19 \mathrm{mg}$ TRP and $80 \mathrm{mg}$ LYS. This diet was identical for all three sessions. marmalade, 2 pieces of fruit, $200 \mathrm{~g}$ applith a total of $1.1 \mathrm{~g}$ protein, margarine, mints (max. $50 \mathrm{~g}$ ). At 7,11 and 14 hours after ade, 3 glasses of lemonade, and on day 1 , an additional $10 \mathrm{~g}$ of that day's aminater administration of the amino acid mixture 
stayed at the ward until after the behavioural (mood and memory) assessment at 45:00 (te). They went home with their food supply and dietary instructions. A detailed description of all food and beverages consumed (time and amount) was kept by each subject, in order to encourage strict adherence to the diet. The next morning, the subjects returned at 9:00 am ( $\mathrm{t}_{24}$ ) for the second delayed recall of the words learned at ts. This was followed by a protein-rich meal to compensate for possible deficiencies. Afterwards, they went home and resumed their normal food intake.

Blood samples were drawn at $t_{0}, t_{6}$, and $t_{24}$ for determination of total plasma levels of TRP, LYS and all other amino acids.

\section{Behavioural ratings}

Behaviour was assessed by means of questionnaires administered at $t_{0}, t_{6}$ and $t_{24}$. Mood states were measured with the Dutch 30 -item validated version of the Profile of Mood States Scale (POMS; McNair et al., 1988), von Zertssen's Mood Adjective Scale (Linden and Krautzig, 1981), and a 100-mm Visual Analogue Scale (WAS) for depression. The POMS consists of five mood scales (depression, tension, vigor, hostility, and tiredness), each based on six items. Von Zerssen's Mood Adjective List consists of 28 bipolar mood states. Subjects are instructed to indicate which of the paired opposites (positive vs. negative) best reflected their current mood state; if neither applied, subjects could fill an item in as 'neutral'. Positive, negative, and neutral scores are then summed over the 28 states, yielding three mood measures: Zer-pos, Zer-neg and $Z$ Eer-meu. The VAS depression was rated $0=$ "no depression" to $100=$ "maximum depression'.

A questionnaire concerning side effects was administered at to and at $1.5,3,5$ and 7 hours after administration (these were averaged to comprise one $t_{6}$ measure) and at 24 hours ( $\left.t_{24}\right)$ after administration. The list contained the following 13 items, rated on 5 point scales $(0=$ not at all to $4=$ very much): dry mouth, dizziness, palpitations. headache, feeling cold, mausea, sleepiness, drowsiness, feeling warm, blurred wision, perspiration, tiredness, and abdominal discomfort.

\section{0- Word learning task}

At $t_{6}$, thirty words were presented on a computer screen. Every 2 seconds, a new word was presented for 1 second. Following the presentation of all thirfy words, subjects were asked to recall verbally as many words as possible (= immediate recall). The first immediate recall triall was followed by two more trials in which the same words were presented in the same order. After 30 minutes they were asked to recall as many of the previously presented words as possible $\left(t_{6 \rightarrow 6}\right)$. At $t_{24}$ subjects were asked to recall the words again $\left(t_{6}, 24\right)$. The delayed recall trials at $t_{6}$ and $t_{24}$ were followed by recognition trials in which subjects were to recognize 15 learned target words from 15 distractor words by means of pressing a yes/no button. Words were presented on a screen for 
2000 msec or until the subject responded. Another 1000 msec elapsed before the next word appeared on the screen. Errors and reaction times were recorded.

Three different lists of 30 monosyllabic words were used, one per session, which were presented in a randomized order over the three sessions. Each list contained 18 nouns and 12 adjectives. The lists were comparable with regard to their level of abstraction and the affective tone of the words. All instructions were standardized and were read to the subjects from an instruction sheet.

One week before the experiment, the subjects practised the task with a separate list of words to reduce learning effects during the test. For a more detailed description see Riedel et al., 1999.

\section{Biochemical analysis}

At $t_{0,} t_{6}$, and $t_{24}$, blood was withdrawn and immediately placed on ice and centrifuged within 30 minutes for 5 minutes at $1000 \mathrm{~g}$ at $4^{\circ} \mathrm{C}$. An aliquot of $100 \mu$ of plasma was then mixed with $4 \mathrm{mg}$ sulphasalicyl-acid and frozen at $-80^{\circ} \mathrm{C}$ until analysis (van Eijk et al., 1994). Analysis of total plasma TRP and LYS concentrations and those of other amino acids was carried out with high-performance liquid chromatography (van Eijk et al. 1993). In addition to total plasma TRP and LYS levels, the ratio of total plasma TRP versus the sum of the following five competing amino acids [the so-called Large Neutral Amino Acids (LNAA)], valine, leucine, isoleucine, phenylalanine, and tyrosine (TRP/ZLNAA), was determined. The same calculation was carried out with regard to LYS and its competitors arginine and ornithine [(Basic Amino Acids (BAAs)] (LYS/LBAAs) (Oldendorf and Szabo, 1976; Tews et al. 1981). These ratios provide an estimation of TRP and LYS uptake in the central nervous system (Fernstrom and Wurtman, 1972).

\section{Statisticall analysis}

All results are presented as means \pm standard deviation. Because the distribution curves of all questionnaire data (including the side effects) were skewed to the right, we used non-parametric tests to analyse the results. Wilcoxon's signed rank test was used to compare TRP versus placebo and LYS versus placebo effects at $t_{0}$ (baseline) and $t_{6}$. After Bonferroni-Holm correction, differences, were considered significant if $p \leq 0.025$. Since there were no baseline differences between conditions, results at to were evaluated as treatment effects. For the analysis of side effects, the sum scores for the six questionnaires completed after TRP depletion were compared with those after LYS and placebo depletion. Scores on the Word Learning tasks were normally distributed "so we used paired t-tests to compare TRP depletion versus the placebo condition and LYS depletion versus the placebo condition. Results from amino acid levels were evaluated using paired t-tests at to. Order effects over the word learning tasks were inspected by plotting the data. Order effects were not expected to occur over the mood questionnaires and were therefore not analysed. 


\section{Results}

\section{Plasma amino acids}

TRP and LYS plasma levels and TRP/LLNAA and LYS/LBNAA ratios are listed in table 2. The TRP plasma level at $t_{0}$ and at $t_{24}$ did not differ between treatment conditions. The TRP plasma level at $t_{6}$ was lower in the TRP depletion condition $(t=10.1, d f=11$, $p<.0001)$. The LY'S plasma level at to did not differ between treatment conditions. The LYS plasma level at $t_{5}$ was lower in the LYS depletion condition $(t=4.7, \mathrm{df}=11, \mathrm{p}<.001)$. The LYS plasma level at $\mathrm{t}_{24}$ was $10 \%$ lower in the LYS depletion condition $(t=3.5, \mathrm{df}=11$, $p<.005)$. The TRP $\Sigma / \Sigma L N A A$ ratio at $t_{0}$ did not differ between treatment conditions. The TRP $/ \Sigma L N A A$ ratio at $t_{6}$, was lower in the TRP depletion condition $(t=8.6, d f=11, p<.001)$. The TRP/ $\Sigma L N A A$ ratio at $t_{24}$ was lower in the TRP depletion condition $(t=3.9, d f=11$, $p<.005)$. The LYS/ $/ 2 B N A A$ ratio at $t_{0}$ and at $t_{24}$ did not differ between treatment conditions. The LYS/ $/$ BNAA ratio at $t_{5}$ was lower in the $L Y S$ depletion condition ( $t=4.7$, $d f=11, p<.001)$.

Table 2. Amino acid levels $(\mathrm{ng} / \mathrm{mll}) \pm S \mathrm{SD}$ and uptake ratios in the different conditions

\begin{tabular}{|l|l|c|c|c|}
\hline Amino Acid & Time & TRP depletion & Lys depletion & Placebo test \\
\hline TRP & 0 & $49.4 \pm 10.8$ & $50.0 \pm 11.2$ & $48.1 \pm 10.2$ \\
\hline & 6 & $12.8 \pm 4.8^{*}$ & $58.3 \pm 18.0$ & $53.7 \pm 15.5$ \\
\hline & 24 & $41.6 \pm 13.3$ & $45.5 \pm 6.5$ & $47.7 \pm 9.4$ \\
\hline LYS & 0 & $170.7 \pm 41.2$ & $178.4 \pm 38.5$ & $178.5 \pm 44.2$ \\
\hline & 6 & $195.2 \pm 48.8$ & $89.4 \pm 45.0$ & $169.7 \pm 58.2$ \\
\hline & 24 & $210.4 \pm 50.5$ & $161.2 \pm 43.7^{* *}$ & $206.5 \pm 50.8$ \\
\hline TRPILLNAA & 0 & $9.0 \pm 1.6$ & $9.0 \pm 1.4$ & $9.2 \pm 1.4$ \\
\hline & 6 & $1.9 \pm 1.4$ & $8.3 \pm 1.7$ & $8.6 \pm 3.1$ \\
\hline & 24 & $7.2 \pm 1.1$ & $8.9 \pm 1.0$ & $8.8 \pm 1.6$ \\
\hline LYSILBNAA & 0 & $1.1 \pm 0.4$ & $1.4 \pm 0.4$ & $1.4 \pm 0.4$ \\
\hline & 6 & $1.1 \pm 0.3$ & $0.7 \pm 0.4$ & $1.5 \pm 0.4$ \\
\hline & 24 & $1.6 \pm 0.4$ & $1.4 \pm 1.3$ & $1.5 \pm 0.3$ \\
\hline
\end{tabular}

"p<0.001 compared to placebo * $p<0.005$ compared to placebo

\section{Mood}

Table 3 shows the mean behavioural measurements $\pm \mathrm{sd}$. at baseline and 6 hours after the different amino acid mixtures. Analysis of baseline ratings showed no significant 
differences between conditions. At to, increased tiredness was observed after TRP depletion compared to placebo as measured on the POMS-tiredness scale $Z=-2.5$, $d f=12, p=0.01)$. Tiredness scores after TRP depletion also tended to be higher than after $L Y S$ depletion $(Z=-1.7$, $d f=12, p=.09$ ). Summed POMS-scores (in which the vigilance score was transformed according to $y=20-x$ ) were significantly higher after TRP-depletion $(Z=-2.8, d f=12, p=.005$ ). Summed POMS-scores after TRP depletion also tended to be higher than after $L Y S$ depletion $(Z=-1.8, d f=12, p=.07)$. Furthermore, a higher score on the total Negative Mood Score of Von Zerssen's Mood Adjective List $(Z=-2.4, \mathrm{df}=12, p<.025)$ was seen after TRP depletion relative to placebo. There were no significant effects of LYS depletion compared to placebo on these measures. No other significant effects on mood were found.

Table 3. Mean behavioural measurements \pm sd. at baseline and 6 hours after the amino acid mixtures

Placebo

to

\begin{tabular}{lcccccc} 
& $t_{0}$ & $t_{6}$ & $t_{0}$ & $t_{6}$ & $t_{0}$ & $t_{6}$ \\
VAS-depression & $3.2 \pm 6.3$ & $4.5 \pm 13.0$ & $2.7 \pm 6.6$ & $8.2 \pm 18.2$ & $2.2 \pm 5.1$ & $3.3 \pm 7.0$ \\
POMS-tiredness & $2.3 \pm 4.1$ & $2.2 \pm 4.4$ & $1.6 \pm 2.9$ & $3.9 \pm 5.1^{*}$ & $1.9 \pm 3.2$ & $2.52 \pm 3.6$ \\
POMSdepression & $0.5 \pm 1.0$ & $0.2 \pm 0.6$ & $0.6 \pm 1.3$ & $1.5 \pm 3.3$ & $0.3 \pm 0.9$ & $0.5 \pm 1.1$ \\
POMS-tension & $1.2 \pm 3.0$ & $1.5 \pm 39$ & $0.8 \pm 1.2$ & $1.6 \pm 2.3$ & $2.3 \pm 4.0$ & $1.5 \pm 3.8$ \\
POMS-hostility & $0.7 \pm 1.3$ & $0.5 \pm 1.1$ & $0.5 \pm 1.1$ & $1.0 \pm 1.8$ & $0.7 \pm 1.9$ & $0.5 \pm 1.0$ \\
POMS-vigilance & $13.2 \pm 6.0$ & $13.7 \pm 3.6$ & $13.2 \pm 4.7$ & $12.1 \pm 4.7$ & $14.1 \pm 5.4$ & $12.9 \pm 3.8$ \\
ZER-pos & $25.2 \pm 3.8$ & $26.0 \pm 2.7$ & $25.4 \pm 2.3$ & $22.4 \pm 4.8$ & $25.2 \pm 3.9$ & $24.2 \pm 3.3$ \\
ZER-neg & $1.3 \pm 1.9$ & $1.2 \pm 1.7$ & $1.3 \pm 1.3$ & $3.3 \pm 3.5 *$ & $1.7 \pm 3.5$ & $2.8 \pm 0.9$ \\
ZER-neu & $1.5 \pm 2.7$ & $0.8 \pm 1.7$ & $1.3 \pm 1.4$ & $2.3 \pm 2.5$ & $1.1 \pm 1.9$ & $1.0 \pm 1.4$ \\
\hline
\end{tabular}

TRP depletion LYS depletion

\begin{tabular}{|c|c|c|c|c|c|c|}
\hline & $t_{0}$ & $t_{s}$ & $t_{0}$ & $\mathfrak{t}_{6}$ & to & $t_{6}$ \\
\hline VAS-depression & $3.2 \pm 6.3$ & $4.5 \pm 13.0$ & $2.7 \pm 6.6$ & $82+18.2$ & $2.2 \pm 5.1$ & $3.3+70$ \\
\hline POMS-tiredness & $2.3 \pm 4.1$ & $2.2 \pm 4.4$ & $1.6 \pm 2.9$ & $3.9 \pm 5.1^{*}$ & $1.9 \pm 3.2$ & $2.52 \pm 3.6$ \\
\hline POMSdepression & $0.5 \pm 1.0$ & $0.2 \pm 0.6$ & $0.6 \pm 1.3$ & $1.5=3.3$ & $0.3 \pm 0.9$ & $0.5 \pm 1.1$ \\
\hline POMS-tension & $1.2+3.0$ & $1.5 \pm 39$ & $0.8 \pm 1.2$ & $1.6 \pm 2,3$ & $2.3 \pm 4.0$ & $1.5+3.8$ \\
\hline POMS-hostility & $0.7 \pm 1.3$ & $0.5 \pm 1.1$ & $0.5 \pm 1.1$ & $1.0 \pm 1.8$ & $0.7 \pm 1.9$ & $0.5 \pm 1.0$ \\
\hline POMS-vigilance & $13.2 \pm 6.0$ & $13.7+3.6$ & $13.2+4.7$ & $12.1+4.7$ & $14.1+5.4$ & $12.9 \pm 3.8$ \\
\hline ZER-pos & $25.2 \pm 3.8$ & 26.042 .7 & $25.4 \pm 2.3$ & $22.4 \pm 4.8$ & $25.2 \div 3.9$ & $24.2 \pm 3.3$ \\
\hline ZER-neg & 1.311 .9 & $1.2 \pm 1.7$ & $1.3 \pm 1.3$ & $3.3 \pm 3.5^{*}$ & $1.7+3.5$ & $2.8 \pm 0.9$ \\
\hline ZER-neu & $1.5 \pm 2.7$ & $0.8 \pm 7.7$ & $1.3 \pm 1.4$ & $2.3 \pm 2.5$ & $1.1 \pm 1.9$ & $1.0 \pm 1.4$ \\
\hline
\end{tabular}

\footnotetext{
*p<0.025 compared to placebo
} 


\section{Word learning task}

Visual inspection of the data revealed no differences among subjects' word learning task performance on the first, second, and third test days. This suggests that there were no relevant order effects that could have modified the results. Memory task performance under the three treatment conditions is summarized in table 4 .

Table 4

Mean recall and recognition sensitivity $(\%)$ and RT (msec) \pm sd of learned words

on the Word Learning Task after the different amino acid Imixtures

Treatment Placebo U.YS depletion TRP depletion

\begin{tabular}{|c|c|c|c|}
\hline Total recall $t_{6}$ & $41.4 \pm 10.0$ & $42.2 \pm 13.8$ & $42.3+10.7$ \\
\hline $1^{\text {st }}$ Delayed recall $\epsilon_{E, \ldots}$ & $13.7 \pm 5.9$ & $14.3 \pm 7.5$ & $12.4 \pm 6.4$ \\
\hline $2^{\text {nt }}$ Delayed recall $t_{6} \rightarrow 2$ d & 12.04 .8 & $11.6 \pm 7.6$ & $9.0+6.8^{\circ}$ \\
\hline Recognition $t_{6 \rightarrow 6}$ & $88.8 \pm 12.9$ & $90.5 \pm 10.9$ & $90.4 \pm 7.0$ \\
\hline Recognition $t_{\hat{\sigma} \rightarrow 24}$ & $83.0 \pm 12.2$ & $81.2 \pm 14.1$ & $77.8 \pm 23.9$ \\
\hline Recogn. RT to & $573 \pm 94$ & $547 \pm 72$ & $587 \pm 66$ \\
\hline Recogn. RT $t_{6 \rightarrow 24}$ & $552 \pm 103$ & $534 \pm 116$ & $582 \pm 105$ \\
\hline
\end{tabular}

* $\mathrm{p}<0.025$ ws. placebo

No significant differences in the immediate and first $\left(t_{6 \rightarrow 36}\right)$ delayed recall of words were found after TRP or LYS depletion compared to placebo. However, there was a tendency that more words were recalled after LYS depletion than after TRP depletion $(t=2.3$, $d f=12, p<0.05$ ). No effects were found on recognition. In the second delayed recall test $\left(t_{6 \rightarrow 24}\right)$, a significantly smaller number of learned words were recalled after TRP depletion than after placebo $(t=2.7, d f=12, p<0.025)$. No significant differences in the second $\left(t_{6 \rightarrow 24}\right)$ delayed recognition were found after TRP or LYS depletion compared to placebo. However, recognition RT tended to be faster after LYS depletion than after TRP depletion $(t=2.4, d f=12, p<0.05)$. 


\section{Side effects}

Scores of individual side effects per treatment are shown in table 5 . There were no statistically significant differences in side effects at $t_{0}, t_{6}$ and $t_{24}$ reported after TRP depletion and LYS depletion compared to placebo and neither between TRP and LYS depletion.

\begin{tabular}{|l|l|l|l|}
\hline & Placebo & TRP & LYS \\
\hline Stomach & $1.2 \pm 2.4$ & $1.3 \pm 3.0$ & $1.1 \pm 2.0$ \\
\hline Dry mouth & $2.3 \pm 4.5$ & $1.9 \pm 3.0$ & $1.2 \pm 2.3$ \\
\hline Feeling coid & $1.3 \pm 2.0$ & $1.5 \pm 3.3$ & $1.3 \pm 2.1$ \\
\hline Feeling hot & $1.2 \pm 1.3$ & $1.5 \pm 1.8$ & $1.8 \pm 2.0$ \\
\hline Dizziness & $0.1 \pm 0.3$ & $0.7 \pm 1.2$ & $0.8 \pm 1.7$ \\
\hline Drowsiness & $3.2 \pm 5.2$ & $3.6 \pm 5.5$ & $4.5 \pm 6.1$ \\
\hline Palpitations & $0.0 \pm 0.0$ & $0.2 \pm 0.4$ & $0.1 \pm 0.3$ \\
\hline Headlache & $0.8 \pm 1.2$ & $1.1 \pm 1.3$ & $1.1 \pm 1.9$ \\
\hline Nausea & $1.8 \pm 2.1$ & $2.9 \pm 2.1$ & $3.0 \pm 2.8$ \\
\hline Sleepiness & $5.2 \pm 4.2$ & $4.3 \pm 4.0$ & $4.7 \pm 5.2$ \\
\hline Perspiration & $0.6 \pm 1.1$ & $0.7 \pm 1.2$ & $0.6 \pm 1.1$ \\
\hline Blurred vision & $1.5 \pm 2.4$ & $1.2 \pm 2.1$ & $1.2 \pm 2.3$ \\
\hline Tiredness & $4.5 \pm 4.6$ & $3.8 \pm 4.1$ & $4.0 \pm 5.1$ \\
\hline
\end{tabular}

Table 5. Mean summed side effects i SD after the different amino acid mixtures

\section{Discussion}

We compared effects of TRP depletion to those of LYS depletion in order to test the specificity of the TRP depletion method. We compared LYS and TRP depletion for the following reasons: First. LYS is an essential amino acid. Plasma LYS levels are more easily modified by a diet than those of a non essential amino acid because the body is not able to produce LYS itself. Second, LYS and its derivatives are not involved in the production of any of the known neurotransmitters. Third, LYS is transported through the blood-brain barrier by a special carrier for basic amino acids, distinct from the carrier for TRP (Oldendorf and Szabo, 1976). Although some overlap between these carriers exists, competition among amino acids for transport across the blood-brain barrier occurs mainly within the groups of amino acids carried by each of the systems. Thus, there is no evidence that LYS depletion will influence TRP uptake in the brain. To the best of aur knowledge, no studies have been conducted on lysine and mood or lysine and memory, probably because there is no theoretical support for such a relationship. The results of our study do not indicate that there is a relationship between lysine depletion and mood or memory. 
Our results show that TRP depletion was followed by a significantly higher level of tiredness, together with a lowering of mood, and an impairment of consolidation of information in memory. No significant changes occurred in the placebo condition or after LYS depletion. Thus, the effects of TRP depletion are unikely to have resulted from an aspecific inhibitory effect on protein metabolism in the brain.

The treatments were effective in causing depletion of TRP and LYS. The plasma depletion of LYS was however not as large as that of TRP (51\% versus $74 \%)$, which is probably due to the relatively high levels of LYS in human blood compared to those of TRP. A failure to induce a severe lysine imbalance with a diet has also been observed in rats (Tews et al., 1981). Of course, a better comparison of effects would have been possible if the LYS depletion had been greater. Higher levels of ornithine and arginine in the amino acid mixture might lead to lower levels of LYS uptake in the brain by altering the plasma ratio of LYS/IBNAA.

Our assumption that LYS depletion would not influence TRP uptake in the brain was confirmed by the estimations of brain TRP uptake, as calculated from the TRPALNAA ratios. This ratio was equal in both the placebo condition and the LYS depletion test. In general, ingestion of the amino aciid mixtures cause few side effects (table 5), although three subjects dropped out because of severe nausea and vomiting after the placebo mixture (two subjects) and the TRP depletion mixture (one subject). Because during the tests the side effects of the various challenges were comparable, our results cannot be attributed to side effects produced by TRP depletion.

The addition of a carbohydrate - fat mixture to the amino acid mixture is a feature that distinguishes this TRP depletion method from previous studies, but this method was also used in the Riedel et al. (1999) study. We chose to do so in order to provide sufficient nutrients to the subjects during a 24 hour period. Carbohydrates when given without protein increases the rate of insulin, thus taking away several large neutral amino acids from the circulation (Fernstrom, 1981), and hence might stimulate the uptake of TRP in the brain. However, it has also been argued that when proteins, or AA mixtures that stimulate protein synthesis, and carbohydrates are given simultaneously, the addition of carbohydrates does not alter TRP uptake in the brain (Fernstrom and Fernstrom, 1995). Our data show that in the TRP depletion condition, the uptake of TRP in the brain, as reflected by the TRPISLNAA ratio, was diminished to a fairly low amount.

As to the effects of TRP-depletion on mood in this study several remarks may be made Despite the low number of subjects employed in the study significant effects of TRP. depletion on the POMS summed score and on the POMS item tiredness were found. It may be noted here that 10 of the 13 subjects were women and that 8 of the 13 subject had a positive family history for depression. As was mentioned previously, these factors contribute to the sensitivity of healthy subjects to the effects of TRP depletion (Benkelfat et al. 1994; Ellenbogen et al., 1996). We chose however not to consider these factor in the experimental design of the study because the total number of 13 subjects would render the design insensitive to those factors. The figures on sex and family history may 
however serve as circumstantial evidence to explain that in these healthy volunteers an effect of TRP-depletion on aspects of mood were found. Such effects were not found after LYS depletion and this can be interpreted as supporting the specificity hypothesis that the effects of TRP depletion on mood can be specifically attributed to lowered brain 5-HT. An effect of TRP depletion on tiredness has been reported earlier (Cleare and Bond, 1995; Ellenbogen et al.,1996; Mc Dougle et al., 1996; Neumeister et al. 1997). A mood lowering effect of TRP depletion has also been found in several studies, as was. mentioned in the introduction.

The effects of TRP depletion specifically on learning and memory in humans have been previously investigated by Park et al. (1994). This study showed an impairment of learning after ingestion of the TRP depletion mixture: after TRP depletion subjects needed more trials to learn correctly the spatial locations of abstract patterns and they made more errors in a paired association learning task. TRP depletion did not affect the initial number of correct associations made. Recognition memory was also not significantly affected. In a study designed similarly as the present one, our group investigated the effects of TRP-depletion on learning and memory in 27 healthy volunteers (Riedel et al., 1999). Briefly, the results showed no effects of TRP-depletion on short-term memory performance (immediate recall) and neither on other cognitive parameters (short-term memory scanning, choice reaction time and visual search efficiency and -RT). TRP-depletion specifically impaired delayed recall at 30 minutes $\left(t_{6 \rightarrow 6}\right)$ and at 18 hours $\left(t_{6 \rightarrow 24}\right)$ after word learning. When a new word list was presented at $\left(t_{24}\right)$, no differences in delayed recall 30 minutes after word list presentation were found between TRP depletion and placebo. Therefore it was concluded TRP depletion impairs consolidation of newly learned words, presumably in the 30 minutes after presentation. In the present study, we could only reproduce impaired delayed recall at 18 hours $\left(t_{6 \rightarrow, 24}\right)$ after learning. An explanation for this may be that in the present study only 13 subjects were studied whereas in the previous one 27 subjects were studied. As can be seen in table 4 delayed recall scores after TRP-depletion at $t_{5}$ were on average 1.3 lower than after placebo and 1.9 words lower than after LYS depletion, whereas in our previous study, using the same procedures and tests, the difference between TRP depletion and placebo was 2.3 words. The effects of TRP depletion at $t_{6 \rightarrow 2.4}$ were -3.0 words in the present study and -2.9 words in the previous study. Two explanations may the apparently different resuits at $t_{6}$ to a problem of statistical power in the present study due to the simall number of subjects. The second explanation is that the TRP depletion induced impairment of memory consolidation continues in the period between 30
minutes and 18 hours after learning. The question would then become if we can exclude
any external events that could be of explanatory any external events that could be of explanatory value as to the observed difference in memory consolidation. The factors to exclude are mood and perhaps sleep. It is unlikely
that mood effects explain impaired memory consolidation after TRP depletion as the two
other studies (Park et al. 1994: Riedel et al other studies (Park et al., 1994; Riedel et al., 1999) have both concluded that the observed learning and consolidation impairments were not mediated by mood. In the 
present study this is difficult to conclude, as the number of observations are low, but if lowered mood would explain impaired memory consolidation, than one would have to assume that this relationship is not momentary as they are not observed at the same moments in time. There is some evidence that TRP depletion alters sleep in a manner similar to those seen in depression (Bhatti et al., 1998; Voderholzer et al., 1998). Impaired sleep patterns may contribute to impaired delayed recall performance at the $t_{6 \rightarrow 2^{4}}$ assessment. Future studies could unravel this by including an assessment before sleeping, i.e. at $t_{6 \rightarrow 12}$

Park et al. (1994) demonstrated that after TRP depletion subjects took more trails to learn to associate stimulus pairs. This can be taken as evidence for a relatively immediate effect (in terms of minutes) of TRP depletion on memory consolidation. Interestingly. TRP depletion impaired performance on a visual discrimination task only when TRP depletion was administered in the first session, that is when the procedure still had to be learned. When placebo was given in the first session. TRP depletion in the $2^{\text {nd }}$ session did not impair performance, which is another indication that TRP depletion impairs consolidation of newly learned material. The measures of short-term memory (storage), such as spatial working memory and the memory score in paired associate learning were typically unaffected in the Park et al. (1994) study, so it may be concluded that the results of Park et al. (1994), Riedel et al. (1999) and the present study are well in line, except for the lack of (significance of) a TRP depletion effect on the $t_{6 \rightarrow 6}$ delayed recall memory measure. Finally, the extended $t_{6 \rightarrow 24}$ measure may be a more sensitive procedure to probe delayed recall because it may be assumed that the memory trace becomes weaker over time and hence the task of recall and also recognition becomes more difficult at that time. In the case of the sensitivity of recognition performance as a measure for treatment induced changes, this is clearly an advantage as the $t_{6>0}$ measure of recognition efficiency may also be easily subjected to a ceiling effect.

Future studies of mood responses to TRP depletion should include depressed patients in remission, who are usually more sensitive to the effects of TRP depletion than normal subjects, and at least twice as many subjects with a more equal distribution of sex and age. Visual Analogue Scales should preferably be bipolar, to ensure a more normal distribution of results occurs so that more advanced statistics can be used.

In conclusion, the effects of TRP depletion in our study were specifically caused by TRP depletion and were not found after LYS depletion. The results of this study make general effects on protein metabolism an unlikely explanation for the effects of TRP depletion on mood and memory. Thus, our study provides evidence for the specificity of the TRP depletion method. 


\section{References}

Benkelfat, C., Ellenbogen, M.A., Dean, P., Palmour, R. M. and Young, S.N. (1994) Mood-lowering effect of tryplophan depletion. Archives of General Psychiatry 51: $687-697$

Bhatti, T., Gillin, J.C. Selfriz, E., Moore, P., Clark. C., Golshan, S., Stahl, S. Rapaport, M., and Kelsoe J (1998) Effects of a tryptophan-fiee amino acid drink challenge on normal human steep electroencephalogram and mood. Biological Psychiatry 43:52-59

Blazek, R. and Shaw, D.M. (1978) Tryptophan availability and brain protein synthesis. Neuropharmacology 17(12): 1065-1068

Cleare, A.J, and Bond, A.J. (1995) The effect of tryptophan depletion and enhancement on subjective and behavioural aggression ir normal male subjects. Psychopharmacology 118: 72-81

Cortamira, N. O., Seve, B., Lebreton, $Y$., and Ganier, P. (1991) Effect of dietary tryptophan on muscle, liver and whole-body protein synthesis in weaned piglets; relationship to plasma insulin. British: Journal of Nutrition $66(3) ; 423-435$

Delgado, P.L., Charney, D.S. Price, L.H. Aghajanian, G.K. Landis, H, and Heninger, G.R. (1990) Serotonin function and the mechanism of antidepressant action. Archives of General Psychiatry 47 : $411-418$

Delgado, P.L., Price, L.H., Miller, H.L., Salomon, R.M., Licinio, J., Krystal, J.H., Heninger, G. R, and Charney, D.S. (1991) Rapid serotonin depletion as a provocative challenge test for patients with: major depression: relevance to antidepressant action and the neurobiology of depression. Psychopharmacology Bulletin 27(3): 321-330

Ellenbogen, M.A. Young, S.N., Dean, P., Palmour, R.M., and Benkelfat, C. (1996) Mood response to acute tryptophan depletion in healthy volunteers: sex differences and temporal stability. Neuropsychopharmacology 15 (5): 465-474

Fernstrom, J.D., and Wurtman, R.J. (1972) Brain serotonin content: physiological regulation by plasma neutral amino acids. Science 178: 414-416

Fenstrom, J.D. (1981) Dietary precursors and brain neurotransmitter formation. Annual Review of Medicine 32: $413-425$

Fernstrom, M.H.s and Fernstrom, J.D. (1995) Brain tryptophan concentrations and serotonin synthesis remain responsive to food consumption after the ingestion of sequential meals. American Journal of Clinical Nutrition 61: $312-319$

Gessa, G.L., Biggio, G., Fadda, F. Corsini, G.U., Tagliamonte, A. (1974) Effect of the orall administration of tryptophan-free amino acid mixtures on serum tryptophan, brain tryptophan and serotonin metabolism. Joumal of Neturochemistry 22: 869-870

Kent, J.M. Coplan, J. D. Martinez, J., Karmally, W., Papp, L.A., and Gorman, J.A. (1996) Ventilletory effects of tryptophan depletion in panic disorder: A prefiminary report. Psychiatry Research 64: 83-90

Klaassen, T., Riedel, W.J., van Someren, A. Deutz, N. E.P., Honig. A and Van Praag, H.M. (1999) Mood effects of 24 -hour tryptophan depletion in healthy first degree relatives of patients with affective

Lam, R.W., Zis. A.P., Grewal, A. Delgado, P.L., Chamey, D.S., and Krystal, J.H. (1996) Effects of rapid tryptophar depletion in patients with seasonal affecive diosrder in remission after light therapy.
Archives of General Psychiatry 53: 41-44

Linden, M., and Krautzig. E. (1981). Befindlichkeitsmessung in kurzzeitigen Abstunden; ein experimenteller Beitrag zur Validierung der Befindlichkeitsskala (Bf-S) nach v. Zerssen. Pharmacopsychiatria 14:40-44

McNair, D.M., Lorr, M., and Droppelman, L.F. (1988) Manual for the Profile of Mood States. Educational and industrial Testing Service, San Diego, California

Menkes, D.B., Coates, D.C., and Fawcelt, J.P. (1994) Acute tryptophan depletion aggravates premenstrual syndrome. Joumal of Affective Disorders 32: $37-44$ 
Miller, H. Deakin, J.F.W., and Anderson, 1. (1996) Acute tryptophan depletion increases panic anxiety in panic disorder patients. [Abstract] Journal of Psychophamacology 9 (3) suppl. A18

Moja. E.A. Cipolla, P., Castoldi, D., and Tofanethi O. (1989) Dose-response decrease in plasma tryptophan and in brain tryplophan and serotonin after tryptophan free amino acid mixtures in rats. Lifte Science 44: $971-976$

Moeller, F.G., Dougherty, D.M., Swann, A.C., Collins, D. Davis, C., and Cherek, D.R. (1996) Tryptophan depletion and aggresive responding in healthy males. Psychopharmacology 126:97-103

Oldenidorf. W.H., and Szabo, $\rfloor$ (1976) Amino acid assignment to one of three blood-brain barrier amino acid carriers. American Joumal of Physiology 230 (1): 94-98

Park, S.B., Coull, J.T., McShane, R.H., Young, A.H., Sahakian, B.J., Robbins, T.W., and Cowen, P.J., (1994)Typtophan depletion in normal volunteers produces selective impairments in learning and memory. Neuropharmacology $33(3 / 4): 575-588$

Riedel WJ, Klaassen T, Deutz NEP, wan Someren A, van Praag HM (1999) Tryptophan depletion in normal volunteers produces selective impairment in memory consolidation. Psychopharmacology 141 $362-369$

Schaechter, J.D., and Wurtman, R.J. (1990) Serotonin release varies with brain tryptophan levels. Brain Research 532: 203-210

Sheehan, D., Janavs, J., Knapp, E. Sheehan, M., Baker, R, and Sheehan, K.H. (1994) Mini International Neuropsychiatric Interview. University of south Florida, Tampa

Smith, S.E., Pihi, R.O., Young, S.N., and Ervin, F.R. (1986) Elevation and reduction of plasma tryptophan and their effects on aggression and perceptual sensitivity in normal males. Aggress Behav 12 $393-407$

Smith, S.E., Pihl, R.O., Young, S.N., and Ervin, F.R (1987) A test of possible cognitive and environmental influences on the mood lowering effect of tryptophan depletion in normal males Psychopharmacology 91: 451-457

Smith, K.A., Fairburn, C.G., and Cowen, P.J. (1997) Relapse of depression after rapid depletion of tryptophan. Lancet 349: 915-919

Tews, J.K., Bradford. A.M., and Harper, A.E. (1981) Induction of lysine imbalance in rats: relationships between tissue amino acids and diet. Journal of Nutrition 111:968-978

Van Eijk, H.M.H., Rooyakkers, D.R. and Deutz, N.E.P. (1993) Rapid routine determination of amino acids in plasma by high performance liquid chromatography with a 2-3 um Spherisorb ODS II column. Journal of Chromatography 620 : $143 \cdot 148$

Van Eijk, H.M.H. Dejong, C.H.C., Deutzm N.E.P., and Saeters. P.B. (1994) intluence of storage conditions on normal plasma amino-acid concentrations. Clinical Nutrition 14: 3744380

Voderhalzer, U., Hornyak, M., Thiel, B., HuwigPoppe, C. Kiemen, A., Konig, A, Backhaus, J., Riemann,

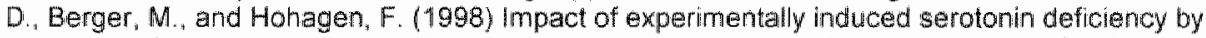
tryptophan depletion on sleep EEG in healthy subjects. Neuropsychopharmacology $18,112-124$

Weltzin, T.E. Fernstrom, J.D. McConaha, $C_{\text {, }}$ and Kaye. W.H. (1994) Acute tryptophan depletion in bulimia: effects on large neutral amino acids. Biological Psychiatry 35: 388-397

Weltzin, T.E. Fernstrom, M.H. Fernstrom, J.D. Neuberger, S.K, and Kaye, W.H. (1995) Acute tryptophar depletion and increased food intake and irritability in bullimia nervosa. Americal Journal of Psychiatry 1995: 1668-1671

Young, S.N., Smith, S.E. Pihl, R.O., and Ervin F.R. (1985) Tryptophan depletion causes a rapid lowering of mood in normal males. Psychophamacology 87: 173-177

Young, S.N. Tourjman, S.V., Teff, K.L., Pihl, R. O, and Anderson, GH. (1988) The effect of lowering plasma typtophan on food selection in normal males. Pharmacology. Biochemistry and Behavior 31 : 149-152.

Young, S.N., Ervin, F.R., Pihl, R.O., and Finn, P. (1989) Biochemical aspects of tryptophan depletion in primates. Psychopharmacology Berlin 98 (4): $501-511$ 
$38 \mid$ CHAPTER 1

Zimmermann, R.C., McDougle, C.J, Schumacher, M. Oclese, J., Mason, J.W. Heninger, G.R., and Price. L.H. (1993) Effects of acute tryptophan depletion on noctumal melatonin secretion in humans. Joumal of Clinical Endocrinology and Metabolism 76: 1160-1164 


\section{Mood effects of 24-hour tryptophan depletion in healthy first degree relatives of patients with affective disorders}

T. Klaassen, W.J. Riedel, A. van Someren, N. E.P. Deutz, A. Honig \& H.M. van Praag

Published in: Biological Psychiatry (1999) 46:489-49

\section{Abstract}

Acute tryptophan (TRP) depletion was evaluated in healthy volunteers with or without a family history of major affective disorder (FH+ vs.FH-). Twenty seven subjects (16 $\mathrm{FH}+11 \mathrm{FH}$-) received $100 \mathrm{~g}$ of an amino acid mixture with and without TRP according to a placebo-controlled, double-blind cross-over design and a diet devoid of TRP for the next 24 hours. The ratio TRP/large neutral amino acids declined to $22 \%$ of baseline values after 6 hours, and increased during the night reaching $85 \%$ of baseline after 24 hours. Overall, after 6 hours, TRP depletion lead ta a lowering of mood, but after 24 hours these changes were no longer detected. Mood changes and gastrointestinal side effects were significantly more evident in $\mathbb{F H}+$ subjects than in FH-subjects. Our data support the hypothesis that subjects with a positive family history for depression are predisposed to increased vulnerability to the adverse consequences of serotonergic imbalance.

KEY WORDS: Tryptophan depletion, Mood, Affective disorder, Family history. Healthy subjects 


\section{Introduction}

Acute tryptophan (TRP) depletion as a biochemical madel for depressed mood has become increasingly popular since it was first described (Moja et al., 1984 \% In rats, TRP depletion leads to a diminished turnover of serotonin (Schaechter and Wurtman, 1989; Young et al. 1989). In humans, ingestion of $50-100 \mathrm{~g}$ of a balanced amino acid mixture without TRP leads to a $75-90 \%$ reduction in plasma TRP concentrations within 4 to 6 hours (Young et al. 1985). Recently, it has also been shown that in human subjects TRP depletion leads to a decreased rate of 5-HT synthesis in the brain (Nishizawa et al. 1997) and to a lowering of CSF 5-HIAA 8-12 hours after the amino acid drink (Carpenter, 1998). These data suggest that TRP depletion results in substantial reduction of central 5-HT turnover.

TRP depletion affects many psychological and physiological functions such as cognition, noctumal melatonin secretion, sleep, breathing patterns, memory and learning, anxiety, aggression, and food selection (Benkelfat et al., 1994; Cleare and Bond, 1995; Kent et al., 1996; Menkes et al. "1994; Miller et al., 1995; Moeller et al., 1996; Park et al. 1994; Smith et al. 1987; Weltzin et al., 1994; Weltzin et al, 1995; Young et al., 1988; Young et al., 1985; Zimmermann et al., 1993). However, several studies have shown that TRP depletion usually does not lead to a lowering of mood in healthy subjects. One study with healthy male subjects who had elevated scores on a depression scale, showed a slight, but not clinically significant, mood-lowering effect of tryptophan depletion (Young et al., 1985). Two studies with healthy subjects showed that healthy female subjects were sensitive to the mood-lowering effect of tryptophan depletion, whereas healthy male subjects were not (Ellenbogen ef al., 1996; Smith et a., 1997a). Healthy subjects with a positive family history of depression show significantly more depressed mood after TRP depletion than healthy subjects without such a family history (Benkelfat et al., 1994). Acute TRP depletion in depressed patients in remission who had been treated with serotonergic antidepressants caused climically significant depressive symptoms within 6 hours (Delgado et al., 1989; Delgado et al., 1991; Lam et al., 1996; Smith et al, 1997b) These symptoms disappeared within 24 hours after discontinuation of the TRP depletion.

A possible explanation for these findings might be that it is more difficult to disrupt brain neurotransmitter systems in healthy subjects than in subjects who have been depressed or in subjects with a positive family history (FH) for depression. This alleged biological factor (trait-marker) could render some groups of subjects more sensitive to TRP deptetion. Alternatively, symptoms could be elicited in any group of subjects provided the depletion lasts long enough. Hence TRP depletion for 5 to 7 hours may be too short to elicit symptoms in healthy subjects. In rats, it has been possible to achieve a sharp and longlasting (24 hr) decline in plasma and brain tryptopham and in brain 5-HT (Biggio et al., 1974). Delgado et al. (1990) found a 
significant lowering of moad after 24 hours in remitted depressed patients using an amino acid mixture devoid of tryptophan.

For that reason, we developed a method to deplete subjects of TRP for 12 to 24 hours, using an amino acid mixture and a diet devoid of TRP. Our first hypothesis was that prolonged TRP depletion would lead to more symptoms of depression in healthy subjects after 24 hours than after 6 hours. Fuithermore, we were interested in the influence of the family history on symptoms of depression after TRP depletion. Benkelfat et al. (1994), showing that a positive family histony of depression was associated with increased sensitivity to TRP depletion, used a rather strict definition of positive family history of depression (FH+) in that subjects had to have three or more registered family members with recurrent depression of whom at least one should be a first degree relative (Benkelfat et al., 1994). The lifetime risk for major affective disorder (MAD) is estimated to be $7-25 \%$ in the general population (Chamey and Weissman, 1988). Family studies, however , have shown that the presence of one depressed first-degree relative already leads to a two-to three-fold increased relative risk for major depression (Charney and Weissman, 1988). For this reason, we defined $\mathrm{FH}+$ as having at least one first-degree relative with depression and hypothesized that $\mathrm{FH}+$ subjects would experience greater mood changes as a result of TRP depletion than subjects without a first-degree rellative with depression. One of the aims of this study was to maintain a depleted state for 24 hours. Ideally, one should have assessed the TRP blood levels frequently during the 24 hours in all subjects. However, this would impose too great a burden on the subjects. For that reason, we decided to conduct in addition to the main behavioural study a separate small pharmacokinetic study to monitor TRP levels regularly during 24 hours following TRP depletion.

We report the results and methods of the main study and the pharmacokinetic study subsequently.

\section{Main Behavioural Study}

\section{Materials and Methods}

\section{Subjects}

Thirty-four healthy volunteers were recruited, of whom 15 women and 12 men

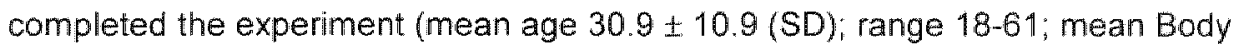
Mass Index (weight/ length $\left.{ }^{2}\right) 23.5 \mathrm{Kg} / \mathrm{m}^{2}$ ). The subjects were free of medication, except for oral contraceptives. A complete medical examination was carried out. Exclusion criteria were cardiac, hepatic, renal, pulmonary, neurological, 
gastrointestinal, haematological, or psychiatric conditions, as determined from the history, physical examination, ECG, and routine blood chemistry analyses. Further exclusion criteria were a history of alcohol or drug abuse, excessive drinking, dieting, and susceptibility to premenstrual syndrome as determined by questioning the subject. The latter susceptibility was assessed with the question Do you regularly experience significant mood swings during your menstrual cycle, especially in the week before the onset of the periods? A structured psychiatric interview, the MINI (Sheehan et al., 1994), was carried out to exclude psychiatric disorders. A validated Dutch version of the Subjective Complaint List, SCL-90 (Arrindell and Ettema, 1986), was used to verify the absence of other psychopathology. The Research Diagnostic Criteria (RDC) (Spitzer et al., 1975) were used to ascertain that subjects had no prior episode of MAD or Manic Depressive lllness. Inclusion criterion for subjects at risk for MAD was the presence of at least one first-degree relative (siblings or parents) with at least one episode of depression (including Bipolar Disorder type II). For subjects without genetic risk for MAD, the absence of MAD in all first- and second-degree relatives was the inclusion criterion. Family History Research Diagnostic Criteria were used to verify these criteria (Endicott et al., 1975),

All subjects were interviewed about their family history before the start of the study. Parents or nearest other first-degree relatives were telephoned for additional information. Depressed relatives had to be registered at our clinic and had to have experienced at least one episode of major depression or bipolar disorder type II and had to meet Research Diagnostic Criteria for major depression or bipolar disorder type I or II. Second- or third degree-relatives had to meet Family History Research Diagnostic Criteria (Endicott et al., 1975) for these disorders in order to be considered affected.

Two groups were formed, one consisting of first-degree relatives with depression (positive family history $(\mathrm{FH}+) 7$ males, 9 females, $29 \pm 11$ (SD) years) and one group without first-degree relatives with depression (negative family history (FH-), 6 females, 5 males; $33 \pm 10$ (SD) years). All subjects came from different families. Eight female subjects took oral anticonceptives.

Table 1 shows the demographic and family history characteristics of the two groups. There were no statistically significant differences with regard to demographic and family characteristics between the groups.

The study was approved by the Medical Ethics Review Committee of the University Hospital Maastricht, The Netherlands. All subjects signed voluntary informed consent prior to the study and were paid for their participation. 
Table 1 Demographic characteristics of the $\mathrm{FH}+$ and $\mathrm{FH}$-groups (meant sd)

\begin{tabular}{lll}
\hline & FH+ & FH- \\
\hline Women & $n=9$ & $n=6$ \\
Men & $n=7$ & $n=5$ \\
Age & $29 \pm 11$ years & $33 \pm 10$ years \\
Body Mass Index & $22 \pm 2 \mathrm{~kg} / \mathrm{m}^{2}$ & $25 \pm 5 \mathrm{~kg}^{2} \mathrm{~m}^{2}$ \\
SCL-90 score & $110 \pm 24$ & $97 \pm 6$ \\
Depressed Family Members: & & \\
1st degree & 19 & 0 \\
2nd degree & 8 & 2 \\
3rd degree & 9 & 4 \\
\hline
\end{tabular}

*Includes both subjects with unipolar and bipolar depression. The numbers represent the total number of subjects in the whole group that met Family History Research Diagnostic Criteria.

\section{Procedures}

Subjects arrived at the laboratory at 8.30 a.m. after an overnight fast. Mood assessment was completed at $9.00 \mathrm{a} . \mathrm{m}$. ( = baseline or $t_{0} ; t_{x}$ denotes time elapsed since treatment administration, $x$ referring to the number of hours after $\left.t_{0}\right)$. The day of the menstrual cycle was recorded in female subjects. Thereafter, subjects ingested the amino acid mixture as quickly as possible, but within 2 hours. The subjects remained in the laboratory until after the subjective mood assessments at $t_{6,}$ except for a 30-minute guided standardised walk through the hospital with the test assistant, and were allowed to read, study, or watch an emotionally neutral video.

The study was conducted according to a double-blind, placebo-controlled, balanced cross-over design. All subjects participated in a TRP depletion (TRP-) session and in a placebo (PLA) session, which were separated by at least 4 days. In each of the two sessions subjects had to ingest $100 \mathrm{~g}$ of an amino acid mixture with or without TRP. followed by a diet containing $19 \mathrm{mg}$ TRP which had to be adhered to for the next 24 hours. This diet was identical in both sessions and consisted of six slices of bread with a tolal of $1.1 \mathrm{~g}$ protein, butter, jam, two apples, $200 \mathrm{~g}$ apple sauce, tea, lemonade, and mints ad libitum. At $\mathrm{t}_{7}, \mathrm{t}_{11}$, and $\mathrm{t}_{14}$, an additional $10 \mathrm{~g}$ of that days" 
amino acid mixture was ingested in order to keep TRP levels low. These timepoints were arbitrarily chosen.

After these assessments, subjects went home with their food supply and dietary instructions. A detailed description of all food and beverages consumed (time and amount) was kept by each subject, in order to encourage strict diet adherence. The next moming, the subjects returned for the last assessments at $t_{24}$. Afterwards they received a protein-rich meal to compensate for possible deficiencies.

\section{Amino Acid Mixtures}

The TRP-deficient amino acid mixture was made according to Young et al. (1985) and contained 15 free amino acids in a total amount of $100 \mathrm{~g}$. The placebo mixture contained the same amino acids plus $3 \mathrm{~g}$ of L-tryptophan. A mixture of $33 \mathrm{~g}$ fat and $63 \mathrm{~g}$ carbohydrate was added in order to dissolve the amino acids. Mixtures were flavoured with artificial orange (first test day) or apricot flavour (second test day). The mixture contained 1000 Kcall. Tap water $(300 \mathrm{ml}$ ) was added to the mixture on the morning of the experiment. The mixtures were identical in appearance. We added $3 \mathrm{~g}$ of TRP to the amino acid mixture instead of $2.3 \mathrm{~g}$, as used by Young et al. (1985), on the basis of the results of Weltzin et al. (1994). They added $2.3 \mathrm{~g}$ and $4.6 \mathrm{~g}$ of TRP to the amino acid mixture and assessed the ratio of TRPIZLNAA (sum of the Large Neutral Amino Acids: tyrosine, leucine, isoleucine, valine and phenylalanine) at 3 and 7 hours after the administration of the mixture. The ratio provides an estimation of TRP uptake in the central nervous system (Fermstrom, 1981).

The mixture containing $2.3 \mathrm{~g}$ of TRP led to a significant $45 \%$ decrease in brain uptake of TRP, while $4.6 \mathrm{~g}$ of TRP led to a maximum $154 \%$ increase at 3 hours. We chose an amount in between, assuming that this amount would not affect the TRP/ZLNAA ratio and hence brain TRP uptake and would thus serve as an inactive placebo. Our findings showed that our placebo amino acid mixture with $3.0 \mathrm{~g}$ TRP lead to a slight decrease $(11 \%)$ in the TRP/ $L$ LNAA ratio.

\section{Subjective Assessments}

At $t_{0}, t_{6}$ and $t_{24}$ subjects were administered the Profile of Mood States Scale (POMS) (MoNair et al, 1971). The POMS consists of five separate mood scales (depression. tension, vigour, anger, and fatigue), ranging from 0-24, each based on six items ranging from 0-4. Thus, each of these five mood dimensions yielded a score. Furthermore, an overall POMS score, reflecting mood level, was constructed by summing the scores for the five subscales, after changing the polarity of the vigour subscale $(y=24-x)$.

A list (5-point scales) of 10 vegetative side effects was used to determine the severity of the side effect. The list contained the following items: headache, feeling cold, feeling hot, dizziness, transpiration, blurred vision, nausea, palpitations, dry mouth, 
and abdominal complaints. Scores for the 10 side effect items were summed. yielding one vegetative side effect severity measure at each assessment. Finally some computerised cognitive tests were carried out which are described elsewhere (Riedel et al., 1999).

\section{Biochemical Analysis}

At $t_{0}, t_{6}$, and $t_{24}$, venous blood was taken and immediately placed on ice and centrifuged within 30 minutes for 5 minutes at $1000 \mathrm{~g}$ at $4{ }^{\circ} \mathrm{C}$. An aliquot of $100 \mu \mathrm{l}$ of plasma was then mixed with $4 \mathrm{mg}$ sulphasalicyl-acid and frozen at $-80^{\circ} \mathrm{C}$ untit analysis (van Eijk et al. 1994). Total plasma concentrations of TRP and other amino acids were measured by high-performance liquid chromatography (van Eijk et al. 1993). In addition to total plasma TRP concentrations, the ratio of TRP/ determined.

\section{Statistical Analysis}

Results were analysed using SPSS 8.0 for Windows statistical packages. Primary outcome measures were the POMS scores. As distributions of the scores were skewed, non-parametric tests were used. Differences between TRP depletion and placebo were analysed using Wilcoxons' signed rank tests at $t_{0}$, $t_{6}$ and $t_{24}$. TRP depletion $p$ lacebo difference scores at $t_{0}, t_{6}$ and $t_{24}$ were tested for the $\mathrm{FH}+/ \mathrm{FH}$ groups, using Mann-Withney U tests. Results were considered significant if $p<.05$. Trend significant results will be described when $.05<p<.10$. Differences between TRP blood concentrations and TRP/LLNAA ratio in TRP depletion and placebo sessions at $t_{0}, t_{6}$ and $t_{24}$, were analysed using two-way repeated measures MANOVA, using treatment condition as the within subjects factor (TRP depletion vs placebo) and FH as between subjects factor.

\section{Results}

\section{Adverse Events}

Thirty-four subjects entered the study. Seven subjects withdrew from the experiment after the first treatment session. Two subjects withdrew for reasons unrelated to the treatment. Five withdrew because of adverse effects related to the treatment: four felt nauseous, three of whom vomited, and one subject could not adhere to the tryptophan-poor diet. All were women, six FH- and one FH+. They all dropped out during the first session. Three subjects dropped out after TRP-depletion and four subjects dropped out after ingestion of the placebo mixture. 


\section{Missing data}

Because of difficulties in taking blood, samples were not available for two subjects at $t_{6}$ and one subject at $t_{24}$ in the TRP-depletion condition and for two subjects in the piacebo condition at $t_{24}$.

\section{Side effects}

At to the incidence of side effects was low, with most subjects rating side effects as 0 . The only side effect which distinguished TRP.depletion from placebo was the feeling of nausea. One subject in the placebo condition and seven subjects in the TRPdepletion condition reported nausea at $\mathrm{t}_{6}$. Five of them were in the $\mathrm{FH}+$ group and five were women. However, these subjects were not the same as those who responded to TRP depletion by reporting more depressed feelings. Six female and two male subjects in the $\mathrm{FH}+$ group and one male subject in the $\mathrm{FH}$ - group reported more depressed feelings at ts after TRP depletion relative to placebo. There were only two female subjects and one male subject in the $\mathrm{FH}+$ group who reported both an increase in feelings of depression and nausea at ts after TRP depletion relative to placebo.

\section{Subjective Mood Assessments}

Overall, there were no significant differences in baseline (to) POMS scores between the placebo and the TRP depletion session. TRP-depletion led to a significant lowering of mood as expressed by the summed POMS scores at to compared to placebo $(Z=-2.18, \mathrm{df}=26, \mathrm{p}=.029)$. This was due to an increase in the mean POMS depression score to 1.3 whereas after placebo this score was $0.2(Z=-2.16, d f=26$, $p=.03)$. No other POMS subscales and none of the secondary outcome measures were significantly different at $t_{6}$. At $t_{24}$, POMS scores did not differ between groups. At $t_{6}$, significantly more side effects were reported after TRP depletion $(Z=-2.90$, $d f=26, p=.004)$, and especially more reports of nausea $(Z=-2.27, d f=26, p=023)$. No differences in side effects were found at to and $t_{24}$.

TRP-depletion affected subjects with and without first-degree relatives with depression differently at $t_{6}$. The results are summarised in table 2 . The $\mathrm{FH}+$ group responded to TRP-depletion with a significant lowering of mood, as expressed by the summed POMS scores at $t_{6}$, whereas the FH- group did not (Mann-Whitney $U, Z=-$ $227, d f=26, p=029$ ). FH+ subjects had significantly higher scores for the depression $(Z=-2.06, d f=26, p=.04)$ and fatigue $(Z=-2.19, d f=26, p=.029)$ subscales than $F H-$ subjects. FH+ subjects also tended to feel more anger than FH-subjects $(Z=-1.65$ $d f=26, p<.1)$. There were no significant differences between the two groups at $t_{24}$. $\mathrm{FH}+$ subjects experienced significantly more vegetative side effects, as expressed by the summed side effect scores, as a result of TRP depletion vs. placebo at $t_{6}(Z=-$ 
2.50. $d f=26, p=0.013$ ), although no one side effect was experienced significantly more often when analysed separately.

Correlational analysis of POMS scores with side effects showed that the summed POMS and the summed vegetative side effect scores were positively associated ( $r$ $=43, n=27, p=.024$ ). However, there was no significant association between POMS subscalles and vegetative side effect items on an item by item basis.

Table 2.

Subjective mood assessments. Means and sd and the respective TRP.PLA difference scores assessed at $t_{6}$ and $t_{24}$ of sepiarate subscales of POMS are broken down by $\mathrm{FH}$.

\begin{tabular}{|l|c|c|c|c|c|c|c|}
\hline & & \multicolumn{5}{|c|}{ T=6 } & \multicolumn{3}{|c|}{ T=24 } \\
\hline \multirow{2}{*}{$\begin{array}{l}\text { POMS- } \\
\text { depression }\end{array}$} & + & $2.1 \pm 3.2^{*}$ & $0.2 \pm 0.5$ & $1.9 \pm 3.2$ & $0.4 \pm 0.8$ & $0.2 \pm 0.6$ & $0.1 \pm 1.1$ \\
\cline { 2 - 9 } & - & $0.2 \pm 0.4$ & $0.2 \pm 0.6$ & $0.0 \pm 0.5$ & $0.1 \pm 0.3$ & $0.1 \pm 0.3$ & $0.0 \pm 0.0$ \\
\hline POMS-tension & + & $1.6 \pm 2.2$ & $1.3 \pm 3.5$ & $0.3 \pm 2.0$ & $0.9 \pm 1.3$ & $0.8 \pm 2.3$ & $0.0 \pm 1.7$ \\
\cline { 2 - 9 } & - & $0.6 \pm 1.2$ & $0.2 \pm 0.4$ & $0.5 \pm 1.0$ & $0.1 \pm 0.3$ & $0.1 \pm 0.3$ & $0.0 \pm 0.0$ \\
\hline POMS- & + & $4.4 \pm 5.8^{*}$ & $2.3 \pm 4.1$ & $2.1 \pm 4.4$ & $2.6 \pm 4.2$ & $1.3 \pm 3.1$ & $1.3 \pm 4.1$ \\
\hline POMS-anger & + & $1.3 \pm 1.5$ & $2.7 \pm 4.5$ & $-1.5 \pm 4.3$ & $0.3 \pm 0.5$ & $0.1 \pm 0.3$ & $0.2 \pm 0.4$ \\
\cline { 2 - 9 } & - & $1.1 \pm 1.7$ & $0.5 \pm 1.1$ & $0.6 \pm 1.5$ & $0.6 \pm 1.1$ & $0.2 \pm 0.6$ & $0.4 \pm 1.1$ \\
\hline POMS-vigour & + & $12.4 \pm 5.5$ & $14.3 \pm 2.9$ & $-1.9 \pm 4.5$ & $13.8 \pm 4.9$ & $15.1 \pm 3.6$ & $-1.3 \pm 3.1$ \\
\cline { 2 - 8 } & - & $15.4 \pm 5.1$ & $14.8 \pm 4.7$ & $0.5 \pm 3.0$ & $16.3 \pm 3.8$ & $16.6 \pm 4.0$ & $-0.7 \pm 1.6$ \\
\hline
\end{tabular}

* P 0.05 ws. FH.

\section{Blood levels}

Plasma TRP concentrations at baseline and at $t_{24}$ did not differ between groups and treatment conditions. Plasma TRP concentrations were $33 \%$ at to relative to the baseline value in the TRP depletion condition (plasma tryptophan after TRP depletion vs. placebo at t. $F_{1,22}=85.03, p<.0001$ ). TRP to $\Sigma L N A A$ ratio at baseline did not differ between groups and treatment conditions. This ratio was $22 \%$ of the baseline at to $\left(F_{1,22}=87.10, p<.0001\right)$ and $85 \%$ at $t_{24}$ in the TRP-depletion condition $\left(F_{1,24}=7.79\right.$, $p<05$ ). There were no differences between $F H+/ F H$-groups as to TRP and TRP/ $\Sigma L N A A$ and no interaction between treatment and $\mathrm{FH}$.

The tyrosine (TYR)/ $\Sigma L N A A$ ratio at $t_{5}$ was increased relative to $t_{0}$ and $t_{24}$, both in the placebo and TRP depletion sessions but there was no difference between conditions. 
After 24 hours the plasma levels of TRP and the TRP/ LLNAA had returned practically to normal.

Table. 3. Means and Standard Errors of the Blood Plasma Levels of TRP and TYR and the TRP/LLNAA and TYR/LLNAA Ratio

\begin{tabular}{|c|c|c|c|c|}
\hline \multirow[b]{2}{*}{ Measure } & \multirow[b]{2}{*}{ Treatment } & \multicolumn{3}{|c|}{ Tivne after $A A$ drink } \\
\hline & & to Mean $(\mathrm{SE})$ & to Mean (SE) & ${ }_{24}$ Mean (SE) \\
\hline \multirow[t]{2}{*}{ TRP (mmolls) } & $T+$ & $46.7 \pm 1.8$ & $56.8 \pm 3.4$ & $45.6 \pm 1.8$ \\
\hline & $T$ & $47.0 \pm 1.6$ & $15.6 \pm 3.3$ & $41.5+21$ \\
\hline \multirow[t]{2}{*}{ TRP/ELNAA $(\%)$} & $T+$ & $9.1 \pm 0.2$ & $7.6 \pm 0.5$ & $8.6 \pm 0.3$ \\
\hline & $T_{-}$ & $8.8 \pm 0.2$ & $2.0 \pm 0.4$ & $7.6 \pm 0.2$ \\
\hline \multirow[t]{2}{*}{ TYR (mmollL) } & $T+$ & $59.5 \pm 2.6$ & $146.7 \pm 13.0$ & $62.5 \pm 3.7$ \\
\hline & $T-$ & $59.8 \pm 3.2$ & $142.4 \pm 12.0$ & $57.9 \pm 2.8$ \\
\hline \multirow[t]{2}{*}{ TYRIELNAA $(\%)$} & $T+\infty$ & $11.4 \pm 0.4$ & $18.0 \pm 1.0$ & $11.7 \pm 0.7$ \\
\hline & $T-$ & $11.0 \pm 0.3$ & $15.7 \pm 0.8$ & $10.7 \pm 0.4$ \\
\hline
\end{tabular}

\section{Menstrual cycle phase}

In both the placebo and the TRP condition, 8 subjects participated in the test in the follicular phase (day 1-14) and four in the premenstrual phase (day 21-28). Two subjects in both conditions attended the test in the third week of the cycle.

\section{Study on the pharmacokinetics of 24 hour TRP depletion}

\section{Subjects}

Seven healthy subjects ( 5 men, 2 women, aged $20-56$ years; mean 32.9 years) were recruited to study TRP blood levels at 2 -hour intervals during the 24 hours after TRP depletion. Apart from good physical health as the major inclusion criterion, exclusion criteria were excessive drinking and a history of depression. The study was approved by the Medical Ethics Review Committee of the University Hospital Maastricht, The Netherlands. All subjects signed voluntary informed consent forms before the study and were paid for their participation.

\section{Procedure}

Seven subjects arrived at the laboratory at $8.30 \mathrm{a} . \mathrm{m}$. after an overnight fast. At to ( 9.00 a.m.) baseline blood samples were collected and TRP depletion treatment was started. Subjects ingested $100 \mathrm{~g}$ TRP-free amino acid mixtureas quickly as possible, but within 2 hours and adhered to the TRP depleted diet (see above) for 24 hours. Blood samples were taken using an intravenous catheter every 2 hours from to to $t_{24}$. 
The subjects remained in the laboratory for 24 hours and were allowed to read, study or watch $t v$. A detailed description of all food and beverages consumed (time and amount) was kept by each subject. After the last blood samples at $t_{24}$, the subjects received a protein-rich meal to compensate for possible deficiencies.

\section{Results}

Tryptophan leveis in all 7 subjects declined rapidly after the TRP depleted amino acid mixture was ingested: TRP concentrations reached a minimum at th in three subjects and at $t_{6}$ in four subjects. At its nadir, the mean TRP concentration was $12 \%$ of the baseline concentration. At $t_{16}$ the average TRP level was still $32 \%$ of baseline value, and at $t_{24}$ it was $81 \%$ of baseline. The average TRP/LLNAA ratio was lowest at $t_{4 n}$ when it was $5 \%$ of the baseline ratio. At $t_{16}$ the average TRP/ LLNAA ratio was still $28 \%$ of the baseline ratio, and at $t_{24}$ it was $75 \%$ relative to baseline. The additional ingestion of $10 \mathrm{~g}$ of the TRP-depleted amino acid mixture at $t_{7} t_{11}$ and $t_{14}$ most probably had an effect on the TRP/ LLNAA ratio (see fig. 1). Especially after $t_{14}, a$ decrease in the ratio is seen, which cannot be accounted to anything else but the additional $10 \mathrm{~g}$ of the amino acid mixture. Two subjects accidentally did not receive the additional $10 \mathrm{~g}$ of TRP-depleted amino acid mixture at $\mathrm{t}_{14}$, which can clearly be seen in figure 1 as their ratio did not decrease but increased instead.
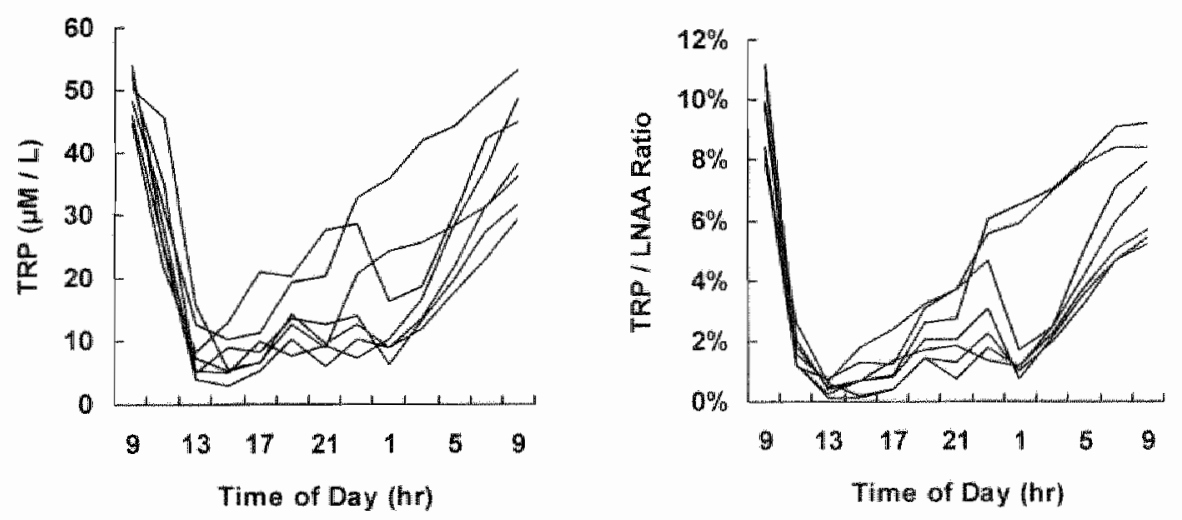

Figure y Serum TRP concentrations and TRP/LLNAA ratios in 7 SLbjects determined every 2 hours after the start of the tryptophan depletion treatment at 9.00 a.m. 


\section{General Discussion}

The aim of this study was to achieve a 24 hours lasting TRP depletion. The pharmacokinetic study showed that plasma TRP and the ratio TRPI LLNAA was significantly lowered at $t_{6}$ and remained low untill about $t_{16}$. However, they normalised during the night when the subjects were sleeping. Possibly, the TRP pool was replenished by protein degradation during sleep.

Our hypothesis that mood would be more affected after 24 hours than after 6 hours of depletion was disproven. After an initial mood lowering ( $\left.t_{6}\right)$, at $t_{24}$ mood had returned to its baseline level. The data suggest that the relationship between low TRP and lowered mood is momentary. In a study investigating the effects of TRP depletion on 5-hydraxyindoleacetic acid (5-HIAA) concentration in the cerebrospinal fluid (CSF) (in humans), it was shown that CSF 5-HIAA concentrations were lowest 8-12 hours after the amino acid drink (Carpenter, 1998). It would be interesting to assess mood not only at $t_{5}$ but also at $a$ time between $t_{8}$ and $t_{12}$, to confirm a presumed momentary relationship between brain 5-HT turnover and mood. Although a time lag exists between lowering of blood TRP and lowering of brain 5HIAA concentrations ( in vitro studies suggest that brain 5-HT neurons will turnover all available 5-HT stores in about 1 to 2 hours after depletion of TRP (Lin et al. 1969)), we do not expect the same time lag to exist when blood TRP rises again after a period of depletion. If TRP would be orally administered during a TRP-depleted state, one would expect a rapid transport through the blood-brain-barrier and a subsequent rapid rise of 5-HT levels, since the tryptophan hydroxylase enzyme is normally unsaturated (Fernstrom, 1977). The best estimate of brain 5-HT is the ratio TRP/LLNAA. As can be seen in the figures, the time-curve of TRP/ $2 L N A A$ is almost equal to that of plasma TRP. Thus, we have reasons to believe that in our study, brain serotonin levels could easily have normalised by $t_{24}$.

Delgado et al. (1990) found a significant lowering of mood after 24 hours in remitted depressed patients, eventhough the TRP depletion was achieved only with an amino acid mixture and without additional diet. There are several reasons for a difference in outcome between our study and that of Delgado et al. First, Delgado et al. (1990) do not present TRP blood levels at $t_{24 .}$. Thus, is might be possible that TRP blood levels in their study have not returned to normal at $t_{24}$. Second it could be that subjects who have been depressed show a different response to TRP depletion than normals, due to either differences in TRP and/or 5-HT metabolism, or a different emotional response to similar metabolic changes. Our study differs from others by the addition of carbohydrates and fat to the AA mixture. It is generally very difficult to withold carbohydrates for a period of 24 hours. Adding carbohydrates to the AA mixture is a way to provide the subjects' necessary nutrition in a standard manner. Furthermore. the carbohydrates were necessary to dissoive the amino acids. Carbohydrates, however, are known to increase insulin release, thus taking away severai LNAA from the circulation. which might enhance the uptake of TRP in the brain (Fernstrom, 
1981). However, this logic only applies to protein-free carbohydrate rneals. In proteincontaining meals, carbohydrates would fail to enhance brain TRP concentrations. Their ingestion causes both serum TRP concentrations and the concentrations of its transport competitors to rise by proportionally similar amounts. resulting in no net change in competition for uptake (Fernstrom and Fernstrom. 1995). As the TRP/ LLNAA ratio was convincingly low in our study, at least at $t_{6,}$, the addition of carbohydrates and fat to the AA mixture does not seem to have altered the desired effect of TRP depletion and hence did not influence the results in a negative fashion.

\section{Family history, Sex and Mood Response to TRP depletion}

After TRP depletion, eight of 16 subjects ( 5 females and 3 malles) with first-degree relatives with depression showed a depression of mood (with at least one point on the POMS-depression scale) compared with only 1 (male) of 11 subjects without a family history of depression. This strongly suggests that family history plays an important role in the sensitivity to TRP depletion as we expected. As can been seen from the table, the magnitude of the mood effects was only small ( $1.9 \pm 3.2$ for the $\mathrm{FH}+$ group on a scale 0-24) as can be expected in normal subjects who have never been depressed. Benkelfat et al. (1994) found a similar effect, and of comparable magnitude, in male subjects with a highly positive family history for depression. In our study, the group sizes would become very small if one was to statistically evaluate the main effects of sex and $\mathrm{FH}$ and their interactions. However within the $\mathrm{FH}+$ group the 5 female subjects showed the strongest increases on the POMS depression score (range 4-10), whereas the 3 male subjects showed only an increase of one point. Nevertheless, the observed pattern of results appears to be quite compatible with the finding of other authors who report females to be more sensitive to the effects of TRP depletion than males (Ellenbogen et al., 1996; Menkes et al., 1994; Smith et al. 1997a; Weltzin et al., 1994).

\section{Menstrual cycle phase}

Ideally, testing should have been carried out in the follicular phase of the menstrual cycle. We did not attend to this rule. However, testing in both the placebo and the TRP depletion condition took place in exactly the same phase of the menstrual cycle (except for one subject with missing data). Furthermore, eight out of 15 subjects took oral anticonceptives and the question can be raised whether phase of the menstrual cyle is of great importance in these cases. Another way in which we tried to rule out confounding influences of menstrual phase is by excluding subjects who regularly experience significant mood swings in the course of the menstrual cycle. 


\section{Side effects}

Although increased POMS depression scores can not be explained by an increased incidence of nausea and other vegetative side effects in a causal manner, it would seem logical that they are associated in some way. There are abundant peripheral 5 HT receptors in the gastrointestinal tract. Subjective mood changes and an increase in gastrointestinal side effects after TRP depletion might both be associated to sensitised 5-HT receptors. The former might reflect increased central 5-HT receptor sensitivity, whereas the latter might reflect peripheral 5-HT receptor hypersensitivity. The data suggest that central or peripheral $5-4 \pi$ receptors, or both, may be more sensitive in $\mathbb{H}+$ subjects. However, six of the seven subjects who withdrew, mainly because of adverse events, were from the FH-group. We have no evidence that the $\mathrm{FH}+$ group tolerated the procedure better. Probably, the subjects in the $\mathrm{FH}+$ group were more motivated to continue their participation in the experiment after experiencing side effects, because they were a relative of a depressed patient in our outpatient clinic.

\section{No interference of TRP depletion with tyrosine availlability}

In discussing the limitations of the TRP depletion method, it has been suggested that TRP depletion might interfere with TYR availability and that the change in ratio of TYR / LLNAA has not been measured in TRP depletion studies (Reilly et al., 1997). TYR availability could be of importance since TYR is the amino acid precursor for both noradrenaline and dopamine both of which have been implicated in mood disorders. Assays of the plasma amino acids showed that tyrosine levels were increased substantially and the TYR / LLNAA ratio slightly at $t_{6}$, but not differently across treatment conditions. Thus, theoretically, brain levels of catecholamines could have increased at $t_{6}$, but again, in a similar fashion in the TRP depletion and placebo conditions.

\section{Conclusion}

The previously described mood-lowering response to TRP-depletion 6 hours after the start of treatment was conftrmed and was shown to be more prominent in subjects with a first degree relative with depression. A heightened semsitivity to changes in 5 $H \mathrm{HT}$ concentrations in $\mathrm{FH}+$ subjects is a possible explanation for this finding. The hypothesised increased effect of prolonged tryptophan depletion on mood at 24 hours after treatment administration could not be demonstrated, because we did not succeed in maintaining low tryptophan levels throughout the night, despite maintenance treatment doses and a tryptophan deficient diet. 


\section{References}

Arrindeli, W.A., and Ettema, J.H.M. (1986) SCL-90. Een muttidimensionele psychopathologie indicator [SCL-90. A multidimensional indicator of psychopathology]. Lisse. The Nethertands: Swets \& Zeitlinger

Benkelfat, C., Ellenbogen, M.A., Dean, P. Paimour, R.M., and Young, S.N. (1994) Mood-lowering effect of tryptophan depletion. Enhanced susceptibility in young men at genetic risk for imajor affective disorders. Archives of General Psychiatry 51: 687-697

Biggio, G., Fadda, F. Fanni P., Tagliamonte, A. and Gessa, G.L. (1974) Rapid depletion of serum tryptophan, brain tryptophan, serotonin and 5-hydroxyindoleacetic acid by a tryptophan-free diet. Life Sciences 14:1321-1329

Carpenter, L.L. (1998) Tryptophan depletion during continuous CSF sampling in healthy human subjects. Neuropsychopharmacology 19: 26-35

Charney, E.A. and Weissman. M.M. (1988) Epidemiology of Depressive and Manic Syndromes. In: Georgotas A, Cancro R (eds) Depression and Mania, pp. 26-52 New York: Elsevier

Cleare, A.J., and Bond, A.J. (1995) The effect of tryptophan depletion and enhancement on subjective and behavioural aggression in normal male subjects. Psychopharmacology Berllin 118: 72-81

Delgado, P.L., Charney, D.S., Price, L.H., Landlis, H., and Heninger, G.R. (1989) Neuroendocrine and behavioural effects of dietary tryptophan restriction in healthy subjects. Life Sciences 45: $2323-$ 2332

Delgado, P.L. Charney, D.S. Price, L.H. Aghajanian, G.K., Landis, H., smf Heninger, G.R. (1990) Serotonin function and the mechanism of antidepressant action; Reversal of antidepressantinduced remission of rapid depletion of plasma tryptophan. Archives of General Psychiatry 47:411418

Delgado, P.L., Price, L.H., Miller, H.L., Salomon, R.M., Licinio, J., Krystal, J.H., Heninger, G. R., Charney, D.S. (1991) Rapid serotonin depletion as a prowocative challenge test for patients with major depression: relevance to antidepressant action and the neurobialogy of depression. Psychopharmacol Bull 27: 321-330

Elenbogen, M.A. Young,S.N., Dean, P. Palmour, R.N., Benkelfat, C. (1996) Mood response to acute tryptophan depletion in healthy volunteers: Sex differences and temporal stability Neuropsychopharmacology 15: 465-474

Endicott, J, Andreasen, N.C. Spitzer, R.L. (1975): Family History-Research Diagnostic Criteria. New York: Biometrics Research. New York State Psychiatric Institute

Fernstrom, J.D. (1977) Effects of the diet on brain neurotransmitters. Metabolism 26: 207-223

Fernstrom, J.D. (1981) Dietary precursors and brain neurotransmitter formation. Annual Review of Medicine 32: 413-425

Femstrom, M.H. and Fernstrom, J.D. (1995) Brain tryptophan concentrations and serotonin synthesis remain responsive to food consumption after the ingestion of sequential meals. Amercian Journal of Clinical Nutrition 61: 312-319

Kent, J.M. Coplan, J.D., Martinez, J., Karmally, W., Papp, L.A., and Gorman, J.M. (1996) Ventilatory effects of tryplophan depletion in panic disorder: A preliminary report. Psychiatry Research 64: 8390

Lam, R.W., Zis, A.P. Grewal, A., Delgado, P.L. Chamey, D S, and Krystal, J.H. (1996) Effects of rapid tryptophan depletion in patients with seasonal affective disorder in remission after light therapy. Archiwes of General Psychiatry 53:41-44

Lin, R.C., Costa, E., Neff, N.H. Wang, C.T., Ngai, S.H. (1969) In vivo measurement of 5 hydroxytryptamine turnover rate in the rat brain from the conversion of $\mathrm{C}^{14}$-tryptophan to $\mathrm{C}^{14}-5$ hydroxytryptamine. The Journal of Pharmacology and Experimental Therapeutics 170:232-238 
McNair, D.M. Lorr, M. and Droppleman, L.F. (1988) Manual for the Profile of Mood States. San Diego: Educational and Industrial Testing Sevice

Menkes, D.B., Coates, D.C., and Fawcett, J.P. (1994) Acute tryptophan depletion aggrawates premenstrual syndrome. Jourral of Affective Disorders 32: $37-44$

Miller, H. Deakin, J.F.W., and Anderson, I. (1995) Acute iryptophan depletion increases panic anxiety in panic disorder patients. Journal of Psychopharmacology 9: A18

Moeller, F., Dougherty, D. Swann, A., Collins, D., Davis, C., and Cherek D (1996) Tryptophan depletion and aggressive responding in healthy males. Psychopharmacology 126: $97-103$

Moja, E. A. Antinoro, E. Cesa-Bianchi, M., Gessa, G.L. (1984) Increase in Stage 4 after ingestion of a tryptophan-free diet in humans. Pharmacological Research Communications 16: 909-91.4

Nishizawa, S. Benkelfat, C., Young, S.N., Leyton, M. Mzengeza, S. de Montigny, C., Blier, P.. and Diksic. M. (1997) Differences between males and Females in rates of serotonin synthesis in human brain. Proceedings of the National Academy of Sciences of the United States of America 94: 5308 5313

Park, S.B. Goull, J.T., McShane, R.H., Young. A.H., Sahakian, B.J., Robbins, T.W. Cowen, P.J. (1994) Tryptophan Depletion in Normal Volunteers Produces Selective Impairments in Learning and Memory. Neuropharmacology 33: 575,588

Reilly, J.G., McTavish, S.F.B. Young. A.H. (1997) Rapid depletion of plasma tryptophan: a review of studies and experimental methodology. Joumal of Psychopharmacology 11:381-392

Riedel, W. Klaassen, T. Deutz, N., Honig. A., Van Someren, A., Van Praag, H. (1999) Tryptophan depletion in normal volunteers produces selective impairment in memory consolidation. Psychopharmacology 1.41:362-369

Schaechter, J.D., and Wurtman, R. \&. (1989) Tryptophan availability modulates serotonin release from rat hypothalamic slices. Journal of Neurochemistry 53: 1925-1933

Sheehan, D., Lecrubier, Y., Janaws, J., Knapp, E., Weiller, E. et all (1994) MINI International Neuropsychiatric Interview. Tampa: University of South Florida.

Smith, K.A., Clifford, E.M. Hockney, R.A., and Clark, D.M. (1997a) Effect of tryptophan depletion on mood in male and female volunteers: A pilot study. Human-Psychopharmacology-Clinical-andExperimental 12: 111-117

Smith, K.A., Fairburn, C.G., and Cowen, P.J. (1997b) Relapse of depression after rapid depletion of tryptophan. Lancet 349: 915-919

Simith, S.E., Pinl, F.O., Young, S.N., Ervin, F.R. (1987) A test of possible cognitive and environmental influences on the mood lowering effect of tryptophan depletion in normal males.

sychopharmacology Bertin $91: 451-457$

Spitzer, R.L. Endicott, J. and Robinsi, E. (1975) Reseanch Diagnostic Criteria (RDC) for a Selected Group of Functional Disorders. Ed, 2. Biometrics Research. New York: New York State Psychiatric Institute

van Eijk, H.M., Huinck, M.P., Rooyakkers, D.R., Deutz, N.E. (1994) Automated simultaneous isolation and quantitation of labeled amino acid fractions from plasma and tissue by ion-exchange chromatography, Journal of Chromatography. Biomedical Applications 660: 251-257

van Eijk, H.M., Rooyakkers, D.R., and Deutz, N.E. (1993) Rapid routine determination of amino acids in plasma by high-performance liquid chromatography with a 2-3.3 microns Spherisorb ODS I: column. Joumal of Chromatography 620: 143-148

Weltzin, T.E, Fernstrom, J.D., McConaha, C. and Kaye, W.H. (1994) Acute tryptophan depletion in bulimia: effects on large neutral amino acids. Biological Psychiatry 35: 388 397

Weltzin, T.E., Fernstrom, M.H. Fernstrom, J.D., Neuberger, S.K. Kaye, W.H. (1995) Acule tryptophan depletion and increased food intake and irritability in bulimia nervosa. American Journal of Psychiatry 152: 1668-1671 
Young, S.N. Erwin, F.R., Pihl, R.O., and Finn, P. (1989) Biochemical aspects of typlophan depletion in primates. Psychopharmacology Berlin 98: 508-5.11

Young, S.N., Pihl , R.O., and Ervin, F.R. (1988) The effect of altered tryptophan levels on mood and behavior in normal human males. Clinical Neuropharmacology $11: 5207-215$

Young, S.N. Smith, S.E., Pihl, R.O., and Ervin, F.R. (1985) Tryptophan depletion causes a rapid lowering of mood in nomal males. Psychopharmacology Bertin 87: 173-177

Zimmermann, R.C., McDougle, C.J., Schumacher, M., Olcese J., Mason, J.W. Heninger, G.R., and Price LH (1993) Eftects of acute tryptophan depletion on nocturnal melatonin secretion in humans. Journal of Clinical Endocrinology and Metabolism 76: 1160-1164 



\title{
Mood congruent memory bias induced by tryptophan depletion
}

\author{
T. Klaassen, W.J. Riedel, N.E.P. Deutz, and H.M. van Praag \\ Psychological Medicine: In Press
}

\section{Abstract}

Mood congruent memory bias predicts a more superior recall memory of learnt material congruent with the mood state at the time of learning. The present study is the first report of an experimental study in which a biological mood induction was used to test this hypothesis. The influence of acute tryptophan (TRP) depletion, inducing low serotonin neurotransmission and a depression of mood, on memory bias was evaluated in healthy volunteers with or without a positive family history of major affective disorder ( $\mathrm{FH}+$ versus $\mathrm{FH}-$ ).

Twenty-seven subjects ( $16 \mathrm{FH}+, 11 \mathrm{FH}-$ ) received $100 \mathrm{~g}$ of an amino acid mixture with and without TRP according to a placebo-controlled, double-blind, balanced. cross-over design. An affective memory test consisting of a 30-word list with words of positive, neutral, and negative affective valence and a mood questionnaire were assessed at 6 and 24 hours following treatment administration.

TRP depletion impaired delayed recall of neutral and positive words, but not of negative words. There was no interaction of family history and treatment and there was no post-hoc association between the influence of TRP-depletion on mood and on affective memory bias.

Experimentally induced serotonergic depletion in normal individuals shifts affective memory bias towards negative affective valent verbal stimuli.

KEYWORDS: Tryptophan depletion, Depression, Memory bias, Family history, Healthy subjects 


\section{Introduction}

One of the features of the depressive syndrome is impaired memory function. In an extensive meta-analysis But et al.(1995) revealed that the processes most consistently affected by depression include those involved in the recall of information characterised by a positive, hedonic tome. Furthermore, depressed subjects are more likely to store or recall information that is congruent with their mood state (Bower, 1981; Blaney, 1986), a phenomenon that is called 'mood congruence'. This mood congruence may play a role in real-life memory (Clark and Teasdale, 1982), and newly learnt information (Teasdale and Russel, 1983). Several studies have shown that MCM is both found in explicit memory (Denny and Hunt, 1992; Watkins et al. 1996), and in implicit memory bias (Ruiz-Caballero and Gonzalez, 1994;1997). MCM may act to maintain depression by inducing a vicious cycle of negative memories and avoidance of what may be mood-elevating behaviour or situations Teasdale (1983). Thus, investigating mood congruent memory (MCM) in depression may be important in determining specific mechanisms accounting for the maintenance of depression. An explanation for MCM bias is found in the theories of Beck. According to Beck (1967), depressed subjects are characterised by negative cognitive schemata. These negative schemata are assumed to affect the encoding, storage and retrieval of information, leading to a memory bias for negatively coloured information. Arlificial depression of mood may provide an appropriate way to assess the influence of mood on memory, especially when an induction method is used that avoids cognitive priming. Several methods have been used to induce depressed mood. These methods have employed verbal (Velten, 1968), hypnotic (Bower, 1981) and musical processes (Clark and Teasdale, 1985). To the best of our knowledge, studies using a biological procedure for inducing depressive symptomatology have not been described in research on mood congruent memory bias.

A biological method for inducing symptoms of depression is the "tryptophan (TRP) depletion method" (Young et al., 1985). Ingestion of an amino acid mixture devoid of tryptophan substantially depletes the braim of TRP, leading to a decreased production of serotonin. This method has been shown to induce a recurrence of depression in depressed subjects in remission (Delgado et al., 1990, 1991; Lam et al., 1996), and a depressed mood in normal subjects (Young et al., 1985; Benkelfat et al. 1994; Weltzin et al. 1994). Healthy subjects with a positive family history of depression showed significantly more depression of mood after TRP depletion than healthy subjects without such a family history (Benkelfat et al., 1994). Also, TRP depletion influences cognitive processes (Danjou et al. 1990; Park et al., 1994; Riedel et al., 1999).

We conjectured that a shift in affective memory bias as a consequence of TRP depletion. might be the expression of an intervening process between mood and mood-congruent memory bias. 
It was hypothesised that TRP depletion induces differentiall effects on the recall of positive, negative and neutral information. If so, this so-called shift of affective memory bias will be more pronounced in subjects with a positive family history of depression than in subjects without such a family history, and affective memory bias will be mood congruent, i.e. a negative shift will occur in particular in subjects who show a pronounced "low-mood response' to TRP-depletion.

\section{Materials and Methods}

\section{Subjects}

Twenty-seven healthy subjects ( 12 men and 15 women) aged $30.9 \pm 10.9$ (mean \pm $\mathrm{SD}$; range 18 - 61) were recruited through local newspaper advertisements. Inclusion took place after extensive somatic and mental screening of the subjects and their family history (see Klaassen et al. 1999). Two groups were formed: one with a positive family history of major affective disorder (FH+, 16 subjects) and one without (FH-, 11 subjects). The groups did not differ with respect to distribution of age and sex. The FH+ group consisted of 9 women and 7 men aged $29 \pm 11$ (SD) years. The FH-group consisted of 6 women and 5 men with a mean age of $33 \pm 10$ (SD) years. All subjects came from different families.

The study was approved of by the Medical Ethics Committee of the University Hospital Maastricht, The Netherlands. All subjects signed informed consent prior to the study and were paid for their participation.

\section{Experimental Design and Treatment}

The study was conducted according to a double-blind, placebo-controlled, orderbalanced, cross-over design. The treatment consisted of $100 \mathrm{~g}$ of an amino acid mixture without tryptophan, adjusted with $63 \mathrm{~g}$ carbohydrates and $33 \mathrm{~g}$ fat and $300 \mathrm{ml}$ water. The placebo drink was identical of appearance, colour, taste and content except that it contained $3 \mathrm{~g}$ of tryptophan (Klaassen at al., 1999).

\section{Affective Memory Assessment}

The VisualWerbal Learning Test (VLT) is an adapted version of the Rey Auditory Verbal Learning Test (Lezak, 1995). Thirty Dutch monosyllabic meaningful nouns and adjectives were consecutively presented on a computer screen. The subjects had to recall verbally as many words as possible (=immediate recall). The first immediate recall trial was followed by two more trials. Scores were summed to comprise the total immediate recall score. After 30 min of other psychometric tests subjects were asked to recall as many of the previously learnt words as possible $c=$ first 
delayed recall, $\left.t_{3}, 6\right)$. The next day, at $t_{24}$, another delayed recall trial of words that were presented on the preceding day, was done $\left(t_{6} \rightarrow 24\right)$.

The affective valence of the words in the test had been measured previously by giving two groups of normal subjects (aged 18 to 65 years) a list of 300 nouns (50 subjects) or 137 adverbs (46 subjects). The subjects had to rate each noun as positive, negative, or neutral. The adwerbs were only rated as positive or negative. Scores were summed for each word and the words that were most often judged as positive, neutral, or negative were selected to comprise the affective memory test word lists. We designed four separate lists of 30 words, each containing 18 nouns and 12 adjectives. Of these words, 12 had previously been judged as positive, 12 as negative, and 6 as neutral. All neutral words were nouns; the positive and negative words each included 6 nouns and 6 adjectives. All words were monosyllabic and meaningful. The words in the lists had been matched for abstraction.

Before the experiment, subjects were familiarised with the test procedure using a training version of the VLT. As primary outcome measures of affective memory bias the percentages of positive, negative, and neutral words recalled in each recall trial were calculated.

\section{Assessment of mood}

Mood was assessed with the 32-item abbreviated Profile of Mood States scalle (POMS, Mc Nair et al., 1992), consisting of five subscales (depression, tension, vigour, anger, and fatigue).

\section{Amino Acid Assessment}

Blood was immediately placed on ice and centrifuged within $30 \mathrm{~min}$ for $5 \mathrm{~min}$ at 1000 $g$ at $4 \circ \mathrm{C}$. Total plasma concentrations of TRP and other amino acids were measured by highmperformance liquid chromatography (van Eijk et al.; 1993). In addition, the ratio of tryptophan to the sum of the large neutral amino acids: tyrosine, leucine isoleucine, valine, and phenylalanine; TRP/LLNAA was determined. This ratio provides an estimate of TRP uptake in the central nervous system (Fernstrom, 1981).

\section{Procedure}

All subjects participated in a treatment session and in a placebo session, separated by at least 4 days. Subjects arrived at $8: 30$ a.m. after an overnight fast and filled out the POMS. At 9:00 a.m. $\left(=t_{0} ; t_{x}\right.$ denotes time elapsed since the subjects started to consume the drink, $x$ referring to the number of hours after $t_{0}$ ), the amino acid mixture with or without TRP was ingested as fast as possible but within 2 hours. The subjects remained in the experimental room until after the VLT and POMS at $t_{6}$, except for a half-hour standardised walk accompanied by an assistant. They were allowed to read 
magazines, study or watch an emotionally neutral video. After the tests, the subjects went home, where they took an additional $10 \mathrm{~g}$ of that days amino acid mixture at $t_{7}$. $t_{11}$ and $t_{14}$ and adhered a low tryptophan diet (Klaassen et al. 1999).

The subjects returned at $\mathrm{t}_{24}$ for the last mood and memory assessments. Venous blood samples for measurement of tryptophan plasma levels were taken at $t_{0}, t_{0}$ and $t_{24}$.

\section{Statistical analysis}

The effects of treatment on memory performance for positive, negative, and neutral words were evaluated at $t_{6}$ and $t_{24}$ using two-tailed t-tests for paired samples. Effects of Family History were compared between subjects using the Mann-Whitney U test. Interaction of treatment with $\mathrm{FH}$ on affective memory were evaluated by comparing TRP depletion-placebo difference scores between $\mathrm{FH}+/ \mathrm{FH}$-groups, again using Mann-Whitney $U$. Effects of moad response on affective memory were evaluated using one sample t-test. A Bonferroni-correction was applied.

\section{Results}

\section{Memory Assessment}

Impaired delayed recall at $t_{6}$ of the word list learnt at to was due to impaired recall of neutral $\left(t_{6 \rightarrow 6}: t=2.38, d f=26, p=0.009\right)$ words, while at $t_{24}$, the second delayed recall was affected significantly by the positive words $\left(t_{6}, 24: t=3.13, d f=24, p=\right.$ 0.005). Delayed recall of negative words was not affected by TRP depletion (table 1). Immediate recall performance was not affected by TRP depletion either. No main effects of Family History or interaction effects of FH with TRP depletion were seen on any memory measure.

Table 1 . Influence of tryptophan depletion on affective memory. Means $\$$ SE of percentages of words learnt at to and recalled after a delay of 30 minutes $\left(t_{6}\right)$ and 18 hours $\left(1, b_{3}\right)$

\begin{tabular}{|c|c|c|c|c|c|c|}
\hline \multirow[b]{2}{*}{ Words } & \multicolumn{3}{|l|}{$t_{5} \rightarrow t_{5}$} & \multicolumn{3}{|l|}{$t_{5} \rightarrow t_{21}$} \\
\hline & Placebo & TRP depletion & $p=$ & Placebo & TRP depletion & $p=$ \\
\hline Pasitive & $44.2 \% \pm 3.9$ & $39.2 \% \pm 4.0$ & 0.158 & $40.1 \% \pm 4.0$ & $27.3 \% \pm 4.3$ & $0.005^{*}$ \\
\hline Negative & $43.8 \% \pm 4.8$ & $36.8 \% \pm 42$ & 0.108 & $34.0 \% \pm 4.1$ & $27.3 \% \pm 3.8$ & 0.255 \\
\hline Neutral & $53.2 \% \pm 4.9$ & $39.5 \% \pm 5.7$ & $0.009^{\circ}$ & $43.6 \% \pm 4.2$ & $27.0 \% \pm 58$ & 0.038 \\
\hline
\end{tabular}

* sigmificant after Bonferroni correction 


\section{Relation between mood response and selective memory bias}

A post-hoc analysis of the mood effect of TRP depletion on affective memory bias was carried out by comparing 'mood responders' and 'non responders' to TRP depletion. As described previously (Klaassen et al., 1999). TRP depletion led to a significant lowering of mood only at $t_{6}$ especially in $\mathrm{FH}+$ subjects as expressed by the POMS depression score.

'Mood response' was defined as an increase in the POMS-depression score of at least four points in the TRP depletion session compared to the placebo session. There were five mood responders, all subjects from the $\mathrm{FH}+$ group. Analysis of the delayed recall difference scores using twests for independent samples showed that TRP depletion impaired delayed recall at $\mathrm{t}_{6}$ in mood-responders more than in nonresponders (TRP minus placebo $=-25.3 \%$ in the mood responders versus $-4.4 \%$ in the non-responders, $t=3.19, d f=22, p=.004)$. However, this was not specifically due to a loss of positive words.

\section{Tryptophan blood levels}

Plasma TRP concentrations were $33 \%$ at $t_{6}$ relative to to in the TRP depletion condition and $88 \%$ at $t_{24}$. The TRP/LLNAA ratio at $t_{6}$ was $22 \%$ of the baseline value in the TRP depletion condition and $85 \%$ at $1_{24}$. There were no differences between FH+/FH-groups as to TRP or TRPIZLNAA ratio.

\section{Discussion}

In the present study, we found that tryptophan depletion led to memory impairment, with a preferential loss of positive words, fitting the concept of MCM. Tryptophan depletion was not associated with more specific memory bias in the $\mathrm{FH}+$ group than in the $\mathrm{FH}$-group. Furthermore post hoc analysis revealed no selective memory bias in mood-responders. Thus, it seems that although changes in mood parallel selective deficits in memory in the group as a whole, the depressed mood does not seem to mediate the cognitive disturbances represented by mood-congruent learning on an individuallevel.

Some methodological remarks, however, can be made. First, a mixed group of both men and women was used, while there may be gender differences with regard to the effects of TRP depletion (Ellenbogen et al.,1996; Menkes et al., 1994).

Second, we choose to use only nouns for the neutral words as we predicted that adverbs would have an affective valence by definition. We do not think that the discrepancy between word type will have affected the findings. Finally, our balanced mixture, may have had some effects on $5-\mathrm{HT}$, while it lead to slightly increased TRP plasma levels. However, the ratio TRP/ILNAA was decreased after 6 hours, 
suggesting that a decrease in 5-HT function will have been more probable than an increase, with unknown effects on memory performance.

The TRP depletion induced memory impaiment, with a preferential loss of positive words, found in our study, is in agreement with what is found in clinically depressed subjects. Several studies in which series of positive and negative words were presented to depressed subjects and normal controls (Breslow et al., 1981; Dunbar and Lishman, 1984; Watkins et al. 1992) provided evidence of an under-recall of positive material and/or a relative over-recall of negative material among depressed individuals compared to controls (Blaney, 1986). McDowall (1984) observed that this recall bias was only found when positive and negative words are presented in mixed lists, in which positive and negative material competed with each other. If presented in separate lists, depressed subjects remembered positive and negative words equally well.

As far as we know, only four studies (Mathews and Bradley, 1983; Riskind et al. 1982; Riskind, 1983; Bradley et al. 1993) have actually examined whether the extent of the mood-congruent recall was significantly associated with mood change. Three studies showed a consistent lack of correlation between mood change and the extent of mood-congruent recall. Only Bradley et al. (1993) found a significant correlation between the POMS depression score and the number of words recalled. According to Blaney (1986) MCM requires a certain degree of mood lowering, beyond which there is no further increase in effect. The results of our study do not support this hypothesis.

Finally, Perrig and Perrig (1988) carried out a study in which subjects were instructed to behave as if they were depressed or happy. A mood congruity effect was obtained in the absence of a depressed mood, and was stronger in subjects who predicted the relationship between mood and affective word valence than in subjects who were unaware of this relationship. They suggest that one should consider the possibility that mood induction procedures invite subjects to pretend to be in a certain mood state. This factor was prabably not present in our study, as the mood induction procedure we used was carried out in a double-blind fashion. Asso, the subjects in our experiment could not have guessed which day they were given the TRP depleted mixture. Both the procedure and the intensity of effects did not reveal the nature of the mixture.

The selective memory bias was, surprisingly, only found at $t_{24}$, at which time both mood and TRP levels had returned to baseline. Thus, the formation of memory bias must have occurred at $t_{6}$, when TRP levels were low. Furthermore, the fact that memory impairment did not occur at immediate recall but only at delayed recall suggests that there is a selective consolidation effect and that retrieval is unaffected by TRP levels.

In conclusion, we found evidence of mood congruent memory bias after TRP depletion. Thus, a biological serotonin depletion intervention may mimic specific cognitive deficits often found in depression. We assume that the specific memory 
deficit observed is a consolidation problem and related to low blood TRP levels and, ultimately, to the low availability af brain serotonin. We were not able to detect a causal relationship between depressed mood and selective memory.

\section{References}

Beck, A.T. (1967) Depression: clinical "experimental and theoretical aspects. New York: Harper \& Row

Benkelfat, C., Ellenbogen, M.A. Dean, P., Palmour, R.M., and Young, S.N. (1994). Mood-lowering effect of tryptophan depletion. Archiwes of General Psychiatry 51:687-697

Blaney, P. (1986) Affect and memory: a review. Psychological Magazine 99: 229-246

Bower, G.H. (1981) Mood and memory. American Psychologist 36: 129-148

Bradley, B., Mogg, K., Galbraith, M. and Perrett, A. (1993) Negative recall bias and neuroticism: state vs trait effects Behaviout Research and Therapy 31 (1): 125-127

Breslow, R., Kocsis, $\mathrm{J}_{3}$, and Beikin, B. (1981) Contribution of the depressive perspective to memory function in depression. American Joumal of Psychiatry 138: 227.230

Burt, D. B., Zembar, M.J., and Niederehee, G. (1995) Depression and memory impairment: a metaanalysis of the assiociation, it's pattern and specificity. Psychological Bulletin 117: 285-305

Clark, D.M., and Teasdale, J.D. (1982) Diurnal variation in clinical depression and accessibilty of memories of positive and negative experiences. Journal of Abnormal Psychology 91: 87-95

Clark, D.M. and Teasedale J.D. (1985) Constraints on the effects of mood on memory. Journal of Personality and Social Psychology 48 (5): 1595-1608

Danjou, P., Hamon, M. Lacomblez, L., Warot, D., Kecskemeti, S., and Puech, A.J. (1990) Pisychomotor, subjective and neuroendocrine effects of tryptophan depletion in the healthy volunteer. Psychiatry and Psychobiology 5: 31-38

Delgado, P.L., Charney, D.S., Price, L.H., Aghajanian, G.K., Landis, H., and Heninger, G.R. (1990) Serotonin function and the mechanism of antidepressant action. Archiwes of General Psychiatry 47 : $411-418$

Delgado, P.L., Price, L.H. Miller, H.L. Salomon, R.M., Licinio, J., Krystal, J.H., Heninger, G.R, and Chamey, D.S. (1991) Rapid serotonin depletion as a provocative challenge test for patients with major depression: relevance to antidepressant action and the neurobiology of depression. Psychopharmacology Builletin 27(3): $321-330$

Denry, E.B., and Hunt, R.R. (1992) Affective valence and memory in depression: dissociation of recall and fragnient completion. Journal of Abnormal Psychology 101(3): 575-580

Dunbar, G.C., and Lishman, W.A. (1984) Depression, recognition-memory and hedonic tone, A signal detection analysis. British Journal of Psychiatry 14:376-382

van Eijk, H.M.H, Rooyakkers, D.R. and Deutz, N.E.P. (1993) Rapid routine determination of amino acids in plasma by high performance liquid chromatography with a $2-3$ um Spherisorb ODS II column. Joumal of Chromatography 620:143-1.48

Ellenbogen, M.A. Young, S.N., Dean, P., Palmour, R.N., and Benkelfat, C. (1996) Mood response to acute tryptophan depletion in healthy volunteers: Sex differences and temporal stability. Neuropsychopharmacology 15: 465-474

Fernstrom, J.D (1981) Dietany precursors and brain neurotransmitter formation. Annual Reviews in Medicine 32: 413-425

Klaassen, T. Riedel, W. ., van Someren, A. Deutz, N.E.P. Honig, A., and van Praag. H.M. (1999) Effects of 24-hour tryptophan depletion in healthy first degree relatives of patients with affective disorders. Biological Psychiatry 46 (4): $489-497$ 
Lam, R.W., Zis, A.P., Grewal, A., Delgado, P.L. Charney, D.S., and Krystal, J.H (1996) Effects of rapid tryptophan depletion in patients with seasonal affective disorder in remission after light therapy. Archives of General Psychiatry 53: $41-44$

Lezak, M.D. (1995) Neuropsychological assessment, 3rd ed, Oxford University Press, New York

Mathews, A. and Bradley, B. (1983) Mood and the self-reference bias in recall. Behaviour Research and Therapeutics 21 (3): 233-239

McDowall, $J$. (1984) Recall of pleasant and unpleasant words in depressed subjects. Journai of Abnormal Psychology 93: 401-407

Mc Nair, D.M. Lorr M., and Droppleman, L.F. (1988). Manual for the Profile of Mood States. Educational and Industrial Testing Service, San Diego, California

Menkes, D. B., Coates, D.C., and Fawcett, J.P. (1994) Acute tryptophan depletion aggravates premenstrual syndrome. Jounal of Affective Disorders 32: 37-44

Park, S.B., Coull, J.T. McShane, R.H., Young, A.H., Sahakian, B.J, Robbins, T.W., Cowen. P.J. (1994). Tryptophan depletion in normal volunteers produces selective impairments in learning and memory. Neuropharmacology 33(3/4), 575-588

Perrig. W.J, and Perrig, P. (1988) Mood and memory: Mood-congruity effect in absence of mood. Memory and Cognition 16(2); 102-109

Riedel, W. ., Klaassen, T., Deutz, N.E.P., van Someren, A, and van Praag, H.M. (1999) Tryptophan depletion in normal volunteers produces selective impairment in memory consolidation. Psychopharmacology $141(4): 362-368$

Riskind, J.H., Rholes, W.S., and Eggers, J. (1982) The velten mood induction procedure: Effects on mood and memory. Journal of Consulting and Clinical Psychology 50: 146-147

Riskind, J.H. (1983) Nonverbal expressions and the accessibility of life experience memories: A congruency hypothesis. Social Cognition 2: 62-86

Ruiz-Caballero, J.A. and Gonzalez, P. (1994) Implicit and explicit memory bias in depressed and nondepressed subjects. Cognition and Emotion. 8(6): 555-569.

Ruiz-Caballero, J.A. and Gonzalez, P. (1997). Effects of level of processing on implicit and explicit memory in depressed mood. Motivation and Emotion 21(2), 195-209

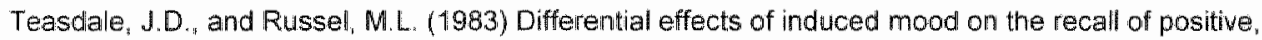
negative and neutral words. British Journal of Clinical Psychology 22 (3): 163-171

Teasdale, J.D. (1983) Negative thinking in depression: cause, effect or reciprocal relationship? Advances in Behaviour Research and Therapy 5: 3-25

Velten, E. Jr. (1968) A laboratory task for induction of mood states. Behaviour Research and Therapy 6: $473-482$

Young, S.N., Smith, S.E., Pihl, R.O., and Ervin, F.R. (1985). Typtophan depletion causes a rapid lowering of mood in normal males. Psychopharmacology 87: 173-177

Watkins, P.C. Mathews, A., Williams, D.A., and Fuller, R.D. (1992) Mood-congruent memory in depression Emotional priming or elaboration? Joumal of Abnormal Psychology 101: 581-586

Watkins, P.C., Vache, K., Verney, S.P., Muller, S., and Mathews, A. (1996) Unconscious moodcongruent memory bias in depression. Journal of Abnomal Psychology 105: 34-41

Weltzin, T.E., Fernstrom, J.D. McConaha, C, and Kaye, W.H. (1994) Acute tryptophan depletion in bullimia: effects on large neutral amino acids. Biological Psychiatry 35: 388-397 



\title{
Tryptophan depletion in normal volunteers produces selective impairment in memory consolidation
}

\author{
W.J. Riedel, T. Klaassen, N.E. P. Deutz, A, van Someren and H.M.
} van Praag

Published in: Psychopharmacology (1999) 141:362-369

\begin{abstract}
Serotonin (5-hydroxytryptamine; 5-HT) circuits may play a role in cognitive performance, particularly in learning and memory. Cognitive impairment is often seen in depressed patients, in whom 5-HT turnover in the brain is thought to be lowered. A possible human pharmacological model to study the involvement of the serotonergic system in cognitive impairment is to reduce central 5-HT synthesis through L-tryptophan depletion in healthy subjects. In this study, the cognitive effects of tryptophan depletion were assessed and whether genetically or developmentally determined vulnerability factors were predictive of the cognitive impairment induced by tryptophan depletion. Sixfeen healthy volunteers with a positive family history of depression and 11 without were given $100 \mathrm{~g}$ of an amino acid mixture with or without tryplophan, according to a double-blind, cross-over design. Tryptophan depletion specifically impaired long-term memory performance in all subjects: delayed recall performance, recognition sensitivity, and recognition reaction times were significantly impaired after tryptophan depletion relative to placebo. Short-term memory and
\end{abstract}


perceptual and psychomotor functions were unchanged. There were no differences between groups with a positive and a negative family history for depression. On the basis of these results it is concluded that tryptophan depletion specifically impairs long-term memory formation, presumably as a result of an acute decrease in 5-HT turnover in the brain.

KEYWORDS: Attention, Cognition Disorders etiology. Competing amino acids, Memory Disorders chemically induced, Serotonin biosynthesis, Serotonergic system, Tryptophan metabolism, Verbal Learning.

\section{Introduction}

The serotonergic system is considered important for learning and memory, and 5-HT function is reported to diminish with aging and in Alzheimer's Disease (AD) and depression (McEntee and Crook, 1991) In animal studies, stimulation of 5-HT activity in the brain impairs learning, memory (Altman and Normile, 1988) and visual discrimination (Sirvio et al. 1994), whereas inhibition of 5-HT activity enhances learning and memory (Altman and Normile, 1988) without affecting frontal lobe functions (Sirvio et al. , 1994). Interestingly, 5-HT reuptake inhibitors improve memory performance in animals and humans (McEntee and Crook, 1991), whereas interference with 5-HT synthesis or storage has been shown to induce depression in vuinerable individuals (Meltzer, 1989). Patients with depression have decreased levels of 5-hydroxyindoleacetic acid (5 HIAA) in cerebrospinal fluid, decreased plasma tryptophan (TRP) concentrations, a low TRP to neutral amino acid ratio, and abnormalities in serotonergic function, as indicated by neuroendocrine challenge tests (Maes and Meltzer, 1995), and reduced 5-HT synthesis in the brain (Grahame Smith, 1992). Other serotonergic disturbances in depressed patients include upregulation of 5-HT2 and a down-regulation of 5mHT Ha receptors (Van Praag, 1996). This serotonergic deficit may occur at any of several levels: diminished availability of precursor (TRP), impaired activity of tryptophan hydroxylase, abnormalities in 5-HT release or uptake, 5-HT receptor abnormalities, or interactions with other neurotransmitters (Maes and Meltzer, 1995). The involvement of diminished serotonergic activity in mood disorders is evidenced by the fact that most antidepressants augment serotonergic activity (Blier and de Montigny, 1994), while TRP depletion has a depressogenic effect (Young et al., 1985).

Cognitive dysfunctions are common, rather than rare concomitants of depression (Siegfried, 1989) and are not restricted to single functions such as memory, drive or energy deficits, but affect all major cognitive abilities. Patients with depression have an impaired perfomance in recall and recognition memory (Brand et al., 1992), visual span (Deijen et al., 1993), complex information processing tasks (Tarbuck and Paykel, 1995), and poor immediate and delayed free recall of verbal material (Ilsley 
et al., 1995\%. Antidepressant therapy, provided that anticholinergic side effects do not occur, often improves cognitive functions, and alleviates depression (Riedel and Van Praag. 1995). This improvement in cognitive functions may result from improved serotonergic, noradrenergic, or dopaminergic neurotransmission or from relief of the depressive symptoms.

Although experimentally induced serotonergic deficit, evoked by TRP depletion, causes depressed mood and cognitive impaiment (Danjou et al., 1990; Young et al., 1985), there is no evidence that cognitive dysfunction in depression is specifically associated with 5-HT dysfunction. Until now there are only a few studies describing the effect of TRP-depletion on human cognitive function. In two studies an increased number of errors in a proofreading task was found (Danjou et al. 1990; Young et al., 1985). In one study a specific impairment of learning and memory induced by TRP. depletion is reported (Park et al. 1994), while in another an effect of TRP depletion on focussed attention is reported (Coull et al., 1995). Park et al. (1994) reported an effect of TRP depletion in the absence of an effect on mood. They concluded that TRP depletion had relatively selective effects on cognitive function, namely impairments in learning and retrieval processes, while leaving performance on tests sensitive to frontal tobe dysfunction substantially unaffected. Coull et al. (1995) found that TRP depletion selectively increased the speed of stimulus-incompatible responses and not of compatible responses in an attentional search task. They concluded that serotonergic depletion might disrupt the inhibitory control of behavior. The purpose of this study was to extend the findings of Park et al. (1994) using a word learning task paradigm in which effects of treatments on short-term memory and on long-term memory can be distinguished by multiple assessments as a function of time after word list presentation. In this manner, treatment effects on storage, consolidation and retrieval processes can be distinguished. The results reported by Park et al. suggest an effect on long term memory processes (consolidation and retrieval), rather than on short-term memory (storage). Another purpose of the study was to determime the time course of TRP depletion. We wanted to see whether it was possible to maintain low TRP levels for 24 hours by sustaining the TRP depletion treatment by a low TRP diet. It was hypothesized that, if TRP can be kept low for this period of time, the impact of low brain 5HT would be augmented rather than diminished. This paradigm also allowed us to distinguish retrieval from consolidation processes by probing the word list learned on the previous day. followed by a new assessment of a parallel version of the word learning task, at 24 hours after the start of the treatment. Furthermore, as specifically noted by Park et al., mood effects of TRP depletion may be linked to a vulnerability for depression factor, as several studies have shown this (Benkelfat et al., 1994; Park et al., 1994), but such an association has not been reported for vulnerability for depression and cognitive effects of TRP depletion.

Therefore we investigated the relation between 5 HT function and cognition in healthy volunteers and in healthy first-degree relatives of patients diagnosed as 
suffering from major depression. We hypothesized that (1) TRP depletion in healthy subjects would impair learning and memory and would attenuate response interference and hence may improve performance on stimulus-incompatible responses; (2) TRP depletion would impair signal-detection performance in a visual search task; and (3) healthy subjects with a positive family history of depression would be more vuinerable to the cognitive effects of TRP depletion than heaithy subjects without a family history of depression.

\section{Materials and methods}

\section{Subjects}

Thirty-four healthy volunteers were recruited of whom 15 women and 12 men completed the experiment (mean age $31 \pm 11$ (SD); range 18-61). A complete medical examination was carried out. Exclusion criteria were cardiac, hepatic, renal, pulmonary, neurological, gastrointestinal, hematological, or psychiatric conditions, as determined from the history, physical examination, ECG, and routine laboratory blood screens, a history of alcohol or drug abuse, excessive drinking, and sensory or motor impairments which could reasonably be expected to affect psychomotor performance. A structured psychiatric interview, the MINI (Sheehan et al.. 1994), was carried out to exclude psychiatric disorders. Dieting and susceptibility to the premenstrual syndrome were exclusion criteria. All subjects were furthermore screened for depression or manic-depressive illness in the past with Research Diagnostic Criteria (RDC) (Spitzer et al., 1975). All first-degree family members were contacted and had to meet Family History Research Diagnostic Criteria (Endicott et al. 1975) for depression in order to consider the subjects as having a family history of depression.

Two groups were formed, one with first-degree relatives with depression (positive family history: $\mathrm{FH}+; 7$ males / 9 females; $29 \pm 11$ years) and one group without firstdegree relatives with depression (FH-; 5 males / 6 females; $33 \pm 11$ years). The study was approved by the standing Medical Ethics Review Committee of the University and written informed consent was given by all subjects. The subjects were paid for their participation.

\section{Study Design}

The study was conducted according to a full-factorial mixed design. The within subjects Treatment factor had two levels: placebo $(T+)$ and TRP depletion $(T-)$. This factor was studied according to a 2-period placebo-controlled, double-blind, crossover design. Treatment order was balanced. The between subjects factor was Family History for depression and consisted of two levels: positive ( $\mathrm{FH}+$ ) and negative ( $\mathrm{FH}-$ ). 


\section{Treatment}

The TRP-free (T-) mixture contained 15 free amino acids (AA's) and the placebo mixture contained the same AA's plus L-TRP (Young et al, 1985); see table 1. Subjects were given a drink of $100 \mathrm{~g}$ AA mixture plus $300 \mathrm{ml}$ tap water, $33 \mathrm{~g}$ fat, and $63 \mathrm{~g}$ carbohydrates, flavoured with artificial orange or apricol in order to improve taste. Its total caloric value was $1000 \mathrm{Kcal}$. Additional portions of $10 \mathrm{~g}$ of the drink were given at 7,11 , and 13 hours after ingestion of the $100 \mathrm{~g}$. Furthermore, subjects were given a low TRP meal at lunch and dinnertime. This consisted of 6 slices of low protein bread ( $0.2 \mathrm{~g} /$ slice) with margarine and marmalade, 2 pieces of fruit, tea, 3 glasses of lemonade, $200 \mathrm{~g}$ apple compote and mints (max. $50 \mathrm{~g}$ ).

Table 1 Composition of the placebo $(T+)$ amino-acid mixture. In the $T$ - mixture the $3.0 \mathrm{~g}$ L-iryptophan is omitted.

$\begin{array}{lllllll}5.5 \mathrm{~g} & \text { L-alanine } & 3.2 \mathrm{~g} & \text { Glycine } & 3.2 \mathrm{~g} & \text { L-histidline } & 8.0 \mathrm{~g} \text { L-isoleucine } \\ 13.5 \mathrm{~g} & \text { L-leucine } & 8.9 \mathrm{~g} & \text { L-lysine } & 5.7 \mathrm{~g} & \text { L-phenylalanine } & 12.2 \mathrm{~g} \text { L-proline } \\ 6.9 \mathrm{~g} & \text { L-serine } & 6.5 \mathrm{~g} & \text { Luthreonine } & 6.9 \mathrm{~g} & \text { L-tyrosine } & 8.9 \mathrm{~g} \text { L-waline } \\ 4.9 \mathrm{~g} & \text { L-arginine } & 2.7 \mathrm{~g} & \text { L-cysteine } & 3.0 \mathrm{~g} & \text { L-methionine } & 3.0 \mathrm{~g} \text { L-tryptophan }\end{array}$

\section{Assessments}

The cognitive test battery took approximately 40 minutes to complete and consisted of tasks measuring visual verbal learning, memory scamning, visual search and motor cholce reaction time (MCRT). All tasks have been described in detail previously (Riedel et al., 1995) and will be described briefly below. However, the first two have been modified and will be described in detall below. The primary outcome variables were measures of memory functions; immediate and delayed recall and delayed recognition sensitivity and reaction time ( $R T)$. The secondary outcome variables were measures of perceptual, attentional, psychomotor, and executive functions; slope and intercept of memory scanning, visual perceptual sensitivity and RT and simple RT, choice RT and stimulus-incompatible RT.

\section{The Visual Verbal Leaming Test (VVLT)}

This test is an adapted version of the Rey Auditory Verbal Learning Test (Lezak. 1995). The test consisted of a list of 30 monosyllabic words (18 nouns and 12 adjectives) in Dutch, which were presented in three trials on a computer screen. The 
words occur very frequently in Dutch and are acquired early in life. Items were presented in the same sequence at a rate of one per 2 seconds. Each trial ended with a free recall of the words (immediate recall). Thirty minutes after the third trial, the subject was requested to recall as many words as possible (delayed recall). A yes/no recognition test, consisting of 15 former words and 15 new but comparable words, was given after the delayed recall test. The words remained on the screen for $2000 \mathrm{msec}$ or until the subject responded. Another $1000 \mathrm{msec}$ elapsed before the next word appeared on the screen. After presentation of each word the subject had to respond "YES / NO" as fast as possibie to indicate recognition of the word (delayed recognition). The reaction times (RTs) were recorded. There were two different recognition lists to probe the long-term retention of each 30 word tist. Both recognition lists consisted of 15 formerly learned and 15 new words (distractors). According to the theory of signal detection (Pollack and Norman, 1964), the proportion of correctly recognized words $(c r)$ and the proportion of falsely recognized (fr) constitute the nonparametric sensitivity measure: $A^{\prime}=1-1 / 4(\mathrm{fr} / \mathrm{cr}+(1-\mathrm{cr}) /(1-\mathrm{fr}))$. $A^{\prime}$ is in fact the proportion of correctly recognized words, corrected for the subject's response tendency. Because the distribution of $A^{\prime}$ is skewed due to a ceiling effect, $A^{\prime}$ was arcsin transformed before being used in statistical analysis. In this study word lists were presented $a t_{6}$ and at $t_{24}$. After $t_{6}$, delayed recall and recognition were assessed twice: once after a delay of 30 minutes $\left(t_{6-6}\right)$ and once after a delay of 18 hours $\left(t_{6 \rightarrow 24}\right)$. After the list presented at $t_{24}$ recall and recognition were assessed only once after a delay of 30 minutes $\left(t_{24-24}\right)$. The variables used were the total number of words recalled after the first three trials as a measure of short-term memory, the number of correct words on delayed free recall as a measure of retrieval from longterm memory (LTM), $A^{\prime}$ as a measure of storage in LTM, and the median RT of correctly recognized target words as a measure of speed of retrieval from LTM. In each of the assessments, a different word list was presented. The lists were comparable with regard to their level of abstraction and the affective tone of the words. Parallel lists were order balanced over assessments

\section{Memory Scanning}

The subjects were briefly shown a set of 1,2 or 4 letters and told to memorize them. This is called the "memory set" (Sternberg, 1969). Subjects then saw a series of 75 letters, each of them displayed for $1000 \mathrm{msec}$ on a VCR connected to an IBM computer, followed by another $2000 \mathrm{msec}$ before the next letter appeared. Half of the presented letters were part of the memory set and had to be recognized as targets. The subjects' task was to decide and respond as rapidly as possible by pressing either 'YES' or 'NO' to indicate whether or not each successive letter was one of those contained in the memory set. The median RT of correct responses (targets and non-targets) was taken as a dependent variable. Memory sets and stimulus sets were generated at random by the computer before each subtask. Individual RT * set 
size functions were calculated. This function is defined by the equation $R T=A * S s * B$, in which: $A=$ slope of the function (i.e. the amount of extra time needed per item in the memory set), Ss = size of the memory set, and $B=$ intercept with the $Y$-axis. The slope is a measure of the speed of scanning shortterm memory whereas the intercept measures sensorimotor speed.

\section{Visual Search Task}

Dots were presented on a computer screen in a random fashion. Every second two dots changed position. When four dots formed a square, the subject had to push a button as quickly as possible (within 2 seconds). Efficient and rapid visual search is required to obtain a high signal-detection performance on this task. The reaction time and the perceptual sensitivity measure $A^{\prime}$ were taken as dependent variables.

\section{Motor Choice Reaction Time Task}

The subject held one button and was asked to press one of five other buttons located equidistantly from the hold button when lit. This yielded reaction times consisting of an initiation phase (time from stimulus onset until release of the hold button) and a movement phase (time from release of the hold button until the response button is pushed). The response set consisted of pressing the one button that lit up (simple $\mathrm{RT}$ ), pressing one of three buttons which lit up (3-choice RT), or pressing the button to the right of the lit button (incompatible three-choice RT) as quickly as possible. Initiation times and movement times thus comprised the dependent variables obtained for each of the three reaction time tasks. This task measures sensorimotor speed choice-reaction speed, and choice-reaction speed with response competition.

\section{Procedure}

A few days before the first experimental session, all subjects had individual training sessions in which they practiced all the tasks used in the study. Then the subjects received the first drink with or without TRP and completed the test battery. At least 4 days later, they received the other drink and completed the test battery. The subjects were not allowed any CNS-active drugs during the week before, or alcohol from $24 \mathrm{~h}$ before the testing sessions began. Day of the menstrual cycle was recorded; the distribution did not differ between treatment conditions. On the experimental day, at 9 hours (baseline or to) the drink was ingested as fast as possible, but within 2 hours. At $t_{6}$ and at $t_{24}$, all memory and cognitive tests were carried out; cognitive tests were also carried out at $t_{0}$. Blood samples for measurement of plasma TRP concentrations were taken at $t_{0}, t_{6}$ and $t_{24}$. Blood was immediately placed on ice and centrifuged within 30 minutes at $4^{\circ} \mathrm{C}$. One hundred microlitres plasma was mixed with $4 \mathrm{mg}$ 
sulfasalicyl-acid and subsequently frozen at $-80^{\circ} \mathrm{C}$ until determination of aminoacids by high-performance liquid chromatography (van Eijk et al., 1993).

\section{Statistical Analysis}

Primary and secondary outcome cognitive performance variables were analysed by using two-way repeated measures MANOVA (SPSS 6.1.1 on Apple Macintosh). Within subjects, factors were treatment condition ( $T$ - or $T+$ ) and in the memory scanning test and MCRT also the level of difficulty of the test: 1 .e. memory set $(1,2$, 4) and response set (simple, choice, incompatible). The between subjects factor was group ( $\mathrm{FH}+/ \mathrm{FH}-$ ). Changes in plasma concentrations of TRP and of other large neutral amino acids (LNAA) and the ratio TRPRLLNAA were analysed by using paired t-tests. Order effects were evaluated separately using treatment order $(\mathrm{T}+/ \mathrm{T}$ - or $\mathrm{T}-1$ $T+$ ) as a between subjects factor.

\section{Results}

\section{Adverse effects}

During the study, seven subjects withdrew from the experiment after the first treatment session. Five subjects withdrew because of adverse effects related to the treatment: four subjects felt nauseous, three of whom vomited, and one subject could not adhere to the TRP-poor diet. One subject became ill the day after the treatment session and one subject withdrew for no particular reason. All were women, $6 \mathrm{FH}$ and $1 \mathrm{FH}+, 3$ in the $\mathrm{T}$ - and 4 in the T+condition.

\section{Missing data}

Twenty-seven subjects, 15 females and 12 males, completed the experiment. Because of difficulties in taking blood, blood samples were not available for two subjects in the $T$-condition at $t_{6}$ and one subject at $t_{24}$ and for two subjects in the $T+$ condition at $t_{24}$. Word learning data were missing for two subjects in the $t_{5-24}$ delayed recall trial, one in the $T$ - and one in the $T+$ condition and from two subjects in the $t_{24}$. 324 delayed recall trial, both in the $T+$ condition. Because of a computer failure, one subject at to in the T+ condition missed the Memory Scanning task and one subject at $t_{24}$ in the $T$ - condition missed the entire test battery including Recognition, Memory Scanning, Visual Search, and Choice RT. MANOVA analyses of variance were carried out without subjects with missing data at the relevant time points. 


\section{Word Learning}

The total number of words remembered in the immediate recall trials at $t_{5}$ did not differ between $\mathrm{FH}+/ \mathrm{FH}$ - groups and treatment conditions. Delayed recall performance of the word list presented at te was impaired in the $T$. condition at to $\left(F_{1,25}=5.00\right.$, $p<.05)$ and also at $t_{24}\left(F_{, 23}=7.99, p<.01\right)$. There were no differences between $\mathrm{FH}+1 \mathrm{FH}$-groups. Immediate and delayed recall of the word list presented at $\mathrm{t}_{24}$ did not differ between groups and treatment conditions. In figure 1 TRP depletionplacebo difference scores are plotted as a function of time after presentation.

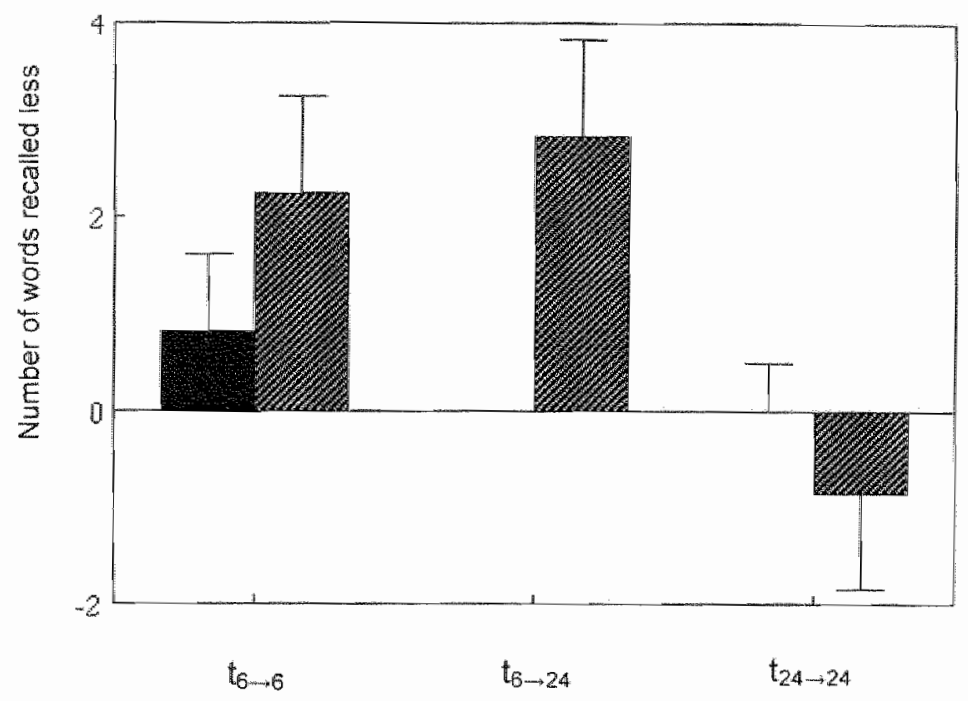

Figure 1. TRP-depletion - placebo difference scores of immediate (black bars) and delayed recall (shaded bars) of word lists: presented and recalled at $t_{6}$ ( $\left.t_{6} \rightarrow t_{6}\right)$, presented at $t_{6}$ and recalted at $t_{24}\left(t_{15}\right.$ $\left.\rightarrow t_{24}\right)$ and presented and recalled at $t_{24}\left(t_{25} \rightarrow t_{24}\right)$. Positive scores denate inpaired recalli performance after TRP depletion relative to placebo.

Recognition of the word list presented at $t_{\hat{\sigma}}$ did not differ between groups and treatment conditions at $t_{6}$, but at $t_{24}$ recognition of the same word list was impaired in the $T$ - condition $\left(F_{1,25}=4.43, p<0.05\right)$. There was no difference between the $F H+/ F H$ groups. Recognition of the word list presented at $t_{24}$ did not differ between groups and treatment conditions. Speed (RT) of recognition of the word list presented at $t_{6}$. did not differ between groups and treatment conditions. At $t_{24,}$ speed of recognition of the same word list was slower in the $T$ - condition $\left(F_{1,25}=10.77, p<0.005\right)$. There was no difference between $\mathrm{FH}+/ \mathrm{FH}$ - groups, bul there was an interaction effect of groups and treatment condition $\left(F_{1,25}=5.48, p<0.05\right)$. At $t_{24}$, both groups were slower at 
recognizing the words learned at th than they were at $t_{6}$ and this slowing was more pronounced in the FH-group ( +71 msec) than in the $\mathrm{FH}+$ group ( +12 msec). Speed of recognition of the word list presented at $t_{24}$ did not differ between groups and treatment conditions. The results are listed in table 2.

Table 2 The means and standard errors of the primary outcome measures oblained in Word List Leaming: Immediate Recall Delayed Recall and Delayed Recognition Sensitivity and RT, broken

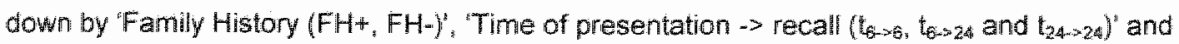
'Treatment $(T+, T-)$.

\begin{tabular}{|c|c|c|c|c|c|c|c|}
\hline \multirow[b]{2}{*}{ Time } & & \multicolumn{3}{|c|}{$\mathrm{FH}+(\mathrm{n}=16)$} & \multicolumn{3}{|c|}{$\mathrm{FH}-(n=11)$} \\
\hline & & $t_{6}>3$, & $t_{6,324}$ & $t_{24-\infty 24}$ & $\operatorname{tat}_{x \rightarrow 6}$ & $t_{b \rightarrow 24}$ & $\operatorname{tat}_{24-\infty}-24$ \\
\hline \multirow[t]{2}{*}{ Immediate recall } & $T *$ & $41.7(3.2)$ & & $42.5(3.1)$ & $37.3(2.8)$ & & $39.5(2.7)$ \\
\hline & T- & $38.4(3.6)$ & & $41.1(4.1)$ & $36.1(3.6)$ & & $41.5(3.1)$ \\
\hline \multirow[t]{2}{*}{ Delayed recall } & $\mathrm{T}+$ & $14.9(1.9)$ & $11.9(1.7)$ & $15.1(1.7)$ & $12.1(1.2)$ & $10.3(1.2)$ & $10.3(1.8)$ \\
\hline & $T_{-}$ & $12.4(1.6)^{4}$ & $9.0(1.8)^{*}$ & $14.4(2.1)$ & $10.1(1.6)$ & $7.5(1.6)$ & $13.4(1.6)$ \\
\hline \multirow{2}{*}{$\begin{array}{l}\text { Dellayed recognition } \\
\text { Sensitivity }(\%)\end{array}$} & $T+$ & $92.1(1.6)$ & $87.9(2.6)$ & $90.1(3.6)$ & $88.1(2.5)$ & $82.4(2.9)$ & $88.9(2.7)$ \\
\hline & T. & $90.9(1.4)$ & $79.3(5.5)^{*}$ & $89.5(2.4)$ & $88.9(2.5)$ & $80.0(3.7)^{*}$ & $91.4(2.1)$ \\
\hline \multirow[t]{2}{*}{ Recoginition RT } & $T+$ & $611(29)$ & $606(36)$ & $583(29)$ & $609(32)$ & $585(32)$ & $608(21)$ \\
\hline & T- & $632(31)$ & $618(34)^{*}$ & $613(26)$ & $618(23)$ & $656(31)^{*}$ & $586(21)$ \\
\hline
\end{tabular}

"significantly different from placebo $(T+)$

None of the secondary cognitive measures obtained for the memory scanning, visual search, and choice reaction time tasks differed between groups or treatment conditions. The results are listed in table 3 . 
Table 3 The means and standard errors of the secondary outcome measures: slope and intercept of the Short-Term Memory Scanning function, Perceptual sensitivity and RT, Simple RT, Choice RT, S-R incompatible RT and movement RT, broken down by 'Family Histoy (FH+. FH-)'. 'Time after treatment administration $\left(t_{0}\right.$ or baseline, $t_{0}$ and $\left.t_{24}\right)$ " and "Treatment $(T+, T-y$.

\begin{tabular}{|c|c|c|c|c|c|c|c|}
\hline \multirow[b]{2}{*}{ Time } & & \multicolumn{3}{|c|}{$F H+(n=16)$} & \multicolumn{3}{|c|}{ FH- $(n=y 1)$} \\
\hline & & $t_{0}$ & $t_{6}$ & $\mathrm{t}_{24}$ & to & 4 & $t_{24}$ \\
\hline \multicolumn{8}{|c|}{ Short time Memory Scanning } \\
\hline \multirow[t]{2}{*}{ Slope } & $T+$ & $37(4)$ & $34(4)$ & $32(5)$ & $27(3)$ & $30(4)$ & $27(4)$ \\
\hline & $T-$ & $3: 1(5)$ & $34(3)$ & $34(3)$ & $33(4)$ & $35(4)$ & $33(5)$ \\
\hline \multirow[t]{2}{*}{ 1-intercept } & $T+$ & $410(11)$ & $411(14)$ & $406(16)$ & $442(12)$ & $432(17)$ & $418(12)$ \\
\hline & $T-$ & $429(16)$ & $419(13)$ & $411(13)$ & $430(13)$ & $415(10)$ & $416(10)$ \\
\hline \multicolumn{8}{|l|}{ Visual Search } \\
\hline \multirow[t]{2}{*}{ Perceptual sensitivity $(\%)$} & $T+$ & $84.3(1.9)$ & $81.9(2.8)$ & $82.7(2.7)$ & $81.3(2.7)$ & $84.2(2.8)$ & $84.4(2.4)$ \\
\hline & $T-$ & $811,8(1.8)$ & $83.5(2.8)$ & $82.6(2.6)$ & $82.4(3.3)$ & $82.2(2.8)$ & $813(3.1)$ \\
\hline \multirow[t]{2}{*}{ Perceptual RT } & $T+$ & $763(13)$ & $757(20)$ & $756(26)$ & $772(26)$ & $764(21)$ & $744(26)$ \\
\hline & $T-$ & $773(24)$ & $767(20)$ & $747(20)$ & $759(24)$ & $742(19)$ & $744(24)$ \\
\hline \multicolumn{8}{|l|}{ Motor choise Reaction Ttime } \\
\hline \multirow[t]{2}{*}{ Simple RT } & $T+$ & $286(7)$ & $280(8)$ & $278(6)$ & $304(9)$ & $295(11)$ & $287(7)$ \\
\hline & $T-$ & $279(7)$ & $276(7)$ & $285(10)$ & $306(8)$ & $283(9)$ & $287(6)$ \\
\hline \multirow[t]{2}{*}{ 3-Choice RT } & $T+$ & $334(9)$ & $336(8)$ & $334(9)$ & $342(9)$ & $346(12)$ & $335(7)$ \\
\hline & $T-$ & $335(10)$ & $336(10)$ & $344(11)$ & $349(B)$ & $337(9)$ & $342(10)$ \\
\hline \multirow[t]{2}{*}{ S-R incomp RT } & $T+$ & $404(11)$ & $390(13)$ & $396(15)$ & $414(14)$ & $413(17)$ & $405(19)$ \\
\hline & T- & $409(13)$ & $402(11)$ & $393(12)$ & $416(13)$ & $400(15)$ & $395(12)$ \\
\hline \multirow[t]{2}{*}{ Movement time } & $T+$ & $120(5)$ & $115(5)$ & $119(6)$ & $131(11)$ & $126(10)$ & $128(8)$ \\
\hline & $T-$ & $122(5)$ & $119(5)$ & $121(6)$ & $130(9)$ & $126(10)$ & $130(11)$ \\
\hline
\end{tabular}

\section{Blood levels}

Plasma TRP concentrations at baseline and at $t_{24}$ did not differ between groups and treatment conditions. Plasma concentrations of TRP were $67 \%$ lower at to than at baselime in the $T$ - condition $\left(F_{1,22}=85.03, p<.0001\right)$. The ratio TRP/ 2 LNAA at baseline did not differ between groups and treatment conditions. This ratio was $78 \%$ lower at $t_{6}$ than at baseline in the $T$ - condition $\left(F_{1,22}=87.10, p<.0001\right)$ and was $15 \%$ lower at $t_{24}$ than at baseline in the $T$ - condition $\left(F_{1,21}=7.79, p<.05\right)$. The results are listed in table 4. 
Table 4. The means and standard errors of the blood plasma levels of TRP and the ratio TREPILLNAAS'S

\begin{tabular}{|l|c|c|c|c|c|c|c|}
\hline & & \multicolumn{3}{|c|}{$F H+(n=16)$} & \multicolumn{3}{c|}{$F H-(n=11)$} \\
\hline Time & & $t_{0}$ & $t_{5}$ & $t_{24}$ & $t_{0}$ & $t_{5}$ & $t_{24}$ \\
\hline TRP (minolin) & $T+$ & $45.0(1.7)$ & $54.8(5.3)$ & $44.6(1.8)$ & $49.7(2.9)$ & $59.7(3.9)$ & $6.9(3.6)$ \\
\hline & $T-$ & $45.6(1.9)$ & $161(5.4)^{*}$ & $40.3(3.4)$ & $48.2(3.3)$ & $15.0(3.1)^{*}$ & $3.3(1.9)$ \\
\hline TRP/LLNAA $\%)$ & $T+$ & $9.1(0.3)$ & $7.3(0.6)$ & $8.8(0.3)$ & $9.1(0.5)$ & $7.9(1.0)$ & $8.3(0.5)$ \\
\hline & $T-$ & $8.8(0.4)$ & $1.9(0.5)^{*}$ & $7.4(0.3)^{*}$ & $8.8(0.3)$ & $2.2(0.7)^{*}$ & $7.9(0.3)$ \\
\hline
\end{tabular}

significantly different from placebo $(T+)$

\section{Treatment Order}

Thirteen subjects received the $T$ - mixture first and 14 received the $T+$ mixture first. Analysis of the dependent variables by treatment order showed that there was no effect of treatment order on the effect of $\mathrm{T}$ - on delayed recall and delayed recognition. However, there was a complex interaction of treatment order with treatment and group on delayed recognition $R T$ at $t_{6 \rightarrow 24}$. The effect of $T$ - on Recognition RT could largely be attributed to 6 subjects in the $F H$-group in whom $T$. slowed their RT by 125 msec and who received $T$ - in the first session.

\section{Sex differences}

Although females tended to score better on immediate and delayed recall performance of the word learning task, the differences were not significant. The same was true for the effect of $T$ - on delayed recall performance.

\section{Discussion}

To the best of our knowledge, this is the first study demonstrating the effects of TRP depletion specifically on long-term memory (LTM) in humans. TRP depletion seemed to have a specific effect on LTM, with LTM consolidation being impaired 6 hours after ingestion of a TRP-free drink. Thus, information learned at to seemed to be more rapidly forgotten between $t_{6}$ and $t_{24}$ by subjects in the TRP depletion condition than by subjects in the placebo condition. The finding that none of the other cognitive parameters were affected can be interpreted as an absence of TRP depletion effects on short-term- or working memory, perceptual., attentional-, psychomotor- and executive functions. This highly specific effect of TRP depletion on LTM appears to confirm the findings of Park et al. (1994), who also reported specific long-term effects of TRP depletion on learning and memory. Regarding the specificity of the observed 
LTM impairment after TRP depletion, this seems to be a robust effect, as it is expressed by several parameters of LTM performance, which yield rather converging evidence that indeed LTM consolidation is impaired when information is presented at $t_{6}$ after $T$. That is, information learned at $t_{6}$ seems to more rapidly decay in the 30 minutes between immediate and delayed recall at $t_{6}$ and this difference is sustained in the 18 hours between delayed recall at $t_{6}$ and delayed recall at $t_{24}$ in the TRP depletion condition relative to the placebo condition. Retrieval of newly learned material at $t_{24}$ is unaffected in the TRP-depletion condition relative to placebo which leads us to conclude that consolidation rather than retrieval is affected. Further inspection of the difference in rate of decay of the learned words in the 18 hour period between delayed recall at $t_{6}$ and delayed recall at $t_{24}$ between both treatment conditions reveals that the $t_{6-3.4}$ decay in the $T$-condition is 3.4 words and 2.5 in the $T+$ condition. This difference is not statistically significant $(t=-1,11, d f=24 ; n$.s.). As long-term memory is mainly formed during the minutes following presentation (Izquierdo, 1989), the most plausible explanation of the T-effect on LTM performance is that $T$ - hampers memory consolidation primarily during the 30 minutes between immediate recall and delayed recall. The difference in LTM performance would then be sustained in the 18 hour period between delayed recall at $t_{6}$ and $t_{24}$. The finding that recognition performance is only impaired at $t_{24}$ might then be explained not by enhanced rate of decay in the period between $t_{6}$ and $t_{24}$, but merely by a threshold phenomenon which would be dependent on the time since presentation rather than on the rate of decay. Passive recognition is in general not a very sensitive procedure to test word learning, but might become so when the time between presentation and recognition is prolonged.

We assumed that TRP depletion would cause an acute reduction in 5-HT synthesis in the brain (Nishizawa et al. 1997). However, TRP depletion could also reduce protein synthesis (Cortamira et al 1991), and drug-induced inhibition of protein synthesis in the brain is a model of memory disorders in experimental animals (Sarter et al. 1992). Moreover, if inhibition of protein synthesis is responsible for the LTM impairment observed after TRP depletion, then a similar effect should be observed after depletion of any other essential aminomacid. This hypothesis was tested in a pilot experiment involving 13 subjects in which the effect of TRP depletion was compared to that of lysine depletion and placebo (Klaassen et al., 1999). The results showed that in contrast to TRP depletion, lysine depletion did not cause LTM impairments or have an effect on cognitive performance. Further experiments should be performed to confirm the effect of TRP depletion on LTM impairment and whether such depletion leads to a decreased synthesis of $5 \mathrm{HT}$. The lack of effect of TRP depletion on memory at t24 was parallelled by the return of plasma TRP concentrations to normal. The TRP/ $L$ LNA ratio was still significantly different between $T$ - and $T+$ at $t_{24}$, but this difference was small and can probably be attributed to increased concentrations of LNAAs rather than low concentrations of TRP at $t_{24}$. The delayed recall and recognition impairments at $t_{24}$ of words learmed at $t_{6}$ can be 
attributed to impaired consolidation of information between $t_{6}$ and $t_{24}$. At $t_{24}$ there were no longer impairments of memory for new information and neither were there any other cognitive effects of $T$. This was surprising because we had intended that prolongation of the TRP deficient diet would lead to prolonged depletion of TRP and hence to prolongation or exaggeration of its effects on memory or cognitive performance. Even if TRP concentrations had returned to normal, there is no reason to assume that 5-HT concentrations would also return to normal. It would be reasonable to assume that there is a delay between the decline of TRP in plasma and 5-HT in the brain. There are two possible explanations for this lack of effect at $t_{24}$. The first is that the TRP-deficient diet did not in fact affect 5-HT concentrations, and the second is that the synthesis of 5-HT was restored "possibly by 'recycling" of TRP released by protein degradation. A feature of the TRP depletion method in which our study differs from others is the addition of carbohydrates and fat to the AA mixture. One might raise the possibility that the addition of carbohydrates to the $A A$ mixture alters the brain entry of TRP in an undesired manner. Carbohydrates are known to increase the rate of insulin release, thus taking away several LNAAs from the circulation, which might stimulate the uptake of TRP in the brain (Fernstrom, 1981). However, this logic only applies to pratein-free meals. Protein-containing meals, or mixtures which strongly enhance protein synthesis such as our mixtures, would fail to rise brain TRP concentrations because their ingestion causes serum TRP concentrations and the concentrations of its transport competitors to rise by proportionally similar amounts, resulting in no net change in competition for uptake (Fernstrom and Fernstrom; 1995). Meal-induced changes in brain TRP concentrations appear to be predicted by the alterations produced by the meal in the serum concentration of TRP relative to that of the other LNAAs, as expressed by the ratio TRP/LLNAA (Fernstrom and Fernstrom, 1995). As this ratio was convincingly low in our study, at least at to, the addition of carbohydrates and fat to the AA mixture does not seem to alter the method of TRP depletion and hence did not corroborate the results. Furthermore, it must be noted that it is very difficult in general to refrain the subjects rom carbohydrates during a prolonged period of 24 hours. Adding carbohydrates to the AA mixture is a way to provide the subjects' necessary nutrition in a standard manner and besides might even contribute to a decrease of the brain entry of TRP since it leads to a further enhancement of protein synthesis and would thereby bind (more) free TRP.

A family history of depression did not influence the results, and thus individuals with such a history would not appear to be more susceptible to the effects of TRP depletion on cognitive function. Further studies with larger numbers of subjects are needled to confirm this result. Another factor which could have affected the results is the sex of the subjects. Women are more susceptible to a lowering of mood as a function of TRP withdrawal (Ellenbogen et al., 1996). However, little is known about Sex-related effects of TRP depletion on cognitive functions because previous studies (Coull et al., 1995; Park et al., 1994) investigated only male subjects. Our data show 
that women had a somewhat greater memory impairment during TRP depletion, but this could also be an initial values problem, because the women had better memory performance at baseline.

The effect of $T$ - on mood was also studied and the results showed that only $\mathrm{FH}$. subjects showed a mood-lowering response to $T$ - These results were presented elsewhere (Klaassen et al., 1999) and can be considered a replication of the findings by Benkelfat et al. (1994). There was no effect of $\mathrm{FH}$ on cognitive performance and since there appeared to be no association between cognitive and mood responses to $T-$, it seems that these effects are not dependent on one another.

In conclusion, our data indicate that TRP depletion specifically impairs LTM consolidation in healthy human volunteers. The effect is presumed to be mediated via impaired synthesis of 5-HT and hence lowered 5-HT availability in the brain. The method used could serve as a model for studying cognitive dysfunction in 5 -HT related disorders.

\section{References}

Altman, H.J., and Normile, H.J. (1988) What is the nature of the role of the serotonergic nervous system in learning and memory: prospects for development of an effective treatment strategy for senile dementia. Neurobiology of Aging 9: 627-38

Benkelfat . C. Ellenbogen, M.A., Dean, P., Palmour, R.M., and Young, S.N (1994) Mood-lowering effect of tryptophan depletion. Enhanced susceptibility in young men at genetic risk for major affective disorders. Archives of General Psychiatry 51:687-97

Blier. P., and de Montigny, C. (1994) Current advances and trends in the treatment of depression [see comments]. Trends in Pharmacological Sciences 15:220-226

Brand, A.N. Jolles, J, and Gispen de Wied C. (1992) Recall and recognition memony deficits in depression. Joumal of Affective Disorders 25: 77-86

Cortamira, N. O. Seve, B., Lebreton, Y, and Ganier, P. (1991) Effect of dietary tryptophan on muscle, liver and whole-body protein synthesis in weaned piglets: relationship to plasma irsulin. British Journal of Nutrition $65: 423-35$

Coull, J. T., Sahakian, B.J., Middleton, H.C., Young, A.H. Park, S.B., McShane, R.H., Cowen, P.J., and Robbins, T.W. (1995) Differential effects of clonidine, haloperidol, diazepam and tryptophan depletion on focused attention and attentional search. Psychopharmacology 121:222-230

Danjou, P., Hamon, M. Lacomblez, L., Warot, D., al e (1990) Psychomotor, subjective and neuroendocrine effects of acute tryptophan depletion in the healthy volunteer. Psychialtie and Psychobiologie 5: $31-38$

Deijen, J.B., Oriebeke, J.F., and Rijsdijk, F.V. (1993) Effect of depressior on psychomotor skills, eye movements and recognition-memory. Journal of Affective Disorders 29: 33-40

Ellenbogen, M.A. Young, S.N., Dean, P. Palmour, R.N., Benkelfat, C. (1996) Mood response to acute tryptophan depletion in healthy wolunteers: Sex differences and temporal stability. Neuropsychopharmacology 15: 465-474

Endicott, J., Andreasen, N.C., and Spitzer, R.L. (1975) Family History-Research Diagnostic Criteria. Biometrics Research, New York State Psychiatric Institute, New York 
Fernstrom, J.D. (1981) Dietary precursors and brain neurotransmitter formation. Annual Review of Medicine 32: $413-425$

Fernstrom, M. H. and Fernstrom J.D. (1995) Brain tryptophan concentrations and serotonin synthesis remain responsive to food consumption after the ingestion of sequential meals. American Journal of Clinical Nutrition 61: $312-319$

Grahame-Smith, D.G. (1992) Serotonin in affective disorders. International Clinical Psychopharmaco$\log y: 4: 5-13$

Ilstey, ل.E., Moffoot, A.P., and O'Carroll, R.E. (1995) An analysis of memory dystunction in major depression. Journal of Affective Disorders 35: 1-9

izquierdo, 1. (1989) Different forms of posttuaining processing. Behavioural and Neural Biology 51 $172-202$

Klaassen, T., Riadel, W.J., Deutz, N.E.P., Van Someren, A., and Van Praag, H.M. (1999) Specificity of the tryptophan-depletion method. Psychopharmacology 141:279-286

Klaassen, T. Riedel, W.J., van Someren, A., Deutz, N.E. P., Honig, A. and Van Praag, H.M. (1999) Mood effects of 24 hour tryptophan depletion in healthy first degree relatives of patients with affective disorders. Biological Psychiatry 46: $489-497$

Lezak, M. D. (1995) Neuropsychological Assessment, 3rd edn. Oxford Uniwersity Press, New York

Maes, M., and Meltzer, H.Y. (1995) The Serotonin Hypothesis of Major Depression. In: Bloom FE. Kupter DJ (eds) Psychopharmacology: The Fourth Generation of Progress. pp. 933-944. New York: Raven Press

McEntee, W. J., and Crook, T.H. (1991) Serotonin, memory, and the aging brain. Psychopharmacology Berlin 103: 143-149

Meltzer, H. (1989) Serotonergic dysfunction in depression. British Journal of Psychialry 155 (Suppl 8) 25-31

Nishizawa, S., Benkeifat, C., Young, S.N., Leyton, M., Mzengeza, S., de Montigny, C., Blier, P., and Diksic, M. (1997) Differences between males and females in rates of serotonin synthesis in human brain. Proceedings of the National Academy of Sciences of the United States of America 94: 53085313

Park, S.B., Coull, J.T., MCShane, R.H., Young, A.H., Sahakian, B.J., Robbins, T.W., and Cowen, P.J (1994) Tryptophan Depletion in Normal Volunteers Produces Selective Impaiments in Learning and Memory. Neuropharmacology 33: 575-588

Pollack, I., Noman, D.A. (1964) A non-parametric analysis of recognition experiments. Psychonomic Sciences 1: 125-126

Riedel. W. Hogervorst. E, Leboux, R. Verhey, F., Van Praag. H., and Jolles J (1995) Caffeine attenuates scopolamine-induced memory impairment in humans. Psychopharmacology 122: 158168

Riedel, W.J., and Van Praag HM (1995) Avoiding and Managing Anticholinergic Eftects of Antidepressants. CNS Drugs 3: 245-259

Sarter, M. Hagan, $d$, and Dudchenko, P. (1922) Behavioural screening for cognition enhancers: From: indiscriminate to valid testing: 1. Psychopharmacology 107: 144-159

Sheehan, D., Lecrubier, Y., Janavs, J., Knapp, E., Weiller, E., et al (1994) MINI International Neuropsychiatric Interview. University of South Flarida, Tampa

Siegfried, K. (1989) Depression and dementia of the Azhemer type: Implications for psychopharmacological research. Human Psychopharmacology 4: 237-245

Sirvio, J., Riekikinen, P.J., Jakala, P.. Riekkinen, P.J. (1994) Experimental studies on the role of serotonin in cognition. Progress in Neurobiology 43: $363-379$ 
Spitzer, R.L. Endicott, J, and Robins, E. (1975) Research Diagnostic Criteria (RDC) for a Selcted Group of Functional Disorders. Ed. 2. Biometrics Research, New York State Psychiatric Institute. New York

Sternberg. S. (1969) Memory scanning: mental processes revealed by reaction time experiments. American Scientist 57: 421-457

Tarbuck, A.F. and Paykel, E.S. (1995) Effects of major depression on the cognitive function of younger and older subjects. Psychological Medicine 25: 285-95

Van Eijk, H.M., Rooyakkers, D.R., and Deutz, N.E. (1993) Rapid routine determination of amino acids in plasma by high-performance liquid chromatography with a $2-3$ microns Spherisorb ODS II column. Journal of Chromatography 620: 143-148

Van Praag, H.M (1996) Serotonin related, anxiety/aggression driven, stressor precipitated depression: a psycho biological hypothesis. European Psychiatry 11: 57-67

Young, S.N., Simith, S.E., Pihl, R.O., and Ervin, F.R. (1985) Tryplophan depletion causes a rapid lowering of mood in normal males. Psychophamacology Berlin 87: 173-177 



\title{
Effects of tryptophan depletion on anxiety and on carbondioxide- provoked panic
}

T. Klaassen, J. Klumperbeek, N.E.P. Deutz, H.M. van Praag and

E. Griez

Published in: Psychiatry Research (1998) 77: 167-174

\begin{abstract}
Results of several studies suggest that anxiety is under serotonergic control. We studied the influence of tryptophan depletion on generalized anxiety and on the response to a $35 \%$ carbon dioxide $\left(\mathrm{CO}_{2}\right)$ challenge. Fifteen healthy male volunteers received both a mixture of amino acids without tryptophan and a placebo mixture under double-blind canditions. The tryptophan-free mixture led to a $80 \%$ decrease in blood tryptophan levels compared to the placebo. There was a significant increase in anxiety on the Spielberger Anxiety Inventory and a trend towards more tension on the Profille Of Mood States' tension" items, both of which were interpreted as increased nervousness. Furthermore, a significant increase in neurovegetative panic symptoms occurred after the $\mathrm{CO}_{2}$ challenge. We conclude that the serotonergic system is causally involved in anxiety-related mechanisms and that it may be worth pursuing the role of ryptophan depletion on $\mathrm{CO}_{2}$-induced panic in patients with anxiety disorders.
\end{abstract}




\section{Introduction}

Both animal and human studies suggest that serotonergic disturbances may play a role in the pathophysiology of anxiety and panic (Kahn et al., 1988; Coplan et al.. 1992). An increasingly popular method used to explore the serotonergic system is the administration of an amino acid mixture lacking tryptophan, the tryptophan depletion method (Young et al., 1985). With this method, tryptophan levels in blood and in the brain are reduced artificially to approximately $15 \%$ of the original value. The model is based on the observation that tryptophan depletion leads to reduced levels of serotonin in the brain of rats (Gessa et al., 1974; Tagliamonte et al., 1973; Moja et al., 1989).

Acute tryptophan depletion induces a clinically significant return of symptoms in remitted depressive patients (Delgado et al., 1990, 1991; Lam et al., 1996). Less clear-cut changes have been found in healthy subjects. Although there is considerableevidence of a relationship between anxiety and the serotonergic system, it is generally thought that tryptophan depletion does not lead to increased generalized anxiety. What has been observed, however, is that administration of $5 \%$ carbon dioxide $\left(\mathrm{CO}_{2}\right)$ after tryptophan depletion leads to significantly higher levels of anxiety in panic patients than does a placebo mixture (Miler et al., 1996). This suggests that tryptophan depletion may sensitize anxiety-related mechanisms and that increased anxiety may only become apparent after provocation.

Another valid (Griez et al., 1987; Verburg et al., 1995), specific (Griez et al., 1990), and reliable (Verburg et al. 1998) method for inducing panic is the $35 \% \mathrm{CO}_{2}$ challenge, which induces panic attacks in panic patients but seldom in normal controls (Griez et al., 1987; Perna et al., 1994). In this challenge paradigm, subjects inhale one vital capacity breath of $35 \% \mathrm{CO}_{2}$ and $65 \% \mathrm{O}_{2}$.

Inhalation of $\mathrm{CO}_{2}$ affects the respiratory system, leading to increased ventilation. Very recently, Kent et al. (1996) published a study on serotonergic mechanisms and $\mathrm{CO}_{2}$ inhalation. Tryptophan depletion led to a significant increase in ventilatory activity. Thus, the results of this study, like the ones of Miller et al. (1996), suggest that tryptophan depletion might influence respiratory control.

To further explore serotonergic mechanisms in the $35 \% \mathrm{CO}_{2}$ probe, we challenged normal subjects who were pretreated with an amino acid mixture that did not contain tryptophan. It was hypothesized that the tryptophan depletion mixture would induce more panic symptoms after the $35 \% \mathrm{CO}_{2}$ challenge than the placebo mixture. We were also interested in the influence of tryptophan depletion on generalized anxiety. 


\section{Materials and Methods}

\section{Subjects}

Nineteen healthy male subjects were recruited through newspaper adwertisements. Inclusion criteria were: good physical and mental health (as assessed by medical history, physical examination, and SCL-90), no history of psychiatric disorder, no current axis I DSM IV diagnosis (as assessed by the Mini International Neuropsychiatric Interview), and no psychotropic medication within 1 week of the onset of the test. All subjects gave written informed consent prior to the test and were paid for their participation.

\section{Design and procedures}

The experiment was a randomized, double-blind, placebo-controlled cross-over study. The tryptophan depletion session and the placebo session were carried out 7 days apart.

The subjects arrived at the clinic at $8: 30$ in the morning [time point $1(T=1)]$ after an overnight fast. They filled in the Spielberger State Anxiety Scale (STAl; Spielberger et al., 1970), the Profile of Moods States (POMS, Mc Nair et al., 1971) and a $100 \mathrm{~mm}$ Visual Analogue Scale for Anxiety (VAS-anxiety). After ingestion of the amino acid mixture the subjects remained on the ward.

Side effects (headache, feeling cold, feeling hot, dizziness, sleepiness, perspiration, blurred vision, drowsiness, nausea, palpitations, dry mouth, abdominal complaints, fatigue) were monitored on a self-constructed 5-point list at 9:00, 11:00, 13:00 and 15:00 $\mathrm{h}$ in the afternoon. At time point $2(T=2 ; 15: 00 \mathrm{~h})$, the POMS, STAI and VASanxiety were filled in again, after which a blood sample was taken for measurement of total plasma tryptophan levels. Within five minutes, this was followed by a $\mathrm{CO}_{2}$ challenge in which the subjects had to inhale through a mask one vital breath capacity of a gas mixture containing $35 \% \quad \mathrm{CO}_{2}$ and $65 \% \quad \mathrm{O}_{2}$. Directly before timepoint $3(T=3)$ ] and after [timepoint $4(T=4)$ ] the inhalation, the subjects had to fill in the VAS-anxiety and a panic symptom list (PSL-IIIR) consisting of 13 symptoms of a panic attack, as described by DSM III-R on a scale from 0 to 4.

\section{Amino acid mixtures}

The $100 \mathrm{~g}$ tryptophan deficient amino acid mixture was made according to the method used by Young et al. (1985) (table 1). 
Table 1.

Composition of the placebo amino acid mixture.

$\begin{array}{ll}\text { L-alanine } & 5.59 \\ \text { L-arginine } & 4.9 \mathrm{~g} \\ \text { L-cysteine } & 2.7 \mathrm{~g} \\ \text { glycine } & 3.2 \mathrm{~g} \\ \text { L-histidine } & 3.29 \\ \text { L-isoleucine } & 8.0 \mathrm{~g} \\ \text { L-leucine } & 13.59 \\ \text { L-methionine } & 3.0 \mathrm{~g} \\ \text { L-phenylalanine } & 5.7 \mathrm{~g} \\ \text { L-proline } & 12.2 \mathrm{~g} \\ \text { L-threonine } & 6.5 \mathrm{~g} \\ \text { L-tyrosine } & 6.9 \mathrm{~g} \\ \text { L-valine } & 8.99 \\ \text { L-lysine } & 8.9 \mathrm{~g} \\ \text { L-serine } & 6.9 \mathrm{~g} \\ \text { L-tryptophan } & 3.0 \mathrm{~g}\end{array}$

In the iryptophan depleted mixture, Hryptophan was lleft ouf.

The placebo mixture contained $3 \mathrm{~g}$ of L-tryptophan. In order to dissolve the amino acids, a mixture of $33 \mathrm{~g}$ fat and $63 \mathrm{~g}$ carbohydrates was added, flavored with artificial orange or apricot flavour. To this $200-\mathrm{g}$ mixture, $300 \mathrm{ml}$ of tap water was added. The mixture was swallowed by the subjects as fast as possible.

\section{Plasma tryptophan measurements}

Following the venipuncture, blood was immediately placed on ice and centrifuged within $30 \mathrm{~min}$ for $5 \mathrm{~min}$ at $11000 \times \mathrm{g}$ at $4^{\circ} \mathrm{C}$. After that, $100 \mu \mathrm{l}$ of plasma was mixed with $4 \mathrm{mg}$ sulfosalicylic acid and subsequently frozen at $-80^{\circ} \mathrm{C}$ until analysis (van Eijk et al., 1994). Analysis of total plasma tryptophan concentration was dome by high performance liquid chromatography (van Eijk et al., 1993).

\section{Data analysis}

Data were analyzed using SPSS 6.0 for DOS statistical packages.

The primary outcome measurements with regard to the effect of tryptophan depletion and placebo on generalized anxiety were VAS-anxiety, POMS-tension, and STAI. 
The effect of tryptophan depletion and placebo on the $\mathrm{CO}_{2}$ challenge was reflected in the scores of VAS-anxiety and PSL-UIR.

Because the scores of the questionnaires were skewed to the left, we used nonparametric statistics for the analysis of results.

Baseline differences at $T=1$ and $T=3$ were calculated using the two-tailed Wilcoxon signed rank test for the placebo condition ws. the tryptophan depletion condition.

Sequence effects (being subjected to tryptophan depletion on the first or second test) were analyzed with the help of Mann-Whitney U-tests.

Differences between the effects of placebo and tryptophan depletion on generalized anxiety and the $\mathrm{CO}_{2}$ challenge were calculated using the two-tailed Wilcoxon signed rank tests for the post-tryptophan depletion scores ( $T=2)$.

For analysis of the effects of the $\mathrm{CO}_{2}$ challenge, we chose to take the net scores (post- $\mathrm{CO}_{2}$ score minus pre- $\mathrm{CO}_{2}$ score) because baselines were already affected by the treatment (placebo or tryptophan depletion).

For the side effects, the total scores of the four questionnaires per day per individual side effect were calculated. Also, the total amount of side effects over the two treatments were calculated. Wilcoxon's tests were used to search for differences in total side effects over the two treatments. Significance levels were set at $p \leq 0.05$. The number of subjects meeting the criteria for a panic attack after $\mathrm{CO}_{2}$ was calculated. A panic attack was defined as an increase in anxiety of more than $20 \mathrm{~mm}$ on the VAS-anxiety and an increase of at least four neurovegetative symptoms.

\section{Results}

\section{Subjects}

Nineteen subjects entered the study. Two dropped out due to vomiting or prolonged nausea. In two subjects, plasma tryptophan levels differed by less than (he arbitrary level of) $50 \%$ and they were excluded from analysis.

The fifteen subjects included in the analysis had a mean age of $29 \pm 4$ years, a mean body mass index [weight $(\mathrm{kg})$ : length $\left.(\mathrm{m})^{2}\right]$ of $24 \pm 2$ and a mean SCL-90 score of $100 \pm 11$. All subjects had a negative history of any antidepressant medication.

\section{Plasma tryptophan levels}

The mean total plasma tryptophan level after placebo was $52 \pm 12 \mu \mathrm{mol} / \mathrm{l}$; after tryptophan depletion, it was $11 \pm 4 \mu \mathrm{mol} / 1$. The ratio tryptophan - Large Neutral Amino Acids [tyrosine, phenylalanine, leucine, isoleucine, walline (LNAA)] gives an indication of the uptake of tryptophan in the brain. According to this calculation, the ratio tryptophan/ 2 LNAA is $0.060+015$ in the placebo session and $0.010 \pm 0.005$ in the tryptophan depletion session. The difference in total plasma tryptophan levels for 
the wo days was $80 \%$; the difference in tryptophan uptake in the brain, as indicated by the ratio TRP/2LNAA was $83 \%$.

\section{Behavioural ratings}

General tryptophan depletion effects $(T=1$ to $T=2)$

Mean values and standard deviations of the different questionnaires before and after tryptophan depletion are shown in Table 2. No significant differences in baseline values for any of the behavioural parameters were observed at $T=0$, nor were any order effects seen. The results show a significant increase in scores on the STAI. Nine of 15 subjects contributed to this effect. There was no significant increase in scores on VAS-anxilety or on POMSutension.

Table 2. Mean anxiery scores \pm sd before and after TRP depletion.

\begin{tabular}{|l|c|c|c|c|}
\hline & \multicolumn{2}{|c|}{ Placebo } & \multicolumn{2}{c|}{ TRP depletion } \\
\hline & Pre & Post & Pre & Post \\
\hline POMS-tension & $0.67(1.05)$ & $0.27(0.59)$ & $0.20(0.56)$ & $0.87(1.73)$ \\
\hline STAI & $26.86(5.48)$ & $26.40(5.02)$ & $26.73(4.42)$ & $29.13(4.44)^{*}$ \\
\hline VAS-anxiety & $1.53(4.61)$ & $0.93(1.53)$ & $0.60(1.18)$ & $0.47(074)$ \\
\hline
\end{tabular}

$Z=-2.02, d f=14, p=0.04$

$\mathrm{CO}_{2}$ effects $(T=3$ to $T=4)$

Table 3 shows the mean outcomes and standard deviations of the PSL-IIIR and the VAS-anxiety before and after the $\mathrm{CO}_{2}$ test.

Table 3.

Mean anxiely and meurovegetative symptoms 1 sd before $\mathrm{CO} 2$ and the net increase (post-pre) as a result of 002 inhalation.

\begin{tabular}{|l|l|l|l|l|}
\hline & \multicolumn{2}{|l|}{ Placebo } & TRP depletion \\
\hline & Pre & Net Increase & Pre & Net Increase \\
\hline PSL UIr & $0.26(0.59)$ & $5.60(5.37)$ & $0.93(1.10)^{*}$ & $8.07(6.45)^{* *}$ \\
\hline VAS-anxiety & $0.87(1.41)$ & $2.79(6.12)$ & $0.67(1.11)$ & $10.13(24.47)$ \\
\hline
\end{tabular}

* $Z=-2.27, \mathrm{~d} f=14, p=0.02$

$Z=-1.96, d f=1.4, p=0.05$

There were significant effects of tryptophan depletion on pre- $\mathrm{CO}_{2}$ PSL-IIIR values. No significant effect of tryptophan depletion on $\mathrm{CO}_{2}$ induced anxiety was found for the net increase ( $T=4$ minus $T=3$ ) in VAS-anxiety. There was a significant net increase in neurovegetative symptoms after tryptophan depletion compared to the 
placebo as measured with the PSL-IIIR. Nine subjects showed a larger increase in PSL-IIIR score after TRP depletion compared to placebo. There was no increase in cognitive symptoms ('fear of dying'and 'fear of losing control') on the PSL after either treatment in any subject. The three somatic symptoms contributing mostly to the difference between TRP depletion and placebo were dizziness ( $a$ total of 29 points increase vs.14), palpitations (a total of 11 points increase vs. 3) and trembling (a total of 5 points increase vs. 1).

Three different subjects met the criteria for a panic attack after $\mathrm{CO}_{2}$ inhalation. Two subjects had been subjected to tryptophan depletion; one had received the placebo mixture.

The total scores of side effects in the tryptophan depletion and placebo conditions are shown in Table 4.

Table 4. Mean side effects \pm sd after placebo

\begin{tabular}{|l|l|l|}
\hline & and after TRP depletion \\
\hline & Placebo & TRP depletion \\
\hline Dry mouth & $0.4(0.8)$ & $0.7(1.1)$ \\
\hline Dizziness & $0.4(0.6)$ & $0.9(1.4)$ \\
\hline Palpitations & $0.0(0.0)$ & $0.2(0.6)$ \\
\hline Headache & $0.3(0.6)$ & $0.7(0.9)$ \\
\hline Feeling cold & $0.1(0.3)$ & $0.2(0.6)$ \\
\hline Nausea & $1.1(1.7)$ & $1.6(2.1)$ \\
\hline Sleepiness & $3.3(3.2)$ & $3.1(1.9)$ \\
\hline Drowsiness & $2.7(2.6)$ & $2.6(2.6)$ \\
\hline Feeling warm & $0.5(1.3)$ & $0.7(1.4)$ \\
\hline Blurred vision & $0.1(0.4)$ & $0.3(0.7)$ \\
\hline Perspiration & $0.0(0.0)$ & $0.4(0.7)$ \\
\hline Tirediness & $2.6(2.8)$ & $2.6(2.8)$ \\
\hline Abdominal distress & $0.5(1.3)$ & $0.9(1.3)$ \\
\hline
\end{tabular}

The maximum score per item was 16 . Mean total scores ( $\pm \mathrm{sd}$ ) of the thirteen side effects over four timepoints were $12.4 \pm 9.1$ and $14.5 \pm 9.1$ for the placebo and the TRP depletion session respectively, which is not significant $(T=9, n=15)$.

\section{Discussion}

After an interval of 5-6 hours, we found that tryptophan depletion induced an increase in generalized anxiety, as measured on the STAI. There was a trend towards an increase in the factor tension on the POMS as well. However, curiously, on the VASanxiety, subjects failed to rate themselves as more anxious. 
With respect to the $35 \% \mathrm{CO}_{2}$ challenge, there were more $\mathrm{CO}_{2}$ induced panic symptorris, as measured on the PSL-IIIR list, after tryptophan depletion than after placebo. Again, on the VAS-anxiety, there was no difference between the tryptophan depletion and placebo conditions.

We could not detect any specific feature in the subgroup of subjects that contributed to the observed effects on the STAI or the PSL-IIIR compared to those that did not. Athough we used a different amino acid mixture than other investigators (i.e., one that also contained carbohydrates and fats), blood analyses showed that the difference in tryptophan level between the two sessions was considerable $(80 \%)$. We have no baseline TRP levels against which to measure the efficacy of our procedure. However, in another study of our group (Klaassen et al., 1999), using exactly the same procedure, we did measure baseline TRP. Results indicated that the procedure was adequate. Although in the latter study. TRP bloodlevels rose to $15 \%$ above baseline in the placebo-condition, the placebo-mixture did not lead to an increase in brain TRP uptake as indicated by the TRP/SLNAA ratio. We have no reason to believe that in this study, the procedure was not equally adequate. Of course, we cannot exclude that a more profound TRPdepletion could have substantially increased the magnitude of the effect. Side effects after both treatments were generally low, and differences in total side effects between the treatments were not significantly different. Results of the study cannot, therefore, be attributed to side effects of the mixtures.

A large number of studies have measured changes in anxiety after tryptophan depletion. As far as healthy subjects are concerned, most studies failed to detect any change in anxiety ratings (Oldman et al., 1995; Cleare and Bond, 1995; Goddard et al., 1995; Barr et al., 1997). Thus, our finding of a lack of a significant anxiety response in healthy subjects (on the VAS) is consistent with the majority of previous reports and is therefore an important negative finding. Only two studies yielded positive results (Smith et al., 1987; Benkelfat et al., 1994). Smith et al. (1987) administered a mixture without tryptophan or a placebo mixture to two groups of healthy men under double-blind conditions. They noticed an increase on the anxiely subscale of the Multiple Affect Adjective Checklist in the group that had received the tryptophan depletion mixture. Benkelfat et al. (1994), using 39 healthy subjects in a double-blind, crossover design, measured anxiety with the POMS, a VAS-anxiety, and the STAI. They were only able to document increased anxiety with the POMS As far as patients with anxiety disorders are concerned, tryptophan depletion did not augment anxiety in subjects with obsessive compulsive disorder (Barr et al., 1994) or in panic patients (Goddard et al., 1994; Kent et al., 1996).

Our own results reflect the somewhat unclear picture of the effect of tryptophan depletion on anxiety. Although scores on the STAl and the POMS-tension were affected, the VAS-anxiety was not. Both the STAI and the POMS-tension are made up of multiple items reflecting negative affects, usually related to anxiety. In contrast. the VAS-anxiety is labeled 0- "no anxiety at all'- on one side and 100- 'maximal 
anxiety - on the other side. The discrepancy between the STAI and the POMS ratings, on the one hand, and the VAS-anxiety ratings, on the other hand, suggests that our subjects may have experienced some negative affects that they did not experience as true anxiety.

That tryptophan depletion may induce heightened nervousness rather than genuine anxiety in healthy subjects has been suggested earlier by Goddard et al. (1995). They hypothesized that healthy subjects might be more prone to rate nervousness than anxiety because the term 'anxiety' is more suggestive of mental disorder. Alternatively, tryptophan depletion may trigger anxiety by acting on a vulnerability that may not exist in healthy subjects. In this context, it is worth noting that tryptophan depletion has been shown to induce a relapse in remitted depressive subjects (Delgado et al., 1990, 1991; Lam et al., 1996). However, it has never led to genuine depression in healthy subjects.

As far as the $\mathrm{CO}_{2}$ challenge is concerned, we found that tryptophan depletion caused $\mathrm{CO}_{2}$ to induce greater changes on the Panic Symptom List than placebo. Tryptophan depletion failed to influence the $\mathrm{CO}_{2}$-induced change on the VAS-anxiety scale. Our comments about rating nervousness in stead of anxiety in healthy subjects "may explain the lack of effects on the anxiety dimension after the $\mathrm{CO}_{2}$ challenge. Reviewing the PSL-UIIR forms, which reflect the DSM-IIIR symptoms of a panic attack, we noticed that the increase in PSL-IIIR scores could not be attributed to the psychological items 'fear of dying' or 'fear of losing control'. In other words, the tryptophan effect might be entirely due to an augmentation of $\mathrm{CO}_{2}$-induced neurovegetative symptomatology.

To the best of our knowledge, to date, only a few studies have addressed the issue of experimental panic provocation after tryptophan depletion in normal subjects. Kent et all. (1996) used $5 \% \mathrm{CO}_{2}$ to provoke anxiety after tryptophan depletion. They found no effect of tryptophan depletion on anxiety or panic ratings, but after tryptophan depletion respiration was relatively more increased as a result of $\mathrm{CO}_{2}$ inhalation than after placebo. Their study, however, included only a small number of subjects. Other panic-provoking agents that have been used in normals after tryptophan depletion are cholecystokinin- tetrapetide (Koszycki et al., 1996) and yohimbine (Goddard et al. 1995). Both of these studies failed to note augmented anxiety ratings after tryptophan depletion, although increased nervousness occurred after tryptophan depletion and yohimbine.

Several studies showed that ventilation decreases after both peripheral and central admininstration of serotonin-agonists (Armijo and Florez, 1974; Mueller el al., 1980), while the tryptophan hydroxylase inhibitor parachlorophenylpiperazine (PCPA) causes hyperventilation in rats (Olson et al. 1979) and goats (Mitchell et al., 1983). It was found (Carlsson et al., 1977) that high $\mathrm{CO}_{2}$ exposure elevated serotonin synthesis and release in the brain stem. It seems possible that serotomin neuronal systems might function to counteract changes in minute ventilation induced by $\mathrm{CO}_{2}$ inhalation, thus serving a modulatory function on respiratory activity. Loss of 
serotonergic function through depletion of the serotonergic system would thereby increase the bodily reaction to $\mathrm{CO}_{2}$.

Our results add to the evidence that the serotonergic system mediates anxietyrelated mechanisms. More specifically, serotonin depletion seems to modulate $\mathrm{CO}_{2}$ induced responses. However, it appears that neither tryptophan depletion nor $\mathrm{CO}_{2}$ be it separately or in combination, can induce a true panic experience in normals. Things may be different in anxious patients. As we pointed out earlier, Miller at al. (1996) reported on $5 \% \mathrm{CO}_{2}$ provocation after tryptophan depletion in 20 panic patients. Following a $5 \% \mathrm{CO}_{2}$ inhalation, there were significant effects of tryptophan depletion on several anxiety and panic-scales, indicating not only increased neurovegetative symptoms but also increased subjective anxiety and panic. It may be worthwhile to pursue the role of tryptophan depletion on the mechanisms underlying $\mathrm{CO}_{2}$ induced panic in patients with anxiety disorders. A study on this topic is currently underway in our laboratory.

\section{References}

Armijo, $d . A$, and Florez, J. (1974) The influence of increased brain 5 -hydrosytryptamine upon the respiratory activity of cats. Neuropharmacology 13:977-986

Barr, L.C., Goodman, W.K, McDougle, C.J., Delgado, P.L. Heninger "G.R, Charney, D. S and Price, L.H. (1994) Tryptophan depletion in patients with obsessive-compulsive disorder who respond to serotonin reuptake inhibitors. Archives of General Psychiatry 51: 309-317

Barr, L.C., Heninger, G.R. Goodman, W. Charney, D.S., and Price., L.H. (1997) Effects of fluoxetine administration on mood response to tryptophan depleticn in healthy subjects. Biological Psychiatry 41: $949-954$

Benkelfat, C., Ellenbogen, M.A., Dean, P., Paimour, R.M., and Young, S.N.(1994) Mood-lowering effect of tryptophan depletion. Archives of General Psychiatry 51: 687-697

Carlsson. A., Holmin, T., Lindqvist, M., and Siesjo, B.K. (1977) Effect of hypercapnia and hypocapnia on tryptophan and tyrosine hydroxylation in rat brain. Acta Phystologica Scandinavica 99 (4): $503-$ 509

Clesre, A.J., and Bond. W.J. (1995) The effect of tryptophan depletion and enhancement on subjective and behavioural aggression in normal male subjects. Psychopharmacology 118: $72-81$

Coplan, J.D., Goman, JM., and Klein, D.F. (1992) Serotonin related functions in panic-anxiety: A. critical overview. Neuropsychopharmacology 6: 189-200

Delgado, P.L., Charney, D.S., Price, L.H. Aghajanian, G.K., Landis, H. and Heninger, G.R. (1990) Serotonin function and the mechanism of antidepressant action. Archives of General Psychiatry 47: $411-419$

Delgado, P. L. Price, L.H. Miller, H.L., Salomon, R.O., Licinio, A., Krystal, J.H. Heninger, G. R., and Charney. D.S. (1991) Rapid serotonin depletion as a provocative challenge test for patients with major depression: relevance to antidepressant action and the neurobiology of depression. Psychopharmacology Bulletin 27: 321.330

Gessa, G.L., Biggio, G., Fadda, F. Corsini, G.U., and Tagliamonte, A. (1974) Effect of the oral administration of tryptopihan-free amino acid mixtures on serum tryptophan, brain tryptophan and serotonin metabolism. Journal of Neurochemistry 22: 869-870. 
Goddard. A. W. Sholomskas, D.E. Waton, K.E. Augeri, F.M. Chamey. D.S. Heninger, D.R. and Goodman, W.K. (1994) Effects of tryptophan depletion in penic disorder. Bologicall Psychatry 36 (11): $775-777$

Goddard, A.W., Chamey. D.S., Germine, M., Woods, S.W. Heninger, G.R., Krystal, J.H. Goodman, W.K. and Price. L.H. (1995) Effects of tryptophan depletion on responses to yohimbine in healthy human subjects. Biological Psychiatry $38: 74-85$

Griez, E. Lousberg. H., van de Hout, M.A., and Van der Molen, G. M. (1987) CO2 vunerability in panic disorder. Psychiatry Research 20: 87,95

Griez, E de Loof, C., Pols, H., Zandbergen, J., and Lausberg, H. (1990) Specific sensitivity of patents with panic attacks to carbon dioxide inthalation. Psychiaty Research $31: 193-199$

Kahn, R.S. van Praag. H.M. Wetzer, S. Asnis, G.M., and Banr. G. (1988) Serotonin and anxiety revisited. Biological Psychiatry 23:189-208

Kent, J.M., Coplan, J.D., Martinez, J., Karmally, W., and Goman, J.M. (1996) Ventilatory effects of tryptophan depletion in panic disorder, a preiminary report. Psychalry Research 64: $33-90$

Koszycki, D., Zacharko, R.M., Le Melledo, J., Young, SN., and Bradwejn, d. (1996) Effect of aculte tryptophan depletion on behavioural, cardiovascullar, and hormonal sensitivity to cholecystokinin-tetrapeptide challenge in healthy volunteers. Biological Psychiatry 40:648-655

Lam, R.W., Zis, A.P., Girewald, A. Delgado, P.L. Charney, D.S. and Krystal, J.H. (1996) Effects of rapid tryptophan depletion in patients wh seasonal affective disorder in remission after light therapy. Archives of General Psychiatry $53: 41-44$

Miller, H. Deakin, J.F.W., and Anderson. 1. (1996) Acute tryptophan depletion increases panic anxiety in panic disonder patients. Journal of Psychophamacology $9(3): 72$

Mitchell, G.A. Smith, C.A., Jameson, L.C. Vidruk, E.H., and Dempsey, U.A. (1983) The efects of pchllorophenylalamine on ventilatory control in goats. Joumal of Applied Physiology $54: 277-283$

Moja, E.A. Cipolla, P. Castoldi, D., and Tofaneti, O. (1989) Dose-response decrease in plasma tryptophan and in brain tryptophan and serotonin after tryptophan-free amino acid mixtures in rats Life Sciences 4 4: $971-976$

Mueller, R.A., Lundberg, D. and Breese, G.R. (1980) Evidence that respiratory depressiom by serotonin agonists may be exerted in the central nerwous system. Phiarmacology Biochemistry \& Behavior 13: $247-255$

MoMair, D.M., Lorr, M., and Droppelman, L.F. (1971) Manual for the Profile of Mood States. Education and Industrial Testing Service, San Diego.

Oldman, A. Walsh, A. Salkowskis, P. Fairburn, C, G. and Comen. P. A. (1995) Biochemical and behavioural effects of acute hyptophan depletion in abstinent bulimic sulbijects: pllot study. Psychological Medicine 25: $995-1001$

OIson, E.B. Jr, Dempsey, J.A, and MCCrimmon, D.A. (1979) Serotonin and control of ventilation in rats. Journal of Clincal Investigation $64: 689-693$

Perna, G., Battaglia, M. Garberi, A., Arancio, C.,Bertami, A., and Bellodi, L. (1994) $35 \% \mathrm{CO}_{2} 65 \% \mathrm{O}_{2}$ inhalation test in panic patients. Psychatry Research $31: 459-171$

Smith, S.E., Phi, R.O. and Ervin. F.R. (1987) A test of possible cognitive and environmental influences on the mood lowering effect of tryptophan deptetion in normal males Psychopharmacology $91: 451-457$

Spiebrerger, C.D. Gorsuch, R.L. and Lusthene, R.D. (1970) STAI manual. Palo Allo, California: Consulting Psychologists Press

Tagliamonte, A., Biggio, G., Vargiu, L, and Gessa, G.L. 1973 ) Free lryptophan in serum controls brain tryptophan level and seratonin synthesis. Life Sciences $12: 277-287$ 
Van Eijk. H.M.H., Rooyakkers, D.R., and Deut, N.E.P. (1993) Rapid routine determination of amino acids in plasma by high performance liquid chromalography with a 2-3 um Spherisorb ODS II column. Journal of Chromatograchy $220: 143-148$

Van Eijk, H.M.H. Dejong, C.H.C., Deutz, N.E.P. and Soeters, P.B. (1994) influence of storageconditions on normal plasma amino-acid concentrations. Clinical Nutrition 14: $374-380$

Verburg, C., Griez, E., Meijer, J., and Pols, H. (1995) Discrimination between panic disorder and generalized anxiety disorder by $35 \%$ carbon dioxide challenge. American Joumal of Psychiatry 152: $1081-1083$

Verburg, C., Pols, H. Hauzer, R., Meijer, J. Overbeek. T. and Griez, E. (1998) Reliability of the 35\% carbon dioxide panic provocation. Psychiatry Research 78(3) 207-214

Young, S.N. Smith, S.E. PHI, R.O., and Ervin, F.R. (1985) Tryptophan depletion causes a rapid lowering of mood in normal males. Psychopharmacology 87: 173-177 


\title{
Effects of tryptophan depletion on carbon dioxide provoked panic in panic disorder patients
}

\author{
K. Schruers, T. Klaassen, H. Pols, T. Overbeek, N.E.P. Deutz, and E \\ Griez
}

Published in: Psychiatry Research (2000) 93: 179-187

\begin{abstract}
Results of an earlier study in healthy volunteers suggest that the serotonergic system is involved in anxiety related mechanisms. We studied the influence of tryptophan depletion on the response to a $35 \%$ carbon dioxide challenge. Twenty four panic disorder patients received a mixture of amino acids, either with or without tryptophan. under double blind conditions. There was a significant increase in anxiety as well as in neurovegetative symptoms in the depletion group, compared to the placebo condition. Furthermore, when we compare the results of the placebo group with earlier panic provocation studies, it seems also that a balanced amino acid mixture might have a protective effect agiainst a panic provocation. We conclude that the panic enhancing effect of tryptophan depletion as well as the potential protective effect of tryptopham administration in panic disorder patients can be explained by the Deakin-Graeff theory of anxiety.
\end{abstract}

KEYMORDS: Serotonin, Tryptophan, Panic, Carbon dioxide 


\section{Introduction}

Arguments for a role of the serotonergic (5-HT) system in panic disorder (PD) come from treatment studies on the one hand (Den Boer and Westenberg. 1991) and challenge studies on the other (Targum, 1991; van Vliet et al., 1996). A method to challenge the 5-HT system is to deplete individuals of tryptophan (Young et al. 1985). In a previous experiment, we examined the effects of tryptophan depletion on carbon dioxide $\left(\mathrm{CO}_{2}\right)$ provoked panic in healthy volunteers (Klaassen et al. 1998) and found a significant increase in neurovegetative symptoms in response to the $35 \% \mathrm{CO}_{2}$ challenge in the 5-HT-depleted subjects. There was however no difference in anxiety over the $\mathrm{CO}_{2}$ challenge, as measured with a visual analog scale, between the subjects who were or were not depleted of tryptophan. It appeared that the combination of 5-HT depletion and a $\mathrm{CO}_{2}$ challenge could not induce panic defined according to DSM IV criteria, in normal subjects.

Two other studies used a combination of TRP depletion and a panic provoking agent to study anxiety in normal volunteers: Goddard et al. (1995) used yohimbine and Koszycki et al. (1996) cholecystokinine. Both failed to find increased anxiety after TRP depletion plus the challenge.

However Goddard et al. (1995) did find that subjects reported an increase in nervousness. They explained that ratings of nervousness and anxiety tend to change in parallel in panic patients but that healthy wolunteers preferentially report nervousness rather than anxiety, perhaps because the term anxiety is more suggestive of mental disorder.

In panic disorder patients. TRP depletion has been shown to increase panic anxiety following a $5 \% \mathrm{CO}_{2}$ challenge (Miller et al., 1996). TRP depletion alone, however, was not anxiogenic or panicogenic in a sample of unmedicated panic disorder patients (Goddard et al., 1994). It is therefore possible that vulnerability to TRP depletion in PD patients may only become apparent after panic provocation. In the present study, we test the hypothesis that panic disorder patients are vulnerable to the combination of TRP depletion and a $35 \% \mathrm{CO}_{2}$ challenge. We predicted that such patients will show more neurovegetative symptoms and anxiety after the $35 \% \mathrm{CO}_{2}$ challenge when depleted of tryptophan than when they are not

\section{Materials and Methods}

\section{Subjects}

Twenty-four patients with panic disorder with or without agoraphobia (DSMIV criteria) participated in the study. Participants were recruited among the patients of the Academic Anxiety Center of Maastricht as well as through advertisement in a local newspaper. The diagnosis was made by means of a semi-structured interview (Mini International Neuropsychiatric Interview, Sheehan et al., 1997) and confirmed 
by two experienced psychiatrists (KS and $E G$ ). There was no concurrent axis I or axis II disorder. Also, none of the patients had a prior history of affective disorder. All subjects had sought professional help for their problem at least once in the past. Inclusion criteria were: age between 18 and 65 , good physical health, and written informed consent. No concurrent psychotropic medication (benzodiazepines, antidepressants or beta-blockers) was allowed in the 14 days before the experimental procedures. None of the patients had been on diazepam or fluoxetine that require a longer wash-out period. The study was approved by the Medical Ethics Committee of the University Hostpital of Maastricht.

\section{Design and procedures}

The experiment was conducted according to a randomized, double blind, placebo controlled, separate group design. Twelve subjects were allocated to the tryptophan depletion condition and twelve to the placebo condition. The subjects arrived at the clinic at $8.30 \mathrm{AM}(\mathrm{t}=0 \mathrm{~h})$ after an overnight fast and filled in a visual analog anxiety scalle (VAAS). Blood samples were drawn to measure plasma tryptophan levels. After ingestion of the mixture, the subjects remained on the ward. They were allowed to read or watch a nature documentary on video. Subjects had ad libitum access to mineral water or linden-blossom tea, a tea without particular stimulating or sedative properties. The amount of water or tea consumed was not monitored. Side effects (headache, feeling cold, feeling hot, dizziness, sleepiness " perspiration, blurred vision, drowsiness, nausea, palpitations, dry mouth, abdominal complaints, fatigue) were monitored at 9.00 and $13.00 \mathrm{~h}(t=5 \mathrm{~h})$ by using a 5-point scale, previously used in a comparable design by Klaassen et al. (1998). Another blood sample was taken to measure total plasma tryptophan levels. This was followed by the $\mathrm{CO}_{2}$ challenge in which subjects hinad to inhale through a mask one vital breath capacity of a gas mixture conlaining $35 \% \mathrm{CO}_{2}$ and $65 \% \mathrm{O}_{2}$.

Directly before and after inhalation, the subjects filled in the VAAS and a panic symptom list (PSL, consisting of 13 symptoms of a panic attack, as described by DSM IV), on a scale from 0 to 4 (total range 0-52)

After the experiment, the participants were offered a meal, consisting of bread, fruit and a salad, to restore their tryptophan levels.

\section{Amino Acid Mixtures}

The tryptophan-deficient amino acid mixture (100 g) was made according to the method used by Young ef al. (1985). It contaimed $5.5 \mathrm{~g} \mathrm{~L}$-alanine, $4.9 \mathrm{~g} \mathrm{~L}$-arginine, $2.7 \mathrm{~g}$ L-cysteine, $3.2 \mathrm{~g}$ glycine, $3.2 \mathrm{~L}$-histidine, $8.0 \mathrm{~g}$ isoleucine, $13.5 \mathrm{~g} \mathrm{~L}$-leucine, 3.0 $\mathrm{g}$ methionine, $5.7 \mathrm{~g} \mathrm{~L}$-phenylalanine, $12.2 \mathrm{~g} \mathrm{~L}$-proline, $6.5 \mathrm{~g} \mathrm{~L}$-threonine, $6.9 \mathrm{~g} \mathrm{~L}$ - 
tyrosine, $8.9 \mathrm{~g} \mathrm{L-valine,} 8.9 \mathrm{~g} \mathrm{~L}$-lysine and $6.9 \mathrm{~g} \mathrm{~L}$-serine. The placebo mixture contained also $3 \mathrm{~g}$ of L-tryptophan (Klaassen el al.1998).

A mixture of $33 \mathrm{~g}$ fatty acids (vegetable fat) and $63 \mathrm{~g}$ of carbohydrates (maltodextrine, Glucose and polysaccharides), flavored with artificial apricot, was added to make the amino acid mixture soluble in water, as well as more palatable (Klaassen et al.,1998).

The subjects drank the mixture whitin 20 minutes. The mixture was purchased from Nutricia Nederland, Zoetermeer, The Netherlands.

\section{Plasma tryptophan levels}

Collected blood was immediately centrifuged for $5 \mathrm{~min}$. at $11,000 \mathrm{~g}$ at $4^{\circ} \mathrm{C}$. Then 100 full of plasma was mixed with $4 \mathrm{mg}$ sulfosalicylic acid and frozen at $-80^{\circ} \mathrm{C}$ until analysis (Van Eijk et al., 1994). Total plasma tryptophan concentration was analysed by high-performance liquid chromatography (Van Eijk et al., 1993).

\section{Data anallysis}

Due to the non-normal distribution of the data, non-parametric tests were used for all analyses. Significance levels were set at $\mathrm{P}<0,05$ (two tailed). The main outcome measures were the VAASand PSL scores. A Mann-Whitney U-test was used to calculate baseline differences at $\mathrm{t}=0 \mathrm{~h}$ and $\mathrm{t}=5 \mathrm{~h}$ between placebo and TRP depletion. The same method was used for analysis of the effects of the $\mathrm{CO}_{2}$ challenge, using the post scores (scores after the $\mathrm{CO}_{2}$ challenge) and the net scores (scores after $\mathrm{CO}_{2}$ minus score before $\mathrm{CO}_{2}$ challenge). To solve possible ceiling effects of the VAAS and PSL-scores, the delta \% scores were also calculated as described in detail by Verburg et al. (1998). The intensity of the individual symptoms of the PSL was compared before and after the $\mathrm{CO}_{2}$ test between the TRP $(+)$ and TRP (4) condition, using a Mann Whitney U-test, and within each condition, using a Wilcoxon Signed Rank test.

For the side effects, the total scores of the questionnaires per individual side effect were calculated, using a Mann-Witney test.

The number of panic attacks following the $\mathrm{CO}_{2}$ challenge was calculated for each group and compared with a chi-square test. Criteria for a panic attack were a rise of at least 25 mm onthe VAAS, plus an increase in panic symptomatology (Pols et al., 1996).

The change in plasma TRP levels within each group was analyzed using Wilcoxon's test and the difference between the conditions with a Mann-Whitney U-test. 


\section{Results}

\section{Subjects}

Twenty-four subjects entered the study. There were no dropouts. All subjects were included in the analysis. There were five men and seven women in the TRP depletion group and four men and eight women in the TRP balanced group. Mean age in the TRP (-) group was 43 (s.d. 12) years and in the TRP (t) group 37 (s.d. 11) years.

\section{Plasma tryptophan levels}

The mean total plasma tryptophan level at $t=0$ was $49(s . d .6) \mu \mathrm{M}$ in the TRP (-) group and 51 (s.d.9) $\mu \mathrm{M}$ in the TRP (t) group (NS). At $t=5$ h the levels were 12 (s.d. 27) $\mu M$ and 74 (s.d.39) $\mu M$ respectively $(P<0,001$ ). In the TRP ( - ) group, the mean drop in TRP level was 28 (s.d. 26) $\mu M(P<0,02)$. In the TRP $(+)$ group, levels rose with a mean of 23 (s.d. 38) $\mu M(P=0,06)$.

\section{Side effects}

No significant difference between the two groups was found for any of the side effects (Table 1).

Table 1: Mean side effects ( \pm sd) in TRP(+) and $\operatorname{TRP}(-)$ condition (maximum score per item is $B$ )

$\begin{array}{lll} & \text { TRP }+ & \text { TRP } \\ \text { Headache } & 0.91 \pm 1.02 & 0.87 \pm 0.85 \\ \text { Sleepiness } & 1.21 \pm 1.25 & 1.33 \pm 1.09 \\ \text { Dizziness } & 1.29 \pm 1.23 & 0.74 \pm 0.75 \\ \text { Nausea } & 1.20 \pm 1.35 & 0.63 \pm 0.92 \\ \text { Palpitations } & 0.54 \pm 1.06 & 0.33 \pm 0.56 \\ \text { Abdiominal distress } & 0.62 \pm 0.87 & 0.17 \pm 0.49 \\ \text { Feeling cold } & 0.50 \pm 0.90 & 0.27 \pm 0.60 \\ \text { Feeling hot } & 0.79 \pm 0.91 & 0.71 \pm 0.90 \\ \text { Dry mouth } & 1.44 \pm 1.31 & 0.71 \pm 0.81 \\ \text { Tiredness } & 1.33 \pm 1.23 & 1.12 \pm 1.02 \\ \text { Blurred vision } & 0.62 \pm 0.97 & 0.50 \pm 0.70 \\ \text { Perspiration } & 0.63 \pm 0.76 & 0.71 \pm 0.80 \\ \text { Drowsiness } & 1.12 \pm 1.26 & 0.88 \pm 0.79\end{array}$




\section{Behaviourall ratings}

Baseline VAAS scores at $t=0$ h did not differ significantly between the two groups. At $t=5 \mathrm{~h}$ (just before the $\mathrm{CO}_{2}$ challenge), tryptophan depletion did not have a significant effect on the PSL or VAAS scores. However, tryptophan depletion had a significant effect on the net increase in the VAAS and PSL scores after the $\mathrm{CO}_{2}$ challenge. The net increase in VAAS score in the TRP ( - ) group was 47 (s.d. 25) and 13 (s.d. 31 ) in the TRP ( $)$ group ( $P<0.02$ ). The mean delta PSL score was 16 (s.d. 10) in the TRP (-) group and 7 (s.d 0.7$)$ in the TRP $(+)$ group $(P<0,05)$ (Table 2 ).

Table 2. Anxiety and neurovegetative symptoms (sd) before and atter $\mathrm{CO}_{2}$ irvcrease and delta $\%$ increase

\begin{tabular}{|c|c|c|c|c|c|c|}
\hline & \multicolumn{3}{|l|}{ Before } & \multicolumn{3}{|l|}{ Alter } \\
\hline & TRP+ & TRP- & $p$ & TRP4 & TRP- & $p$ \\
\hline VAAS & $23.75 \pm 30.81$ & $18.42 \pm 24.76$ & NS & $36.50 \pm 33.37$ & $65.85 \pm 28.56$ & $<0.05$ \\
\hline \multirow[t]{3}{*}{ PSL** } & $5.66 \pm 4.14$ & $9.08 \pm 9.42$ & $\mathbb{N S}$ & $12.46 \pm 7.09$ & 25.1211 .82 & $<0.02$ \\
\hline & \multicolumn{3}{|l|}{ Net increase } & \multicolumn{3}{|c|}{ Delta $\%$ increase } \\
\hline & TRP+ & TRP. & $p$ & TRPA & TRP- & $p$ \\
\hline VAAS* & $12.75 \pm 30.81$ & $47.42 \pm 24.76$ & $<0.025$ & $27.22 \pm 33.17$ & $7.16 \pm 4.73$ & $<0.02$ \\
\hline$P S L^{* * x}$ & $6.08 \pm 6.83$ & $16.08 \pm 10.47$ & $<0.05$ & $58.40+28.02$ & $17.43 \pm 11.72$ & $<0.05$ \\
\hline
\end{tabular}

"Wisual analogue anxiety scale score; "panic symptom hist score

The rise in VAAS-scores in the TRP (+) group was observable in 9 out of 12 patients. In two patients the VAAS remained constant and in one patient there was a small decrease (of $7 \mathrm{~mm}$ ). In the TRP ( - ) group, the VAAS scores rose in 11 patients and remained constant in one. The rise in PSL-score was observable in every patient in each condition. The mean scores of the individual panic symptoms are presented in table 3.

The number of panic attacks following the $\mathrm{CO}_{2}$ challenge was 1 in the TRP (+) group and 10 in the TRP $(-)$ group $(P<0,01)$. There was no significant linear correlation between the response to $\mathrm{CO}_{2}$, as measured by the VAAS and PSL, and baseline TRP levels. Also, whitin each group there was no significant linear correlation between the change from baseline in TRP levels and response to $\mathrm{CO}_{2}$, indicating that the individual responses were fairly heterogeneous. This is also illustrated by the relatively broad standard deviations of both the behavioural measures and the TRP levels. 


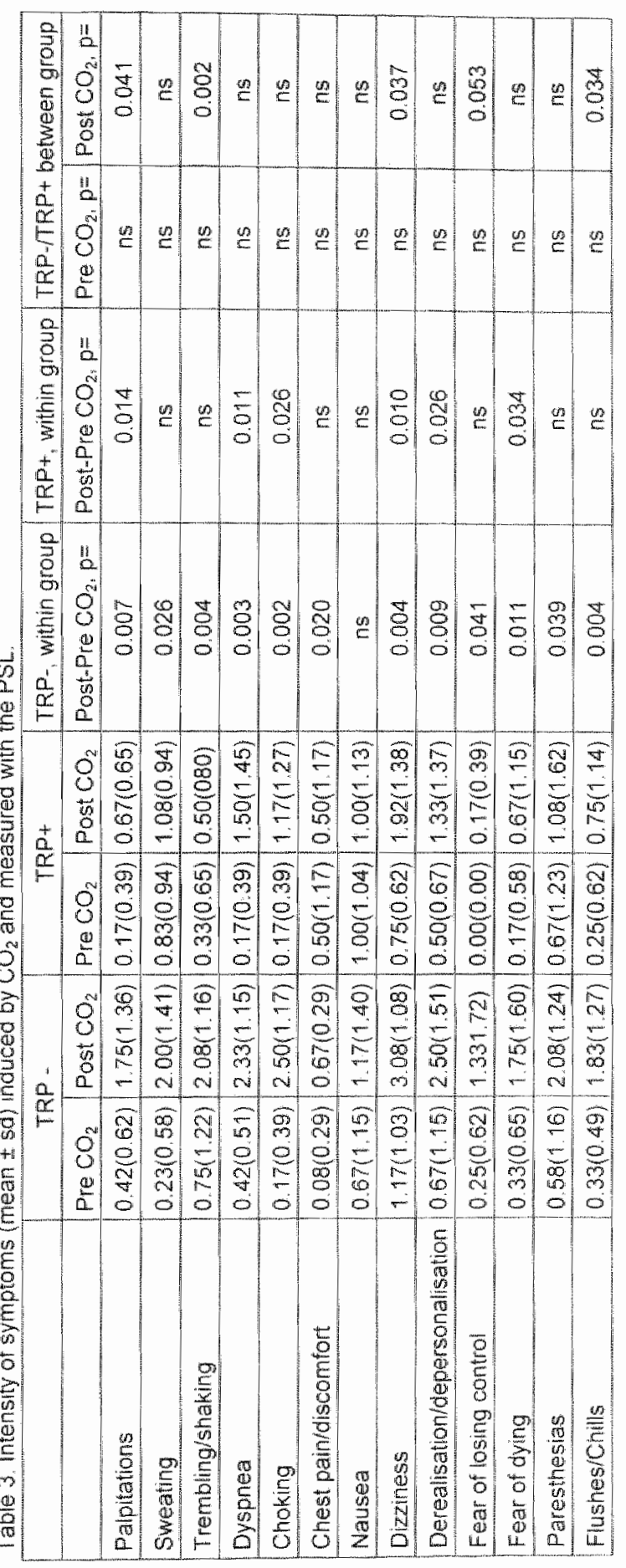




\section{Discussion}

The subjects in the tryptophan depletion group were significantly more anxious and had more panic symptoms than did the subjects in the placebo group after the challenge. Two studies have addressed the issue of panic provocation (with $5 \% \mathrm{CO}_{2}$ ) after tryptophan depletion in patients with panic disorder (Kent et al., 1996; Miller et al., 1996).

Kent et al report two findings specific to panic disorder patients: an increased baseline room air respiratory response to TRP depletion and a decreased ability to clear $\mathrm{CO}_{2}$ during room air breathing and $5 \% \mathrm{CO}_{2}$ challenge. There was however no difference in anxiety measures between depleted and control subjects. They conclude that TRP depletion may exacerbate an existing vulnerability towards an abnormal ventilatory response in PD patients. Miller ef al. found that more patients experienced a crescendo anxiety on the TRP $(-)$ than the TRP $(+)$ occasion. Carbon dioxide is known to stimulate the medullary chemoreceptors that conduct viscerosensory information to the solitary nucleus (Benarroch et al., 1986; Ruggiero et al. 1991; Grove et al., 1997). Additionally, $\mathrm{CO}_{2}$ stimulates peripheral arterial chemoreceptors, located in the aortic and carotid bodies. Increase in activity of these receptors increases discharge frequency in their afferent nerves, which also terminate centrally in the solitary nucleus (Mc Queen and Pallot, 1983).

Evidence suggests that at least part of the response of the peripheral chemoreceptors involves conversion of $\mathrm{CO}_{2}$ to $\mathrm{H}^{+} / \mathrm{HCO}_{3}$ (Mc Queen and Pallot, 1983). The central chemoreceptors are probably mainly stimulated via this conversion of $\mathrm{CO}_{2}$ to $\mathrm{H}^{+}$(Loeschke, 1983). The solitary nucleus stimulates the paraventricular nucleus of the thalamus which in turn activates the periaqueductal gray (PAG). The PAG has been implicated as a structure that appears to be involved in the mediation of panic (Graeff, 1993). During the electrical stimulation of the PAG humans have documented feelings of fear and death as well as autonomic activation such as piloerection, sweating, increase in pulse and respiratory rate and blushing (Nashold et al., 1974). These symptoms are quite reminiscent of the criteria for ideal panic disorder probes postulated by Gorman et al.(1987), suggesting that stimulation of the PAG may be key event in triggering panic (Grove et al., 1997). Deakin and Graeff (1991) point that the PAG may be a site of activation during acute unconditioned aversive stimuli, such as pain, asphyxia, and innate fear inducing stimuli producing panic, fight, flight or freezing behaviors in animals and humans. Additionally, this state may be homologous to the suffocation alarm model proposed by Klein (1993), in which panic disorder patients with poor PAG regulatory control respond with panic attacks and escape responses during the administration of respiratory panicogens (Grove et al., 1997).

Serotonin-containing neurons located primarily in the median raphe nucleus exert predominantly inhibitory effects on brainstem nuclei that control cardiovascular and ventilatory function (Blier et al., 1987; Grove et al., 1997). Tryptophan depletion leads 
to substantially reduced levels of serotonin in the brain (Young et al. "1985; Tagliamonte ef al., 1973; Gessa et al., 1974; Moja et al. 1989). It is conceivable that this would reduce the inhibitory serotonergic control over these brainstem nuclei, thus facilitating stimulation of the PAG and, ultimately, panic. While the decline in the rate of synthesis and level of serotonin in the brain is the most likely factor mediating the observed behavioural effects, it should however be noted that other, non $5 \mathrm{HT}$ metabolic, effects may play a role. Acute TRP depletion may have affected brain peptides, second messengers, receptor synthesis or some other non specific metabolic aspect of brain function (Delgado et al., 1990).

Similarly, TRP depletion and consequent reduction of 5-HT may have altered some balance between 5-HT and other neurotransmitters such as noradrenaline, dopamine, acetylcholine or gamma-amino-butyric acid, which could also contribute to behavioural effects (Delgado et al., 1990; Goddard et al., 1995). In a recent experiment, comparing depletion of tryptophan and lysine, another essential amino acid, Klaassen et al. (1999) found the effects of TRP depletion on mood and memory to be specific for the depletion of TRP and therefore not caused by the depletion of an amino acid per se. Also, Delgado et al. (1990), investigating reversal of antidepressant-induced remission by rapid depletion of plasma tryptophan, noted that the rapidity of the return of depressive symptoms during the TRP-depleted state argues against some non specific reduction in protein synthesis secondarily affecting receptors or peptides. The results from the present situdy are in line with those fron Kent et al. (1996) and Miller et al. (1996), indicating that TRP-depletion aggravates panic. A closer examination of our data suggests however that the matter may be more complicated. In a paper, summarizing the results of several experiments in which a total of $318 \mathrm{PD}$ patients underwent a $35 \% \mathrm{CO}_{2}$ challenge (without TRP depletion), Verburg et al. (1998) report an increase in VAAS and PSL scores of 38 and 11 respectively. In the present study we find higher values in the TRP (-) condition: scores of 47 and 16 resp. In the TRP (+) condition one would expect to find values similar to the scores reported by verburg et al. since this is the placebo condition and with the same population, namely PD patients. We find however a mean increase of only 13 on the VAAS and 7 on the PSL. Furthermore, in our earlier similar study in healthy volunteers (Klaassen et al., 1998) we find increases of 10 for the VAAS and 8 for the PSL in the TRP (-) group, and of 3 and 6 in the TRP ( +$)$ group. These values are in the same range as the ones of the TRP $(+)$ group in the present study. This means that PD patients who were administered an amino acid mixture containing tryptophan react to a $35 \% \mathrm{CO}_{2}$ challenge more or less the way healthy volunteers would. The TRP $(\rightarrow)$ condition therefore seems not to be a true placebo condition. Our results suggest that tryptophan depletion does not only augment the reaction to a $35 \% \mathrm{CO}_{2}$ challenge but also that tryptophan (or a balanced mixture of amino acids) may have a protective effect against the $\mathrm{CO}_{2}$ challenge. Indeed we found a trend for the TRP level to rise in the TRP (+) condition. Furthermore, a rise of TRP in the balanced mixture condition is a consistent finding 
throughout the TRP depletion literature (Smith et al. 1987; Young et al., 1989;

Delgado et al. 1990; Benkelfat et al., 1994; Barr et al., 1994; Weltzin et al., 1994). This is also true for the study of Miller et al. (1996) in PD patients. In the other study in $\mathrm{PD}$, no TRP mixure was used as placebo (Kent et al. 1996). The rise of plasma TRP in the TRP ( 4 ) condition of the present study seems therefore to be expected. especially since the balanced mixture contains $3 \mathrm{~g}$ of L-TRP. which is more than the $2.3 \mathrm{~g}$ used by Young et al. (1985).

Moreover, two studies do also report an opposite behavioural effect in the TRP ( + ) group, compared to the placebo condition: Smith et al. (1987), investigating the effects of 5-HT depletion in normal males, report a rise on the Multiple Adjective Assessment checklist in the depletion condition and a lowering in the balanced mixture condition, for depression as well as anxiety scores.

Similarly, Benkelfat et al. (1994), investigating subjects at risk for affective disorder, find a rise in the TRP (-) condition and a drop in the TRP ( + ) condition for the Spielberger State Anxiety inventory as well as the anxious subitem of the Profile of Mood States. Our results are in line with these findings. A conceptual framework for a panic-enhancing effect of tryptophan depletion as well as for a potential protective effect of tryptophan administration in PD patients is offered by the DeakinGraeff theory (Deakin and Graeff, 1991). According to this theory "serotonergic input to the periaqueductal gray may be involved in the mediation of panic (unconditioned fear), while the amygdala is involved in the pathogenesis of anticipatory anxiety and avoidance (conditioned fear). The PAG receives serotonergic innervation from the dorsal raphe nucleus and the theory proposes that an increased availability of serotonin in this part of the brain increases inthibition in the PAG and thereby restrains panic like responses (Graeff et al., 1996; Nutt, 1998). A decrease of serotonergic input, in this view, would act to aggravate panic. This remains speculative, however. It is conceivable that methodological factors other than being administered an amino acid mixture with TRP could account for differences in findings in the present study and previously published reports. Also, the present study was not designed to examine this topic. In conclusion, the results of the present study support

the view that lowering brain serotonin (by tryptophan depletion) aggravates experimental panic in panic disorder patients. There are also some indications that a rise in serotonin may act to restrain panic. To test this latter possibility in a more direct way, an experiment should be conducted in which the plasma tryptophan level is deliberately raised, for example by administering TRP or 5-OH TRP. An experiment of this kind is currently underway in our laboratory. 


\section{References}

Bar, L.C., Goodman, W.K., McDougle, C.J., Delgado, P.L., Heninger, G.R. Chamey, D.S, and Price. L.H. (1994) Tryptophan depletion in patients with obsessive compulsive disorder who respond to serotonin reuptake inhibitors. Archives of General Psychiatry 51: $309 \cdot 17$

Benarroch, E.E., Granata, A.R., Ruggiero, D.A. Park, D.H., and Reis, D.J. (1986) Neurons of C1 area mediate cardiovascular responses initiated from ventral medullary surface. American Physiological Society 250: R932-R945.

Benkelfat, C. Ellenbogen, M.A., Dean, P., Paimour, R.M., and Young, S.N. (1994)

Mood lowering effect of tryptophan depletion. Enhanced susceptibility in young men at genetic risk for major affective disorders. Archives of General Psychiatry 51: 687-697

Blier, P., De Montigny, $C$.. and Chaput, $Y$. (1987) Modifications of the serotomin system by antidepressant treatments; implications for the therapeutic response in major depression. Joumal of Clinical Psychopharmacology 7 (Suppi. 6) : 245- 355

Deakin, J.F.W., and Graeff, F.G. (1991) 5-HT and mechanisms of defence. Journal of Psychopharmacology $5: 305-3.15$

Delgado, P.L., Charney, D.S., Price, L.H., Aghajanian, G.K. Landis, H., and Heninger, G.R. (1990) Serotonin function and the mechanism of antidepressant action. Reversal of antidepressantinduced remission by rapid depletion of plasma tryptophan. Archives of General Psychially 47 $411-418$

Den Boer, J.A. , and Westenberg. H.G.M. (1991) Do panic attacks reflect an abnormality in serotonin receptor subtypes? Human Psychopharmacology 6 (Suppl.): 25-30

Gessa, G.L. , Biggio , G., Fadda, F. , Corsini, G.U., Tagliamonte, A. (1974) Effect of the oral administration of tryptophan free amino acid mixtures on serum Iryptophan, brain: tryptophan and serotonin metabolism. Journal of Neurochemistry 22: $869-870$

Goddard, A.W., Sholomskas, D.E., Walton, K.E. "Walton, K.E. Augeri, F.M., Charney, D.S. Heninger, G.R., Goodman, W.K. and Price ${ }_{1}$ L.H. (1994) Effects of tryptophan depletion in panic disorder. Biological Psychiatry 36:775- 777

Goddard, A.W., Chamey, D.S. Germine, M., Woods, S.W., Heninger, G.R., Krystal, J.H., Goodman, W.K. and Price, L.H. (1995). Effects of tryptophan depletion on responses to yohimbine in healthy human subjects. Biological Psychiatry 38: 74-85

Gorman, J.M. ,Fyer, M.R. , and Liebowitz, M.R. (1987) Pharmacological provocation of panic altacks. In: Meltzer, H. (Ed.) Psychopharmacology. The Third Generation of Progress pp. $985-993$. Niew York: Raven

Graeff, F.G. (1993) Role of 5-HT in defensive behavior and anxiety. Reviews in the Neurosciences 4 $181-211$

Graeff, F.G. Guimaraes, F.S., De Andrade, T.G., and Deakin, J.F, (1996) Role of 5-HT in stress, anxiety and depression. Pharmacology. Biochemistry and Biehavior 54:129-141

Grove, G. Coplan, J.D. and Hollander, E. (1997) The neuroanatomy of 5-HT dysregulation in panic disorder. The Joumal of Neuropsychiatry and Clinicall Neurosciences 9: 198.207

Kent, J.M., Coplan, J.D., Martinez, J., Karmally, W., Papp, LA., and Gorman, J.M. (1996) Ventilatory effects of tryptophan depletion in panic disorder: a preliminary report. Psychiatry Research 64: 8390

Klaassen, T., Klumperbeek. J., Deutz, N.E.P., van Praag, H.M. and Griez, E. (1998) Effects of tryptophan depletion on anxiety and on panic provoked by carbon dioxide challenge. Psychiatry Research 77: 167-174

Klaassen, T., Riedel, W.J., Deutz, N.E.P., van Someren, A, and Van Fraag, H.M. (1999) Specificity of the tryptophan depletion method. Psychopharmacology $141: 279-286$ 
Klein, D.F. (1993) False suffocation alarms, spontaneous panics, and related conditions. Ar integrative hypothesis. Archives of General Psychiatry 50: 306-317

Koszycki, D. Zacharko, R.M., Le Melledo, J.M., Young, S.N. and Bradwejn. J. (1996) Effects of acute tryptophan depletion on behavioural, cardiovascular and hormonal sensitivity to cholecystokinin-tetrapeptide challenge in healthy volunteers. Biological Psychiatry 40: 648-655

Loeschke. H.H., 1983. Central chemoreceptors, In: Pallot, D.J. (Ed.), Control of respiration. pp. 41-77. Beckenham: Croom Helm Ltd.

McQueen, D. S. and Pallot, D.J. (1983) Peripheral arterial chemoreceptors. in:

Pallot, D.J. (Ed.), Control of respiration, pp. 1-40. Beckenham Croom Hellm Ltd.

Miller, H.E., Deakin, J.F., and Anderson, I.M (1996) Acute tryptophan depletion increases panic anxiety in panic disorder patients. Joumal of Psychopharmacology $9: 72$

Moja, E.A., Cipolla, P., Castoldi, D., and Tofanetti, O (1989) Dose- response decrease in plasma tryptophan and in brain tryptophan and serotonin after tryptophan-free amino acid mixtures in rats. Life Sciences 44: 971-976

Nashold, B.S. Jr. Wilson, W.P., and Slaughter, G. (1974) The midbrain and pain. In. Bonica, J.J. (Ed.), Advances in Neurology 4: International Symposium on Pain. pp. 191-196. New York: Raven

Nuit, D.J. (1998) Antidepressants in panic disorder: clinical and preclinical mechanisms. Journal of Clinical Psychiatry 59 (Suppl. 8): 24-28

Pols, H., Verburg, KK, Hauzer, R., Meijer, J, and Griez, E. (1996) Alprazolam premedication and $35 \%$ carbon dioxide vulnerability in panic patients. Biological Psychiatry 40:913-917

Ruggiero, D.A., Gomez, R., Cravo, S.L., Mtui, E. Arwar, M., and Reis, D.J. (1991) The rostral ventralateral medulla: anatomical substrates of cardiopulmonary integration. In: Koepchen, H.P. and Huopaniemi, T. (Eds.), Cardiorespifatory and motor coordination. pp. $89-102$. New York: Springer

Sheehan, D.V., Lecrubier, Y., Hamett Sheehan, K., Janavs, J., Weiller, E., Keskiner, A., Schinka, J., Knapp, E. Sheehan, M.F., and Dunbar, G.C. (1997) The walidity of the Mini International Neuropsychiatric Interwiew (MINI) according to the SCID-P and its reliability. European Psychiatry 12: $232-241$

Smith, S.E., Pihl, R.O., Young, S.N., and Ervin, F.R. (1987) A test of possible cognitive and environmental influences on the mood lowering effect of tryptophan depletion in normal males. Psychopharmacology 91: 451-457

lagiliamonte, A. Biggio, G. Vargu, L., and Gessa, G.L. (1973) Free tryptophan in serum controls brain tryptophan level and serotonin synthesis. Life Sciences 12: 277-287

Targum, S.D. (1991) Panic attack frequency and vulnerability to anxiogenic challenge studies. Psychiatry Research 36: $75-83$

Van Eijk, H.M.H. Rooyakkers, D.R., and Deutz, N.E.P. (1993) Rapid routine determination of amino acids in plasma by high performance liquid chromatography with a 2-3 microns Spherisorb ODS-1I column. Journal of Chromatography 620 : 143-148

Van Eijk. H.M.H., De Jong, C.H.C. Deutz, N.E.P., and Saeters, P.B. (1994) Influence of storage conditions on normal plasma amino-acid concentrations. Clinical Nutrition 14:374-380

Van Vliet, I.M., Slaap, B.R., Westenberg. H.G., and Den Boer, J.A. (1996) Behavioural, neuroendocrine and biochemical effects of different doses of 5-HTP in panic. European Neuropsychopharmacology 6: 103-110

Verbung. K. Perna, G. Bellodi, L. "and Griez, E. (1998) The $35 \% \mathrm{CO}_{2}$ panic provocation challenge as diagnostic test for panic disorder. In: Bellodi, L., Perna, G. (Eds.), The panic respiration connection. Pp. 51-68. Millan: MdM Medical Media SrL

Weltzin, T.E., Fernstrom, J.D., McConaha, C. and Kaye, W.H. (1994) Acute tryptophan depletion in bulimia: effects on large neutral amino acids. Biological Psychiatry 35: 388-397 
Young, S.N. Smith, S.E., Pihl, R.O., and Ervin, F.R. (1985) Tryptophan depletion causes a rapid lowering of mood in normal males. Psychopharmacology 87: 173-177

Young, S.N., Evin, F.R., Pihl, R.O., and Finn, P. (1989) Blochemical aspects of tryptophan depletion in primates. Psychopharmacology $98: 508-511$ 



\section{Neuroendocrine response to $\mathrm{m}-\mathrm{CPP}$ and ipsapirone in relation to anxiety and aggression}

T. Klaassen, W.J. Riedel, H.M. van Praag. P.P.C.A. Menheere, and E. Griez

Submitted to: Psychiatry Research

\section{Abstract}

The aim of this study was to find out whether a relationship could be established between the sensitivity of serotonergic receptors and levels of anxiety/aggression in a mixed group of patients with affective disorders using a functional approach Receptor sensitivity was defined as the intensity of hypothalamic pituitary axis hormonal responses to an acute challenge with a 5-HT agonist.

Fifteen patients and 16 nomal controls received single oral doses of $0.5 \mathrm{mg} / \mathrm{kg} \mathrm{meta-}$ chlorophenylpiperazine (m-CPP), a $5-H T_{2}$ agonist, and $10 \mathrm{mg}$ of ipsapirone, a 5-HT, agonist, according to a double-blind, placebo-controlled, cross over design. In the patient group, we found a significant correlation between trait anxiety and the cortisol response to m-CPP. No correlation could be established between levels of anxietylaggression, and hormonal response to ipsapirone.

We found evidence of a correlation between measures of anxiety/aggression and hormonal response to m-CPP, irrespective of diagnosis. Thus, in subjects with affective disorders, high levels of anxiely and aggression suggest a higher probability of $5-H_{2}$ disturbances.

KEYWORDS: Cortisol, Affective disorders, Functional approach, M-CPP, Ipsapirone, Anxiety, Aggression 


\section{Introduction}

Although serotonergic dysfunction has been reported in various psychiatric disorders, serotonergic abnormalities may not be the same across, or even within, psychiatric diagnoses. They may differ according to the specific receptor subtypes involved in the disease (Leonard, 1996).

For this reason, several authors have stressed the importance of a functional approach to biological psychiatry (Van Praag et al., 1987; Wetzler et al., 1991: Coccaro, 1992). In such an approach, psychopathological syndromes are broken down into their component parts (c.e. the psychological dysfunctions), and correlations are sought between these psychological components, on the one hand, and biological markers (e.g., elevated hypophyseal-pituitary-adrenal-axis \{HPA-axis\}, hormones) on the other.

With regard to depression, a subgroup of depressed patients with lowered cerebrospinal fluid (CSF) 5- hydroxyindolacetic acid (5-HIAA, the metabolite of serotonin) has been identified (Westenberg and Verhoeven, 1988; Korf and Van Praag. 1971). It was found that a decreased level of 5-HIAA was not associated with the type of depressive syndrome nor with the severity of the depression but rather with components of the depression, in particular, heightened anxiety and aggression (Kahn et al. 1988a; 1988b; Asberg et al., 1976; Coccaro, 1992). The correlation between 5-hydroxytryptamine (serotonine, 5-HT) disturbances and dysregullated anxiety/aggression has also been found in other psychiatric disorders (Van Praag et al. 1987; 1990; Winchel and Stanley, 1991; Coccaro, 1992; Nutt and Lawson, 1992). Anxiety and aggression are not independent phenomena, but rather occur highly intercorrelated in several diagnostic categories (Apter et al., 1990; Coryell et al., 1992).

Lowered levels of 5-HIAA in CSF have been found in patients with personality disorder and a history of criminal acts (Tuinier et al., 1995), as well as in patients with suicidal behavior (Asberg et al., 1976; Van Praag, 1986). Also, low CSF 5-HIAA levels are oftan associated with incireased anxiety and/or a low threshold of anxiety tolerance (Banki et al., 1981; Rydin et al., 1982). Tryptophan (TRP) depletion, a method of antificially decreasing the production of brain serotonin by depleting its precursor tryptophan, has been shown to induce anxiety in normal subjects both on itself (Benkelfat et al., 1994; Klaassen et al. 1998a), and after additional yohimbine administration (Goddard et al., 1995). In panic patients, TRP depletion may increase vuinerability to $\mathrm{CO}_{2}$ inhalation (Schruers et al.,2000). Furthermore, Cleare and Bond (1995) found a significant increase in subjective feelings of aggression in a group of male subjects with high trait aggression after TRP depletion.

Serotonergic drugs such as selective serotonin reuptake inhibitors and the partial 5$H T_{1 A}$ agonist buspirone are effectively used in the treatment of anxiety disorders ( e.g. generalized anxiety disorder, panic disorder, obsessive compulsive disorder) 
and impulsive aggression (Salzman et al., 1995; Pabis and Stanislav, 1996; Masand and Gupta, 1999; Roerig, 1999).

To more specifically assess which components of the serotonergic system are involved in the dysfunction described above, research may be conducted on the sensitivity of specific 5-HT receptor subtypes. Neuroendocrine tests, used to measure receptor sensitivity, are based on the assumption that the 5-HT system exhibits an excitatory influence on the release of cortisol, adrenocorticotropic hormone (ACTH), and prolactin (Yatham and Steiner, 1993). Relatively high hormonal responses to 5-HT agonists are indicative of receptor hypersensitivity while relatively low hormonal responses are indicative of receptor hyposensitivity. Both animal and human data indicate that the $5 \cdot H T_{1}$ and $5 \cdot H T_{2}$ receptor systems may be involved in aggression/anxiety regulation. Activation of 5-HT 1 a receptors produces anxiolytic effects (Stahl et al., 1992; Schreiber and de Vrij. 1993), and reduces aggression (Sanchez and Hyttel, 1994; Olivier and Moss, 1994: Bell and Hobson, 1994). Likewise, stimulation of the postsynaptic 5-HT2 receptor, e.g., with metachlorophenylpiperazine (m-CPP), increases anxiety (Charney ef al, 1987; Kahn et al., 1988a), while blockade reduces anxiety (Kennett et al., 1994). Stimulation of 5 $H T_{2}$ receptors with $m-C P P$ induces anger in patients with generalized anxiety disorder (Germine et al, 1992), in panic disorder patients (Kahn et al, 1988a), and in individuals with antisocial personality disorder (Moss et al., 1990), though not all studies do agree (Wetzler et al, 1991). Thus, high anxiety/aggression has been associated with high activity of 5-HT2 receptors (most probably of the $5-\mathrm{HT}_{2} \mathrm{C}$ subtype) and with low activity of $5-H T_{1 A}$ receptors.

In the present study, two different 5-HT agonists were examined in a neuroendocrine challenge paradigm applied to a group of patients diagnosed with several different affective disorders, as well as in a group of normal controls. The $5-H T_{2}$ receptor was stimulated by meta-chlorophenylpiperazine (m-CPP), and ipsapirone was used to assess 5-HT, receptor function. As far as we know, this is the first study to use both probes in the same group of subjects with affective disorders.

We hypothesized that increased levels of anxiety/aggression would be positively associated with the magnitude of the hormonal response to m-CPP, as evidenced by a significant positive correlation, and negatively associated with the magnitude of the hormonal response to ipsapirone, as evidenced by a significant negative correlation.

\section{Materials and Methods}

\section{Subjects}

Subjects were recruited from our inpatient department and outpatient clinics and through local newspaper advertisements. Inclusion criteria were: age between 18 and 65 years, absence of any major medical, endocrine, or neurological disease; no pregnancy or lactation; no alcohol or drug abuse in the past six montlins and no 
hypertension (diastolic pressure $>100$, systolic pressure $>170$ ). The patients suffered from major depression without psychotic features, from dysthymia, or from an anxiety disorder with depressed mood according to the Diagnostic and Statistical Manual of Mental Disorders, Fourth Edition (DSM N; American Psychiatric Association, 1994). in the anxiety group, the criterion for depressed mood was a score of at least 2 points on the first two items of the Montgomery-Asberg Rating Scale (Montgomery and Asberg, 1979). After the clinical diagnosis was assessed independently by two clinicians (one resident psychiatrist and one psychiatrist), a Structured Clinical Assessment in Neuropsychiatry (SCAN, Wing et al., 1990) was performed by a blinded, trained interviewer to confirm the diagnosis. Control subjects were also subjected to a SCAN. All patients were free of psychotropic medication for at least one week before the test (fluoxetine: 3 months). Normal controls were not allowed to use any regular psychoactive medication. All subjects underwent physical examination and laboratory tests for the routine screening of hematological and biochemical blood parameters, as well as standard electrocardiogram.

Controls were paid for their participation. Patients were only paid if they were not being treated at our department; otherwise, they had their travel costs reimbursed The protocol was approved by the Medical Ethics Committee of the University Hospital Maastricht. All subjects signed voluntary informed consent.

\section{Experimental design and treatment}

On three separate occasions, subjects received single oral doses of ipsapirone 10 $\mathrm{mg}, \mathrm{M}-\mathrm{CPP} 0.5 \mathrm{mg} / \mathrm{kg}$, and placebo, in a balanced order, under double-blind conditions. The three substances were administered as powders, dissolved in a glass of water.

Subjects were divided into a patient group and a normal control group. Correlations between anxiety/aggression and hormonal responses to drug conditions were calculated for patients, normal controls, and for both groups as a whole.

\section{Assessment of anxiety and aggression}

Anxiety laggression was measured using the:

1. Dutch adapted version (Zelf Beoordelings Vragenlijst; van der Ploeg et al., 1980) of the Spielberger Trait-Anxiety Inventory (STAl; Spielberger, 1983a), a 20-item scale measuring individual differences in the disposition to experience anxiety;

2. Dutch adapted version (Zelf Analyse Vragenlijst; van der Ploeg et al., 1982) of the Spielberger Trait-Anger Scale (STAS; Spielberger et al. 1983b), a 10-item scale which measures individual differences in the disposition to experience anger. Both questionnaires measure the particular affect on a frequency scale.

These lists were administered once before the onset of the entire testprocedure. The subjects were instructed to fill out the questionnaires according to the way they felt in 
the week before the test. Thus, when we employ the term "trait" anxietylaggression, we mean the frequency with which anxiety or aggression is experienced in the week before the experiment, which is the result of stable personality traits and the tendency to react differently due to the mental disease.

\section{Hormonal assessments}

Hormonal responses to m-CPP and ipsapirone (changes in cortisol, ACTH, and prolactin) were measured. They were defined as mean levels of eight consecutive assessments taken every 30 minutes from to to 210 minus the mean levels in response to placebo administration. $X$ in $t x$ denotes the time in minutes after administration of the drug.

ACTH has been assayed using a sandwich-type IRMA-method in which the ACTHmolecule is caught in between a first (polyclonal) antibody fixed on a bead and directed versus the $\mathrm{C}$-terminal region and a second monoclonal $125 \mathrm{~J}$ - -labelled antibody directed versus the $\mathrm{N}$-terminal region of the ACTH-molecule (Nichols Institute Diagnostics, San Juan Capistrano, CA, US). Calibration is based on knowm amounts of synthetic human ACTH 1-39. The sensitivity of the assay is better than 5 Hg/l. Intra- and interassay coefficients of variation are better than $3 \%$ resp. $6 \%$. There is a insignificant negative cross-reactivity of the ACTH split products ACTH 1 24 and $\mathrm{ACTH} 18-39$ of $0.7 \%$ and $0.2 \%$ resp. This is without any clinical importance. Cortisol (compound $F$ ) has been analysed using a solid whase chemiluminescent enzyme immunoassay designed to be measured on the Immulite Automated Analyzer (Diagnostic Products Corporation, Los Angeles, USA). Callibration is performed using the standard of the manufacturer. The sensitivity of the assay is about 6 nmol/. Intra and inter-assay coefficients of variation are less than $10 \%$. Prednisolone and prednisone show cross-reactivities of resp. 49 and $5.9 \%$, while the cross reactivity of all other possible interfering substances is less than $0.9 \%$.

The prolactin assay is a solid-phase two site fluoro-immunometric assay designed to be measured on the Autodelfia automatic immunoassay analyser (Perkin Elmer. Wallac, Turku, Finland). The detection with Eu is based on the delayed-enhancedfluorometric immunoassays (DELFIA) technique. The standards have been calibrated against the $84 / 500$ WHO 3 rd International Standard for prolactin. The sensitivity of the assay is better than 0.01 (U/I). Intra and inter-assay coefficients of variation are better than $1 \%$ and $3 \%$ resp. There is a minor cross reactivity of about $4 \%$ with hGH and of about $1 \%$ with hPL. Other substances like LH, hCG, FSH and TSH don't show any cross reactivity at all. 


\section{Procedure}

After an overnight fast, subjects came to the clinic at $8: 45$ a.m. At 8.50 a.m., after having filted out the ZAV and ZBT, an indwelling venous catheter was placed in a forearm wein from which blood was drawn at 30 -minute intervals from 9 a.m. until 1:30 p.m. Blood samples were immediately placed on ice and were centrifuged at 11.15 a.m. and $1.45 \mathrm{p} . \mathrm{m}$. They were then frozen at $-80^{\circ} \mathrm{C}$ until analysis.

The subjects laid down on a bed and were allowed to read emotionally neutral magazines. Sleeping, eating, and drinking, were not allowed, except for two glasses of water together with the medication and one glass at 10:00 a.m. A research nurse was in the room during the entire test. She did administrative work between measurements and was instructed to talk only so much as to make the subjects feel at ease. After the last assessment, the indwelling venous catheter was removed. The subjects received a meal and then went home.

\section{Statistical analysis}

Before significance testing, hormonal and drug data were transformed according to 10-base logarithmic transformation. Pearson's product-moment correlations were calculated to evaluate associations between the level of anxiety and the level of aggression, and between the drug-induced hormonal response and the level of anxiety/aggression, as measured with the STAS/STAI. Significance tests were onetailed and results were considered significant if $p<0.05$.

\section{Results}

Fifteen patients and 16 normal controls completed the three tests. One male patient dropped out because of severe side effects of M-CPP (Klaassen et al., 1998b). The patient group consisted of eight patients with major depressive disorder (DSM IV 296), four patients with dysthymic disorder (DSM IV 300.4), and three patients with an anxiety disorder with depressed mood [one obsessive-compulsive disorder (DSM IV 308.3), one panic disorder with agoraphobia (DSM IV 300.1), and one generalized anxiety disorder (DSM N 300.02$)$ ]. The groups did not differ in terms of age, sex, height, weight, or levell of education (Table 1). 
Table 1. Means and standard errors of subject wariables

\begin{tabular}{lcc}
\hline & Patients & Controls \\
\hline Male/Female & $7 / 8$ & $7 / 9$ \\
Age (yrs) & $46.4 \pm 11.5$ & $46.6 \pm 13.2$ \\
Level of education & $3.2 \pm 1.0$ & $3.2 \pm 1.5$ \\
(scale 1-7) & $173.1 \pm 10.1$ & $171.4 \pm 11.0$ \\
Length (cm) & $74.5 \pm 10.8$ & $71.2 \pm 1.4 .2$ \\
\hline
\end{tabular}

\section{Correlations between mood trait variables and drug-induced hormonal responses}

Levels of aggression (STAS) and anxiety (STAI) were $19 \pm 5 / 57 \pm 9$ and $15 \pm 5 / 30 \pm 11$ (mean \pm sd) for patients and normal controls respectively.

Overall and within the group of normal controls, there were no significant correlations between the STAS/STAI and the hormonal responses to M-CPP.

Within the patient group, however, there was a significant positive correlation between the STAI and the cortisol response to M-CPP "as well as a positive correlation between the STAS and the cortisol response to M-CPP (Table 2). No correlations between the ACTH/prolactin response to M-CPP and mood measures were observed in the patients.

Moreover, the STAS and STAI correlated highly with each other in the group as a whole, i.e. in patients and normal controls taken together $(r=0.54, p=0.01)$, and in patients $(r=0.60, p=0.05)$, but not in the normal controls.

No significant correlations were found between the STAS ISTAI and the hormonal response to ipsapirone. 
Table 2. Correlations (one-tailed) between hormone responses and STASISTAI scores in all subjects $(n=31)$, patients $(n=15)$ and normal controls $(n=16)$.

\begin{tabular}{clccccccc}
\hline & & \multicolumn{2}{c}{ All subjects } & \multicolumn{2}{c}{ Patienis } & \multicolumn{2}{c}{ Normal controls } \\
\hline \multirow{2}{*}{ M-CPP } & STAS & STAI & STAS & STA. & STAS & STAI \\
& ACTH & 0.03 & -0.11 & -0.14 & 0.14 & 0.11 & -0.33 \\
& cortisol & 0.19 & 0.06 & $0.46^{*}$ & $0.54^{*}$ & -0.10 & -0.33 \\
& prolactine & -0.23 & -0.00 & -0.30 & 0.23 & 0.21 & -0.18 \\
& & & & & & & \\
\multirow{3}{*}{ ipsapirane } & ACTH & 0.06 & -0.05 & 0.02 & -0.06 & 0.15 & -0.15 \\
& cortisol & 0.11 & -0.03 & 0.31 & 0.40 & -0.00 & -0.12 \\
& prolactine & -0.04 & -0.06 & 0.06 & 0.07 & -0.07 & -0.01 \\
\hline
\end{tabular}

$\left.{ }^{*} p=0.05 "\right) p=0.02$

\section{Blood levels of M-CPP and ipsapirone}

M-CPP and ipsapirone blood levels are presented in Figure 3. M-CPP had its mean peak level at $t_{120}$. while the mean ipsapirone peak level was already obtained at $\mathrm{t}_{30}$. There were no differences in M-CPP and ipsapirone levels between patients and normal subjects.
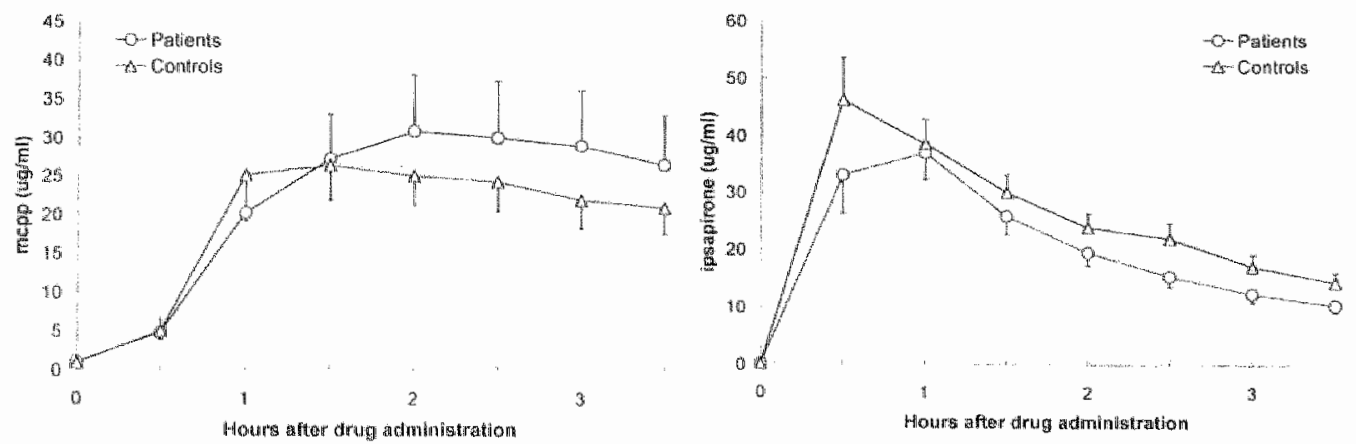

Figure 3 Plasma levels of m-CPP (left) and ipsapirone (right) as a function of time after drug administration broken down by patients with affective disorders $(n=15)$ vs. nealthy control subjects $(n=16)$. 


\section{Discussion}

As far as we know, this is the first study to use m-CPP and ipsapirone in the same group of subjects with affective disorders.

We hypothesized that high levels of anxiety/aggression would be positively correlated with the hormonal response to $\mathrm{m}$-CPP and negatively correlated with the homonal response to ipsapirone.

We found significant correlations between trait measures of both anxiety and aggression and the cortisol response to $\mathrm{m}$-CPP in a mixed group of patients with affective disorders. Furthermore, trait anxiety and trait aggression correlated highly with each other. None of the correlations between measures of anxietylaggression and hormonal response to ipsapirone were significant.

Although we did not exactly replicate the study of Kahn et al. (1988b), our first findings essentially confirm the results they found when taking a functional approach: significant correlations between pre-test anxiety and the maximal cortisol response to M-CPP in a mixed group of 13 patients with panic disorder and 17 patients suffering from major depression.

With the exception of one Kahn et al. study (1988b), most studies that did not use the functional approach found no differential effects of $\mathrm{m}$-CPP on cortisol measures (Charney et al., 1987 "Kahn et al. 1991; Germine et al. 1992). With regard to aggression. Wetzler et al. (1991) were unable to detect a correlation between measures of aggression and the hormonal response to m-CPP. They used other questionnaires [the Schedule for Affective Disorders and Schizophrenia (Endicott and Spitzer, 1978), and the Buss Durkee Hostility Inventory (BDHII, Buss and Durkee, 1957)] to rate hostility, and their hormonal response was defined as "peak minus baseline", which also differs from our method. Handelsman et al. (1998), however, found a positive correlation between the total score on trait hostility, as measured with the $\mathrm{BDHI}$, and the prolactine response to m-CPP in abstinent cocaine addicts.

Thus, only few others before us have used the functional approach in m-CPP-studies in relation to anxiety/aggression, and results have been conflicting, possibly because different questionnaires and outcome measures were used. To the best of our knowledge, no similar studies with ipsapirone have been carried out. It might be worthwhile to recalculate challenge test results in studies that found no homonal effects and used the categorical approach. Thereby one should look for correlations between psychological and biological measures in stead of comparing groups. From our study we conclude that in subjects suffering from various affective disorders, high levels of anxiety and aggression correspond with hyperresponsive 5-HT2c receptors. Scores on the STAS and STAI correlated highly in our study, while the subjects had been selected on the basis of their having depressed affect. A positive correlation between anxiety and aggression has been established before in various diagnostic categories (Rydin et al., 1982; Apter et al., 1990; Coryel et al. 1992) as well as high 
intercorrelations between anxiety, aggression and depressed mood (Mook et al.s 1990). However, these intercorrelations have usually been established at the affective state level, and not at the trait level as in our study.

Furthermore, we found a correlation between measures of trait anxiety and trait aggression

Mook et al. (1990) came to a different conclusion, using the same questionnaires in a group of 50 psychiatric in-patients from unspecified diagnostic categories. They found high inter-correlations between triat-anxiety and trait-depression, but low and insignificant correlations between trait-anger and trait-anxiety/depression. Analysis of the Spielberger Trait-Anger Expression Inventory, which they also administered and we didn't, showed strongly positive correlations between trait inward directed anger and trait-anxiety/depression, and negative correlations between trait outwarddirected anger and trait-anxiety/depression. Trait anger scores in general, as measured with the STAS, appeared to be predominantly related to the anger-out dimension. The psychiatric patients significantly more suppressed their anger compared to normal controls, leading to relatively low STAS-scores and explaining the low correlations with anxiety and depressiom.

Another finding of Mook et al. (1990) was a positive correlation between trait anxiety and trait-anger in a group normal controls, which we did not find. Thus, our findings are essentially opposite to those of Mook et al.

The reason for these opposite findings are unclear to us. Scores on the STAI and STAS were comparable in both studies. Differences in diagnosis may play a rolle, even whille measuring trait variables. It may be that our group consisted of more patients with disorders related to disturbed serotonergic function. Furthermore, although their nomal control group seemed comparable to ours with regard to composition (students and adults from the general population from medium sized university towns in The Netherlands), our normal subjects scored lower on both mean trait anxiety and mean trait aggression ratings than the nomal subjects from the study of Mook et al. (1990) (30 and 15 us. 36 and 17 respectively).

An explanation for high correlations between the STAI and the STAS can be found in the specificity of the questionnaires and the concepts of anxiety and aggression. Van de Ploeg et al. (1982) state that, although high correlations between scores on the two lists are often found, these correlations are not so high that one can doubt the validity of the lists. Some authors, suggest that it is difficult to distinguish between anxiety, aggression and depression and prefer to distinguish between positive and negative affect (Gotlib and Mever, 1986). However, it may be that rating scales in general insufficiently reflect distinctions made at the theoretical level, e.g. they insufficiently measure specific thoughts that are found in different affective disorcers. Our results support the concept of the 5-HT related, anxiety and aggression driven depression as postulated by van Praag (1994), in which 5-HT disturbances are accompanied by high aggression and high anxiety levels, although in his theory, state-levels of anxiety and aggression are meant. However, state-levels are not 
seldomly correlated with trait levels. It would be interesting to measure trait levels of anxiety and aggression in a group medication-free recovered depressed subjects and relate that to 5-HT parameters. Also, the use of the STAXI might prove an useful addition to gain more insight in the specific aspects of aggression that play a role in the pathophysiology of affective disorders.

We were not able to find evidence of any correlation between mood measures and ipsapurone hormonal response. Earlier studies in this area have been contradictory and, therefore, inconclusive. A pasitive correlation (Netter et al. 1999), no correlation (Moeller et al., 1998), and an inverse correlation (Coccaro et al., 1995) between aggression and the cortisol response to ipsapirone have all been found in normal men and in subjects with personality disorders. As far as we know, no reports of correlations between anxiety and ipsapirone challenge results have yet been published.

The question arises as to whether the hormonal response to $\mathrm{m}-\mathrm{CPP}$ is, in fact, a 5 $\mathrm{HT}_{2 \mathrm{C}}$-mediated effect. Although some authors suggest that $\mathrm{m}$-CPP has specific affinity for $5-\mathrm{HT}_{2 \mathrm{C}}$ receptors (Hoyer, 1988; Glennon et al., 1989), others state that it has comparable affinity for all 5-HT receptors (Hamik and Peroutka, 1989).

Furthermore, given the fact that we used a relatively high dosage of $\mathrm{m}-\mathrm{CPP}$, it is quite likelly that not only the 5-HT2c receptor, but other serotonergic receptors were stimulated as well. What we do know, is that the effects of m-CPP are probably not 5$H T$ is mediated, since m-CPP and ipsapirone have opposite effects with regard to several parameters such as temperature and anxiety.

A methodological problem in this context may be the measurement of aggression, although we found correlations with the cortisol response to m-CPP. Based on earlier data, Coccaro (1989) suggests that reduced indices of 5 -HT function correlate most specifically with irritable impulsive aggression, rather than with premeditated aggression or violence. This opinion is shared by Netter et al. (1999) who, on the basis of different biological responses to d-fenfluramine and ipsapirone, conclude that impulsive aggression should be separated from premeditated aggression. Although the trait version of the STAS, as used in this study, is designed for this purpose, impulsive aggression is not easily measured using self-report questionnaires. It would, therefore, seem worthwhile to use aggression-provoking tests to measure this form of aggression more objectively and reliably.

In conclusion, we found evidence of a correlation between measures of traitanxiety/aggression and hormonal response to m-CPP in a group subjects with different affective disorders. Thus, in subjects, with affective disorders, high levels of anxiety and aggression suggest a higher probability of $5-H T_{2}$ disturbances. Furthermore, we found high correlations between measures of trait-anxiety and traitaggression in our patients, but not in normal controls. Several options for further research are suggested. 


\section{References}

APA (1994) Diagnostic and Statistical Manual of Mental Disorders, Fourth Edition. Washington DC: American Psychiatric Association

Apter, A., van Praag, H.M., Plutchik, R., Sevy, S., Korn, M. and Brown, S. (1990) Interrelationships among anxiety, aggression impulsivity, and mood: a serotonergically linked cluster? Psychiatry Research 32: 191-199

Asberg, M., Traskman, L., and Thoren, P. (1976) 5HIAA in the cerebrospinal fluid: a biochemical suicide predictor? Archives of General Psychiatry 33: 1193-1197

Banki, C.M.G. Molnar, G, and Vojnik, M. (1981) Cerebrospinal fluid amine metabolites, tryptophan and clinical parameters in depression. Part 2. Psychopathological symptoms. Journal of Affective Disorders 3: $91-99$

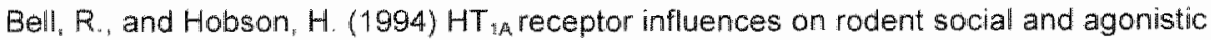
behavior: a review and empirical study. Neuroscience and Biobehavioural Reviews 18: 325-338

Benkelfat, C., Ellenbogen, M.A., Dean, P., Palmour, R.M., and Yaung, S.N. (1994) Mood-lowering effect of tryptophan depletion; Enhanced susceptibility in young men at genetic risk for major affective disorders. Archives of General Psychiatry 51: 687-697

Charney, D.S., Woods, S.W. Goodnam, W.K., and Heninger, G.R. (1987) Serotamin function in anxiety II. Effects of the serotonin agonist M-CPP in panic disorder patients and healthy subjects. Psychopharmacology $92: 14-24$

Cleare, A.J., and Bond, A. J. (1995) The effect of tryptophan depletion and enhancement on subjective and behavioural aggression in normal male subjects. Psychopharmacology $118: 72-81$

Coryell, W., Endicott, J., and Winokur, G. (1992) Anxiety syndromes as epiphenomena of primary major depression; outcome and familial psychopathology. American Journal of Psychiatry 149: 100-107

Coccaro, E.F. (1989) Central serotonin and impulsive aggression. British Journal of Psychiatry 155 (suppl.8): 52-62

Coccaro. E.F. (1992) Impulsive aggression and central serotonergic system function in humans: an example of a dimensional brain-behavior relationship. International clinical Psychopharmacology $7: 3-12$

Coccaro, E.F., Kavoussi, R.J., and Hauger, R.L. (1995) Physiological responses to d-fenfluramine and ipsapirone challenge correlate with indices of aggression in males with personality disorder. International Clinical Psychopharmacology 10(3): 177-179

Germine, M., Goddard, A.W., Woods, S.W., Charney, D.S., and Heninger, G. R. (1992) Anger and anxiety responses to $\mathrm{m}$-chlorophenylpiperazine in generallized anxiety disorder. Biological Psychiatry 32: 457-461

Glennon, R.A. Ismael, A., Mc Carthy, B.J., and Peroutka, S.J. (1989) Binding of anylpiperazines to $5 \mathrm{H} \mathrm{T}_{3}$ receptors. Results of a structure-affinity study. European Journal of Pharmacology $16: 387-392$

Goddard, A.W. Charney, D.S., Germine .M. Woods, S.W. Heninger, G.W. Krystal J.H., Goodman. W.K., and Price, L.H. (1995) Effects of tryptophan depletion on responses to yohimbine in healthy human subjects. Biological Psychiatry 38: 74-85 
Hamik, A., and Peroutka, S.J. (1989) 1-(m-Chloropheny)piperazine (M-CPP) interactions with neurotransmitter receptors in the human brain. Biological Psychiatry $25: 569-575$

Hoyer, D. (1988) Functional correlates of serotonin 5-HT, recognition sites. Journal of Receptor Research 8: 59-81

Kahn, R.S., Wetzler, S., van Praag. H.M., and Asnis, G.M. (1988a) Behavioural indications for serotonin receptor hypersensitivity in panic disorder. Psychiatry Research 25: 101-104

Kahn, R.S., Wetzler, S., van Praag, H.M., and Asnis, G.M. (1988b) Neuroendiocrine evidence for 5-HT receptor hypersensitivity in patients with panic disorder. Psychopharmacology 96: $360-364$

Kahn, R.S. Wetzler, S., Asnis, G.M., and Van Praag, H.M. (1991) Pituitary hormone responses to $m$-chlorophenylpiperazine in patients with panic disorder and healthy subjects. Psychiatry Research $37: 25-34$

Kennett, G.A. Pittaway, K, and Blackburn, T.P. (1994) Evidence that 5-HTzc receptor agonists are anxiolytic in the rat Geller-Seifter model of anxiety. Psychopharmacology 114: $90-96$

Klaassen, T., Klumperbeek, J., Deutz, N.E.P., Van Praag, H.M., and Griez, E. (1998a) Effects of tryptophan depletion an anxiety and on panic provoked by carbon dioxide challenge. Psychiatry Research 77: 167-174

Klaassen, T., Ho Pian, K.L., Westenberg, H.G.M., den Boer, J.A., and Van Praag, H.M. (1998b) Serotonin syndrome after challenge with the 5-HT agonist meta-chlorophenylpiperazine. Psychiatry Research 79: 207-212

Korf, J., and Van Praag, H.M. (1971) Endogenous depressions with and withoul disturbances in the 5-hydroxytryptophan metabolism: a biological classification? Psychopharmacologia $19(2): 148-152$

Leonard, B.E. (1996) Serotonin rceptors and their function in sleep, anxiety disorders and depression. Psychotherapy and Psychosomatics 65(2): 66-75

Masand, P.S., and Gupta, S. (1999) Selective serotonin-reuptake inhibitors: an update. Harvard Review of Psychiatry 7(2): 69-84

Moeller, F.G., Allen, T., Cherek, D.R., Dougherty, D.M., Lane, S., and Swann, A.C. (1998) Ipsapirone neuroendocrine challenge: relationship to aggression as measured in the human laboratory. Psychiatry Research 81(1): $31-38$

Montgomery, S.A. and Asberg, M. (1979) A new depression scale designed to be sensitive to change. British Journal of Psychiatry 143: 382-389

Mook, J, van der Ploeg. H., and Kleijn, W.C. (1990) Anxiety, anger and depression: relationships at the trait level. Anxiety Research 3: 17-31

Moss, H.B., Yao, J.K. and Panzak, G.L. (1990) Serotonergic responsivity and behavioural dimensions in antisocial personality disorder with substance abuse. Biological Psychiatry 28: $325-338$

Netter, P., Hennig. J, and Rohrmann, S. (1999) Psychobiological differences between the aggression and psychoticism dimension. Pharmacopsychiatry 32 (1): $5-12$

Nutt, D., and Lawson; C. (1992) Panic Attacks; a meurochemical overview of models and mechanisms. British Journal of Psychiatry 160:165-178

Olivier, B., and Moss, J. (1994) Serotonin receptor subtypes and aggressive behaviour. Neuropsychopharmacology 10: 944 s. 
Pabis, D.J., and Stanislav, S.W. (1996) Pharmacotherapy of aggressive behavior. Annals of Pharamacotherapy 30(3): 278 . 287

Ploeg. H.M. van der, Defares, P.B., and Spielberger, C.P. (1980) Handleiding bij de Zelf Beoordelings Vragenlijst, ZBV (Manual for the Dutch adaptation of the STAI-Y). Lisse, The Netherlands: Zwets en Zeitlinger

Ploeg, H.M. van der, Defares, P. B., and Splelberger, C.P. (1982) Handleiding bil de Zelf Analyse Vragenlijst, ZAV (Manual for the Dutch adaptation of the STAS). Lisse, The Netherlands: Zwets en Zeitlinger.

Rydin, E., Schalling, D. Asberg, M. (1982) Rorschach ratings in depressed and suicidall patients with low levels of 5 -hydroxyindolactic acid in cerebrospinal fluid. Psychiatry Research 7: 229-243

Roerig, J.L. (1999) Diagnosis and management of generalized anxiety disorder. Joumal of the American Pharmaceutical Association 39(6): 811-821

Salzman, C, Wolfson, B.A., Schatzberg, A., Looper, J., Henke, R., Albanese, M., Schwartz, $J$, and Miyawaki, E. (1995) Effect of fluoxetine on anger in symptomatic volunteers with borderline personality disorder. Journal of Clinical Pscyhopharmacoly $15(1)$ : 23-29

Sanchez, C. Hyttel, J. (1994) Isolation-induced aggression in mice: effects of 5-hydroxytryptamine uptake inhibitors and involvement of pastsynaptic 5-HT, receptors. European Journal of Pharmacology 264: 241-247

Schruers, K, Klaassen, T., Pols, H., Overbeek, T., Deutz, N.E, and Griez, E (2000) Effects of tryptophan depletion on carbon dioxide provoked panic in panic disorder patients. Psychiatry Research 93 (3): 179-187

Schreiber, R., and De Vrij, ل. (1993) Neuronal circuits inwolved in the anxiolytic effects of the 5-HT, receptor agonists 8-OH-DPAT, ipsapirone and buspirone in the rat. European Joumal of Pharmacology 249: 341-351

Spielberger, C.D. (1983a) Manual for the State-Trait Anxiety Inventory STAl-Form Y. Palo Alto, CA: Consulting Psychologists Press.

Spielberger, C.D. Jacobs, G.A., Russell, S., and Crane, R.S. (1983b) Assessment of anger: The State-Trait Anger Scale. In: Butcher, J.N. and Spielberger, C.D. eds. Advances in Personality Asisessment. Vol. 2. pp. 159-187. Hissidale, NJ: L. Erlbaum

Stahl, S.M., Gastpar, M., Keppe1 Hesselink, J.M., and Traber, J. (1992) Serotonin receptors. New York: Raven Press

Tuinier, S., Verhoeven, W.M.A. and Van Praag. H.M. (1995) Cerebrospinal fluid 5-hydroxyincolacetic acid and aggression: a critical reappraisal of the clinical data Intemational Clinical Psychopharmacology 10:147-156

Van Praag. H.M. (1986) Affective disorder and aggression disorders: evidence for a common biological mechanism. Suicide and Life-Threatening Behavior 16(2): 21-50

Van Praag. H.M., Kahn, F. S. Asinis, G.M., Wetzler, S., Brown, S. L., Bleich, A., and Korn, ML. (1987) Denosolgization of biological psychiatry or the specificity of 5-HT disturbances in psychiatric disorders. Journal of Affective Disorders 13: 1-8

Van Praag. H.M. Asnis, G.M. Kahn, R.S., Brown, S.L., Korn, M. Friedman, J.M., and Wetzler, S (1990) Monoamines and abnormal behavior: A multiaminergic perspective. British Joumal of Psychiatry 157: 723-734

Van Praag. H.M. (1994) 5-HT-related, anxiefy and/or aggression-driven depression. A psycho-biolagical hypothesis. International Clinical Psychopharmacology 9 suppl 1:5-6 
Westenberg, H.G.M. and Verhoeven, W.M.H. (1988) CSF monoamine metabohtes in patients and controls: Support for a bimodal distribution in major affective disorders. Acta Psychiatrica Scandinavica 478: $541-749$

Wetzler, S., Kahn, R.S. Asnis, G.M., Korn, M. and van Praag, H.M. (1991) Serotonin receptor sensitivity and aggression. Psychiatry Research 37: 271-279

Winchel, R.M., and Stanley, M. (1991) Self-injurious behavior: a review of the behavior and biology of self-mutilation. American Joumal of Psychiatry 148: 306-317

Wing, J.K., Barbor, T., Brugha, T, Burke, J., Cooper, J.E., Giel, R., Jablenski, A. Regier, D. and Sartorius, N. (1990) SCAN, Schedules for clinical Assessment in Neuropsychiatry. Archives of General Psychiatry 47: 589-593

Yatham, L.N., and Steiner, M. (1993) Neuroendacrine probes of serotonergic function: a critical review. Life Sciences 53: 447-463 



\title{
Dissociable Hormonal, Cognitive and Mood Responses to Neuroendocrine Challenge: Evidence for Receptor-Specific Serotonergic Dysregulation in Depressed Mood
}

\author{
W.J. Riedel, T. Klaassen, E. Griez, A. Honig, P.P.C.A. Menheere, \\ and H.M. van Praag \\ Submitted to: Neuropsychopharmacology
}

\section{Abstract}

Fifteen patients with major depression, dysthymia, or anxiety disorder with depressed mood (DSM-IV diagnoses) and 16 controls received single oral doses of $0.5 \mathrm{mg} / \mathrm{kg}$ metachlorophenylpiperazine (m-CPP), a 5-HT2C agonist, and $10 \mathrm{mg}$ ipsapirone, a 5$H T_{1 A}$ agonist, according to double-blind, placebo-controlled, cross-over design. The groups' levels of cortisol, adrenocorticotrophic hormone (ACTH) and prolactin did not differ at baseline. Both 5-HT agonists significantly elevated cortisol, $\mathrm{ACTH}$ and prolactin. The cortisol response to ipsapirone was significantly blunted in major depression and dysthymia patients. Neuroendocrine responses to $\mathrm{m}$-CPP did not differ between groups, but m-CPP selectively increased POMS depression and tenseness scores in patients. No effects of ipsapirone on mood were found. However, ipsapirone impaired memory performance in controls, but tended to improve memory performance in patients. The results support the evidence for both hypothalamic and possibly hippocampal 5-HT tA receptor desensitisation and nonhypothalamic, $5-\mathrm{HT}_{2 c}$ receptor sensitisation, probably fronto-cortical, in patients with major depression and dysthymia.

KEYWORDS: Neuroendocrine, Prolactin, Cortisol, Acth, Serotonin, Depression, Memory 


\section{Introduction}

Serotonergic abnomalities have been reported in various psychiatric disorders such as depression, anxiety, sleep disorders and schizophrenia. Neurotransmission abnormalities may differ according to the specific receptor subtypes involved and are expressed through biological markers such as elevated levels or exaggerated responses of pituitary hormones to selective receptor agonists (Maes and Meltzer 1995). it has been hypothesised that depressed mood is accompanied by i) downregulation of postsynaptic 5-HT, receptors, and ii) upregulation of $5-\mathrm{HT}_{2 \mathrm{~A} / 2 \mathrm{C}}$ receptors (Maes and Meltzer, 1995; Van Praag, 1996).

The sensitivity of serotonergic receptors in the brain is considered to be one of the measures of the integrity of the 5-HT system. Neuroendocrine tests are based on the assumption that the 5.HT system exhibits an excitatory influence on the release of cortisal, ACTH, and prolactin (Yatham and Steiner, 1993). Neuroendocrine responses to 5-HT agonists are an indication of postsynaptic receptor sensitivity, with relatively high hormonal responses being indicative of receptor hypersensitivity while relatively low hormonal responses suggest receptor hyposensitivity Meta-Chlorophenylpiperazine (m-CPP), a full agonist of 5-HT receptors, was initially thought to be equipotent at all 5-HT receptor subtypes (Hamik and Peroutka, 1989), but later studies describe a relatively high affinity of m-CPP for postsynaptic 5-HT2C and 5-HT 3 receptors (Glennon et al., 1989; Hoyer, 1988). Earlier research using mCPP challenges suggests that hypersensitivity of postsynaptic 5.HT $2 \mathrm{C}$ receptors is associated with high levels of anxiety (Kahn et al., 1991; Kahn et al., 1988a; Kahn et al., 1988b). Several authors provided evidence for 5-HT2A2C upregulation in depression by means of neuroendocrine challenge with 5-HTP (Maes et al., 1995; Meltzer et al., 1984).

Ipsapirone, a partial agonist at 5-HT receptors, exhibits a relatively high affinity for both pre-and postsynaptic 5-HT 1 a receptors and negligible affinity for the $5-H T_{10}, 5$ $H T_{2}$ and $5-H T_{3}$ subtypes (Peroutka, 1988). Ipsapirone was originally developed as an anti-anxiety agent but also has anti-aggressive effects in rodents (De Vry, 1995). In humans, blunted responses of cortisol to ipsapirone (a partial 5-HT ia receptor agonist) were found in patients with major depression (Lesch, et al. 1990; Meltzer and Maes, 1995)

Although blunted hormonal responses to 5-HTiA agonists in patients with affective disorders have been shown before, attempts to compare the specificity of hormonal responses to $5-H_{1} T_{1}$ and $5-H T_{2 C}$ challenges within the same group are surprisingly rare. Broocks et al. (Broocks et al., 1999) compared neuroendocrine challenge in marathon runners and controls and showed that a blunted cortisol response to mCPP $0.4 \mathrm{mg} / \mathrm{kg}$, but not to ipsapirone $0.3 \mathrm{mg} / \mathrm{kg}$, differentiated the marathon runners from controls. Broocks et all. (2000) also reported a study of neuroendocrine challenge with m-CPP and ipsapirone in groups of patients with panic disorder and lor agoraphobia and controls. They repont tendencies toward an increased sensittivity 
of central $5-H T_{2 C}$ receptors and a decreased responsiveness of $5-H T_{A A}$ receptors in patients (Broocks et al. 2000). In order to further study the associations of altered 5 . HT receptor sensitivities in depressed mood, we wanted to determine whether both the sensitivities of 5-HT $1 \mathrm{~A}$ and $5-\mathrm{HT}_{2}$ receptors were altered in patients with depressed mood.

A functional approach to biological psychiatry predicts significant associations of biological markers with psychiatric symptoms, such as anxiety, aggression and that depressed mood, rather than with psychiatric diagnoses (Van Praag et al., 1987). For the study of biological dysregulations underlying depression this implies that the presence and homogeneity of symptoms in the population studied are more important than the homogeneity of diagnoses. Consequently, in this study patients were selected in whom depressed mood was a core symptom, i.e. they had either a diagnosis of major depression, dysthymia, or anxiety with concomitant depression af mood. Two different 5-HT agonists (m-CPP and ipsapirone) were administered to assess 5-HT IA $_{A}$ and $5-H T_{2 C}$ receptor sensitivity in patients and control subjects. The purpose of this study was to explore the relationship between depressed mood and specific 5-HT receptor function as measured by a) neuroendocrine responses b) mood responses and c) cognitive responses to $\mathrm{m}$-CPP and ipsapirone challenge. Elevated hormonal responses to m-CPP and blunted hormonal responses to ipsapirone were hypothesised to distinguish patients with depressed mood from controls.

\section{Materials and Methods}

\section{Subjects}

Patients and healthy control subjects were recruited through the University Hospital outpatient clinic and through local newspaper advertisements, respectively. Inclusion criteria were: age between 18 and 65 years, patients suffered from major depression without psychotic features, from dysthymia, or from an anxiety disorder with depressed mood according to DSM IV criteria (APA, 1994). In the anxiety group the criterion for depressed mood was a score of at least 2 points on each of the first two items of the Montgomery Asberg Rating Scale (MADRS\} (Davidson et al. 1986). After the clinical diagnosis was assessed independently by two clinicians lone psychiatrist in training and a psychiatrist) a SCAN \{Structured Clinical Assessment in Neuropsychiatry\} (Wing et al., 1990) was performed to confirm the diagnosis. Control subjects were also subjected to a SCAN. All patients were free-, or washed out from psychotropic medication for at least one week ( 3 months in the case of fluoxetine). Five patients had been on antidepressant medication (four of whom on fluoxetine) and had not responded to it satisfactorily. Normal controls were also not allowed to use any regular psychoactive medication. All subjects underwent physical examination and laboratory tests for the routine screening of haematological, 
biochemical and hormonal blood parameters and standard ECG. Exclusion criteria were: any major medical, endocrine or neurological disease, pregnancy or lactation, alcohol or drug abuse in the past six months, hypertension (diastolic $>100$, systolic $>170$ ). Controls were paid for their participation. patients were only paid if they were not treated at our clinic; travel costs were being paid. The protocol was approved by the medical ethics committee of the University Hospital Maastricht. All subjects had signed woluntary hinformed consent.

\section{Experimental Design and Treatments}

The study was conducted according to a mixed between/within-subjects $2 \times 3$ design. The between subjects factor (Group) consisted of 2 levels (patients vs. control subjects). The within subjects factor (Drug) consisted of 3 levels (m-CPP $0.5 \mathrm{mg} / \mathrm{kg}$, ipsapirone $10 \mathrm{mg}$ and placebo) according to a double-blind, placebo-controlled. order-balanced, cross-over design. The three substances were administered as powders, dissolved in a glass of water. The powders were of identical appearance and taste. The test days were spaced minimally four days apart. Mcpp was obtained from Aldrich Chemical Company and ipsapirone was provided by Bayer. PlasmamCPP determination was performed using high-performance liquid chromatography (HPLC) (Stolk et al., 1997). Plasma ipsapirone determination was undertaken by Tropon, Cologne, Germany using a specific HPLC method.

\section{Hormonal Assessments}

Every 30 minutes from $t_{0}$ to $t_{210}$ ( $x$ in $t_{x}$ denotes minutes after drug administration), blood was taken for the determination of plasma levels of ACTH, cortisol and prolactin.

ACTH has been assayed using a sandwich-type IRMA-method in which the ACTH. molecule is caught in between a first (polyclonal) antibody fixed on a bead and directed versus the C-terminal region and a second monoclonal $125 \mathrm{~J}$.-labelled antibody directed versus the $\mathrm{N}$-terminal region of the ACTH-moleculle (Nichols institute Diagnostics, San Juan Capistrano, CA, US). Calibration is based on known amounts of synthetic human ACTH 1-39. The sensitivity of the assay is better than 5 $\mu \mathrm{g} / \mathrm{I}$. Intra- and interassay coefficients of variation are better than $3 \%$ resp $6 \%$. There is a insignificant negative cross-reactivity of the ACTH split products ACTH 124 and $\mathrm{ACTH} 18-39$ of $0.7 \%$ and $0.2 \%$ resp. This is without any clinical importance. Cortisol (compound-F) has been analysed using a solid-phase, chemiluminescent enzyme immunoassay designed to be measured on the Immulite Automated Analyzer (Diagnostic Products Corporation, Los Angeles, USA). Calibration is performed using the standard of the manufacturer. The sensitivity of the assay is about $6 \mathrm{nmol} / \mathrm{l}$. Intra and interassay coefficients of variation are less than $10 \%$. Prednisolone and prednisone show 
cross-reactivities of resp. 49 and $5.9 \%$, while the cross reactivity of all other possible interfering substances is less than $0.9 \%$.

The prolactin assay is a solid-phase two site fluorommunometric assay designed to be measured on the Autodelfia automatic immunoassay analyser (Perkin Elmer, Wallac, Turku, Finland). The detection with Eu is based on the delayed-enhancedfluorometric immunoassays (DELFIA) technique. The standards have been calibrated against the $84 / 500$ WHO 3 rd International Standard for prolactin. The sensitivity of the assay is better than 0.01 (U/I). Intra and interassay coefficients of variation are better than $1 \%$ and $3 \%$ resp. There is a minor cross reactivity of about $4 \%$ with hGH and of about $1 \%$ with hPL. Other substances like LH, hCG, FSH and TSH don't show any cross reactivity at all.

\section{Mood Assessments}

Every 30 minutes from to to $t_{210}$, subjects were administered the Profile of Mood States Scale (POMS) (McNair et al. 1971). The POMS consists of five separate mood scales (depression, tension, vigor, anger, and fatigue), ranging from 0-24, each based on six items ranging from 0 4. Thus, each of these five mood dimensions yilided a score. Furthermore, an overall POMS score, reflecting 'mood level', was constructed by summing the scores for the five subscales, after changling the polarity of the vigor subscale $(y=24-x)$.

\section{Cognitive Assessments}

The cognitive test battery took approximately 30 minutes to complete and consisted of tasks measuring visual verbal learning, visual search and motor choice reaction time.

\section{Word Learning Test}

One of twelve parallel lists of 15 monosyllabic meaningful nouns, matched for word frequency was presented at a rate of 2 seconds per word. The subjects were asked to recall verbally as many words as possible as soon as the presentation stopped. This first immediate recall trial was followed by four more trials in which the same words were repeated in the same order. When the fifth trial was completed, the subjects performed the subsequent tasks after 20 minutes they were asked to recall as many of the previously learned words without prompting (delayed recall). The number of correctly recalled words was noted affer each trial. The trial yielding the maximum number of recalled words was taken as the dependent variable (immediate recall). The delayed recall score was the number of words correctly recalled after 20 minutes. 


\section{Visual Search Signal-Detection Task}

Dots were presented on a computer screen in a random fashion. Every second, two dots changed position. When four dots formed a square, the subject had to push a button as quickly as possible (but within 2 seconds). Efficient and rapid visual search is required to obtain a high signal detection on this task. The reaction time $(R T)$ and the perceptual sensitivity measure (the number of hits corrected for response tendency) were taken as the dependent variable.

\section{Choice Reaction Time Task}

The subject held one button and was asked to press one of five other buttons located equidistantly from the hoid button when lit. This yielded reaction times (RT) consisting of an initiation phase (time from stimulus onset until release of the hold button) and a movement phase (time from release of the hold button until the response button is pushed). The subjects responded either to a single button (simple RT), to one of 3 buttons which lit up (3-choice RT), or to the right of the lit button (incompatible 3-choice RT) as quickly as possible. This task measures sensorimctor speed, choice-reaction speed, and choice-reaction speed with response competition.

\section{Procedure}

Subjects attended the clinic after an overnight fast. At $t_{80}$ an indwelling venous catheter was placed in a forearm vein from which blood was drawn with 30-minute intervals until $\mathrm{t}_{210}$. Drug administration occurred at 10:00 a.m. $\left(\mathrm{t}_{0}\right)$. Blood samples were placed on ice immediately and were centrifuged $a t t_{75}$ and $t_{225}$, and were frozen at $-80^{\circ} \mathrm{C}$ until analysis.

Profile of Mood States was assessed every 30 minutes at the same times blood was taken. In between, subjects sat on a bed and were allowed to read magazines. A research nurse was in the room during the entire test. She was instructed to talk only so much that the subjects would feel at ease but to do administrative work in between the assessments. At $t_{210}$, the subjects were subjected to computerised cognitive tests for half an hour. After the test, the subjects received a meal and went home.

\section{Statistical Analysis}

Hormonal responses were defined as the maximal increase following baseline (to) within seven consecutive assessments taken every 30 minutes from $t_{30}$ to $t_{210}$ ( $x$ in $t_{x}$ denotes minutes after drug administration). Mood responses were defined in a similar manner using the profile of mood states \{POMS (McNair et al., 1971); 30-item dutch validated version\} assessments of the depression, tenseness, fatigue, anger and vigour subscales. 
Due to heterogeneity of variance, hormonal and drug data were transformed according to 10-base logarithmic transformation. Hormonal responses were subsequently calculated by taking the peak of the values administered at to to $t_{210}$ subtracted with the value taken at to.

The effects of $\mathrm{m}$-CPP, ipsapirone and placebo on hormonal and behavioural responses were evaluated by analysis of variance (ANOVA) according to a mixed between-fwithin subjects repeated measures design. The within subject factor was drug (placebo, m-CPP, ipsapirone) and the between subject factor was group (patients versus controls).

\section{Results}

Fifteen patients and sixteen normal controls completed all experimental sessions. One male patient had dropped out because of severe side effects to $\mathrm{m}$-CPP (Klaassen et al., 1998). The groups did not differ in terms of age, sex, body mass index (BMI) and level of education (see table 1).

Table 1. Means and standard errors of subject variables

\begin{tabular}{|l|l|l|}
\hline & Patients & Controls \\
\hline MiF & 718 & $7 / 9$ \\
\hline Age (yrs) & $46.4(3.0)$ & $46.6(3.3)$ \\
\hline Level of education (1.7) & $3.2(0.6)$ & $3.2(0.4)$ \\
\hline BMI (weightLength $\left.{ }^{2}\right)$ & $24.3(0.7)$ & $24.1(0.7)$ \\
\hline
\end{tabular}

\section{Hormonal release}

Both drugs elevated hormonal release (figure 1) of cortisol (drug main effect: $F=18.0$, $d f=2,28, p=.000 ; m-C P P: F=35.1, d f=1,29, p=.000 ;$ ipsapirone: $F=14.1, d f=1,29$, $p=.001$ ), ACTH (drug main effect: $F=12.1, d f=2,28, p=.000 ; m-C P P: F=22.8, d f=1,29$, $p=.000$; ipsapirone: $F=13.8, d f=1,29, p=.001$ ) and prolactin (drug main effect: $F=17.5$, $d f=2,28, p=.000 ; m-C P P: F=36.1, d f=1,29, p=000$; ipsapirone: $F=7.4, d f=1,29$, $p=.011)$. Patients and controls did not differ in levels of cortisol, ACTH and prolactin measured at $t_{0}$, prior to drug administration. Cortisol responses to ipsapirone were diminished (blunted) in patients ( $g$ roup by ipsapirone interaction effect: $F=4.7$, $d f=1,29, p=.038)$. ACTH responses to ipsapirone in patients and controls showed a similar but non-significant trend, whereas no differences were observed for ipsapirone-induced prolactin. None of the hormonal responses to m-CPP differed between patients and control subjects. 

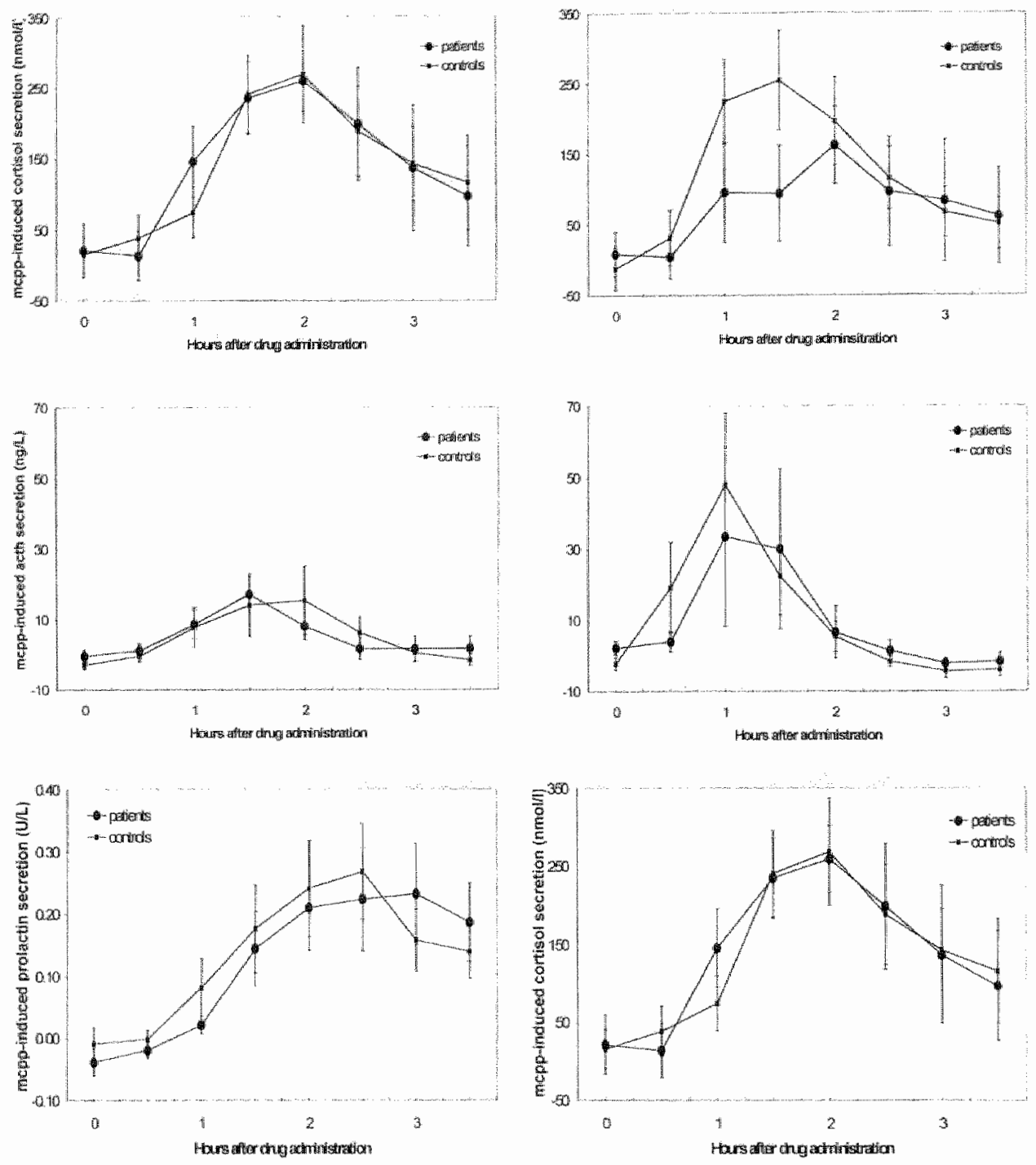

Figure 1. Hormonal responses to 5-HT agonists as a function of time after drug administration broken down by patients with depressed mood $(n=15)$ and healthy control subjects $(n=16)$. Top: cortisol responses; middle; adrenocorticotropic hormone (acth) responses; bottom: prolactin responses; left responses to metachlorophenylpiperazine (mcpp): right: responses to ipsapirone. The $y$-axes on the left and right are similar for enhancing comparability between drug effects. The graphs depict drug-placebo difference values of hormonal responses taken at 30-minute intervals following drug administration at to baseline) 

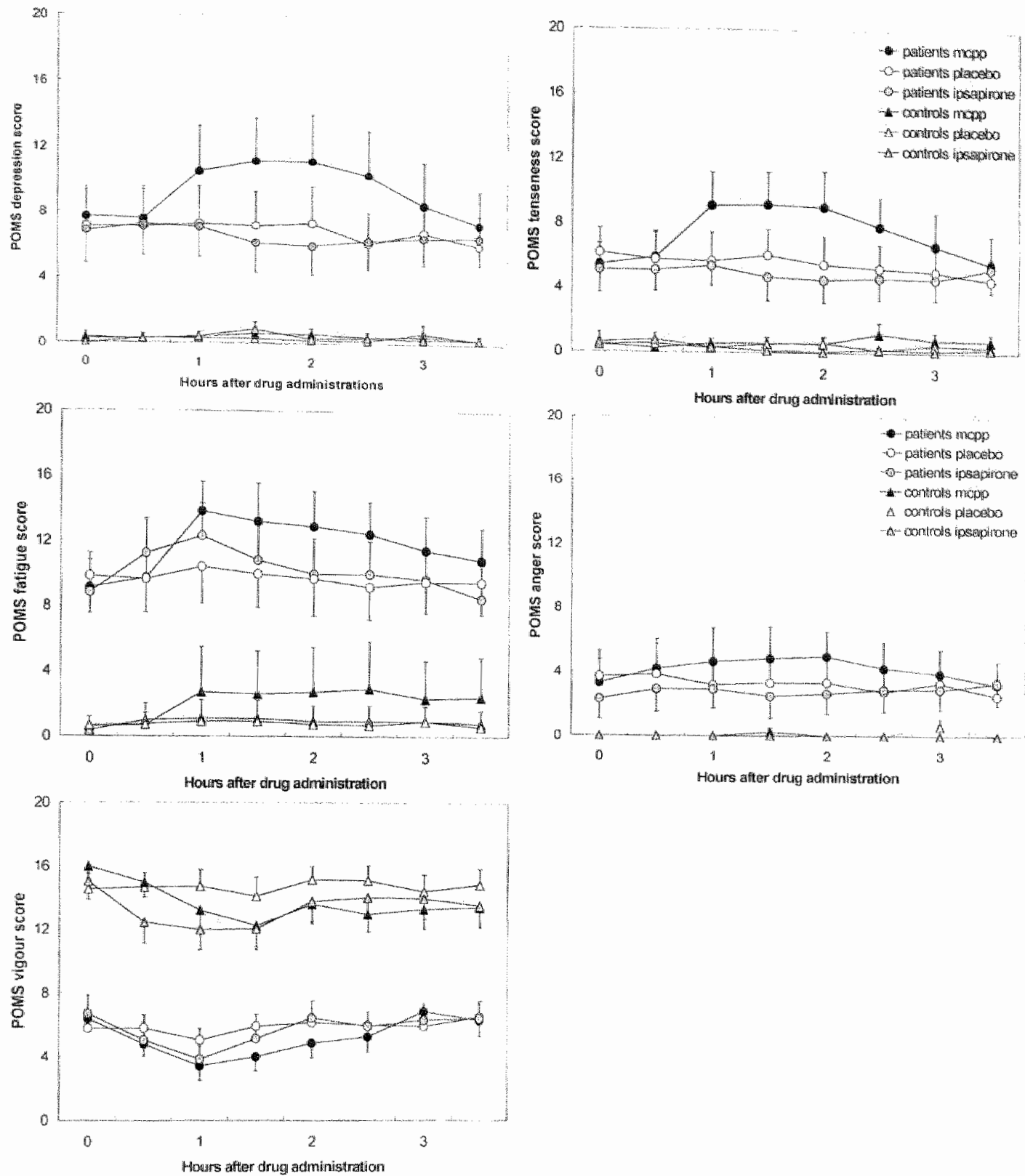

Figure 2. Mood responses to 5-HT agonists as a function of time after drug administration broken down by patients with affective disorders $(n=15)$ vs. healthy control subjects ( $n=16$ ) and drug treatment conditions. The graphs depict scores on the profile of mood states (POMS) subscales of depression (top left), tenseness (top righty, fatigue (midle left), anger (middle right) and vigour (bottom left). 


\section{Mood}

POMS ratings (see figure 2) were significantly higher in patients relative to controls for the items depression $(F=15.3, d f=1,29, p=.001)$, tenseness $(F=16.0, d f=1,29$, $p=000)$, fatigue $(F=22.2, d f=1,29, p=.000)$ and anger $(F=6,8, d f=1,29, p=.015)$ and significantly lower for vigour ( $F=53.9, d f=1,29, p=.000)$.

Mcpp increased feelings of depression ( $F=5.1, d f=1,29, p=012)$, tenseness $(F=8.7$, $d f=1,29, p=.006)$ and fatigue $(F=7.0, d f=1,29, p=.013)$, but not of anger and vigour. Drug-induced worsening of mood was exclusively seen in the patient group after mCPP on the items depression $(F=8.2, d f=1,29, p=.008)$ and tenseness $(F=5.8$, $d f=1,29, p=022$ ) but not on fatigue, anger and vigour. Ipsapirone had no significant effect on mood in patients, nor in normal controls.

\section{Cognilive Performance}

Analysis of placebo scores (effect of group) showed that depressed patients performed significantly worse than controls, particularly with respect to learning (immediate recall: $F=7.3, \mathrm{df}=1,29, \mathrm{p}=.012$ ) and memory (delayed recognition sensitivity: $F=8.1, d f=1,29, p=.008$; delayed recognition $R T: F=5.8, d f=1,29, p=.023$ ) and speed of responding to compatible $(F=4.8, d f=1,29, p=.038$ ) and incompatible stimuli $(F=5.6, d f=1,29, p=025)$ in choice RT.

Table 2 Means and standard errors of dependent measures broken down by subject groups and drug freatment

\begin{tabular}{|l|c|c|c|c|c|c|}
\hline & \multicolumn{3}{|c|}{ Patients } & \multicolumn{3}{c|}{ Controls } \\
\hline & & & & & & \\
Word Learning & ipsapirone & mopp & placebo & ipsapirone & mcpp & placebo \\
Max. Imm. Rec. (0-15) & $11.1 \pm .6$ & $10.7 \pm .7$ & $10.6 \pm 8$ & $10.9 \pm .6$ & $11.3 \pm 4$ & $12.7 \pm 3$ \\
Delayed Recall (0-15) & $8.5 \pm .8$ & $9.1 \pm 7$ & $7.8 \pm 1.0$ & $9.6 \pm 6$ & $9.4 \pm .6$ & $9.7 \pm 5$ \\
Recogn. Sens. (\%) & $91 \pm 1$ & $91 \pm 1$ & $89 \pm 3$ & $96 \pm 1$ & $95 \pm 1$ & $94 \pm 1$ \\
Recogn. RT (msec) & $792 \pm 30$ & $739 \pm 26$ & $766 \pm 27$ & $656 \pm 24$ & $684 \pm 19$ & $690 \pm 31$ \\
& & & & & & \\
Visual Search & & & & & & \\
Sign. Det. Sens. (\%) & $69 \pm 3$ & $69 \pm 3$ & $66 \pm 4$ & $73 \pm 3$ & $66 \pm 3$ & $75 \pm 3$ \\
Sign. Det. RT (msec) & $913 \pm 41$ & $901 \pm 38$ & $866 \pm 37$ & $827 \pm 27$ & $863 \pm 36$ & $807 \pm 20$ \\
& & & & & & \\
Molor Choice RT & & & & & & \\
Mov. Time (msec) & $139 \pm 10$ & $140 \pm 9$ & $147 \pm 11$ & $135 \pm 7$ & $133 \pm 9$ & $135 \pm 8$ \\
Simple RT (msec) & $323 \pm 9$ & $351 \pm 16$ & $328 \pm 11$ & $320 \pm 8$ & $318 \pm 8$ & $310 \pm 8$ \\
Choice RT (msec) & $377 \pm 10$ & $390 \pm 14$ & $375 \pm 9$ & $357 \pm 6$ & $366 \pm 6$ & $352 \pm 7$ \\
S-R inc. RT (msec) & $487 \pm 12$ & $501 \pm 17$ & $478 \pm 14$ & $430 \pm 9$ & $461 \pm 12$ & $436 \pm 11$ \\
\hline
\end{tabular}




\section{Word Leaming}

There was a significant multivariate interaction effect of Drug $\times$ Group $(F=3.1$, $d f=2,28, p=05$ ) indicating different effects of the drugs on immediate recall in patients versus control subjects. Univariate comparisons showed an interaction effect of Ipsapirone $x$ Group $(F=6.4, d f=1,29, p=.017$ ) indicating that ipsapirone improved immediate recall in patients and impaired immediate recall in control subjects.

\section{Visual Search}

M-CPP impaired signal detection efficiency in controls and not in patients. The multivariate Drug by Group interaction effect was significant $(F=7.3$, df $=2,28, p=003$ ) and so was the univariate interaction effect for $m-C P P$ by Group $(F=14.1, d f=1,29$, $p=.001)$. The main effect of $m-C P P$ was also significant $(F=5.3, d f=1,29, p=029)$, but inspection of the data showed that this was entirely due to the interaction effect. There were no effects on signal detection RT. There were no effects of ipsapirone on visual search.

\section{Choice RT}

Irrespective of group, m-CPP significantly impaired simple $R T$ ( $F=4.7, d f=1,29$, $p=.040)$, compatible choice RT $(F=4.7, d f=1,29, p=.038)$ and incompatible choice RT $(F=4.7, d f=1,29, p=.039)$. There were no effects on movement time. There were no effects of ipsapirone on choice RT.

\section{Gender differences}

A rerun of all analyses with the inclusion of the factor Gender did not show any difference in cognitive performance between males and females in either of the patient and control groups. Furthermore, the drug effects hitherto reported did not seem to differ between male and female patients or controls

\section{Effects of Age, Education and BMI}

Correlational analyses of age, education and BMI with hormonal and mood responses, defined as drug-placebo difference scores, showed that withim the patient group m-CPP-induced elevations of depression $(r=.62, n=15, p=.014)$, tenseness $(r=28, n=15, p=.023)$ and anger $(r=53, d f=15, p=.042)$ were positively associated with level of education. There were no associations of drug-induced hormonal and mood responses with age and BMI. 


\section{Intercorrelations of hormonal- with mood responses}

Correlational analyses of hormonal responses to m CPP and ipsapirone, expressed as drug-placebo difference scores, with similarly expressed POMS-derived mood responses revealed that whin the patient group there were positive associations of the m-CPP-induced prolactin response with the m-CPP-induced elevations of depression $(r=57, n=15, p=.028)$ and tenseness $(r=.52, n=15, p=.047)$. There were no indications of a statistical association within the patient group between the ipsapirone-induced blunting of cortisol response and the m-CPP-induced worsening of mood.

\section{Blood levels of $m$-CPP and ipsapirone}

Mcpp and ipsapirone blood levels did not differ significantly between patients and control subjects (see figure 3 ). Mcpp had its mean peak level at $t_{120}$, while the mean ipsapirone peak level was already obtained at tzo.
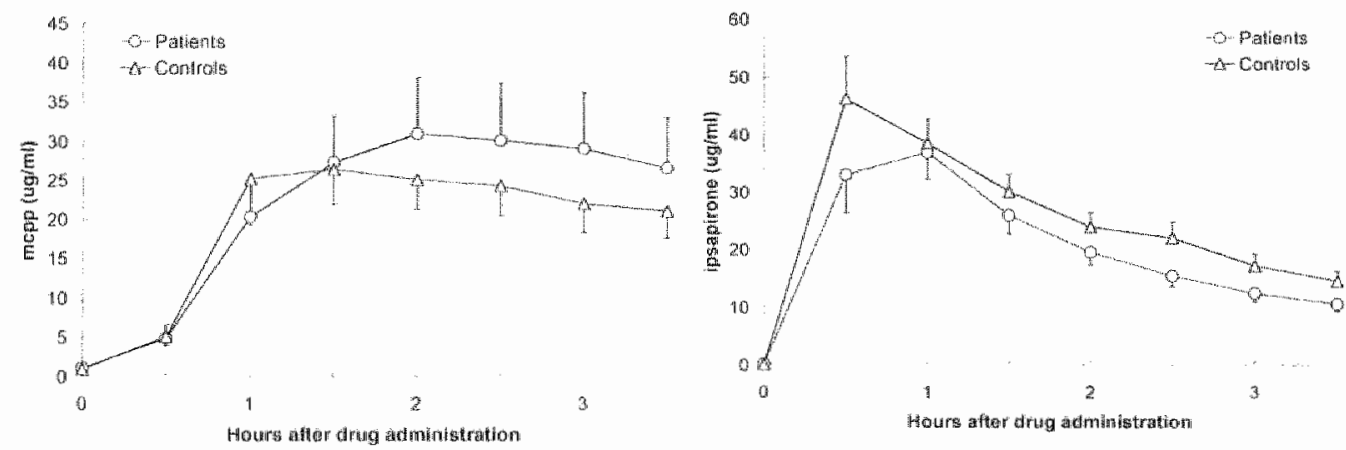

Figure 3 Plasma levels of mcpp (left) and ipsapirone (night) as a tunction of time after drug administration bioken down by patients with affective disorders $(n=15)$ ws. healthy control subjects $(n=16)$

\section{Effects of diagnostic groups}

Re-analysis of the data was performed, now incorporating the diagnostic groups into a between groups factor with 4 levels: major depression $(n=9)$, dysthymia $(n=3)$ anxiety + depression $(n=3)$, controls $(n=16)$ ). In brief, what descriptive statistics 
showed was that the blunted cortisol response to ipsapirone was not observed in anxiety disorder patients with depressed mood. No other findings emerged from this exercise. Between groups statistical tests of significance to substantiate this observation would go below the statistically acceptable level of at least 4 observations per cell. Therefore, a way to substantiate this finding was to redo the analyses with the 3 anxiety+depression patients excluded. The ipsapirone-induced blunted cortisol response in the remaining 12 patients $v s$. 16 controls appeared to be a more robust effect without the 3 anxiety+depression patients (group by ipsapirone interaction effect: $F=5.5, d f=1,26, p=.027$ ).

\section{Discussion}

To the best of our knowledge, this is the first neuroendocrine challenge study in patients with depressed mood, in which two 5-HT receptor types were studied. Drug effects on hormonal secretion can be summarised as robust mmCPP-induced elevations of cortisol, prolactin and $\mathrm{ACTH}$, whereas ipsapirone produced robust elevations of cortisol and ACTH and somewhat less of prolactin. Drug effects on mood can be summarised as m-CPP-induced elevation of depression and tenseness in patients and an overal! m-CPP-induced increase of fatigue. A blunted cortisol response to ipsapirone was seen in patients with depressed mood compared to controls. An exaggerated mood response to $n$-CPP was seen in patients compared to controls. Another significant ipsapirone-induced difference between groups was the impairment of memory performance in controls and improvement in patients. These findings are in agreement with previous separate studies that showed a blunted cortisol response to ipsapirone in depressed patients (Lesch et al, 1990; Meltzer and Maes, 1995) and hyperresponsivity to m.PP in terms of subjective mood (Charney et al. 1987; Kahn and Wetzler, 1991; Lawlor et al., 1989). Our strategy, based on the somcalled functional approach, to include patients with depressed mood on the basis of symptoms rather than diagnostic categories, was partly discarded by the fact that the observation confirming our primary hypothesis of a blunted cortisol response to ipsapirone was not true for anxiety patients with depressed mood.

Stahl (1998) distinguishes five pathways in which serotonergic drugs generally manifest their actions. He describes serotonergic projections to the frontal cortex, the basal ganglia, hippocampus, hypothalamus and to the spinal cord (Stahl, 1998). The effects of m-CPP and ipsapirone most probably reflect different expressions of serotonergic modulation in hypothalamic (hormonall), amygdalo-frontal (mood) and hippocampal (memory) pathways, although if must be noted here that these associations are only well established in the case of endocrine effects mediated via serotonergic modulation of the hypothalamus. 
Even though hormonal responses to m-CPP did not differ in our study, the observed pattern of subjective responses could be taken as an indication of hypersensitivity of fronto-cortical 5-HT2 receptors (where these receptors are most abundant), in depressed patients relative to normal control subjects. This is in contrast to the blunted cortisol response to ipsapirone in patients with depressed mood, which can be taken as a sign of diminished hypothalamic postsynaptic 5-HT 1 A receptor sensitivity. Similarly but more speculatively, the differential effects of ipsapirone on memory in patients and controls could reflect altered hippocampal 5-HT . receptor sensitivity in a manner such that the stimulation of these receptors is positively associated with memory performance, only if these receptors are desensitised. e.g. due to long-term repeated overstimulation with cortisol. The latter would also explain the decreased memory performance seen in patients with depressed mood (McAllister-Williams et al, 1998).

An alternative explanation might be that memory effects are due to agonistic and antagonistic actions of ipsapirone in patients and controls, respectively. This putative differential pharmacological effect might be explained by the partial agonistic property of ipsapirone.

A different explanation may be that low 5-HT has been shown to induce long-term depression (LTD; as opposed to long-term potentiation: LTP) of synaptic plasticity, especially in hippocampal area, possibly through modulation of calcium (2+) channels, through which 5-HT has been shown to normally inhibit LTD (Normann, 2000; Normann et al., 2000). This mechanism may account for positive effects of 5HT in patients and may also explain tryptophan-depletion induced memory consolidation impairment and mood lowering in normal subjects (Riedel et al., 4999). In contrast to a previous study in which no cognitive effects of m-CPP were reported (Silverstone et al., 1994), we found impaired performance after m-CPP on all Reaction Time tasks. However, we assessed performance 3.5 hours after administration whereas the previously mentioned study, performance was assessed 1.2 hours after administration. If m-CPP would be considered having stimulant properties, these observations might fit the pattern of initial activation, or CNS disinhibition, followed by withdrawal or deactivation, leading to a slowing of RT (Gijsman et al., 1998).

We conclude that in patients with major depression and dysthymia, hypothalamic and possibly also hippocampal 5-HT $1 \mathrm{~A}$ desensitisation and non-hypothalamic $5-\mathrm{HT}_{2 \mathrm{C}}$ sensitisation , probably fronto-cortical, mediate depressed mood along with impaired memory performance. 


\section{References}

APA (1994) Diagnostic and Statistical Manual of Mental Disordiers. Fourth Edition. American Psychiatric Association, Washington, DC

Broocks, A. Bandelow, B., George, A., Jestrabeck, C., Opitz, M., Bartmann, U., Gleiter, C.H. Meineke, I, Roed, IS., Ruther, E. and Hajak, G. (2000) Inoreased psychological responses and divergent neuroendocrine responses to m-CPP and ipsapirone in patients with panic disorder In Process Citation]. InternationalCinical Psychopharmacology 15: $153-161$

Broocks, A., Meyer, T., George, A., Hillmer-Vogel, U., Meyer, D., Bandelow, B., Halak, G., Barmann, U. Gleiter, C.H., and Ruther, E. (1999) Decreased neuroendocrine responses to metaw chlorophenylpiperazine (m-CPP) but normal respenses to ipsapirone in marathon runners. Neuropsychopharmacology 20: 150-161

Chamey, D.S. Woods, S.W., Goodman, W.K., and Heninger, G.R. (1987) Serotonin function in anxiely II. Effects of the serotonin agonist m-CPP in panic disorder patients and healthy subjects. Psychopharmacology 92: 14-24

Dawidson, J., Turnbull, C.D., Strickland, R., Miler, R., Graves, K. (1986) The Montgomery-Asberg Depression Scale: reliability and validity. Acta Psychiatrica Scanddinavica 73: 544-548

De Vry, J. (1995) 5-HT(1A) receptor agonists: Recent developments and controversial issues. Psychopharmacology $121: 1-26$

Gijsman, H.J., Van Gerven, J.M. Tieieman, M.C., Schoemaker, R.C., Pieters, M.S. Ferrari, M.D. Cohen, A.F., and Van Kempen, G.M. (1998) Pharmacokinetic and pharmacodymamic profie of oral and intrawenous meta-chlorophenylpiperazine in healthy volunteers. Journal of Clinical Psychopharmacology 18: 289-295

Glennon, R.A., ismael, A. McCarthy, B.J., and Peroutka, S.J. (1989) Binding of arylpiperazines to 5HT3 receptors. Results of a structure-affinity study. European Journal of Pharmacology 168: 387 392

Hamik, A., and Peroutka, S.J. (1989) 1-(m-Chlorophenyl)piperazine (m-CPP) interactions with neurotransmitter receptors in the human brain. Biological Psychiatry 25: 569-575

Hoyer, D. (1988) Functional correlates of serotonin 5-HTH recognition sites. Journal of Receptor Research 8: 59-81

Kahn, R.S., and Wetzler, S. (1991) m-Chlorophenylpiperazine as a probe of serotonin function. Biological Psychiatry 30: 1139-1166

Kahn, R.S. Wetzler, S. Asnis, G.M. Kling, M. A. Suckow, R.F., and Van Praag, H.M. (1991) Pituitary homone responses to meta-chlorophenylpiperazine in panic disorder and healthy control subjects. Psychiatry Research 37: 25-34

Kahn, R.S. Wetzler. S., Van Praag. H.M. and Asnis, G.M. (1988a) Behavioural indications for serotonin receptor hypersensitivity in panic disorder. Psychiatry Research 25: 101-104

Kaln, R.S., Wetzler, S., Van Praag, H.M., and Asnis, G.M. (1988b) Neuroendocrine evidence for 5-HT receptor hypersensitivity in patients with panis disorder. Psychopharmacology $96: 360-364$

Klaassen. T., Ho Fian, K. Westenberg. H.G.M., Den Boer, J.A., and Van Praag, H.M (1998) Serotonin syndrome after challenge with the 5-HT agonist meta-chlorophenylpiperazine. Psychiatry Research 79: 207-212

Lawlor, B.A., Sunderland, T., Mellow, A. M. Hill, J.L., Molchan, S.E., and Murphy, D. L. (1989) Hyperresponsivity to the serotonin agonist m-chlorophenylpiperazine in Alzheimer's disease. A controlled study. Archives of General Psychiatry 46: $542-549$

Lesch, K.P., Sohnle, K. Poten, B., Schoellnhammer, G. Rupprecht, R., and Schulte, H.M. (1990) Conticotropin and cortisol secretion after central 5-hydroxytryptamine-1A. (5-HT 1A) receptor activation: effects of 5 -HT receptor and beta- adrenoceptor artagonists. Journal of Clinical Endocrinology and Metabolism 70: 670-4 
Maes, M., and Melzer. H.Y. (1995) The Serotonin Hypothesis of Major Depression. In: Bloom FE. Kupter DJ (eds) Psychopharmacology. The Fourth Generation of Progress. Raven Press, New York, po $933-944$

Macs, M. Meltzer, H.Y. D"Wondt, P. Cosyns, P., and Blockx, P. (1995) Effects of serotonin precursors on the negative feedback effects of glucocorticoids on hypothatamic-pituitary-adrenal axis function in depression. Psychoneuroendocrinology 20: 149-167

MCAllister-Williams, R.H. Ferrier, I.N., and Young, A.H. (1998) Mood and neurcpsychological function ir depression: the role of corticosteroids and serotonin. Psychological medicine 22: 573-584

MicNair, D.M. Lorr, M, and Droppleman. L.F. (1971) Manual for the Profile of Mood States. Educational and Industrial Testing Service. Educational and Industriai Testing Service

Meltzer H.Y., and Maes M. (1995) Effects of ipsapirone on plasma cortisol and body temperature in major depression. Biological Psychiatry 38: 450-457

Meltzer, H.Y., Umberkoman-Wita, B., Robertson, A., Tricou, B.J., Lowy, M., and Perline, R. (1984) Effect of 5-hydroxytryptophan on serum cortisol levels in major affective disorders. I. Enhanced responise in depression and mania. Archives of General Psychiatry 41:366-374

Normann, C. (2000) Towards a new model for cellular pathophysiology in affective disorder. Acta Neuropsychiatrica 12: 77-80

Normann, C., Peckys, D., Schulze, C.H. Walden, J., Jonas, P.. Bischofberger, J. (2000) Associative long-term depression in the hippocampus is dependent on postsynaptic $\mathrm{N}$-type Ca2+ channels. Journall of Neuroscience 20:8290-8297

Peroutke, S.J. (1988) 5-Hydroxytryptamine receptor subtypes: Molecular, biochemical and physiological caracterization. Trends in Neuroscience 11: $496-500$

Riedel, W.J., Klaassen, T. Deutz, N.E.P., Van Someren, A. Van Praag, H. M. (1999a) Tryptophan Depletion in Normal Volunteers Produces Selective Impairment in Memory Consolidation. Psychopharmacology 141:362-369

Riedel, W.J., Schoenmakers, E, Verneeren, A, and OHanlon, J.F. (19990) The Irftuence of Trazodone Treatment on Cognitive Functions in Outpatients with Major Depressive Disorder. Human Psychopharmacology 14: 499-508

Silverstone, P.H., Rue, J.E., Franklin, M., Hallis, K., Camplin, G., Laver, D., and Cowen, P.J. (1994) The effects of administration of m-CPP on psychological, cognitive, cardiovascular, hormonal and MHPG measurements in human volunteers. International Chinical Psychopharmacology 9: 173-178

Stahl, S.M. (1988) Mechanism of action of serotonin selective reuptake inhibitors. Journal of Affective Disorder's $51215-235$

Slok, L.M.L.. Groothuijsen, H, and Hoogtanders, K. (1997) A semi-automated sensitwe HPLC method for detemination of un-chlorophenylpiperazine in plasme. Therapeutic Drug Monitoring 19: $\$ 588$

Van Praag. H.M. (1996) Serotonin Related Anxiety/Aggression Driven, Stressor Precipitated Depression: a Psycho Biological Hypothesis. European Psychiatry 11:57-67

Van Praag. H.M. Kahn, R.S., Asnis, G.M., Wetzler, S. Brown, S.L., Bleich, A. and Korn, M.L. (1987) Denosologization of biological psychiatry or the specificity of 5-HT disturbances in psychiatric disorders Joumal of Affective Disorders 13: 1-8

Wing. J.K. Babor, T. Brugha, T, Burke, J. Cooper, J.E. Giel, R., Jablenski, A., Regier, D., and Sartorius, N. (1990) SCAN, Schedules for clinical Assessment in Neuropsychiatry. Archives of General Psychiatry 47: 589-593

Yatham, L.N. and Steiner, M. (1993) Newroendocrine probes of serotonergic function: a critical review Life Sciences 53: $447-463$ 


\section{Serotonin syndrome after challenge with the 5 -HT receptoragonist meta- chlorophenylpiperazine (m-CPP)}

T. Klaassen, K.L. Ho Pian, H.G.M. Westenberg, J. A den Boer, H.M. van Praag

Published in: Psychiatry Research (1998) 79: 207-212

\section{Abstract}

meta-Chlorophemylpiperazine (m-CPP) is a nonselective 5-HT-receptor agonist/antagonist that is used extensively in psychiatry to assess central serotonergic function. We report three patients who developed symptoms of the serotonin syndrome when they participated in a m-CPP $(0.5 \mathrm{mg} / \mathrm{kg}$ bodyweight p.o.) challenge test as part of a research protocol. They had relatively high plasma m-CPP concentrations. The syndrome did not occur in normal volunteers who had comparable plasma concentrations of m-CPP. Investigators should be aware of the possible occurrence of the serotonin syndrome after a single oral dose of m-CPP

KEYWORDS: Case-report, HLman, m-CPP, Serotonin syndrome, Plasma 


\section{Introduction}

The serotonin (5-HT) syndrome is a complex of symptoms that is probably caused by hyperstimulation of 5-HT a receptors in the brain stem and spinal cord (Smith and Peroutka, 1986; Yamada et al., 1989). It can be elicited in humans by serotomimetic agents, alone or in combination with monoamineoxidase inhibitors (Bodner ef al, 1995). The 5-HT syndrome is characterized by changes in mental status, most notably hypomanic features. restlessness, confusion, agitation, and several physical symptoms. The latter can be divided into motor symptoms (such as myoclonus, hyperreflexia, tremor, hypertonicity, coordination disturbances) and autonomic symptoms (such as diaphoresis, nausea, diarhoea, fever and shivering). Coma and seizures have also been described (Sternbach, 1991; Bodner el al., 1995). meta-Chloropheny/piperazine (m-CPP) is extensively used to probe central serotonergic function in psychiatry (Kahn and Wetzler, 1991). It is a nonselective 5 $H T$-receptor agonistlantagonist, with affinity for most 5-HT receptors and alpha-2 adrenergic receptors (Hamik and Peroutka, 1989). m-CPP acts (in ascending affinity) as a partial agonist of 5-HT, receptor subtypes (Schoeffter and Hoyer, 1989; Sheldon and Aghajanian, 1991), a partial agonist or antagonist of the 5-HT2 receptor (Conn and Sanders-Bush, 1987), and an antagonist of $5 \mathrm{HT}_{3}$ receptors (Robertson et al.. 1992).

To the best of our knowledge, there are no reports of the 5-HT syndrome being induced by a single dose of m-CPP. We report three patients in whom the 5-HT syndrome occurred after administration of $\mathrm{m}$-CPP as part of a double-blind, placebocontrolled research protocol.

\section{Case histories}

\section{Case 1}

S. is a physically healthy 28-year-old man, with a 13-year history of obsessive-compulsiwe disorder. Forty-five minutes after administration of $\mathrm{m}-\mathrm{CPP}$ ( $t=45 \mathrm{~min}$ ), he complained of severe nausea, light-headedness, diaphoresis, and a marked increase in obsessive-compulsive thoughts. He became restless, sensed mild palpitations, chest pressure, and paresthesia in his hands. Subsequently, he experienced myocloni of facial, chest and abdominal muscles with a frequency of 15 spasms per minute at peak intensity. This resulted in trunk movements and interrupted his regular breathing. The patient however remained well oxygenated, with normal vital signs and no need for artificial respiration. During the challenge, systolic tension varied between 101 and 123 , diastolic tension between 60 and 67 , pulse rate between 42 and 48 and body temperature between 36.1 and $36.8^{\circ} \mathrm{C}$. At $t=120 \mathrm{~min}$, he was in a 
hypomanic state; he laughed almost uncontrollably and was unconcerned about his physical condition.

Treatment of the myocloni with $10 \mathrm{mg}$ diazepam intraveneously was ineffective. At $t=225 \mathrm{~min}$, the myocloni started to subside spontaneously. At this time we administered $20 \mathrm{mg}$ ritanserin orally to the patient. Seven hours after m-CPP administration all symptoms had subsided and he was discharged. Peak plasma concentration of m-CPP was $124 \mathrm{ng} / \mathrm{ml}$ at $t=90 \mathrm{~min}$ and decreased to $76 \mathrm{ng} / \mathrm{ml}$ at $t=240 \mathrm{~min}$.

Consultation the next day revealed that he had mill complaints of nausea and headache and very mild muscle spasms with a frequency of one per hour. One week later treatment with fluvoxamine was started. The dose was slowly increased up to $100 \mathrm{mg} /$ day. His obsessive-compulsive symptoms responded to treatment, but he still experienced a few muscle spasms before falling asleep. Six months later he reported an increase of myocloni that came in bouts of 30 minutes with a high frequency. This was accompanied by uncontrollable laughing. without an apparent reason. After the dose of fluvoxamine was reduced to $50 \mathrm{mg} /$ day the myocloni subsided but the obsessive-compulsive symptoms returned. Plasma levels of fluvoxamine were $24 \mathrm{ng} / \mathrm{ml}$. The patient then stopped taking fluvoxamine.

\section{Case 2}

M. , a physically healthy 28-year-old male, suffered from social phobia and dysthymia. Thinty minutes ( $t=30$ min) after $m-C P P$ administration he reported feeling cold. His oral temperature was $36^{\circ} \mathrm{C}$. He felt tired, dizzy and lightheaded. He experienced this as being 'high'. At $t=60 \mathrm{~min}$, his blood pressure had dropped from 117/64 to 105/43 and remained unstable during the challenge. The concentration of $m$-CPP was maximum ( $92 \mathrm{ng} / \mathrm{ml}$ ) at $t=120 \mathrm{~min}$. His body temperature fluctuated between 35.3 and $36.8^{\circ} \mathrm{C}$. He was therefore observed for 1 hour after the challenge procedure. He reported drinking 10 glasses of beer the evening before the challenge, eventhough he is not an alcoholic.

When driving home he felt insecure about his driving capacity, he experienced muscle weakness and suffered from palpitations. In the evening his temperature was $39.6^{\circ} \mathrm{C}$. He experienced headache, muscle weakness and diarrhoea for 3 days. At consultation, 5 days after the challenge test, his vital functions were nomal and physical and laboratory examination revealed no abnormalities. He withdrew from the study.

Compared to the other patients, this patient showed increased anger and tiredness after $m$-CPP (more than 1 standard deviation above the mean of the group, $n=14$ ). However, the level of anger was already high at baseline. These feelings were accompanied by a very low level of vigilance ( 0 ; the group mean was about 5 over the whole session). which had been high at baseline (11 at 10.00 am; group mean $t$ sd was $7 \pm 2.65)$. 


\section{Case 3}

B. is a physically healthy 46 -year-old woman who suffered from major depression. She discontinued clomipramine 1 week before the challenge procedure, but continued to use bromazepam $3 \mathrm{mg}$ per day during the study.

She became lightheaded within 90 min of m-CPP administration ( $t=90 \mathrm{~min}$ ), and she complained of being tired and drowsy and reported having palpitations. At $t=120 \mathrm{~min}$, she felt sad without knowing why. Vital signs during the challenge procedure were unstable: Systolic blood pressure rose from 116 to 129 and diastolic pressure fluctuated between 72 and $99 \mathrm{mmHg}$. Heart rate varied from 59 to 78 beats per minute. Oral temperature rose from $35.2^{\circ} \mathrm{C}$ to $36.2^{\circ} \mathrm{C}$. At $\mathrm{t}=90 \mathrm{~min}$, when she experienced maximal side effects, diastolic bload pressure and heart rate were at the lowest level. The plasma concentration of $\mathrm{m}$-CPP was maximum $(73 \mathrm{ng} / \mathrm{ml})$ at $t=120$ min. The patient was observed for 1 hour after completion of the challenge procedure. Her husband reported that she was confused and drowsy when she came home and during the next day. The 2 days following the challenge she suffered from hot flushes and cold chills, aching muscles and palpitations. At consultation on the third day after the challenge, she appeared to be tense and anxious and was still bothered by painful muscles. Physical and laboratory examinations were normal. We prescribed paracetamol for the muscle pain and increased the dose of bromazepam to $6 \mathrm{mg}$ per day. Six days after the challenge, clomipramine was started up to 300 mig per day without any problems.

Blood prolactin concentrations were between 1 and 2 standard deviations higher than the patient group mean from $t=30$ min until the end of the session ( $t=210 \mathrm{~min}$ ). ACTH and cortisol blood concentrations were similar to the group means. From $t=120 \mathrm{~min}$ onwards, behaviourall ratings were also at least 1 standard deviation higher than the group means [depression, tension, anger and tiredness on the Profile of Mood States Scale (Mc. Nair, 1970)].

\section{Discussion}

The symptoms exhibited by our patients resemble those seen in the 5-HT syndrome (Stermbach, 1991; Lejoyeux et al. 1994). These symptoms occurred after an oral dose of $0.5 \mathrm{mg} / \mathrm{kg} \mathrm{m}-\mathrm{CPP}$, a dose which is frequently used in clinical investigations (Kann et al., 1991; Sevy et al., 1994; Stein et al. 1996). Two cases of the 5-HT syndrome have been repoited after the use of trazodane (which is metabolized into $\mathrm{m}$-CPP) in combination with buspirone (Goldberg. 1992) and paroxetine (Reeves and Bullen, 1995).

It is puzzling that the 5-HT syndrome has never been described before after a single dose of $m$-CPP. Some studies have monitored physical side effects (Brewerton et al. . 1992; Joseph-Vanderpool et al., 1993) but these were not significantly different from 
those in the placebo condition. Could tt be that the syndrome is under-recognised in many cases? In our study, the patients who experienced the 5-HT syndrome reported markedly more side effects shortly after administration of m-CPP than did subjects without the 5-HT syndrome. Thus, early onset and high intensity of side effects might predict the occurrence of the syndrome.

A possible explanation for the 5-HT syndrome observed in these patients might be the relatively high peak plasma m-CPP concentrations $(124,92$ and $73 \mathrm{ng} / \mathrm{ml}$ ) which were much higher than those of patients who did not develop these symptoms (mean $28.7 \mathrm{ng} / \mathrm{ml}$ ) and volunteers (mean $35.2 \mathrm{ng} / \mathrm{ml}$ ). The latter plasma concentrations are comparable with those found reported by others (Kahn et al. $1990^{\text {a: }}$; Sevy et al., 1994; Stein et al., 1996). We have no explanation for the high plasma m-CPP concentration in the three patients. Furthermore, apart from a history of prior 5-HT syndrome and the concurrent use of other serotomimetic agents, there are no clinical signs and symptoms that predict an unusual response to m-CPP. A familial history of 5-HT syndrome might be a risk factor (Lejoyeux et al., 1993). In case 3 , the patient had been using clomipramine until 1 week before the first challenge. This drug free period might have been too short, especially because there are large intra-individual differences in absorption and metabolism of the drug. However it is frequently difficult to keep patients drug-free for a long time because for ethical reasons. Asnis et al. (1990) suggested screening patients for the presence of tricyclic antidepressants just prior to a challenge test, particularly if the drug-free period was 2 weeks or less. The drug-free period might need to be even longer in subjects who have been on chronic oral antidepressants, especially for the $5-12 \%$ of the population who are slow metabolizers (Garvey et al., 1984).

The role of alcohol (as used in case 2 ) in the development of the 5-HT syndrome is not yet established. Some studies suggest that m-CPP has some ethanol-like effects in detoxified alcoholics (Benkelfat et al., 1991; Krystal et al., 1994). A blunted glucose response to $\mathrm{m}$-CPP in the basal ganglia was found in alcoholics compared to healthy control subjects using positron emission tomography (Hommer et al. 1997). There is also evidence that the serotonergic system is dysregulated in alcoholics (Roy et al. 1987), however, depletion of tryptophan does not decrease the effects of alcohol in healthy subjects (Zacchia et al., 1987). Furthermore, as far as we know, m-CPP has no effect on the GABA system. Thus, the potential impact of alcohol consumption is unclear

In case 1 , treatment with SSRIs after the m-CPP challenge caused mild 5-HT syndrome-like symptoms (e.g. myocloni), despite the plasma fluvoxamine concentration being within the normal range. Lejoyeux et al. (1993) found myoclonus in 14 out of 38 depressed subjects receiving $150 \mathrm{mg}$ clomipramine/day. The myoclonus was transient (less than 1 week) in 12 patients and lasted more than 1 week in 2 patients. Thus, it seems that myoclonus alone does not necessitate an immediate change in regimen. Though conclusions concerning treatment cannot be 
drawn from one isolated case, it might be prudent to institute seratonergic treatment with caution when the serotonergic syndrome has occurred.

The acute management of the 5-HT syndrome consists of immediate discontinuation of all serotonergic medications. Supportive measures (e.g. anticonvulsants for seizures, clonazepam for myoclonus, nifedepine for hypertension) may be necessary. 5-HT antagonists such as methysergide and propranolol may also be beneficial (Sandyk, 1986; Guze and Baxter, 1986). The syndrome usually resolves quickly when the offending agents are removed, but recovery may be delayed for days when drug halffives are long. Fatalaties have been reported (Bremnan et al.,1988; Kline et al., 1989; Neuwonen et al., 1993), making early recognition and treatment of vital importance.

Although three patients developed the 5-HT syndrome after a single dose of m-CPP, many subjects have undergone m-CPP challenge without experiencing any serious side effects. Therefore, there is no need to regard $\mathrm{m}$-CPP challenge as dangerous, provided that certain preventive measures are implemented. First, subjects should not use concurrent serotonergic medication. Second, the drug-free period before the onset of the test should be at least 1 to 2 weeks (longer if possible), and third, plasma drug concentrations should preferably be measured before the test. This latter measure also increases the validity of the m-CPP test. If subjects report relatively severe side effects during the testprocedure, they should be monitored closely until the side effects resolve. Most importantly, the investigator should be aware that the 5-HT syndrome is not an uncommon phenomenon after a single dose of $\mathrm{M}-\mathrm{CPP}$.

\section{References}

Asnis, G.M. Harkawy Friedman, J.M. Iqbal, N., Bajwa, W.K., Kalus, O. Rubinson, E., Grosz, D., van Praag. H.M., and Cooper, T.B. (1990) The drug-free period: a methodological issue.[comment] Biological Psychiatry 27: 657-660

Benkelfat, C., Murphy, D.L., Hill, J.L., George, D.T., Nutt, D., and Linnoila, M. (1991) Ethanol-like properties of the serotonergic partial agonist m-chiorophenylpiperazine in chronic alcoholic patients. Archives of General Psychiatry 48, (4):383

Bodner, R.A., Lynch, T., Lewis, L., and Kahn, D. (1995) Seratomin syndrome. Neurolagy 45: 219-222

Brennan, D. Mac Manus, M., Howe, J., and McLoughthin, J. (1988) Neuroleptic malignant syndrome without neuroleptics (letter). British Journal of Psychiatry 152:578-579

Brewerton, T.D. Mueller, E.A., Lesem, M.D., Brandt, H.A., Quearry, B., George, T., Murphy, D.L., and Jimerson, D C. (1992) Neuroendocrine responses to m-chlorophenylpiperazine and I-tryptophan in bulimia. Archives of General Psychiatry 49: 852-861

Comn, P.J. and Sanders-Bush, E.(1987) Relative efficacy of piperazines at the phosphoinositide hydrolysis-linked serotonergic $\left(5-\mathrm{HT}_{2}\right.$ and $5-\mathrm{HT}_{1 \mathrm{c}}$ ) receptors. The Journal of Pharmacology and experimental therapeutics 2142: 552-557

Garvey, M.J., Tuason, V.B., Johnson, R.A., Valentine, R.H, and Cooper, T.B. (1984) Elevated plasma tricyclic levels with therapeutic doses of imipramine. American Joumal of Psychiatry 141: 853-856 
Goldberg, R. J. (1992) Serotonin Syndrome From Trazodone and Buspirone [letter]. Psychosomatics 33: 235

Guze, B.H., and Baxter, L.R. Jr. (1986) The serotonin syndrome; case responsive to propianolol (letter) Journal of Clinical Psychopharmacology 6:119-120

Hamik, A., and Peroutka, S.J. (1989) 1-(m-Chlorophenyl)piperazine (m-CPP) interactions with neurotransmitter receptors in the human brain. Biological Psychiatry 5: 569-575

Hommer, D., Ancreasen, P., Rio, D. Williams, W. Ruttimann, U., Momenan, R., Zametkin, A. Rawlings, R., and Linnoila. M. (1997) Effects of m-chlorophenylpiperazine on regional brain glucose utilisation: a positron emission tomographic comparison of alcoholic and control subjects Journal of Neuroscience 17 (8): 2796-2806

Joseph-Vanderpool, J.R., Jacobsen, F.M., Murphy, D.L. Hill, J.L., and Rosenthal, N.E. (9993) Seasonal variation in behavioural responses to $\mathrm{m}$-CPP in patients with seasonal affective disorder and controls. Biological Psychiatry 33: 496-504

Kahn, R.S. Wetzler, S. Asnis, G.M. Kling, M.A. Suckow, R.F., and Van Praag, H.M. (1990") Eflects of $\mathrm{m}$-chlorophenyipiperazine in normal subjects: a dose-response study. Psychopharmacology 100: 339-344

Kahn, R.S., Kalus, O., Wetzler, S. Cahn, W., Asnis, G.M., and Van Prasg. H.M. (1990") Effects of serotonin antagonists on m-chlorophenylpiperazine-mediated responses in normal subjects. Psychiatry Research 33: 189-198

Kahn, R.S. and Wetzler, S. (1991) m-Chlorophenylpiperazine as a probe of serotonin function. Biol Psychiatry 30: 1139-1166

Kline, S.S., Maruo, L.S., Scala-Barnett, D.M., and Zick, D. (1989) Serotonin syndrome versus neuroleptic malignant syndrome as a cause of death. Clininical Phamacology 8:510-514

Krystal, J.H. Webb, E. Cooney, N., Kranzler, H.R., and Chamey, D.S. (1994) Specificity of ethanolike effects elicited by serotonergic and horadrenergic mechanisms. Airchives of General Psychiatry 51: 898-911

Lejoyeux, M. Rouillon, F., and Adès. J. (1993) Prospective evaluation of the serotonin syndrome in depressed inpatients treated with clomipramine. Acta Psychiatrica Scandinavica 88: 369-371

Lejoyeux. M. Ades. J, and Rouillon, F. (1994) Serotonin syndrome-Incidence, symptoms and treatment. Cns. Drugs 2:132-143.

McNair, D.M. Lorr, M. and Droppelman, L.F. (4988) Manual for the Profile of Mood States. San Diego, California: Educational and Industrial Testing Service

Newwonen, P.J. Pohjola-Sintonen, S. Tacke, U., and Vuori, E. (1993) Five falal cases of serotonin syndrome after moclobemide-citalopram or moclobenide-cionipramine overdoses. Lancet 342 (It): 1419

Reeves, R.R., and Bullen, J.A. (1995) Serotonin syndrome produced by paroketine and low-dose trazodone [Letter]. Psychosomatics $36(2): 159$

Raberston, D.W. Bloomquist, W., Wong, D.T., and Cohen, M.L. (1992) M-CPP but not TFMPP is an antagonist at cardiac $5.4 T_{3}$ receptors. Life Sciences $50: 599-605$

Roy, A., Virkkunen, M., and Linnoila, M. (1987) Reduced central serotonin turnover in a subgroup of alcoholics? Progress in Neurapsychopharmacology and Biological Psychiatry 11: 173-177

Sandyk, R. (1986) 1-Dopa induced serotonin syndrome in a parkinsonian patient on bromocriptine (leter). Joumal of Clinical Psychopharmacology 6 : 194-195

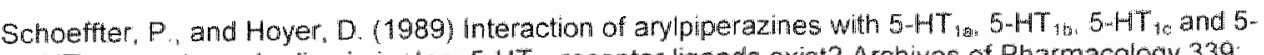
$H T_{10}$ receptors: do discriminalory 5-HT, 1 receptor ligands exist? Archives of Pharmacology 339 : $675-683$ 
Sevy, S. Brown, S.L. Wetzler, S. Kotler, M., Molcho, A., Plutchik, R, and Van Praag, H.M. (1994) Effects of aplrazollam on increases in hormonal and anxiely levels induced by metaChlorophenylpiperazine. Psychiatry Research 53:219-223

Sheldon, P.W. and Aghajamian, G.K. (199il) Excitatory responses to serotonin (5.HT) in neurons of the rat pirtorm cortex evidence for mediation by $5-H T_{i c}$ receptors in pyramidal celis and $5-H T_{2}$ receptors in intermeurons. Symapse 9:208-218

Smith, L.M., and Peroutka, S.J. (1986) Differential effecls of 5-hydroxytryptamine 1a selective drugs on the 5-HT behavioural syndrome. Pharmacology, Biochemistry and Behavior 24: 1513-1519

Sternbach, H. (1991) The serotonin syndrome [see conments]. American Joumal of Psychiatry 148 . $705-713$

Stein, D.J, Hollander, E. DeCaria, C.M., Simeon, D., Cohen, L., and Aronowitz, B. (1996) mChlorophenylpiperazine challenge in borderline personality disorder: relationship of neuroendocrine response. behavioural response and cilinical measures. Biological Psychiatry 40: 508-513

Yarmada, J., Sugimoto, $Y$, and Horisaka, $K$. (1989) The evidence for the involvement of the 5HTHA receptor in the 5-HT syndrome induced in mice by tryptamine. Japanese Joumal of Pharmacology 51: $421-424$

Zacchia, C., Pihl, R.O., Young, S., and Ervin, F. (1987) The influence of altered tryptophan availability on ethanol intoxication in hormal men. Journal of Studies on Alcohol 48:535-540 


\section{Epilogue}

A great deal of uncertainty remains as to the exact nature of 5-HT disturbances in affective disorders. The aim of the studies presented in this thesis was to shed some light on the role of 5-HT in the pathophysiology of affective disorders.

\section{Main results}

The most important results of the above mentioned studies are as follows:

1. There are strong indications that the effects of TRP depletion are specific, caused by a shortage of TRP, rather than by a general defect in protein metabolism. They cannot be attained by depletion of another essential amino acid such as lysine. 2. TRP depletion, in our study, was accompanied by an increase in brain tyrosine levels, im both the TRP depletion and the placebo condition. Thus, the TRP depletion method most probably does not lead to deficiencies in dopamine or noradrenaline synthesis, which is additional evidence of the specificity of the method.

3. It was not possible to attain a 24-hour state of TRP depletion without seriously interfering with the normal day-night activity rythm. The maximum duration of lowered plasma TRP was 12 hours. In earlier studies, effects of TRP depletion have been observed after 24 hours. The results of our study suggest that TRP plasma levels must have returned to baseline at that time

4. TRP depletion induced a specific memory bias in which subjects tended to forget neutral and positive words rather than negative words. This effect existed irrespective of mood changes. Thus, there is some evidence that the term 'mood' in 'mood congruent memory bias" wrongly suggests a causal relationship between mood and memory bias.

5. TRP depletion increases the panic-inducing effects of $35 \% \mathrm{CO}_{2}$ inhalation both in normal volunteers and in panic patients.

6. Subjects with affective disorders display both a hyper-responsivity of $5-H T_{2 C}$ receptors and a hypo-responsivity of 5-HT, receptors. 
7. Trait anxiety and trait aggression are positively correlated with the cortisol response to $5-\mathrm{HT}_{2 \mathrm{C}}$ stimulation in a group of subjects with depiressive and/or anxiety disorders, indicating that higher trait anxiety and aggression are accompanied by a higher sensitivity of the 5-HT2 receptor.

Next, we will discuss the results in more detail, thereby addressing the issues of clinical relevance and further research.

\section{Part I: TRP depletion studies}

The TRP depletion method is a fascinating research method for studying the 5-HT system that can be carried out relatively easily and without too many side effects. It is, therefore, not surprising that the method has been gaining popularity throughout the years.

\section{Specificity of the method}

In order to be considered an adequate probe for serotonergic functions, the TRP depletion method should be reliable, and specific and the consequences reversible We focused on the issue of specificity. It was observed that the effects of TRP depletion were significantly different from those of placebo, white the effects of lysine depletion were not (chapter 1). Therefore, it was concluded that the effects of TRP depletion were specifically related to lowered 5 HT synthesis and not to an aspecific effect of TRP depletion on protein metabolism. Yet, the direction of effects of lysine depletion, with regard to both mood and memory, was the same as that of TRP depletion, although of lesser magnitude. Thus, it may be worth replicating the study, preferably using subjects with an even greater sensitivity to the effects of TRP depletion, such as former depressives shortly in remission after SSRIs.

Apart from aspecific effects on protein metabolism. TRP depletion may also affect the metabolism of other neurotransmitters and their precursors, such as the cathecholamines or the precursor molecule tyrosine. Earlier research in monkeys (Young et al. 1989) found that TRP depletion did not affect the metabolism of tyrosine and the catecholamines. Our study, presented in chapter 2, showed that tyrosine uptake in the brain as a result of TRP depletion is hardly affected and comparable to that after placebo, leading to increased uptake rather than a decrement after 6 hours. This increase is due to the fact that, after the administration of the tyrptophan-depleted amino acid mixture, the amount of tyrosine is raised relatively more than the sum of other large neutral amino acids with which it competes for entrance through the blood-braim barrier. Thus, in humans, it is not very likely that the effects of TRP depletion are mediated by changes in tyrosine uptake. This finding provides further evidence of the specificity of the TRP depletion method. 
Further research into the specificity of the TRP depletion method should focus on effects of TRP depletion on specific substances containing TRP and playing a regulatory role in certain neuronal circuits, such as somatostatin. melatonine, and the so-called delta-sleep-inducing peptide.

\section{Specificity of effects}

The specificity of the effects of 5-HT dysregulation is one of the major research questions of the presemt thesis. Although the question of specificity of effects is more explicitly verbalized in the neuroendocrine challenge section of this thesis, where a functional approach has been adhered to, it is relevant to the TRP depletion studies as well.

The question arises as to whether the TRP depletion method can serve as a valid model for depression. Although a group of depressed subjects reported a relapse of depressive symptoms within 24 hours after TRP depletion, it would be interesting to do an analysis of the nature of the symptoms that re-emerged. Investigators in earlier studies (Delgado et al. 1990; 1991; Oldman, 1995) employed depression questionnaires such as the Hamilton Depression Rating Scale (HDRS) or the Beck Depression Inventory (BDI) that are used in clinical practice to measure the intensity of symptoms after the diagnosis "depression" has been established on the basis of the clinical assessment. However, an increase in symptoms, as measured with these scales, does not necessarily mean that a depressive syndrome has occurred again. There may only be an increase of only aspecific symptoms. Furthermore, both the HDRS and the BDI contain items that cannot be measured over a short time span, e.g., items pertaining to sleep and activity level. Also, the aspecific physical symptoms that are measured with these questionnaires may be side effects of the TRP depletion challenge itself rather than symptoms of depression.

Nowadays, the concept of depression is based on a heterogeneous collection of symptoms that may be part of other psychiatric disorders as well. What, then, is the core of depression?

It would be useful to perform research into specific symptoms that are considered specifically depressive and that distinguish the depressive syndrome from other syndromes, e.g. specific cognitive factors such as feelings of guilt or self-doubt. Our study regarding mood congruent memory bias (chapter 4 ) is in line with this view. Mood-congruent memory bias, in which emotionally negative information is remembered more often than emotionally neutral or positive information, is one feature that is often seen in the depressive syndrome. Our study suggests that a biological intervention (TRP depletion) may induce this memory bias. It is striking that the memory bias is independent of mood, a finding that has occurred earlier after other types of mood induction (chapter 4). Thus, the term "mood-congruent memory bias" wrongfully suggests that the mood is causally involved in the memory bias. The results of our study point instead to a biological basis of this psychological 
phenomenon. Unfortunately, when we speak of the biompsycho-social model in psychiatry, we too often postulate that a given behavior can be considered from the biological, the psychological, and/or the social point of view, regardless of causality. The interrelationship between these points of view has not yet been fully explored. As mentioned before, van Praag postulated the hypothesis that anxiety and aggression are 5-HT regulated psychological variables and that in a subgroup of depression, clepressed mood is a derivative of dysregulated anxiety and/or aggression. If $\mathrm{so}$, one would expect symptoms of anxiety and aggression to appear after TRP depletion, rather than depressed mood. At first glance, our studies do not support this hypothesis. We found increased anxiety in only one study with normal male subjects, while in the two other studies no symptoms of increased anxiety developed. The use of different questionnaires may have played a role here. The fact that anxiety increased in panic patients after TRP depletion and a subsequent $\mathrm{CO}_{2}$ challenge, while it did not after TRP depletion without $\mathrm{CO}_{2}$ challenge, suggests that increased anxiety may only become apparent after provocation. This has also been postulated with regard to aggression, and especially impulsive aggression. The latter, which is thought to be related to 5 - HT disturbances, may be best measured with the use of provocation methods. Thus, the methodology of our studies does not allow us to consider anxiety and aggression, while they are probably best measured after prowocation. This is in accordance with the theory of Handley (Handley, 1995), who states that serotonin is more related to the interpretation of, and reaction to noxious stimuli than to anxiety per se. Whether depressed mood is a derivative cannot be answered on the basis of our results. It should indeed be mentioned that van Praags hypothesis is based on the occurrence of symptoms over time in depressed subjects in real life. Our results are based on three measurements, over time periods of maximum 6-24 hours, in experimental conditions.

\section{Longer lasting TRP depletion}

We did not succeed in keeping TRP levels downfor 24 hours. In order to attain this goal, the subjects should have taken additional amounts of the amino-acid mixture during the night. This would have affected sleep in such a disturbing way that it would have been an unacceptable confounding factor in the experiment. Thus, using our method, a 24-hour TRP depletion probably cannot be attained. It is, however, possible to take measurements in the evening, about 12 hours after intake of the amino acid mixture, when TRP levels are still low. Recently, in our laboratory, a study was carried out in which memory tests were done 5 and 9 hours after depletion (Schmitt et al. 2000). After 9 hours, TRP levels were still low. However, there were no additional memory impairments after 9 hours of TRP depletion compared to after 5 hours, suggesting that a longer-lasting depletion does not necessarily lead to additional impairments. 
We have no explanation for the fact that some studies have reported effects of TRP depletion 24 hours after ingestion of the amino acid mixture (Delgado et al., 1991:1994), while the subjects returned to normal eating patterns. In our studies. mood effects paralleled TRP blood levels, which were approximately at their original baseline level after 24 hours.

\section{Effects of the placebo mixture}

An important issue regarding the placebo mixture is discussedin chapter 6 . This particular study strongly suggests a protective effect of the placebo mixture on the $\mathrm{CO}_{2}$ challenge in panic patients, who became less anxious after the placebo mixture and $\mathrm{CO}_{2}$ than they usually do after $\mathrm{CO}_{2}$ in general. This casts doubts on the tryptophan-containing mixture as a true placebo condition that is supposed to have no measurable physiological effects.

Our placebo mixture differed from that used in other studies in terms of the amount of TRP we added to it. Originally, $2.3 \mathrm{~g}$ TRP was used by Young et al. (1985).

Weltzin and co-workers (Weltzin et al., 1994) doubled this amount since a lowering of TRP levels was observed with $2.3 \mathrm{~g}$. but $4.6 \mathrm{~g}$ led to an increase in plasma TRP after 6 hours. Thus, we decided to use $3 \mathrm{~g}$, leading to a small increase in the TRP level and a small decrease in the ratio TRPIILNAA.

It is unclear to what extent this change in TRP level and TRP/LLNAA ratio had measurable physiological effects. However, if there was a physiological effect, it must have been in the direction of lowered brain 5-HT levels, as the ratio TRP/ELNAA was probably lowered. This does not support the protective effect of the placebo mixture as found in our study. Other explanations should then be sought in the plasma TRP levels, which were lowered, and in a protecting (psychological) 'placebo effect' of the mixture.

\section{Part II: Neuroendocrine challenge studies}

By employing two different challenges in one group of subjects, it is possible to determine the functional status of two different receptor subtypes in the same time period, assuming that this status is relatively stable as long as the disorder is present.

We found a hyposensitivity of 5-HT, 1 receptors as deduced from lowered cortisol levels after ipsapirone stimulation, together with a hypersensitivity of $5-\mathrm{HT}_{2} \mathrm{C}$ receptors as expressed by an exaggerated mood response to m-CPP, in the direction of a more depressed mood and more tenseness. At first sight, it may not seem logical to use one outcome variable for ipsapirone and a different outcome variable for m-CPP. However, one has to bear in mind that the specific receptors on which ipsapirone and m-CPP act have different anatomical locations and different 
functions. To test a certain receptor sensitivity, one has to use an outcome measure that is tallored to the function of that specific receptor subtype. If the 5 HT 4 A receptor is involved in memory processes while the $5-H T_{2}$ receptor is not, it is not reasonable to use memory performance as an outcome measure of both challenges. The same is true for mood and hormonal outcome measures.

On the other hand, although no differences were found in hormonal responses to mCPP between patients and normal controls, there was a significant correlation between cortisol response to m-CPP and trait measures of anxiety and aggression in patients. Thus, hormonal responses to m-CPP are not as closely related to DSMdefined disorders as they are to psychological dysfunctions such as anxiety and aggression. The fact that this correlation is only present in patients and not in controls may be related to the fact that in normal controls, anxiety and aggression levels were generally low and showed only a small variance.

\section{Clinical relevance of the results}

The studies presented in this thesis are controlled experiments, that primarily investigate mechanisms. They bear clinical relevance when seen from a broader perspective.

First of all, they add to the understanding of the pathophysiology of affective disorders, uitimately leading to better, and hopefully more specific, pharmacotherapy Secondly, the TRP depletion method may be developed into a method of predicting the outcome of antidepressant treatment with serotonergic medication. There is existing evidence that subjects treated with serotonergic medication, such as SSRIs or MAOIs, react with more depressive symptoms to TRP depletion than subjects treated with reuptake inhibitors of norepinephrine (desipramine) or dopamine (bupropion) (Delgado et al., 1991; 1993; 1994). Although drug-free, fully symptomatic depressed subjects seldom show any clinical worsening of symptoms after TRP depletion (Delgado et al., 1994), probably due to a ceiling effect. Other outcome measures, obtained with hormonal challenges or modern imaging techniques, may be used to develop useful tools for clinical psychiatry. The possible predictive value of TRP depletion with regard to response to medication needs to be investigated in a systematic way, e.g. by challenging depressed subjects with TRP depletion, followed by a comparison of treatments (e.g., with SSRIs or other antidepressant therapies). The functional approach to biological psychiatry is not only useful for research purposes, but may also be adhered to in day-to-day practice. In clinical work, a categorical diagnosis cannot usually be made within a short time span. often because the clinical picture is very complicated or atypical. In such cases, it may be worthwhile thinking in functional terms rather than in categorical terms alone. In situations where anxiety and/or aggression are prominent, serotonergic treatment may be a viable option, even when the DSM-defined diagnosis is unclear. 
Furthermore, the functional approach may lead to a better understanding of psychopathology and to a better distinction of diagnostic entities once the core symptoms of the different disorders are defined.

Finally, our demonstration of the biological basis of 'mood-congruent memory', is illustrates of the fact that the bio-psycho-social model, as often used in clinical psychiatry nowadays, not only implies that all problems have biological. psychological, and social aspects, but also that these aspects are interrelated and influence each other directly.

\section{Directions for further research}

Further research in the area of serotonin and affective disorders should be directed towards gaining better insight into the specific function of different serotonin receptors. Challenge studies should be used, in combination with such imaging techniques as PET or SPECT. Not only should the serotonin systembe investigated as a system in its own right, but equilibria between the different neurotransmitter and hormonal systems should be mapped, in both a static and a dynamic way. This can be achieved, for example, by linking two or more receptor agonists to receptors of different neurotransmitter systems in one group of subjects.

More insight into the specific function of serotonin receptors and their deregulation in psychopathology may lead to more specific psychopharmacology, i.e., medication that links more specifically to certain receptors that are thought to be deregulated. with fewer side effects and higher rates of remission.

An important condition for biological research, however, is a thorough insight into psychopathology. The core symptoms of the diverse psychiatric "diseases" should be defined more clearly. For example, using current diagnostic tools, no clear distinction can be made between depression, burn-out, dysthymia, and abnormal grief in the sense that each disorder has its own specific features apart from the aspecific symptoms. More research into the specific and core symptoms of psychiatric entities is necessary.

As mentioned before, future experimental psychiatry may provide the clinical practitioner with useful tools, to the benefit of our patients. The TRP depletion method may be developed into a predictive test for the response to SSRls. The use of such a tool may prevent subjects who do not respond to SSRI treatment from unnecessary treatment with ineffective medication. 


\section{References}

Delgado, P.L. Charney, D.S. Price, L.H. Aghajanian, G.K. Landis, H., and Heninger, G.R. (1990) Serotonin function and the mechanism of antidepressant action: Reversal of antidepressantinduced remission by rapid depletion of plasma tryptophan. Archives of General Psychiatry 47 : $411-418$

Delgado, P.L. Price, L.H., Miller, H.L., Salomon, R.M. Licinio, J., Krystal, J.H. Heninger, G.R, and Charney. D.S. (1991) Rapid serotonin depletion as a provocative challenge test for patients with major depression: Relevance to antidepressant action and the neurobiology of depression. Psychopharmacology Bulletin 27:321-330

Delgado, P.L. Miller, H.L., Salomon, R.M. Licinio, J., Heninger, G R., Gelenberg, A.J, and Charney, D.S. (1993) Monoamines and the mechanism of antidepressant action: Effects of catecholamine depletion on mood of patients treated with antidepressants. Psychopharmacology Bulletin 29: 389393

Delgado, P.L. ,Price, L.H. Miller, H.L., Salomon, R.M., Aghajanian, G.K. Heninger, G.R., and Charney, D.S. (1994) Serotonin and the neurobiology of depression: Effects of tryptophan depletion in drug-free depressed patients. Archives of General Psychiatry 51: 865-874

Handiey, S.L. (1995) 5-Hydroxytryptamine pathways in anxiety and its treatment. Pharmacology and Therapeutics 66: 103-148

Oldman, A, Walsh, A, Salkovskis, P., Fairburn, C.G., and Cowen, P.J. (1995) Biochemical and behavioural effects of acute tryptophan depletion in abstinent bulimic subjects; a pilot study. Psychological Medicine 25: 995-1001

Schmitt, J.A.J., Jorissen, B.L., Sobczak, S., wan Boxtel, M.P.J., Hogervorst, E. Deutz, N. E. P., and Riedel, W.J. (2000) Tryptophan depletion impairs memory consolidation but improves focussed attention in healthy young volunteers. Journal of Psychopharmacology 14 (1): $21-29$

Weltzin, T.E. Fernstrom J.D., McConaha, C., and Kaye, W.H. (1994) Acute tryptophan depletion in bulimia: Effects on large neutral amino acids. Biological Psychiatry 35: 388-397

Young, S.N., Smith, S.E., Fihi, R.O., and Ervin, F.R. (1985) Tryptophan depletion causes a rapid lowering of mood in normal males. Psychopharmacology 87: 173-177

Young, S.N. Ervin, F.R., Pihl , R.O. and Finn, P. (1989) Bicchemical aspects of tryptophan depletion in primates. Psychopharmacology 98: 508-511 


\section{Samenvatting}

In dit proefschrift worden een achttal studies beschreven waarin de relatie tussen affectieve stoornissen en stoornissen in de serotoninehuishouding nader wordt onderzocht. Serotonine is een neurotransmitter waarvan wordt verondersteld dat deze zijn functie inadequaat uitoefent in angststoornissen en depressie.

In een korte introductie worden de gebruikte onderzoeksmethoden uitgelegd. In deel I worden een zevental experimenten beschreven waarin de tryptofaan (TRP) depletiemethode gebruikt is. Met deze methode wordt via de inname van een aminozuurmengsel kunstmatig een tekort aan (TRP) en (als gevolg daarvan) aan serotonine in de hersenen geinduceerd. Er wordt gekeken naar de emotionele en cognitieve effecten van deze interventie. In deel 2 worden een tweetal experimenten beschreven waarin de gevoeligheid van serotoninereceptoren wordt gemeten. Hiervoor worden twee stoffen (metachlorophenylpiperazine en ipsapirone) toegediend die aan serotoninereceptoren aanhechten. Vervolgens wordt gekeken hoe de hormonale, emotionele en cognitieve responsen hierop zijn in patienten en proefpersonen. Aan de hand hiervan kan een uitspraak worden gedaan over de gevoeligheid van specifieke serotoninereceptoren.

\section{Deel I: Inhibitie van het 5-HT systeem}

In hoofdstuk 1 wordt ingegaan op de specificiteit van de TRP depletie methode. In een groep gezonde proefpersonen werd niet alleen de effecten van TRP depletie onderzocht, maar ook die van lysine depletie. Zowel TRP als lysine, beiden essentiele aminozuren, beinvloeden het eiwitmetabolisme, met dat verschil dat er bij TRP depletie wel een serotoninetekort ontstaat en bij lysine depletie niet. Na TRP depletie werd een significante daling van de stemming en verslechtering van het geheugen ten opzichte van placebo gevonden, die niet werd geconstateerd na lysine depletie. Er werd geconcludeerd dat de effecten van TRP depletie niet het gevolg zijn van een verstoord eiwitmetabolisme maar direct samenhangen met de verminderde serotonineproductie. 
In hoofdstuk 2 wordt een experiment beschreven waarin als hypothese werd verondersteld dat een positieve familieanamnese voor depressie samenhangt met een grotere kwetsbaarheid voor verstoringen van de serotoninehuishouding en derhalve worden grotere effecten van TRP depletie venwacht. Er werd daarbij gepoogd gedurende 24 uur tryptofaanspiegels laag te houden, teneinde daarmee de effecten ervan zo groot mogelik te maken. Dit bleek echter niet geheel te lukken. Tijdens de slaap werden de plasma TRP spiegels door het lichaam weer zodanig aangevuld, dat zij na 24 uur weer nagenoeg op het oude peil waren. Ook stemmingseffecten die na zes uur werden gemeten, waren de volgende ochtend weer verdwenen. Proefpersonen met een positieve familieanamnese voor depressie vertoonden, zaals verondersteld, significant meer stemmingseffecten na zes uur dan proefpersonen zonder positieve familieanamnese.

Hoofdstuk 3 gaat in op cognitieve effecten van TRP depletie. Na TRP depletie werd een significante verslechtering van het lange termijn geheugen gezien in gezonde proefpersonen, terwijl het korte termijn geheugen en testen met betrekking tot de waarneming en psychomotoriek niet werden aangetast. Er werden geen effecten van familieanamnese gevonden.

In hoofdstuk 4 wordt ingegaan op inhoudelijke aspecten van het geheugen, waarbij gezonde proefpersonen positief, negatief en neutraal geladen woorden moesten leren. Er werd een stemmingscongruente geheugen-'voorkeur' geconstateerd; de proefpersonen onthielden na TRP depletie zowel neutraal als positief geladen woorden minder goed dan de negatief gekleurde woorden. Een dergelijk selectief geheugen wordt ook gezien in depressieve patienten. Opvallend was dat de geheugen-'voorkeur' onafhankelijk van de stemming optrad, hetgeen betekent dat stemming niet als oorzakelijke factor voor de geheugen-'voorkeur' kan worden aangemerkt. Ook in deze studie werden geen effecten van familieanamnese gevonden.

In de volgende twee hoofdstukken wordt ingegaan op de invloed van TRP depletie op CO2 geinduceerde paniek in gezonde proefpersonen (hoofdstuk 5) en paniekpatienten (hoofdstuk 6). TRP depletie leidde tot een toename van angst en spanning en tol een toename van neurovegetatieve angst symptomen na $\mathrm{CO}_{2}$ inhalatie vergeleken met de placebo conditie. In paniek patienten werd geen effect van TRP depletie gezien op het niveau van angst maar na $\mathrm{CO}_{2}$ inhalatie was er een sigrificant grotere respons met zowel angst als neurovegetatieve symptomen vergeleken met de placebogroep. De resultaten van beide studies ondersteunen elkaar in de veronderstelling dat een verminderde serotonerge functie angst en panieksymptomen doet toenemen.

\section{Deel II: stimulatie van het $5-H T$ systeem}

In het tweede deel van het proefschrift worden twee experimenten beschrewen waarin de gevoeligheid van serotoninereceptoren in een groep patienten wordt 
gemeten met behulp van M-CPP (5-HT 20 receptor agonist) en ipsapirone (partiele 5$H T_{1 A}$ receptor agonist). Er wordt een functionele benadering van psychiatrische aandoeningen gehanteerd. In deze benadering wordt uitgegaan van het idee dat biologische stoornissen vermoedelijk meer samenhangen met specifieke psychologische onderdelen van een psychiatrisch ziektebeeld dan met de psychiatrische ziektes zoals worden gedefinieerd in een classificatiesysteem als bijvoorbeeld de DSM of ICD. Deze samenhang tussen biologische en psychologische variabelen zou dwars door alle psychiatrische diagnoses heen terug te vinden moeten zijn. Derhalve worden in deze experimenten metingen gedaan in een groep patienten met verschillende soorten affectieve stoornissen (hoofdstuk 7) en wordt gezocht naar correlaties tussen serotonine-receptorgevoeligheid en intensiteit van emoties als angst en agressie (hoofdstuk 8 ). Er werd een verhoogde gevoeligheid van de 5-HT2c receptor gemeten, zich uitend in een verhoogde stemmingsrespons op M-CPP, en een verlaagde 5-HT 1 A receptorgevoeligheid, die tot uitdrukking kwam in een verlaagde cortisol respons op ipsapirone. Dit patroon komt overeen met de hypotheses die op basis van eerdere literatuur waren geformuleerd. Verder was opvallend dat ipsapirone leidde tot een verbetering van het geheugen in patienten , terwijl gezonde proefpersonen als gevolg van ipsapirone juist minder goed presteerden op een geheugentaak.

Wat betreft de correlatie tussen receptorgevoeligheid en intensiteit van angst/agressie: er bleek een significante positieve correlatie te zijn tussen de cortisol respons op M-CPP en de mate van angstagressie zoals die werd ervaren in de week voor de test. Dit wordt beschreven in hoofdstuk 8. Er werden geen correlaties van angst/agressie met de 5-HT, receptorgevoeligheid gevonden, zoals gemeten met ipsapirone.

In hoofdstuk 9 wordt verslag gedaan van reacties van een drietal patienten, aikomstig van twee onderzoekscentra, die ten gevolge van een eenmalige dosering van M-CPP een serotoninesyndroom ontwikkelden. Dit syndroom ontstaat wanneer het serotoninesysteem overmatig wordt gestimuleerd. De beschreven proefpersonen hadden duidelijk hogere plasma concentraties van M-CPP vergeleken met de andere proefpersonen. Een dergelijk syndroom na eenmalige toediening van M-CPP is nog niet eerder gerapporteerd.

Na de beschrijving van de experimenten en hun resultaten volgt een epiloog, waarbij de bevindingen in hun context worden geplaatst, kritische kanttekeningen worden geplaatst bij de experimenten en aanbevelingen worden gedaan voor verder onderzoek. Zo dient onder andere de functie van de diverse specifieke serotominereceptoren gedetalleerd in kaart gebracht te worden en dient meer onderzoek te worden gedaan naar de interactie tussen de diverse neurotransmittersystemen. Verder is het ook voor de biologische psychiatrie noodzakelijk dat een beter inzicht wordt verkregen in de kernproblemen en kernsymptomen van de diverse psychiatrische ziektebeelden. 

DANKWOORD 163

\section{Dankwoord}

Een proefschrift schrijf je miet alleen. Er zijn veel mensen die elk op hun eigen manier een bijdrage hebben geleverd aan het tot stand komen van dit proefschrift, waarvoor ik hen erg dankbaal ben. Ik besef dat ik dat hier niet volledig kan beschrijven en dat ik misschien zelfs wel iemand zal vergeten te bedanken; dat spijt me erg. Naast hun specifieke bijdrage heb ik genoten van het contact met de mensen met wie ith heb samengewerkt, wat mede heeft bijgedragen aan het plezier dat ik heb gehad in het doen van onderzoek.

Allereerst Professor Dr. van Praag: U heeft mij de gelegenheid gegeven om onderzoek te komen doen en bovendien heb: $u$ zich ingespannen om financien rond te krijgen voor het tryptophan depletie project. Dat $u$ blikbaar vertrouwen had in het projekt heb ik als een eer beschouwd, evenals het feit dat ik nauw met u mocht samenwerken.

Wim Riedel is degene geweest die mij gedurende de afgelopen zes jaar voortdurend met raad en daad terzijde heeft gestaan. Zonder zijn deskundigheid, praktische hulp, kritisch commentaar en positieve instelling was het niet gelukt de beide projekten en de promotie af te ronden. Ik ben je daarvoor zeer erkentelijk en hoop dat je dat al eerder hebt gemerkt.

Professor Dr. Griez is degene geweest die mij in zijn onderzoeksgroep heeft opgenomen en daarmee een veilige thuishaven heeft gecreeerd waarin veel ruimte was voor discussie en eigen inbreng. Zijn pragmatische instelling en moito: "Keep it simple" hebben mij erg geholpen, met name ook in de laatste fase, en blijven voor mij een inspiratiebron om verder onderzoek te doen. Zijn secretaresse Leni Noteborn heeft een cruciale rol gespeeld in de afronding van dit proefschrift. Zij fungeerde sinds mijn vertrek van de universiteit als postadres en stond mij op alle mogelijke manieren bij. Haar kamer op Vijverdal bleef een plek waar ilk mij, ook toen hik niet meer via andere banden aan de Universiteit en Vijverdal verbonden was, thuis voelde, overigens mede door de gezellige en betrokken aanwezigheid van Jolande Kach, len Kusters en Lea Esten. 
Het idee om onderzoek te doen is geboren nadat ik als student-assistent met Frans Verhey een meta-analyse had gedaan naar de behandeling van depressie bij de Ziekte van Parkinson. Hiermee heb ik een theoretische basis gelegd die mij erg van pas is gekomen in de opzet van de tryptofaan depletie studies.

Adriaan Honig heeft mij als assistent op zijn depressie-poli laten werken en mij daarmee de kans gegeven patienten voor de challenge-studie te werven.

Waarschijnlink voelde thij wel aan dat patienten werven niet mijn sterkste punt is. vandaar dat hij zich daar flink voor heeft ingezet. Bedanki.

Patienten werden ook voor mil geworven op het Academisch Angscentrum, waar Roos Hauzer. Trea Overbeek en Jaap Meyer hun ogen goed de kost gaven. Of de klinisch gestelde diagnoses klopten werd geverifieerd door Theo Lamers, die alle patienten onderwierp aan een SCAN, een semigestructureerd vraaggesprek waarvan ik de computeruitslagen nog steeds niet begrijp. Daar moet je niet voor niets voor opgeleid zijn!

Het uitvoeren van alle testen en het verwerken wan de gegevens is veel werk en alleen had ik dat niet gekund. Gelukkig ben ik daarin bijgestaan door onder andere Inge Lensink, Jos Jazie, Nicolette Bongaerts, Harry Schiepers, Jurgen Klumperbeek en niet te vergeten Astrid van Someren. Deze laatste bracht naast haar immer goede humeur ook nog het een en ander aan kunstvormen met zich mee, waar ik erg van heb genoten. Brenda Jorissen, Chantal Hendriks en Kristien Scheepers vielen in wanneer de reguliere testassistenten niet beschikbaar waren.

Verder dank aan de leden van de leescommissie, Prof. Dr. M. Maes, Prof. Dr. H. Merckelbach, Prof. Dr. H. Steinbusch, Prof. Dr. A. Jansen, Dr. A. van der Does en Dr. S. Young voor het lezen en beoordelen van het manuscript.

De computer is tegenwoordig een onmisbaar hulpmiddel bij het doen van onderzoek. Helaas doet ze niet altijd wat ik zou willen. Joep Jansma hielp mij altijd uit de brand, vrije dag of weekend, het deed er niet toe, hij stond altijd klaar om de techniek te lijf te gaan, en met succes!

Om enig zich te krigen op het verloop van de challenge procedures mocht ik een kijkje nemen bij het onderzoek van Kamini Ho-Plan, die onder leiding wan Prof. Westenberg dergelijk onderzoek deed in Utrecht. Ook hem en zijn collega Prof. Dr. J. den Boer wil ik bedanken voor hun bijdrage aan het artikel over het serotoninesyndroom na m-CPP

De prikpoli van het AZM heeft mij wee weken ontvangen en daar leerde ik daar alle kneepjes van het prik-vak. Dat was een goed ervaring. Kees Verburg, die destijds als AlO op het Academisch Angstcentrum werkte, introduceerde mij in het leven van de onderzoeker. Bij hem kon ik terecht als ik iets niet wist en hij gaf mij altijd het gevoel dat het probleem toch niet zo groot was als ik dacht.

De aminozuurmengsels en teststoffen voor de challengetesten werden voor ons verzorgd door de apotheek van het AZM. De intensieve samenwerking met Francien de Stoppelaar, verantwoordelijke apotheker in opleiding, was niet alleen vruchtbaar maar ook gezellig. Tini Raadschilders had de spullen altijd stipt op tijd klaarstaan, en 
de bloedmonsters werden in het farmaceutisch laboratorium ontvangen en verwerkt door onder andere Huub Groothuizen en Jaques vd. Heyden. In het klinisch chemisch laboratorium van Dr. Menheere werden de hormoonbepalingen gedaan. Ook daar voelde ik mij kind aan huis. Het derde laboratorium waar ik regelmatig binmenwipte om bloed af te geven en in cupjes te doen werd beheerd door Mick Deutz die mij het gevoel wist te geven dat ik met leuk en interessant onderzoek bezig was en best zou kunnen promoveren als ik dat wilde. Hans van Eijk en Dennis Rooyakkers voerden de analyses van de aminozuurconcentraties uit.

Bayer bv. schonk ons de ipsapirone en deed de bloedanalyses van de ipsapirone. Tevens gaat mijn dank uit naar de in de colofon genoemde farmaceutische instellingen, die de druk van dit proefschrift mede hebben bekostigd.

Nancy Nicholson, Michael Maes en Eric Griez leverden belangeloos hun commentaar op een deel van de in dit proefschrift gepubliceerde artikelen. Alle artikelen zijn door Pamela Falger-Cohen geredigeerd en gecontroleerd op de juistheid van het engeise taalgebruik. Zelfs na acht artikelen blijft dat ernstig noodzakelijk, zo blijkt.

Dit onderzoek was natuurlijk niet mogelijk zonder de medewerking van alle proefpersonen, die zo elk om hun eigen redenen hun tijd en energie gaven om aan de niet altijd even prettige testen mee te doen. $\mathrm{k}$ heb gelukkig niemand echt horen klagen. Bedankt!

Voor zaken die geld kostten kon ik altijd terecht bij Ankie Hochstenbach en Laurent Louwies. Marco van Hertrooij, hun kamergenoot drukte mij regelmatig weer een of ander artikel onder de neus, dat een onderwerp behelsde dat mogelijk interessant voor mijn studie zou kunnen zijn.

Aan Christel Bruggeman had ik een uiterst gezellige en inspirerende kamergenoot. De oefeningen die wij op de cursus emotioneel lichaamswerk hadden geleerd vormden soms aanleiding tot hilarische taferelen. Desalnietemin is dit een belangrijke periode voor mij geweest en het was fijn in haar een deelgenoot te vinden. Jan Wiersma, Koen Schruers en Rob Havermans waren al even gezellige kamergenoten, die mij woorgingen in de opleiding tot psychiater en via wie ik alvast wat kon uitkijken naar wat nog komen zou.

Lex van Bemmel, mijn opleider in de opleiding tot psychiater, gaf mij toestemming om een half jaar keuzeondewijs aan het afronden van mijn proefschrift te wijden. Ik was daar erg blij om, want zonder die tijd had ik het ongetwijfeld niet volgehouden. Johan Huisman deed mij inzien dat het ook voordelen kan hebben om gepromoveerd te zijn, zelfs wanneer je geen ambitie hebt om professor te worden.

Dank ben ik ook verschuldigd aam Gerlinda Sneijders en Liesbeth Kraayveld, die als paranimfen mij tijdens de promotie-plechtigheid letterlijk en figuurijk ter zijde zullen staan. \#k voel me erg bevoorrecht dat ik hen beide al zoveel jaren tot mijn goede wriendinnen mag rekenen. Bedank woor alles wat jullie voor mij betekenen. Verder wil ik mijn ouders en schoonouders bedanken. Jullie hebben je altijd liefdevol en voorwaardenscheppend voor mij ingezet niet in de laatste plaats tijdens het 
bijzondere projekt van de laatste twee jaren: de verbouwing van ons huis. Jullie belangstelling en meeleven is hartverwarmend en ik weet dat jullie van mij houden om wie k ben, niet om wat ik presteer.

Mijn schoonvader heeft verder de prachtige illustratie op de voorkant van het boekje ontworpen, waar ik erg blli mee ben.

Tot slot wil ik Rob bedanken: Rob, je hebt mij altijd vril gelaten om aan mijn proefschrift te werken als ik daar behoefte aan had, ook al waren er nog zoweel andere dingen ook heel belangrijk op dat moment. Je hebt mij een stabiele thuisbasis gegeven, vanwaaruit ik de energie heb kunnen opbrengen om dit project tot een einde te brengen, me gesteund en gestimuleerd als dat nodig was en mij voorgeleefd dat er nog meer in het leven is dan je plicht doen en werken.

Maar bovenal ben je de vader van ons kindje, aan wie ik dit proefschrift wil opdragen. 


\section{Curriculum Vitae}

Tineke Klaassen werd op 22 februari 1969 geboren te Culemborg, als oudste in een gezin met drie kinderen. Op haar zesde jaar woonde het gezin een half jaar in Amerika, waar zij de lagere school volgde. Ze is protestants-christelijk opgevoed, hetgeen zij nog steeds ais een waardevol aspect van haar leven ervaart. In 1987 behaalde zij haar Atheneum-diploma op het Christelijk College Stad en Lande te Huizen. Daarna studeerde zij van 1987 tot en met 1994 geneeskunde aan de Rijksuniversiteit Limburg (tegenwoordig: Universiteit Maastricht). In die periode was zij actief in het bestuur van de Medische Faculteitsvereniging Reflex en werkte zij als studentassistent aan de validering van emotionaliteitstesten bij ratten en aan een inventarisatie van het zorgaanbod binnen de GGZ in de regio Zuidelijk Zuid Limburg. Aansluitend aan het behalen van haar artsexamen werkte zij gedurende twee jaar als arts-onderzoeker bij Prof. Dr. H.M. van Praag aan de vakgroep Psychiatrie en Neuropsychologie van de Universiteit Maastricht. In deze periode heeft zij de gegevens voor de in dit proefschrift gepresenteerde studies verzameld.

In april 1997 startte zij met de A-Opleiding psychiatrie onder leiding van Dr. A.L. van Bemmel. Sinds Januari 2000 woont zij in Velden. Momenteel voigt zij een keuzestage kinderpsychiatrie in "De Drie Vennen" te Venlo. Tevens volgt zil supervisie in het kader van een opleiding tot systeemtherapeut. De opleiding tot psychiater hoopt zij op 1 april 2002 af te ronden.

Tineke is getrouwd met Rob Schonck en verwacht half november een kindje. 